\title{
Improving the use of data to support management of piscirickettsiosis in Chile
}

\section{Verbetering van het gebruik van data ter ondersteuning van de beheersing van piscirickettsiose in Chili}

(met een samenvatting in het Nederlands)

\section{Proefschrift}

ter verkrijging van de graad van doctor aan de

Universiteit Utrecht

op gezag van de

rector magnificus, prof.dr. H.R.B.M. Kummeling, ingevolge het besluit van het college voor promoties

in het openbaar te verdedigen op

dinsdag 1 juni 2021 des middags te 4.15 uur

door

\author{
Anne Meyer \\ geboren op 18 september 1987 \\ te Laxou, Frankrijk
}




\section{Promotor:}

Prof. dr. J.A. Stegeman

\section{Copromotor:}

Dr. A.R. Cameron

The work presented in this dissertation was partly supported by Ausvet Europe (Lyon, France). 
DOI: https://doi.org/10.33540/486 


\section{Table of contents}

Chapter $1 \quad$ General introduction

Chapter 2 Effectiveness of antimicrobial treatment of salmonid rickettsial

9 septicaemia in commercial salmon and trout farms in Chile

Chapter 3 Quantifying the effects of sea lice burden and lice bathing treatments on salmonid rickettsial septicaemia in commercial salmon and trout farms in Chile

Chapter 4 Is between-farm water-borne pathogen dissemination an important driver in the epidemiology of salmonid rickettsial septicaemia in Chile?

Chapter $5 \quad$ Barriers to the adoption of a fish health data integration initiative 117 in the Chilean salmonid production

Chapter 6 Current status of veterinary epidemiological research in two species regarding the FAIR guiding principles

Chapter $7 \quad$ General discussion

Appendix Summary

Samenvatting 233

About the author 236

Acknowledgments 


\section{CHAPTER 1}

General introduction 


\section{History and current state of salmon aquaculture in Chile}

Salmonids are not native from the southern hemisphere. They were introduced in the wild in southern Chile in the 1900's, voluntarily for recreational fishing purposes as well as escapes from ranching enterprises and later net-pen aquaculture. In particular, introductions of the four species that are of commercial farming interest today have been recorded in Chile: Atlantic salmon (Salmo salar), coho salmon (Oncorhynchus kisutch), Chinook salmon (Oncorhynchus tshawytscha) as well as rainbow trout (Oncorhynchus mykiss) (Pascual and Ciancio, 2007). Rainbow trout populations are found in most freshwater bodies, although most are freshwater residents rather than anadromous populations (Soto et al., 2006). Chinook salmon populations seem established (Ciancio et al., 2005), while Atlantic and coho salmons found in lakes appear to be escapees from commercial farming rather than results of a successful invasion (Soto et al., 2006). In the early 1920s, government institutions supported further introductions in order to develop domestic salmon fish production (United Nations, 2006). These efforts to acquire and further develop technologies to support commercial aquaculture have proven successful and salmon is now the country's second export product, after copper (SalmonChile, 2020), while Chile is the second largest producer of salmon worldwide (Iversen et al., 2020).

A shadow to the success of the salmonid aquaculture industry in Chile is the fish health burden caused by salmonid rickettsial septicaemia (SRS or piscirickettsiosis), a non-zoonotic bacterial infection caused by Piscirickettsia salmonis. The disease was first described in coho salmon in 1989 (Bravo and Campos, 1989) and has been causing significant losses to the industry in Chile to date. Rickettsia-like organisms very similar to P. salmonis have been described in various other countries and farmed finfish species (Rozas and Enriquez, 2014). The origin of the pathogen found in Chile remains unknown: it may have been introduced with imported salmonid eggs, or it may have been present in other finfish species before infecting the newly introduced salmonid species. While pathological lesions similar to SRS have been described in other locations, for example in British Columbia, rickettsia-like organisms do not cause clinical disease to the extent observed in Chile in other aquaculture production systems (Rozas and 
Enriquez, 2014). While management measures to prevent and control SRS include antibiotic treatments, limiting fish stress, screening brood stock and vaccination (Rozas and Enriquez, 2014), the efficacy of these measures remain limited. As vaccines for SRS in field conditions are not very effective at controlling mortality outbreaks, antibiotic treatments remain the main tool available to Chilean producers to control SRS outbreaks. Consequently, the use of antibiotic treatments in the Chilean salmon aquaculture is much higher than in other large salmon producing countries such as Norway, Scotland and Canada (Miranda et al., 2018). The high level of antibiotic use is one of the main obstacles to the competitiveness of Chilean salmon on international markets, along the impacts of infectious salmon anaemia and harmful algae blooms on production volumes in the past decade (Poblete et al., 2019). Thus, SRS is considered a major threat to the future profitability and sustainability of the salmon industry in Chile (Ibieta et al., 2011). Many authors have documented both the challenges posed by such heavy use of antibiotics (Avendaño-Herrera, 2018) and the impacts of antimicrobial use in aquaculture on the health of people, animals and the marine environment (Burridge et al., 2010; Cabello, 2006; Cabello et al., 2013). The situation calls for a more systemic approach to disease management, which better considers the interplay between the host, pathogens and environment (Buschmann et al., 2009; Cabello and Godfrey, 2019).

\section{Context of the work and research questions}

To address these concerns, SRS became one of the main topics of a large joint government-industry program ('Programa para la gestión sanitaria en la Acuicultura', PGSA) initiated in 2017. The program aimed at systematically improving the management of fish health in the Chilean aquaculture, in particular in salmonid production. One of the projects looked at addressing some of the critical knowledge gaps about the SRS control in field conditions in Chile and providing fish health managers with evidence and insights to support their decision making in managing the disease on the farms. Building on previous work relative to the development of powerful and sustainable health information systems (Hutchison et al., 2018), a research platform was developed to integrate the health 
and management data routinely collected on salmonid aquaculture farms, an initiative named PIISAC ('Plataforma Integrada de Investigación Sanitaria para la Acuicultura'). This platform was then used to further examine the risk factors for SRS and evaluate the effectiveness of various interventions to control the disease in farmed salmon and trout in Chile.

This thesis presents work conducted during and after the PIISAC project, with the overall objective to investigate how data may be used more effectively to improve the management of fish health in salmonid farming, in particular for salmonid rickettsial septicaemia in Chilean sea farms. The main research questions that are addressed in this dissertation are:

1. Can the analysis of routine production and health data support assessments of the effectiveness of within-farm interventions to control SRS on sea farms?

2. How can management systems be developed for fish health data that would better support both routine management but also epidemiological research?

3. How is the aquaculture epidemiology community progressing towards sharing and re-using data?

\section{Outline of this thesis}

More specifically, this work used the PIISAC platform to investigate the effect of two within-farm interventions, antibiotic treatments (chapter 2) and improved control of sea lice (chapter 3), and to assess the role of between-farm dissemination as a potential source of infection for healthy farms (chapter 4). After the completion of the PIISAC project, the barriers to the adoption of the platform were analysed using a qualitative approach (chapter 5). Finally, taking a step back, the use and re-use of data in salmon epidemiological research was assessed more generally in a systematic review of published literature (chapter 6). This dissertation is concluded with a general discussion, summarising the main lessons learned during this work and discussing some key overarching topics (chapter 7). 


\section{References}

Avendaño-Herrera, R., 2018. Proper antibiotics use in the Chilean salmon industry: Policy and technology bottlenecks. Aquaculture 495, 803-805. https://doi.org/10.1016/j.aquaculture.2018.06.072

Bravo, S., Campos, M., 1989. Coho salmon syndrome in Chile. FHSAFS Newsl. 17, 3 .

Burridge, L., Weis, J.S., Cabello, F., Pizarro, J., Bostick, K., 2010. Chemical use in salmon aquaculture: A review of current practices and possible $\begin{array}{llll}\text { environmental } & \text { effects. } & \text { Aquaculture } & \text { 306, }\end{array}$ https://doi.org/10.1016/j.aquaculture.2010.05.020

Buschmann, A.H., Cabello, F., Young, K., Carvajal, J., Varela, D.A., Henríquez, L., 2009. Salmon aquaculture and coastal ecosystem health in Chile: Analysis of regulations, environmental impacts and bioremediation systems. Ocean Coast. Manag. 52 , $243-249$. https://doi.org/10.1016/j.ocecoaman.2009.03.002

Cabello, F.C., 2006. Heavy use of prophylactic antibiotics in aquaculture: a growing problem for human and animal health and for the environment. Environ. Microbiol. 8, 1137-1144. https://doi.org/10.1111/j.1462-2920.2006.01054.x

Cabello, F.C., Godfrey, H.P., 2019. Salmon aquaculture, Piscirickettsia salmonis virulence, and One Health: Dealing with harmful synergies between heavy antimicrobial use and piscine and human health. Aquaculture 507, 451-456. https://doi.org/10.1016/j.aquaculture.2019.04.048

Cabello, F.C., Godfrey, H.P., Tomova, A., Ivanova, L., Dölz, H., Millanao, A., Buschmann, A.H., 2013. Antimicrobial use in aquaculture re-examined: its relevance to antimicrobial resistance and to animal and human health: Aquacultural antimicrobial use and antimicrobial resistance. Environ. Microbiol. 15, 1917-1942. https://doi.org/10.1111/1462-2920.12134

Ciancio, J.E., Pascual, M.A., Lancelotti, J., Rossi, C.M.R., Botto, F., 2005. Natural Colonization and Establishment of a Chinook Salmon, Oncorhynchus tshawytscha, Population in the Santa Cruz River, an Atlantic Basin of Patagonia. Environ. Biol. Fishes 74, 219-227. https://doi.org/10.1007/s10641-005-0208-1 
Hutchison, J., Mackenzie, C., Madin, B., Happold, J., Leslie, E., Zalcman, E., Meyer, A., Cameron, A., 2018. New approaches to aquatic and terrestrial animal surveillance: The potential for people and technology to transform epidemiology. Prev. Vet. Med. https://doi.org/10.1016/j.prevetmed.2018.10.009

Ibieta, P., Tapia, V., Venegas, C., Hausdorf, M., Takle, H., 2011. Chilean Salmon Farming on the Horizon of Sustainability: Review of the Development of a Highly Intensive Production, the ISA Crisis and Implemented Actions to Reconstruct a More Sustainable Aquaculture Industry. Aquac. Environ. - Shar. Destiny. https://doi.org/10.5772/30678

Iversen, A., Asche, F., Hermansen, Ø., Nystøyl, R., 2020. Production cost and competitiveness in major salmon farming countries 2003-2018. Aquaculture 522, 735089. https://doi.org/10.1016/j.aquaculture.2020.735089

Miranda, C.D., Godoy, F.A., Lee, M.R., 2018. Current Status of the Use of Antibiotics and the Antimicrobial Resistance in the Chilean Salmon Farms. Front. Microbiol. 9, 1284. https://doi.org/10.3389/fmicb.2018.01284

Pascual, M.A., Ciancio, J.E., 2007. Chapter 18 - Introduced anadromous salmonids in Patagonia: risks, uses, and a conservation paradox, in: Ecological and Genetic Implications of Aquaculture Activities. Springer, Dordrecht, The Netherlands, p. 537.

Poblete, E.G., Drakeford, B.M., Ferreira, F.H., Barraza, M.G., Failler, P., 2019. The impact of trade and markets on Chilean Atlantic salmon farming. Aquac. Int. 27, 1465-1483. https://doi.org/10.1007/s10499-019-00400-7

Rozas, M., Enriquez, R., 2014. Piscirickettsiosis and Piscirickettsia salmonis in fish: a review. J. Fish Dis. 37, 163-188. https://doi.org/10.1111/jfd.12211

SalmonChile, 2020. Exports [WWW Document]. Website Asoc. Ind. Salmón Chile AG Chil. Salmon Ind. Assoc. URL https://www.salmonchile.cl/en/exports/ (accessed 12.6.20).

Soto, D., Arismendi, I., González, J., Sanzana, J., Jara, F., Jara, C., Guzman, E., Lara, A., 2006. Southern Chile, trout and salmon country: invasion patterns and threats for native species. Rev. Chil. Hist. Nat. 79. https://doi.org/10.4067/So716-078X2006000100009 
United Nations, 2006. A Case Study of the Salmon Industry in Chile, Transfer of Technology for Successful Integration into the Global Economy. United Nations Conference on Trade and Development, New York and Geneva. 


\section{CHAPTER 2}

\section{Effectiveness of antimicrobial treatment of salmonid rickettsial septicaemia in commercial salmon and trout farms in Chile}

Jonathan Happold ${ }^{\mathrm{a}}$, Anne Meyer ${ }^{\mathrm{a}}$, Rohan Sadler ${ }^{\mathrm{a}, \mathrm{b}}$, Brendan Cowled ${ }^{\mathrm{a}}$, Catriona Mackenzie ${ }^{a}$, Mark Stevenson ${ }^{c}$, Michael P. Ward ${ }^{d}$, Alicia L. Gallardo Lagno ${ }^{\mathrm{e}}$, Angus Cameron $^{\mathrm{a}}$

a Ausvet, 34 Thynne St, Bruce ACT 2617, Australia

b The University of Western Australia, Mo89 School of Agriculture and Environment, 35 Stirling Hwy, Crawley, WA 6008, Australia

c Faculty of Veterinary and Agricultural Sciences, The University of Melbourne, Parkville 3010, Victoria, Australia

d Sydney School of Veterinary Science, The University of Sydney, 425 Werombi Road, Camden 2570, New South Wales, Australia

e Servicio Nacional de Pesca y Acuicultura, Victoria 2832, Valparaíso, Chile

Aquaculture 525 (2020) 735323

https://doi.org/10.1016/j.aquaculture.2020.735323 


\section{Abstract}

Salmonid rickettsial septicaemia (SRS) is the most important disease of farmed salmonid fish in Chile and the main driver of a high rate of antimicrobial use. This study evaluated the effectiveness of antimicrobial treatment of SRS outbreaks, using industry-generated data from 8318 cage-level production cycles stocked between 2003 and 2018. We defined SRS outbreaks by a specified level of SRS-attributed mortality over a 3-week period and calculated the mortality rate attributed to SRS and unknown causes during a follow-up period from the start of treatment until resolution of the outbreak. The post-treatment mortality rate was used as a proxy for assessing the effectiveness of the antimicrobial treatment on the magnitude of the SRS outbreak. After developing a causal diagram, we analyzed the data with generalized, mixed-effects regression models within an informationtheoretic framework. For producers of Atlantic salmon, our results suggest that treatment should be provided to all infected cages on the farm, without interruption, as soon as possible after the start of the SRS outbreak. For producers of rainbow trout, our results suggest that treatment should be initiated as early as possible after the start of the SRS outbreak and with longer treatment durations if using in-feed florfenicol treatments. In the rainbow trout model, the large proportion of unexplained variance at the company and farm level indicates that lessons can be learned from the experience of other companies and farms. This study demonstrates the value of integrating aquaculture industry-generated health and management data to support applied epidemiological research.

\section{Key words}

Aquaculture; epidemiology; salmonid rickettsial septicaemia; piscirickettsiosis; Atlantic salmon; rainbow trout; antimicrobial treatment; Chile 


\section{Introduction}

Salmonid rickettsial septicaemia (SRS) is a severe disease of salmonid fish associated with infection with the intracellular bacterium Piscirickettsia salmonis (Rozas and Enriquez, 2014). Since the disease was first described in Chile in 1989 (Bravo and Campos, 1989), SRS has become one of the major production diseases of the Chilean salmonid aquaculture industry. The disease has also been detected in several other major salmon-producing countries including Norway (Olsen et al., 1997) and Canada (Brocklebank et al., 1992). In Chile in 2017, SRS accounted for approximately $70 \%$ of all mortalities in Atlantic salmon attributed to infectious causes (Sernapesca, 2018a) and treatment of SRS accounted for almost 95\% of the antimicrobial medication used in the salmon aquaculture industry (Sernapesca, 2018b). The rate of antimicrobial use in 2017 - approximately $500 \mathrm{~g}$ of antimicrobial medication per ton of biomass harvested (Sernapesca, 2018b) - was the lowest rate of use in five years but was substantially higher than the rate of use (less than one gram per ton) in salmon in Scotland and Norway (Watts et al., 2017). The effect of SRS combined with the associated high rate of antimicrobial use is a major threat to the profitability and sustainability of the Chilean salmon aquaculture industry, with losses from SRS estimated to be as high as US\$700 million per year (Maisey et al., 2017). Globally, there is growing concern about the potential effects of antimicrobial use in aquaculture in terms of antimicrobial resistance and associated threats to the health of people, animals and the marine environment (Cabello et al., 2013; Watts et al., 2017). In addition, the potential presence of antimicrobial residues in food products has major public health importance (Cabello, 2006; Okocha et al., 2018). Consequently, the salmon industry in Chile is seeking ways to move towards more prudent antimicrobial use (Barton and Fløysand, 2010). The rate of antimicrobial use in the Chilean salmonid industry reflects the high rate of occurrence of SRS, relatively poor responses to antimicrobial treatment (Almendras and Fuentealba, 1997; Price et al., 2016; Rozas and Enriquez, 2014) and limited effectiveness of other control measures such biosecurity, vaccination, reducing fish stress and early harvest (Evensen, 2016). Antimicrobial resistance of $P$. salmonis to florfenicol or oxytetracycline 
appears uncommon (Henriquez et al., 2016) and it is critical to identify other factors that may explain the limited effectiveness of treatments.

Studies of antimicrobial effectiveness in aquaculture typically take the form of randomized controlled trials or prospective cohort studies (Coyne et al., 2006; Martinsen et al., 1993; Namdari et al., 1998; Samuelsen et al., 1998). Although randomized controlled trials are considered to provide the highest quality of evidence (Dohoo et al., 2003), they are seldom conducted in commercial aquaculture settings because of high cost and the reluctance of producers to participate in a study in which random allocation to a potentially inferior treatment group may result in production losses. Prospective cohort studies are appropriate as a form of observational study; however, the costs of recruitment and data collection using traditional means often constrain sample size and reduce study power and the ability to detect subtle differences in treatment effectiveness. Consequently, there are few published studies on the effectiveness of antimicrobial treatment to control SRS in farmed salmon (Price et al., 2016; Mardones et al., 2018), despite the importance of SRS and strong reasons to reduce antimicrobial use. Alternatively, retrospective studies of industry-generated data may provide insights without the need for resource-intensive data collection (Hutchison et al., 2018).

In this study, we used industry-generated data to evaluate the effectiveness of antimicrobial treatment of SRS in farmed salmonid fish in commercial aquaculture systems in Chile. We aimed to identify and quantify the effect of factors related to fish health and susceptibility, treatment, management and environment on the effectiveness of specific antimicrobial treatment regimens and to recommend antimicrobial treatment strategies that minimize mortality associated with SRS outbreaks.

\section{Methods}

\subsection{Study design}

This population-based open cohort study investigated the effect of a range of potential risk factors on the effectiveness of antimicrobial treatment to reduce mortality during SRS outbreaks. A literature review was conducted to identify all 
factors associated with antimicrobial treatment for SRS, in vitro and in vivo, as well as factors associated with SRS incidence and mortality. In parallel, two workshops were conducted to elicit these factors and their relationships, in an approach similar to a method previously used (Inam et al. 2015) and following good practice for stakeholder engagement (Reed, 2008). The workshops gathered 22 and 35 stakeholders from the Chilean salmonid industry, in March and May 2018, respectively. Results from the stakeholder consultation and literature review were combined to develop a causal diagram (Greenland et al., 1999) indicating postulated causal relationships between explanatory variables and the effectiveness of antimicrobial treatment (Figure Suppl 1.1). All potential factors influencing post-treatment SRS mortality were extracted from the causal diagram. After discarding factors for which no data were available, 20 factors were retained for the analysis. We identified biologically plausible hypotheses for each of the remaining factors, classified into four groups: (1) hypotheses related to antimicrobial treatment, (2) hypotheses related to factors about fish health and susceptibility, (3) hypotheses related to management practices, and (4) hypotheses related to environmental conditions (Table Suppl 1.1).

\subsection{Setting}

The seawater phase of salmonid production in Chile is located in regions $\mathrm{X}$ (Los Lagos), XI (Aysén) and XII (Magallanes), ranging from $-55^{\circ}$ to $-40^{\circ}$ of latitude. As of May 2018, 21 companies were in operation, producing Atlantic salmon (Salmo salar), coho salmon (Oncorhynchus kisutch) and rainbow trout (Oncorhynchus mykiss). The three regions are divided into management areas (also called neighbourhoods) (Sernapesca, 2009), where sea farms are located. Within a farm, fish are housed in a variable number of separate cages.

At the time of this study, 7 companies operating in regions $\mathrm{X}$ and XI were voluntary participants in a research project that included integration of their health and production data in an online platform designed to support epidemiological research ('Plataforma Integrada de Investigación Sanitaria para la Acuicultura Chilena', PIISAC). This research project was part of a larger government-executed initiative supported by funding from a Chilean public-private partnership. The 
study population comprised all farms and cage-level production cycles managed by the companies participating in PIISAC during the period August 2003 to May 2018. During this period, approximately 830 farms reported at least one production cycle, with an average of 300 (range $240-380$ ) farms in production during any given week (Sernapesca, personal communication).

\subsection{Variables}

\subsubsection{Unit of analysis}

The unit of analysis was the cage-level SRS outbreak. We defined the start of a cage-level SRS outbreak as the first day of a 3-week period during which the average weekly cage-level SRS-attributed mortality risk was greater than $0.05 \%$. This threshold defining the start on an outbreak was based on inspection of cagelevel epidemic curves, published literature and consultation with producers, with consideration to the implications of different thresholds on the sensitivity and specificity of the outbreak definition. We defined the end of an SRS outbreak as the first day of a 3-week period during which the average weekly cage-level mortality risk attributed to both SRS and unknown causes was less than 0.1\%. We used SRSattributed mortality (rather than all-cause mortality) to define the start of an SRS outbreak, assuming that management decisions to control SRS are based on SRSattributed mortality.

During the two workshops, industry personnel highlighted that the majority of 'unknown cause' mortalities during an SRS outbreak are thought to be associated with SRS. External examination of dead fish and even post-mortem examination have a relatively low sensitivity given the unspecific nature of external signs and the occurrence of subclinical disease (Rozas and Enriquez, 2014). As a consequence, we included mortalities attributed to unknown causes in both the end-of-outbreak threshold and the outcome measure (next section). This is consistent with the approach used in previous studies on SRS, where total mortality was used after a diagnosis of SRS was reached on a farm (Jakob et al. 2014; Price et al., 2016). 


\subsubsection{Outcome: post-treatment mortality}

The outcome of interest was the rate of mortality attributed to either SRS or unknown causes during the period from the first day of treatment to the end of the outbreak (the post-treatment follow-up period). The outcome is referred to as 'post-treatment mortality' in the remainder of this manuscript and used as a proxy for effectiveness of the antimicrobial treatment. Cause of death was based on classification by farm personnel based on physical examination, necropsy or (in some cases) laboratory test results.

\subsubsection{Primary exposure: antimicrobial treatment type}

The primary exposure was the antimicrobial treatment type administered during the first treatment event of each SRS outbreak, with treatment type defined by active ingredient (florfenicol, oxytetracycline or first-generation fluoroquinolones) and route of administration (in-feed or by injection). Treatment events were defined as consecutive days of administration of a specific treatment type, with gaps between treatment days no longer than 6 days. Only outbreaks with at least one treatment event were used in the analysis. Data on dosage were not available in a consistent format and could not be used in this analysis.

\subsubsection{Other exposure variables}

Table 1 describes other exposure variables considered in this study, which were identified in relation to each of the hypotheses. These variables are also possible confounders of the association between the antimicrobial treatment type and post-treatment mortality. Sea lice count data were not available at the time of analysis, so lice burden was represented by two variables: the time since the last lice treatment and the total number of lice treatments from smolt entry until the SRS outbreak. In the absence of a standard measure of smolt quality, this factor was represented by the all-cause mortality during the first four weeks at sea and the smolt weight at sea entry.

We calculated area infection pressure using regulatory data (in order to include the SRS infection status of all farms that were active in the period prior to 
each outbreak) and a previously published method (Rees et al., 2014). All farms in a radius of $10 \mathrm{~km}$ were considered, given that the influence of SRS-infected farms appears to not exceed that range (Rees et al., 2014). The seaway distance between farms was computed using a least-cost path algorithm implemented in Python and the geographical coordinates of sea farms (Sernapesca, personal communication).

Table 1 Definition of exposure variables considered in a study of the effectiveness of antimicrobial treatment of SRS, by hypotheses group.

\begin{tabular}{|c|c|}
\hline Variable name & Definition (and unit where relevant) \\
\hline \multicolumn{2}{|c|}{ Hypotheses group 1: antimicrobial treatment factors } \\
\hline Treatment type & $\begin{array}{l}\text { Variable comprising the active ingredient ( } 3 \text { levels: florfenicol, } \\
\text { oxytetracycline and first-generation fluoroquinolones) and the route of } \\
\text { administration ( } 2 \text { levels: in-feed and injection) }\end{array}$ \\
\hline Treatment duration & $\begin{array}{l}\text { Duration of treatment, which may include days when the treatment was } \\
\text { interrupted (days) }\end{array}$ \\
\hline \multicolumn{2}{|c|}{ Hypotheses group 2: fish-level factors } \\
\hline $\begin{array}{l}\text { Mortality from other } \\
\text { diseases }\end{array}$ & $\begin{array}{l}\text { Mortality rate attributed to infectious causes other than SRS and } \\
\text { unknown causes over the } 21 \text { days preceding the beginning of treatment } \\
\text { (per fish-day-at-risk). Other diseases include, for example, infectious } \\
\text { pancreatic necrosis, bacterial kidney disease and fungal diseases. }\end{array}$ \\
\hline $\begin{array}{l}\text { Time since lice } \\
\text { treatment }\end{array}$ & $\begin{array}{l}\text { Number of days between the last lice treatment and the beginning of } \\
\text { antimicrobial treatment; proxy for lice burden }\end{array}$ \\
\hline $\begin{array}{l}\text { Number of lice } \\
\text { treatments }\end{array}$ & $\begin{array}{l}\text { Number of days when a lice treatment was administered between the } \\
\text { beginning of the cycle and the beginning of treatment; proxy for lice } \\
\text { burden }\end{array}$ \\
\hline Biomass density & Biomass density at the beginning of treatment $(\mathrm{kg} / \mathrm{m} 3)$ \\
\hline Time at sea & $\begin{array}{l}\text { Number of degree-days between the beginning of the cycle and the } \\
\text { beginning of treatment }\end{array}$ \\
\hline Smolt weight & Average fish weight at sea entry (grams) \\
\hline Smolt mortality & $\begin{array}{l}\text { All-cause mortality rate during the first } 28 \text { days at sea (per fish-day-at- } \\
\text { risk) }\end{array}$ \\
\hline Time since vaccine & $\begin{array}{l}\text { Number of days between the last SRS vaccination and the beginning of } \\
\text { treatment; proxy for SRS-specific immunity }\end{array}$ \\
\hline Weight variability & $\begin{array}{l}\text { Coefficient of variation of the fish weight within the cage, estimated at } \\
\text { one point in time during the production cycle. Included in the post hoc } \\
\text { analysis due to missing data }\end{array}$ \\
\hline \multicolumn{2}{|c|}{ Hypotheses group 3: management factors } \\
\hline Treatment continuity & $\begin{array}{l}\text { Proportion of actual treatment days (number of days when the drug was } \\
\text { effectively administered divided by treatment duration) }\end{array}$ \\
\hline Time to treatment & $\begin{array}{l}\text { Number of degree-days between the beginning of the outbreak and the } \\
\text { beginning of treatment }\end{array}$ \\
\hline
\end{tabular}




\begin{tabular}{|c|c|}
\hline Variable name & Definition (and unit where relevant) \\
\hline $\begin{array}{l}\text { Pre-treatment SRS } \\
\text { mortality }\end{array}$ & $\begin{array}{l}\text { SRS-attributed mortality rate during the } 21 \text { days preceding the } \\
\text { beginning of treatment (per fish-day-at-risk) }\end{array}$ \\
\hline $\begin{array}{l}\text { Pre-treatment } \\
\text { unknown mortality }\end{array}$ & $\begin{array}{l}\text { Unknown-cause mortality rate during the } 21 \text { days preceding the } \\
\text { beginning of treatment (per fish-day-at-risk) }\end{array}$ \\
\hline $\begin{array}{l}\text { Pre-treatment farm } \\
\text { coverage }\end{array}$ & $\begin{array}{l}\text { Proportion of cages within a farm treated with antimicrobials during the } \\
21 \text { days before the start of treatment }\end{array}$ \\
\hline $\begin{array}{l}\text { Post-treatment farm } \\
\text { coverage }\end{array}$ & $\begin{array}{l}\text { Proportion of cages within a farm treated with antimicrobials over the } \\
\text { post-treatment follow-up period }\end{array}$ \\
\hline \multicolumn{2}{|c|}{ Hypotheses group 4: environmental factors } \\
\hline Water temperature & Average sea temperature during the follow-up period (degrees Celsius) \\
\hline Turbidity & $\begin{array}{l}\text { Mean water turbidity for the } 21 \text { days before the start of treatment. } \\
\text { Included in the post hoc analysis due to missing data }\end{array}$ \\
\hline Oxygen & $\begin{array}{l}\text { Mean dissolved oxygen concentration for the } 21 \text { days before the start of } \\
\text { treatment (mg/L). Included in the post hoc analysis due to missing data }\end{array}$ \\
\hline Salinity & $\begin{array}{l}\text { Mean salinity for the } 21 \text { days before the start of treatment (parts per } \\
\text { trillion). Included in the post hoc analysis due to missing data }\end{array}$ \\
\hline $\begin{array}{l}\text { Area infection } \\
\text { pressure }\end{array}$ & $\begin{array}{l}\text { SRS infection pressure arising from nearby farms during the } 21 \text { days } \\
\text { before the start of treatment, calculated as the weighted density average } \\
\text { of the SRS mortality rate on all farms within a } 10 \text { km radius. The } \\
\text { variable was computed as the product of the SRS mortality rate on each } \\
\text { neighbor farm and a weight obtained from the seaway distance between } \\
\text { farms, and a Gaussian kernel density with a bandwidth equal to the } \\
\text { geometric mean of a random sample of the observed bandwidths, } \\
\text { divided by the sum of weights. The SRS mortality rates were extracted } \\
\text { from the regulatory mortality declarations to obtain data from all active } \\
\text { farms. }\end{array}$ \\
\hline $\begin{array}{l}\text { Farm infection } \\
\text { pressure }\end{array}$ & $\begin{array}{l}\text { Local SRS infection pressure calculated as SRS mortality rate in other } \\
\text { cages from the same farm over the } 21 \text { days before the start of treatment } \\
\text { (per fish-day-at-risk). In the absence of data on the spatial location of } \\
\text { cages with each site, all cages within a site were considered equal when } \\
\text { calculating the farm infection pressure. }\end{array}$ \\
\hline
\end{tabular}

\subsubsection{Confounder variables}

In addition to the variables listed in

Table 1, six variables were included in each of the regression models because a priori they were believed to potentially confound the association between the explanatory variables and the outcome. These variables were farm location (expressed as latitude and longitude of the centroid of the lease), rank of the outbreak within the production cycle (outbreaks were ranked by order of appearance in each cycle), number of subsequent treatments during the outbreak and calendar day of the beginning of the outbreak. The occurrence of harvest during outbreaks (harvest before resolution) and the number of subsequent 
treatments were also included as confounding variables for the same reason: they are critical management variables and were therefore included in all models rather than as separate hypotheses. Harvest-truncated outbreaks (i.e. where harvest occurred before resolution of the outbreak) were included in the analysis because harvest to reduce diseases losses is an important management option for producers, these outbreaks represented a large proportion (34\%) of the data, and their exclusion did not substantially affect the model results.

\subsection{Data sources and management}

We extracted daily cage-level records from each company's database and compiled these in an integrated PostgreSQL database within PIISAC. All farms, cages and groups of fish included in the data provided by participating companies were eligible for analysis. Production cycles were considered valid when the duration was six months or more and the initial weight of the smolt was less than $500 \mathrm{~g}$ : these criteria ensured that broodstock farms were not erroneously included in the analysis. The PIISAC database also included mortality declarations for all active salmonid sea farms in Chile from the regulatory database (Sistema de Información para la Fiscalización de Acuicultura) of the Chilean National Fisheries and Aquaculture Service (Sernapesca).

\subsection{Statistical methods}

\subsubsection{Model building}

Consistent with the information-theoretic approach proposed by Burnham and Anderson (2002), we defined a series of statistical models based on the hypotheses developed a priori. The modelling adopted a generalized linear mixed effect regression framework (Bates et al., 2015), implemented in the R statistical environment (R Core Team, 2018). A minimal model was defined that included the potential confounders described above and several variables that represented clustering of the data: management area, farm and cage were modelled as nested random effects, while region and company were included as fixed effects because these variables were comprised of a small number of categories. 
The statistical models considered were either a single variable hypothesis model, which added the exposure variable(s) or interaction term corresponding to a given hypothesis to the minimal model described above, or a block model that included all variables related to a hypothesis group. The four variable blocks, corresponding to each of the four hypothesis groups, were added singly, pairwise, three at a time and all four together to the minimal model, to define a total of 15 separate block combinations. The model containing all four blocks of variables was termed the maximal model.

\subsubsection{Model fitting}

We used negative binomial models of the post-treatment mortality count because initial data exploration showed count overdispersion relative to a Poisson distribution. The post-treatment mortality count was offset by the total number of fish-days-at-risk during the follow-up period, effectively modelling the outcome as a mortality rate (Dohoo et al., 2003). Atlantic salmon and rainbow trout were modelled separately. We were unable to develop a robust statistical model for coho salmon because of the small number of outbreaks observed in this species. Atlantic salmon and rainbow trout are referred to as 'salmon' and 'trout' in the remainder of the manuscript. Each continuous explanatory variable was centered and scaled to a z-score. Variables with a high variance inflation factor $(>3)$ were dropped from the models in which they appeared (Zuur et al., 2010): this affected the time since lice treatment in the trout models and longitude in the salmon models. Residual and fitted value plots were used to assess the model fit and the influence of individual data points.

\subsubsection{Model selection}

The 38 resulting models (22 single variable hypothesis models, 15 block models and the minimal model) were ranked according to their Akaike weight computed from their bias-corrected Akaike information criterion (AICc) (Akaike, 1974). The Akaike weights reflect the extent to which each model is supported by the data and thus provide a ranking of the hypotheses considered. The modelaveraged coefficients presented are an average of the coefficients from each of the 
models with a non-zero Akaike weight, weighted by the Akaike weights of each model. Posterior marginal means were computed from the maximal model (Lenth, 2018). Where multiple pairwise comparisons were made, standard errors of the differences between two means were adjusted according to the Tukey method.

\subsubsection{Post-hoc modelling}

With the information-theoretic approach, all models included in the selection process must be fitted to the same dataset. Several variables - coefficient of variation in fish weight, dissolved oxygen, salinity and turbidity - had a large number of missing values and were excluded from the main dataset to retain the largest possible amount of data for model selection. To investigate the role of these variables on post-treatment mortality, we added these explanatory variables one at a time to the final model for each species.

\section{Results}

\subsection{Descriptive results}

The Atlantic salmon dataset comprised 4782 complete production cycles and 3183 outbreaks of SRS with at least one antimicrobial treatment event. The rainbow trout dataset comprised 2755 complete production and 1149 outbreaks of SRS with at least one treatment event. Outbreaks of SRS occurred in 174 farms in 42 management areas, and $62 \%$ of salmon cages and $78 \%$ of trout cages experienced at least one SRS outbreak during the production cycle. In salmon, outbreaks lasted on average 66 days in total, including an average of 15 days after the end of treatment. The corresponding values in trout were 74 and 29 days, respectively. Table 2 shows the distribution of the outcome and selected continuous exposure variables for the SRS outbreaks included in the analysis. In salmon, the treatment types used during SRS outbreaks were mostly in-feed florfenicol ( $\mathrm{N}=2825,89 \%)$ and in-feed oxytetracycline $(\mathrm{N}=289,9 \%)$, with some outbreaks being treated with injectable oxytetracycline $(\mathrm{N}=47,1 \%)$ or in-feed firstgeneration fluoroquinolones $(\mathrm{N}=17,<1 \%)$. In trout, the treatment types were infeed florfenicol $(\mathrm{N}=741,64 \%)$, injectable oxytetracycline $(\mathrm{N}=140,12 \%)$, 
injectable florfenicol $(\mathrm{N}=130,11 \%)$, in-feed oxytetracycline $(\mathrm{N}=110,9 \%)$ and infeed first-generation fluoroquinolones $(\mathrm{N}=28,2 \%)$.

Table 2 Summary of the outcome and selected exposure variables for the SRS outbreaks in salmon ( $\mathrm{N}=3183)$ and trout $(\mathrm{N}=1149)$ included in a study of the effectiveness of antimicrobial treatment of SRS.

\begin{tabular}{|c|c|c|c|c|c|c|c|}
\hline Species & Variable & Min & Q1 & Median & Mean & Q3 & Max \\
\hline \multirow{8}{*}{$\begin{array}{l}\text { Atlantic } \\
\text { salmon }\end{array}$} & $\begin{array}{l}\text { Post-treatment mortality } \\
\text { (rate per 100,000 fish-days- } \\
\text { at-risk) }\end{array}$ & 0.0 & 15 & 29 & 49 & 52 & 1513 \\
\hline & Time at sea (degree-days) & 10 & 2249 & 3276 & 3153 & 4106 & 5739 \\
\hline & Treatment duration (days) & 1 & 14 & 16 & 17 & 20 & 53 \\
\hline & Treatment continuity (\%) & 38 & 94 & 100 & 95 & 100 & 100 \\
\hline & $\begin{array}{l}\text { Time to treatment (degree- } \\
\text { days) }\end{array}$ & 8 & 162 & 268 & 426 & 454 & 4791 \\
\hline & $\begin{array}{l}\text { Pre-treatment SRS mortality } \\
\text { (rate per 100,000 fish-days- } \\
\text { at-risk) }\end{array}$ & 0.0 & 2.8 & 6.5 & 18 & 15 & 786 \\
\hline & $\begin{array}{l}\text { Total outbreak duration } \\
\text { (days) }\end{array}$ & 1.0 & 31 & 47 & 66 & 74 & 550 \\
\hline & $\begin{array}{l}\text { Post-treatment outbreak } \\
\text { duration (days) }\end{array}$ & $<0.0^{*}$ & $<0.0^{*}$ & 5.0 & 15 & 17 & 432 \\
\hline \multirow{8}{*}{$\begin{array}{l}\text { Rainbow } \\
\text { trout }\end{array}$} & $\begin{array}{l}\text { Post-treatment mortality rate } \\
\text { (per 100,00o fish-days-at- } \\
\text { risk) }\end{array}$ & 0.0 & 26 & 53 & 170 & 133 & 7101 \\
\hline & Time at sea (degree-days) & 513 & 1784 & 2142 & 2146 & 2553 & 8176 \\
\hline & Treatment duration (days) & 1 & 10 & 15 & 14 & 18 & 39 \\
\hline & Treatment continuity (\%) & 55 & 94 & 100 & 95 & 100 & 100 \\
\hline & $\begin{array}{l}\text { Time to treatment (degree- } \\
\text { days) }\end{array}$ & 10 & 161 & 315 & 406 & 531 & 1755 \\
\hline & $\begin{array}{l}\text { Pre-treatment SRS mortality } \\
\text { rate (per 100,000 fish-days- } \\
\text { at-risk) }\end{array}$ & 0.0 & 4.5 & 13 & 32 & 34 & 982 \\
\hline & $\begin{array}{l}\text { Total outbreak duration } \\
\text { (days) }\end{array}$ & 2.0 & 34 & 62 & 74 & 99 & 305 \\
\hline & $\begin{array}{l}\text { Post-treatment outbreak } \\
\text { duration (days) }\end{array}$ & $<0.0^{*}$ & 1.0 & 15.0 & 29 & 41 & 253 \\
\hline
\end{tabular}

\footnotetext{
${ }^{*}$ these values were negative, indicating that the outbreak was considered as resolved before the end of the treatment.
}

Q1: first quartile, Q3: third quartile 


\subsection{Atlantic salmon models}

Two multivariable models were supported by the Atlantic salmon data (Table Suppl 2.1), both of which included the block of variables corresponding to management and environmental hypotheses. The most supported model comprised only the management and environmental blocks of variables (Akaike weight 90\%), while the other supported model also included the block of variables corresponding to fish-level hypotheses. The models ranked third and fourth had a 12- and 16-point difference in AICc with the first model, indicating a modest difference in fit. An AICc difference of 181 points separated these four models from the fifth-ranked model, suggesting that the most supported models provide a much better fit to the data than any of the other models.

Table 3 Adjusted incidence rate ratios of SRS-attributed mortality based on model averaging of the two supported models for Atlantic salmon ( $N=3183)$.

\begin{tabular}{lllll}
\hline Variable & $\begin{array}{l}\text { Rate } \\
\text { ratio }\end{array}$ & $\begin{array}{l}\mathbf{9 5 \%} \text { CI } \\
\text { lower }\end{array}$ & $\begin{array}{l}\text { 95\% } \\
\text { CI } \\
\text { upper }\end{array}$ & P-value \\
\hline Management variables & & & & \\
\hline Treatment continuity & $0.91^{\mathrm{a}}$ & 0.88 & 0.94 & $<0.01$ \\
\hline Time to treatment & 1.25 & 1.16 & 1.34 & $<0.01$ \\
\hline Pre-treatment SRS mortality & 1.52 & 1.44 & 1.61 & $<0.01$ \\
\hline Pre-treatment unknown mortality & 1.38 & 1.31 & 1.44 & $<0.01$ \\
\hline Pre-treatment farm coverage & 0.87 & 0.84 & 0.91 & $<0.01$ \\
\hline Post-treatment farm coverage & 1.10 & 1.05 & 1.15 & $<0.01$ \\
\hline Fish variables & & & & \\
\hline Biomass density & 1.02 & 0.96 & 1.09 & 0.53 \\
\hline Time at sea & 0.98 & 0.93 & 1.03 & 0.42 \\
\hline Mortality from other diseases & 0.99 & 0.96 & 1.03 & 0.67 \\
\hline Smolt weight & 0.97 & 0.93 & 1.01 & 0.13 \\
\hline Smolt mortality & 1.04 & 1.00 & 1.07 & $0.03^{\mathrm{b}}$ \\
\hline Time since lice treatment & 0.96 & 0.91 & 1.03 & 0.25 \\
\hline Number of lice treatments & 0.92 & 0.87 & 0.98 & 0.01 \\
\hline Time since vaccine & 1.06 & 1.01 & 1.12 & 0.01 \\
\hline Environment variables & 1.00 & 0.97 & 1.03 & 0.94 \\
\hline Area infection pressure & 1.36 & 1.29 & 1.43 & $<0.01$ \\
\hline Farm infection pressure & & & & \\
\hline
\end{tabular}




\begin{tabular}{|c|c|c|c|c|c|}
\hline \multirow{2}{*}{\multicolumn{2}{|c|}{$\begin{array}{l}\text { Variable } \\
\text { Water temperature }\end{array}$}} & $\begin{array}{l}\text { Rate } \\
\text { ratio }\end{array}$ & $\begin{array}{l}\text { 95\% CI } \\
\text { lower }\end{array}$ & $\begin{array}{l}95 \% \\
\text { CI } \\
\text { upper }\end{array}$ & P-value \\
\hline & & 1.20 & 1.14 & 1.27 & $<0.01$ \\
\hline \multicolumn{6}{|l|}{ Confounding variables } \\
\hline \multicolumn{2}{|l|}{ Calendar day } & 1.28 & 1.15 & 1.42 & $<0.01$ \\
\hline \multicolumn{2}{|l|}{ Calendar day, squared } & 1.03 & 0.95 & 1.11 & 0.46 \\
\hline \multicolumn{2}{|l|}{ Calendar day, cubed } & 0.90 & 0.84 & 0.96 & $<0.01$ \\
\hline \multicolumn{2}{|l|}{ Latitude } & 0.85 & 0.64 & 1.14 & 0.23 \\
\hline \multirow[t]{2}{*}{ Harvest before resolution } & No & \multicolumn{4}{|c|}{1 (reference category) } \\
\hline & Yes & 0.79 & 0.72 & 0.87 & $<0.01$ \\
\hline \multirow[t]{5}{*}{ Outbreak rank } & 1st outbreak & \multicolumn{4}{|c|}{1 (reference category) } \\
\hline & 2nd outbreak & 1.07 & 0.98 & 1.16 & 0.10 \\
\hline & 3rd outbreak & 1.02 & 0.87 & 1.19 & 0.80 \\
\hline & 4th outbreak & 0.73 & 0.49 & 1.10 & 0.10 \\
\hline & $5^{\text {th outbreak }}$ & 0.68 & 0.19 & 2.38 & 0.49 \\
\hline \multirow[t]{5}{*}{ Additional treatments } & None & \multicolumn{4}{|c|}{1 (reference category) } \\
\hline & $\begin{array}{l}1 \text { additional } \\
\text { treatment }\end{array}$ & 0.58 & 0.51 & 0.65 & $<0.01$ \\
\hline & $\begin{array}{l}2 \text { additional } \\
\text { treatments }\end{array}$ & 0.42 & 0.34 & 0.52 & $<0.01$ \\
\hline & $\begin{array}{l}3 \text { additional } \\
\text { treatments }\end{array}$ & 0.32 & 0.21 & 0.49 & $<0.01$ \\
\hline & $\begin{array}{l}4 \text { additional } \\
\text { treatments }\end{array}$ & 0.11 & 0.04 & 0.27 & $<0.01$ \\
\hline \multirow[t]{2}{*}{ Region } & Region 10 & \multicolumn{4}{|c|}{1 (reference category) } \\
\hline & Region 11 & 0.80 & 0.46 & 1.39 & 0.39 \\
\hline
\end{tabular}

$\overline{\mathrm{CI}}=$ confidence interval; FLO = florfenicol; FLU = first-generation fluoroquinolones; OTC $=$ oxytetracycline

a Parameter estimates of continuous variables are presented for the scaled variables.

b Apparent small discrepancies with confidence intervals including 1 but $P$ values smaller than 0.05 are due to the model averaging procedure. They only occurred for variables that were not significant in all models, and which were associated with a large standard error estimate in at least one of the models. Such estimates were interpreted with caution and did not substantially influence the overall results. 

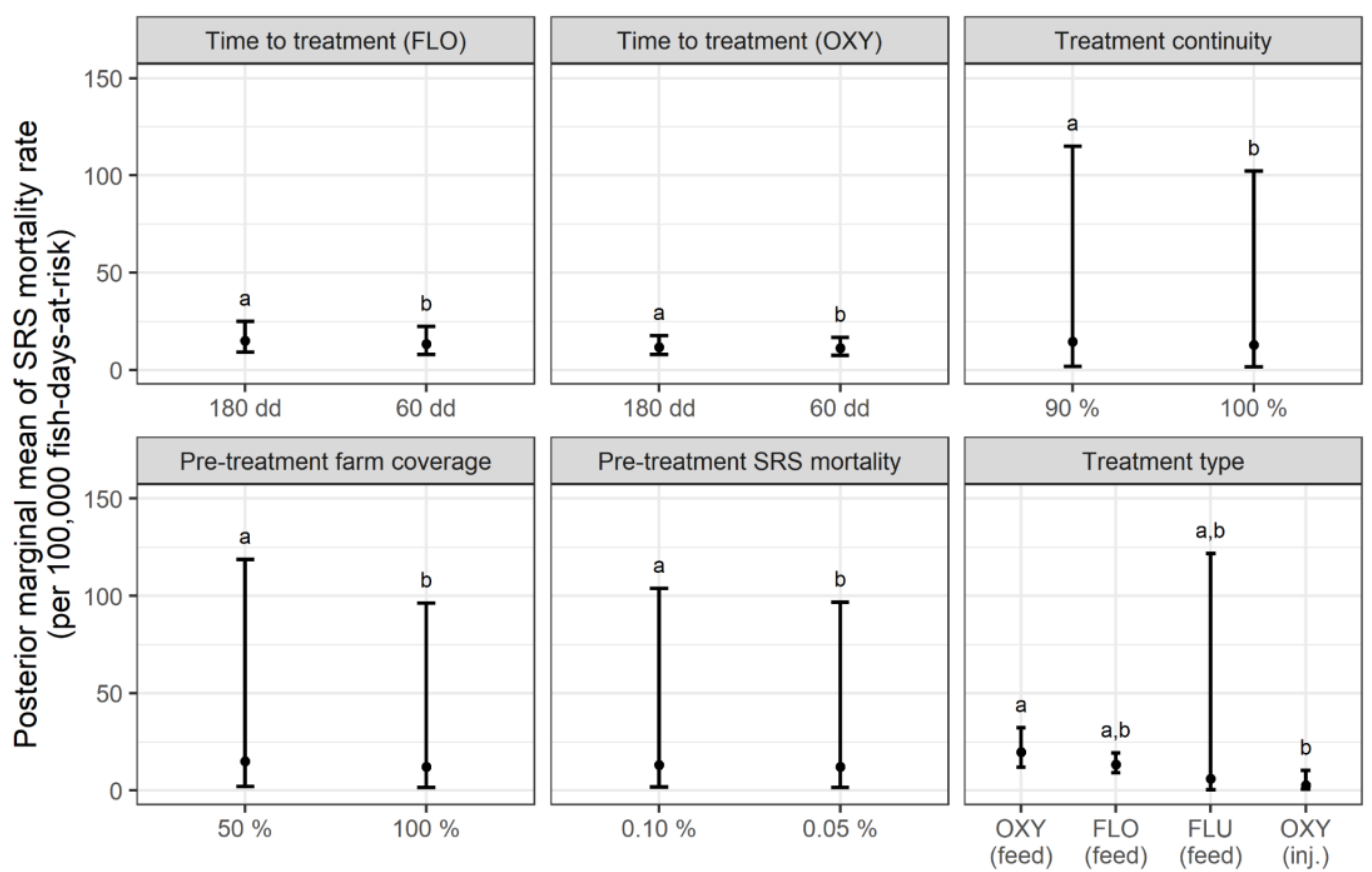

The bars correspond to the $95 \%$ prediction intervals of the marginal means. Marginal means corresponding to a given intervention with different superscripts were significantly different, based on comparison of the adjusted standard errors of the differences between two means. FLO: florfenicol; FLU: first-generation fluoroquinolones; OXY: oxytetracycline; inj.: injectable; dd: degreedays.

Figure 1 Posterior marginal means and comparisons of the effect of selected interventions on the SRS-attributed mortality after treatment in Atlantic salmon.

In-feed oxytetracycline appeared less effective than injectable oxytetracycline in salmon when using multiple comparisons based on the maximal model (Figure 1). However, the treatment type variable was not retained in the averaged model (Table 3), as it did not appear in any of the model components with non-zero weight in the model selection procedure.

All the management factors were statistically significant predictors of mortality incidence rate. Reducing treatment interruptions by one standard deviation decreased the post-treatment mortality rate by $9 \%$ (95\% CI $6 \%-12 \%$ ). Decreasing the time to treatment from the mean to one standard deviation below the mean resulted in a $20 \%$ (95\% CI $14 \%-25 \%)$ decrease in the post-treatment 
mortality rate. Treatments initiated when SRS mortality was one standard deviation lower than the average mortality at the start of treatment were associated with a $34 \%$ (95\% CI 31\%-38\%) lower post-treatment mortality. Last, increasing the pre-treatment farm coverage (proportion of cages treated in the 21 days prior to treatment) by one standard deviation from the mean reduced the post-treatment mortality by $13 \%$ (95\% CI 9\%-16\%). Posterior marginal means associated with different management practices are shown in Figure 1.

Among the other primary exposures, duration of treatment was not retained in the averaged model. The number of lice treatments, the time since last SRS vaccine and the smolt mortality were significant fish-level factors. The number of lice treatments had a negative association with the post-treatment mortality, while the time since last SRS vaccine and the smolt mortality had positive associations. Significant environmental factors were the farm infection pressure and the water temperature.

Variables included as potential confounders that were significantly associated with post-treatment mortality included calendar day of beginning of the outbreak, number of subsequent treatments and harvest before resolution. The association of calendar day with the outcome via a cubic function indicates a seasonal effect, where post-treatment mortality was highest in summer and lowest in winter. No hypothesis testing was conducted for turbidity because most of the data were missing (turbidity data available for only 1.5\% ( $\mathrm{N}=82)$ of outbreaks). Of the remaining hypotheses, higher levels of dissolved oxygen in the 21-day period before treatment were associated with significantly greater effectiveness of treatment (incidence rate ratio 0.90, CI 0.86-0.95). Salinity and within-cage weight variability were not statistically significantly associated with post-treatment mortality $(\mathrm{P}>0.05)$.

\subsection{Rainbow trout models}

Only the maximal model was supported by rainbow trout data (Table Suppl 2.2). The model ranked second had a 24-point difference in AICc with the first model, indicating a modest difference in fit. 
trout $(\mathrm{N}=1149)$.

\begin{tabular}{|c|c|c|c|c|c|}
\hline \multicolumn{2}{|l|}{ Variable } & Rate ratio & $\begin{array}{l}95 \% \\
\text { CI } \\
\text { lower }\end{array}$ & $\begin{array}{l}\text { 95\% CI } \\
\text { upper }\end{array}$ & P-value \\
\hline \multicolumn{6}{|c|}{ Treatment variables } \\
\hline \multirow[t]{4}{*}{ Treatment type ${ }^{a}$} & FLO - in-feed & \multicolumn{3}{|c|}{1 (reference category) } & \\
\hline & FLO - injection & 0.51 & 0.34 & 0.78 & $<0.01$ \\
\hline & OTC - in-feed & 1.18 & 0.70 & 1.99 & 0.54 \\
\hline & OTC - injection & 0.63 & 0.37 & 1.09 & 0.10 \\
\hline Treatment durati & & $0.62^{b}$ & 0.53 & 0.72 & $<0.01$ \\
\hline \multicolumn{6}{|c|}{ Management variables } \\
\hline \multicolumn{2}{|c|}{ Treatment continuity } & 0.96 & 0.88 & 1.04 & 0.34 \\
\hline \multicolumn{2}{|c|}{ Time to treatment } & 1.00 & 0.86 & 1.17 & 0.96 \\
\hline \multicolumn{2}{|c|}{ Pre-treatment SRS mortality } & 1.68 & 1.53 & 1.85 & $<0.01$ \\
\hline \multicolumn{2}{|c|}{ Pre-treatment unknown mortality } & 1.24 & 1.11 & 1.39 & $<0.01$ \\
\hline \multicolumn{2}{|c|}{ Pre-treatment farm coverage } & 0.99 & 0.90 & 1.09 & 0.81 \\
\hline \multicolumn{2}{|c|}{ Post-treatment farm coverage } & 0.91 & 0.83 & 1.00 & 0.03 \\
\hline \multicolumn{6}{|c|}{ Fish variables } \\
\hline \multicolumn{2}{|l|}{ Biomass density } & 0.96 & 0.89 & 1.03 & 0.25 \\
\hline \multicolumn{2}{|c|}{ Time at sea } & 0.84 & 0.76 & 0.93 & $<0.01$ \\
\hline \multicolumn{2}{|c|}{ Mortality from other diseases } & 0.96 & 0.89 & 1.04 & 0.31 \\
\hline \multicolumn{2}{|c|}{ Smolt weight } & 1.06 & 0.96 & 1.17 & 0.28 \\
\hline \multicolumn{2}{|c|}{ Smolt mortality } & 1.06 & 0.99 & 1.13 & 0.11 \\
\hline \multicolumn{2}{|c|}{ Number of lice treatments } & 2.05 & 1.67 & 2.51 & $<0.01$ \\
\hline \multicolumn{2}{|c|}{ Time since vaccine } & 1.06 & 0.95 & 1.18 & 0.27 \\
\hline \multicolumn{6}{|c|}{ Environment variables } \\
\hline \multicolumn{2}{|c|}{ Area infection pressure } & 1.10 & 1.02 & 1.19 & 0.01 \\
\hline \multicolumn{2}{|c|}{ Farm infection pressure } & 1.07 & 0.97 & 1.17 & 0.18 \\
\hline \multicolumn{2}{|c|}{ Water temperature } & 1.24 & 1.07 & 1.44 & $<0.01$ \\
\hline \multicolumn{6}{|c|}{ Confounding variables } \\
\hline \multicolumn{2}{|c|}{ Calendar day } & 0.56 & 0.45 & 0.70 & $<0.01$ \\
\hline \multicolumn{2}{|c|}{ Calendar day, squared } & 1.05 & 0.89 & 1.24 & 0.54 \\
\hline \multicolumn{2}{|c|}{ Calendar day, cubed } & 1.32 & 1.18 & 1.48 & $<0.01$ \\
\hline \multicolumn{2}{|c|}{ Latitude } & 0.76 & 0.32 & 1.81 & 0.53 \\
\hline \multicolumn{2}{|l|}{ Longitude } & 1.08 & 0.79 & 1.48 & 0.63 \\
\hline
\end{tabular}




\begin{tabular}{|c|c|c|c|c|c|}
\hline Variable & & Rate ratio & $\begin{array}{l}95 \% \\
\text { CI } \\
\text { lower }\end{array}$ & $\begin{array}{l}95 \% \mathrm{CI} \\
\text { upper }\end{array}$ & P-value \\
\hline \multirow{2}{*}{$\begin{array}{l}\text { Harvest before } \\
\text { resolution }\end{array}$} & No & \multicolumn{4}{|c|}{1 (reference category) } \\
\hline & Yes & 1.15 & 0.97 & 1.37 & 0.10 \\
\hline \multirow[t]{4}{*}{ Outbreak rank } & 1st outbreak & \multicolumn{4}{|c|}{1 (reference category) } \\
\hline & 2nd outbreak & 0.74 & 0.62 & 0.88 & 0.01 \\
\hline & 3rd outbreak & 0.51 & 0.30 & 0.88 & 0.02 \\
\hline & 4th outbreak & 0.92 & 0.23 & 3.63 & 0.91 \\
\hline \multirow{6}{*}{$\begin{array}{l}\text { Additional } \\
\text { treatments }\end{array}$} & None & \multicolumn{4}{|c|}{1 (reference category) } \\
\hline & $\begin{array}{l}1 \text { additional } \\
\text { treatment }\end{array}$ & 1.15 & 0.92 & 1.44 & 0.23 \\
\hline & $\begin{array}{l}2 \text { additional } \\
\text { treatments }\end{array}$ & 0.99 & 0.67 & 1.47 & 0.96 \\
\hline & $\begin{array}{l}3 \text { additional } \\
\text { treatments }\end{array}$ & 0.40 & 0.18 & 0.88 & 0.02 \\
\hline & $\begin{array}{l}4 \text { additional } \\
\text { treatments }\end{array}$ & 0.14 & 0.02 & 0.84 & 0.03 \\
\hline & $\begin{array}{l}5 \text { additional } \\
\text { treatments }\end{array}$ & 0.23 & 0.04 & 1.52 & 0.13 \\
\hline \multirow[t]{2}{*}{ Region } & Region 10 & \multicolumn{4}{|c|}{1 (reference category) } \\
\hline & Region 11 & 0.97 & 0.16 & 6.00 & 0.97 \\
\hline \multirow{4}{*}{$\begin{array}{l}\text { Interaction } \\
\text { between treatment } \\
\text { type and treatment } \\
\text { duration }\end{array}$} & FLO - in-feed & \multicolumn{4}{|c|}{1 (reference category) } \\
\hline & FLO - injection & 1.94 & 1.46 & 2.59 & $<0.01$ \\
\hline & OTC - in-feed & 1.23 & 0.92 & 1.66 & 0.16 \\
\hline & OTC - injection & 1.44 & 1.06 & 1.95 & 0.02 \\
\hline \multirow{4}{*}{$\begin{array}{l}\text { Interaction } \\
\text { between treatment } \\
\text { type and time to } \\
\text { treatment }\end{array}$} & FLO - in-feed & \multicolumn{4}{|c|}{1 (reference category) } \\
\hline & FLO - injection & 1.01 & 0.64 & 1.62 & 0.95 \\
\hline & OTC - in-feed & 1.34 & 0.97 & 1.87 & 0.08 \\
\hline & OTC - injection & 0.93 & 0.71 & 1.22 & 0.60 \\
\hline \multirow{4}{*}{$\begin{array}{l}\text { Interaction } \\
\text { between treatment } \\
\text { type and time at sea }\end{array}$} & FLO - in-feed & \multicolumn{4}{|c|}{1 (reference category) } \\
\hline & FLO - injection & 1.17 & 0.73 & 1.89 & 0.51 \\
\hline & OTC - in-feed & 0.97 & 0.67 & 1.40 & 0.87 \\
\hline & OTC - injection & 1.33 & 0.97 & 1.81 & 0.08 \\
\hline \multirow{4}{*}{$\begin{array}{l}\text { Interaction } \\
\text { between treatment } \\
\text { type and water } \\
\text { temperature }\end{array}$} & FLO - in-feed & \multicolumn{4}{|c|}{1 (reference category) } \\
\hline & FLO - injection & 0.64 & 0.45 & 0.89 & 0.01 \\
\hline & OTC - in-feed & 0.73 & 0.45 & 1.19 & 0.21 \\
\hline & OTC - injection & 0.88 & 0.68 & 1.15 & 0.34 \\
\hline
\end{tabular}

$\overline{\mathrm{CI}}=$ confidence interval; FLO = florfenicol; OTC = oxytetracycline;

a The model initially included observations of in-feed first-generation fluoroquinolones. However, the small number of observations $(\mathrm{N}=28)$ led to extremely large, unstable standard error estimates. Consequently, these observations were dropped from the analysis and are not presented in this table. 

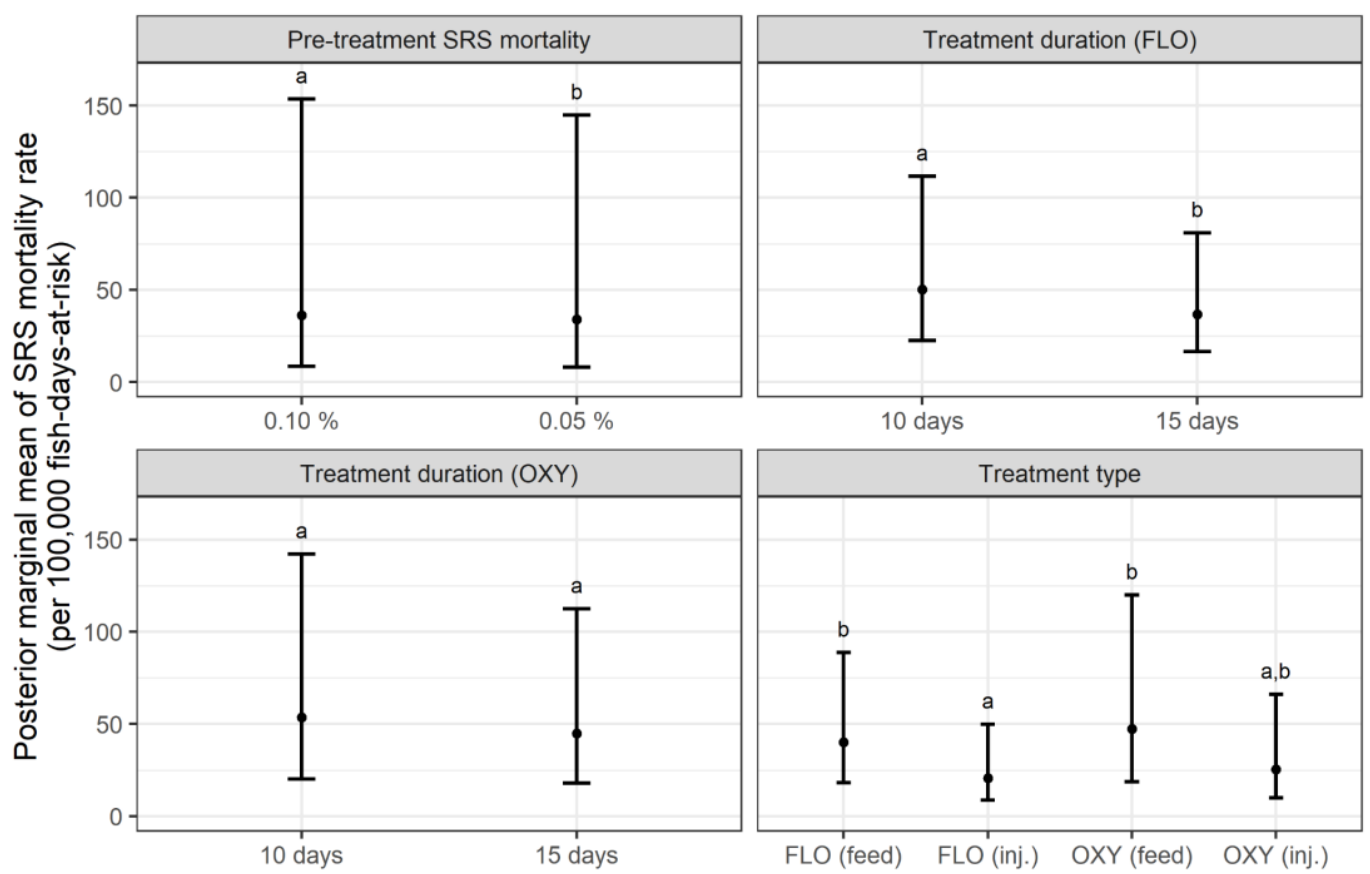

The bars correspond to the 95\% prediction intervals of the marginal means. Marginal means corresponding to a given intervention with different superscripts were significantly different, based on comparison of the adjusted standard errors of the differences between two means. FLO: florfenicol; OXY: oxytetracycline; inj.: injectable.

Figure 2 Posterior marginal means and comparisons of the effect of selected interventions on the SRS-attributed mortality after treatment in rainbow trout.

Injectable florfenicol was more effective that in-feed florfenicol in trout (Table 4). Outbreaks treated with injectable florfenicol had a post-treatment mortality rate $49 \%$ (95\% CI $22 \%-66 \%$ ) lower than those treated with in-feed florfenicol. Other treatment types did not perform significantly better or worse than in-feed florfenicol. The treatment duration was significantly associated with the treatment effectiveness for florfenicol, but not for oxytetracycline. Treatment for 15 days rather than 10 days reduced the post-treatment mortality rate by $25 \%$ for florfenicol (Figure 2).

Among the management factors, pre-treatment mortality attributed to SRS and unknown causes, and the post-treatment farm coverage, had a statistically 
significant association with the post-treatment mortality. Treating when SRS mortality was one standard deviation lower than average was associated with a $40 \%$ (95\% CI 35\%-46\%) lower post-treatment mortality rate.

Four additional exposures were significant: two fish-level factors (number of lice treatments and the time at sea) and two environmental factors (area infection pressure and water temperature). For in-feed florfenicol treatment, post-treatment mortality was lower in larger fish and in colder water. Time at sea and water temperature did not have a significant effect on post-treatment mortality for other treatment types. Among the potential confounders, three variables had a significant association with the post-treatment mortality: the rank of the outbreak within the production cycle, the number of subsequent treatments and the calendar day of the beginning of the outbreak. The association of calendar day with the outcome indicated a seasonal effect similar to the effect observed in salmon. None of the explanatory variables tested in the post-hoc analysis (weight variability, dissolved oxygen and salinity) was found to be statistically significant.

\subsection{Explanatory power and variance distribution}

The conditional $R^{2}$ estimates for the supported models were $59 \%$ for salmon and $72 \%$ for trout. In salmon, the random effects captured only a small part of the variance not explained by the fixed effects $(2 \%, 5 \%$ and $5 \%$ at the management area, farm and company levels, respectively). In trout, the company- and farmspecific effects captured a larger proportion of the unexplained variance (34\% and $22 \%$, respectively).

\section{Discussion}

Insights from this study suggest several practical ways to increase the effectiveness of antimicrobial treatment of SRS. For producers of Atlantic salmon, our results show that treatment should be provided to all infected cages on the farm, without interruption, as soon as possible after the start of an SRS outbreak. For producers of rainbow trout, treatment should be initiated as early as possible after the start of an SRS outbreak, with longer treatment durations if using in-feed florfenicol treatments. In addition, lessons may be learned from the experience of other trout companies and farms, as shown by the large proportion of unexplained 
variance at the company and farm level. The descriptive analysis showed that, despite being treated around the same time after the beginning of an SRS outbreak, the post-treatment mortality rate in trout was much higher than in salmon (on average, 170 and 49 per 100,000 fish-days-at-risk, respectively), suggesting that antimicrobial treatments are not very effective in controlling SRS in trout. In addition, outbreaks in trout tended to last longer than outbreaks in salmon. Price et al. $(2018,2019)$ showed that trout had higher concentrations of florfenicol in tissues than salmon during the course of in-feed treatment. In these studies, the variability within cages was also larger for trout, suggesting that a proportion of fish may not have therapeutic levels of florfenicol in their tissues. These species differences have been partly linked to differences in feeding behaviors, with trout feeding more aggressively than salmon (Talbot et al. 1999). Such differences could affect both the intake of medicated feed and the transmission of $P$. salmonis by direct contact between fish.

In this study, we have used the post-treatment mortality during the remainder of the outbreak as a proxy for effectiveness of the antimicrobial treatment. There is no standard way to measure the effectiveness of antimicrobial treatment in fish in commercial settings. In other domains, authors have used time periods of up to a year to assess the effectiveness of antibiotic treatment (Bråten et al., 2019; Thorlacius-Ussing et al., 2019). In our study, the outcomes were measured over a period of two weeks on average for salmon and four weeks for trout, although the variability was large (results not shown). The half-lives of florfenicol and oxytetracycline were previously estimated at 12 hours at $11^{\circ} \mathrm{C}$ (Martinsen et al., 1993) and 50 hours at $8^{\circ} \mathrm{C}$ (Elema et al., 1996), respectively. Consequently, our measure of treatment effectiveness was taken over a period which is longer than the time needed for complete elimination of the drug from the treated fish. This outcome was selected because reducing mortality in the medium to long term is critical from a production point of view. It is important to note that such outcome is influenced by other factors such as the level of reinfection occurring after the antimicrobial was eliminated. This is different from a previous study of treatment effectiveness for SRS that used the mortality rate three weeks after treatment as the outcome (Price et al., 2016). 
We did not find any significant difference between florfenicol and oxytetracycline in-feed treatments in terms of effectiveness for treating SRS outbreaks in salmon and in trout. These results are to be contrasted with those from a recent study (Price et al., 2016) that found the probability of in-feed treatment failure to be higher in cages treated with oxytetracycline than florfenicol for small fish with high mortality at the beginning of treatment. However, the opposite was true for large fish with low initial mortality, and there was no significant difference for the majority of weight-mortality combinations. Later, Price et al. (2018) showed that a larger proportion of fish had levels of chemotherapeutant above selected thresholds when treated orally with oxytetracycline than with florfenicol.

In our study, injectable administration was more effective than in-feed treatment for oxytetracycline in salmon and for florfenicol in trout. Given the small number of injectable treatments in the dataset compared to in-feed treatments, results regarding injectable treatments must be interpreted with caution. It is likely that a larger proportion of fish receive a therapeutic dose of antimicrobials during injectable treatments than when administered by medicated feed. In addition, injectable treatments are associated with the culling of overtly unhealthy fish. These two factors may explain the observed difference in effectiveness between injectable and in-feed treatments. A recent study found oxytetracycline to be eliminated more slowly when administered by intraperitoneal injection than when administered orally (Norambuena-Subiabre et al., 2018). Also, previous work showed that the bioavailability of oxytetracycline administered orally in seawater was very low due to binding with magnesium and calcium cations (Lunestad and Goksøyr, 1990; Smith et al., 1996). This may explain why injectable treatments were more effective than in-feed treatment for that chemotherapeutant in salmon. The bioavailability of florfenicol administered orally in seawater was very high (Martinsen et al., 1993). Given our results, it is likely that other parameters such as the variability of medicated feed intake within a cage, the period of time above minimum therapeutic levels and drug availability in target sites also have an impact of post-treatment mortality, not only for florfenicol, but for all chemotherapeutants. 
In terms of treatment factors, our results also showed that repeated treatments during the same outbreak resulted in lower post-treatment mortality in salmon, although this was not beneficial in trout. Treatment duration was a significant factor, with longer in-feed florfenicol treatment more effective in trout. Prudent use of these findings is in order, as the risk of development of antimicrobial resistance - a critical issue in Chile (Cabello and Godfrey, 2019) should also be considered when increasing treatment duration or frequency.

Management factors had a relatively strong influence on the effectiveness of antimicrobial treatment of SRS. Initiating treatment as soon as possible after an SRS outbreak is detected (when mortality is still low) increased the effectiveness of treatment in both species. This finding is consistent with previous studies showing that early initiation of treatment is beneficial in treating SRS (Price et al., 2016) and other salmonid diseases such as furunculosis (Samuelsen et al., 1998). It may also be beneficial for producers to be able to detect outbreaks earlier. Breaks in the continuity of treatment, which may occur through logistical constraints or poor weather, had a significant negative impact on the effectiveness of treatment in salmon but not in trout in this study. In salmon, treatment was less effective with increasing infection pressure from other SRS-infected cages at the same farm. Cages treated last on a given site (as measured by the variable proportion of cages treated in the 21 days prior to the start of treatment) had a better outcome. These findings show that simultaneous treatment of all SRS-infected cages on a salmon farm might be more effective than targeted treatment of individual cages. In trout, the effectiveness of treatment was not affected by farm infection pressure or pretreatment farm coverage. The post-treatment coverage was negatively associated with the outcome, indicating that simultaneous treatment of cages on a site may be a more effective strategy. Such measures may increase the amount of antimicrobial used to contain a single outbreak; however, further work is needed to predict the effect on the total amount of antimicrobials used during the full production cycle. Should treatment fail, early harvest may be justified economically, as has been shown for pancreas disease (Pettersen et al., 2015). Here, we included early harvest as a confounding factor given that the post-treatment mortality could not be 
measured over the entire course of the outbreak. Economic analysis would be required to assess the impact of this mitigation measure on profitability.

Fish-level factors had a lesser influence on the effectiveness of treatment. The effect of the total number of lice treatments is difficult to interpret as this variable reflects both the lice burden experienced during the production cycle and the effect of the antiparasitic treatments. There was a small protective effect in salmon, but a negative effect in trout. A lesser lice burden may reduce susceptibility to SRS (Figueroa et al., 2017; Lhorente et al., 2014), but more frequent antiparasitic bath treatments may have a negative effect on immunocompetence (Barton, 2002; González et al., 2016). The PIISAC data was used to assess the impact of lice burden and treatments on SRS mortality in another study (Meyer, A et al., 2019).

Biomass density, smolt weight, smolt mortality and presence of other infectious diseases were not associated with post-treatment mortality. Some authors have suggested that smolt quality influences the occurrence of certain diseases that affect fish relatively soon after sea entry (Coyne et al., 2006). Conversely, another study did not find an association between smolt quality and mortality due to Aeromonas salmonicida, Vibrio sp. and infectious pancreatic necrosis virus (Eggset et al., 1997). As SRS outbreaks tend to occur relatively late in the production cycle (median time to first outbreak of 2300 and 3300 degreedays in trout and salmon, respectively) it is possible that smolt quality play a lesser role as a determinant of disease when SRS is concerned. The time since smolt entry (which is correlated to the weight of the fish at the time of the outbreak) was negatively associated with the outcome in trout, with in-feed florfenicol treatment more effective in larger fish. The association was not significant for other treatments in this species and for salmon. This result differs from previous findings (although the species is different) which showed that in-feed florfenicol treatment of Atlantic salmon was less effective in larger fish (Price et al., 2016), despite larger fish having higher muscle concentration of chemotherapeutant in another study (Price et al., 2018, 2019). However, our results are consistent with previous work in highlighting that there was no significant effect of fish weight for oxytetracycline treatments. 
Several environmental factors influenced post-treatment mortality. In both species, treatment was found to be less effective with higher sea temperatures, although the association varied by treatment type. This finding was consistent with the concentration of antibiotics in fish tissue being negatively correlated with sea temperature for oxytetracycline in a study by Price et al. (2019). Similarly, a pharmacokinetic study showed that the elimination of oxytetracycline was both temperature- and species- dependent (Namdari et al., 1998). The effectiveness of treatment at different temperatures will also be confounded by the influence of the sea temperature on the infection itself, as shown in an experimental study where SRS mortality in salmon was higher at $14^{\circ} \mathrm{C}$ than at $8^{\circ} \mathrm{C}$ (Larenas et al., 1997).

The SRS infection pressure from other infected farms in the neighbourhood was associated with the effectiveness of treatment for SRS outbreaks in trout. This is consistent with a previous spatial study that reported a spatial correlation in the distribution of SRS within a radius of up to $10 \mathrm{~km}$ (Rees et al., 2014). However, there was no significant effect of the area infection pressure in the salmon dataset. The dynamics of the disease (Jakob et al. 2014; Rees et al., 2014), as well as response to treatment (Price et al., 2018; 2019), are different between the two species. In addition, it is possible that the variable used to represent the area infection pressure (weighted density average of the SRS mortality rate in neighbour farms) is not an accurate estimator of the area infection pressure in salmon. A different weighting function, a different time window used in the estimation or including the size of the infected farms in this variable may have provided a better measure of the neighbourhood pressure. It is also worth noting that Rees et al. (2014) looked at spatial correlation in SRS mortality among all farms, while our study specifically selected farms experiencing an SRS outbreak. It is plausible that local infection pressure on a farm during an SRS outbreak is sufficiently high to mask any possible influence of infectious pressure arising from other infected farms in the neighbourhood. Area-level synchronization has been shown to increase the effectiveness of treatment for sea lice in Chile (Arriagada et al., 2017), but no studies of area-level synchronization of treatment of SRS have been published (nor is there strong evidence to support such a strategy). 
Models with a single exposure variable were poorly supported compared with models that incorporated multiple variables: this highlights the multifactorial nature of SRS and the lack of a single predominant risk factor. In the salmon models, little variation resided at the farm and company levels, suggesting there was relatively little difference in the effectiveness of antimicrobial treatment between salmon-producing companies and farms. In contrast, we found that some companies and farms producing trout tend to have better results when using antimicrobial treatments than others. A better understanding of differences between companies and farms may allow risk factors and good management practices to be identified, or such better-performing farms could be used as demonstration sites to stimulate discussions between producers about their own practices.

Classification of cause of death by farm personal was assumed to be imperfect, but we were unable to determine the extent of misclassification or whether it was associated with the exposures of interest. Misclassification is likely to be non-differential with respect to treatment type and, if so, might reduce the power of the study to detect differences between treatment types. It would be useful to conduct a validation study to estimate the sensitivity and specificity of clinical diagnosis of SRS by farm personnel. In this study, misclassification of fish mortality may have affected the unit of analysis (via the outbreak definition), the outcome variable (mortality from SRS and unknown causes) and some of the exposure variables (mortality from other infectious diseases, pre-treatment mortality from SRS and unknown causes). Our definition of SRS outbreaks was also limited by the absence of laboratory results of SRS diagnostic tests. This information would have been useful to validate the approach and thresholds used to identify outbreaks.

We based our analysis on SRS outbreaks rather than treatment events (Price et al., 2016) so we could evaluate the effect of management factors - such as the time from the start of the outbreak to initiation of treatment - and use a continuous measure of mortality rate over a follow-up period of varying length. As mentioned above, it is important to keep in mind that treatment effectiveness was measured as the post-treatment mortality until the end of the outbreak, which may have 
occurred after the antimicrobial drug was eliminated by the fish. Consequently, the outcome used here may have been influenced by other, unaccounted factors in addition to the effect of the antimicrobial treatment itself.

Another limitation of the study is the number of assumptions made to define the variables, the outcome and the modeling approach. Assumptions which could have influenced the results include the thresholds used to define outbreaks and the definition of explanatory variables such as treatment continuity, farm coverage, farm infection pressure and area infection pressure. In particular, it is important to note that several variables were summarized for modelling purposes, and do not capture the local dynamics of the disease and management that may have occurred during and after the antimicrobial treatment. The results obtained for salmon highlight the impact of the choice of analytical procedure on the final results. For instance, the posterior marginal mean estimates showed that the post-treatment mortality was significantly different between treatment types (although not all pairwise comparisons were significant), while the treatment type variable was not retained in the model selection and model averaging procedure, as it did not improve the overall explanatory value of the model. Lastly, some potential risk factors could not be included in this analysis because data were not available. With additional data, future studies of antimicrobial treatment effectiveness might explore the influence of antimicrobial dose, feed additives, sea lice burden, predation and vaccination.

This study demonstrates the value of integration and analysis of aquaculture industry-generated health and management data. The PIISAC platform supports detailed epidemiological studies - such as this study of factors influencing the effectiveness of antimicrobial treatment during outbreaks of SRS - with data covering an extensive time period and a broad range of locations and explanatory variables. These studies improve our understanding of disease in aquaculture and provide relevant, evidence-based recommendations to fish producers.

\section{Conclusion}

The combined impacts of SRS and a very high level of antimicrobial use pose a serious threat to the profitability and sustainability of the Chilean salmonid 
aquaculture industry. Our results highlight the multifactorial nature of SRS outbreaks in farmed salmonids and the need to consider numerous explanatory variables when evaluating the association between antimicrobial treatment and post-treatment mortality. However, despite this complexity, it appears that several factors significantly influence the effectiveness of antimicrobial treatment of SRS during outbreaks. Importantly, key results relate to management decisions or practices and indicate practical, actionable ways in which the effectiveness of antimicrobial treatment could be improved.

\section{Acknowledgments}

The authors gratefully acknowledge the enthusiasm and vision shown by the companies who contributed data to this study: Australis Seafoods, Blumar Seafoods, Camanchaca, Multiexport Foods, Salmones Antartica, Salmones Aysén and Ventisqueros. Other companies have contributed greatly to the discussions about risk factors and hypotheses. We thank representatives from SalmonChile for their technical insights, and contributions to meetings and workshops. Berta Contreras (Conecta SpA) has been invaluable in providing a link between Ausvet and the salmon aquaculture industry in Chile. Finally, we acknowledge the tireless efforts of many people at Sernapesca, who have supported this and other PGSA projects.

\section{Funding}

This study was carried out under the framework of the 'Program for Aquaculture Sanitary Management' (PGSA), a project executed by the Chilean National Fisheries and Aquaculture Service (Sernapesca), with public and private financing from the Ministry of the Economy, Development and Tourism and the Chilean Salmon Industry Association (SalmonChile). 


\section{References}

Akaike, H., 1974. A new look at the statistical model identification. IEEE Transactions on Automatic Control 19, 716-723. https://doi.org/10.1109/TAC.1974.1100705

Almendras, F., Fuentealba, C., 1997. Salmonid rickettsial septicaemia caused by Piscirickettsia salmonis: a review. Diseases of Aquatic Organisms 29, 137-144.

Arriagada, G., Stryhn, H., Sanchez, J., Vanderstichel, R., Campistó, J.L., Rees, E.E., Ibarra, R., St-Hilaire, S., 2017. Evaluating the effect of synchronized sea lice treatments in Chile. Preventive Veterinary Medicine 136, 1-10. https://doi.org/10.1016/j.prevetmed.2016.11.011

Barton, B.A., 2002. Stress in fishes: a diversity of responses with particular reference to changes in circulating corticosteroids. Integr. Comp. Biol. 42, 517525. https://doi.org/10.1093/icb/42.3.517

Barton, J.R., Fløysand, A., 2010. The political ecology of Chilean salmon aquaculture, 1982-2010: A trajectory from economic development to global sustainability. Global Environmental Change 20, 739-752. https://doi.org/10.1016/j.gloenvcha.2010.04.001

Bates, D., Mächler, M., Bolker, B., Walker, S., 2015. Fitting Linear MixedEffects Models Using lme4. Journal of Statistical Software, Articles 67, 1-48. https://doi.org/10.18637/jss.v067.io1

Bravo, S., Campos, M., 1989. Coho salmon syndrome in Chile. FHS/AFS Newsletter 17, 3.

Brocklebank, J., Speare, D., Armstrong, R., Evelyn, T., 1992. Septicaemia suspected to be caused by a rickettsia-like agent in farmed Atlantic salmon. Can Vet J 33, 407-408.

Burnham, K., Anderson, D., 2002. Model selection and multimodel inference: a practical information-theoretic approach, 2nd edition. Springer, New York.

Cabello, F.C., 2006. Heavy use of prophylactic antibiotics in aquaculture: a growing problem for human and animal health and for the environment. Environ. Microbiol. 8, 1137-1144. https://doi.org/10.1111/j.1462-2920.2006.01054.x 
Cabello, F.C., Godfrey, H.P., Tomova, A., Ivanova, L., Dölz, H., Millanao, A., Buschmann, A.H., 2013. Antimicrobial use in aquaculture re-examined: its relevance to antimicrobial resistance and to animal and human health: Aquacultural antimicrobial use and antimicrobial resistance. Environmental Microbiology 15, 1917-1942. https://doi.org/10.1111/1462-2920.12134

Cabello, F.C. and Godfrey, H.P., 2019. Salmon aquaculture, Piscirickettsia salmonis virulence, and one health: Dealing with harmful synergies between heavy antimicrobial use and piscine and human health. Aquaculture 507, 451-456. https://doi.org/10.1016/j.aquaculture.2019.04.048

Coyne, R., Smith, P., Dalsgaard, I., Nilsen, H., Kongshaug, H., Bergh, Ø., Samuelsen, O., 2006. Winter ulcer disease of post-smolt Atlantic salmon: An unsuitable case for treatment? Aquaculture 253, 171-178. https://doi.org/10.1016/j.aquaculture.2005.08.016

Dohoo, I.R., Martin, W., Stryhn, H.E., 2003. Veterinary epidemiologic research.

Eggset, G., Mortensen, A., Johansen, L.-H., Sommer, A.-I., 1997. Susceptibility to furunculosis, cold water vibriosis, and infectious pancreatic necrosis (IPN) in post-smolt Atlantic salmon (Salmo salar L.) as a function of smolt status by seawater transfer. Aquaculture 158, 179-191. https://doi.org/10.1016/So044-8486(97)00178-6

Elema, M., Hoff, K., Kristensen, H., 1996. Bioavailability of oxytetracycline from medicated feed administered to Atlantic salmon (Salmo salar L.) in seawater. Aquaculture 143, 7-14. http://dx.doi.org/10.1016/o044-8486(96)01253-7.

Evensen, Ø., 2016. Immunization Strategies against Piscirickettsia salmonis Infections: Review of Vaccination Approaches and Modalities and Their Associated Immune Response Profiles. Frontiers in Immunology 7, 482.

Figueroa, C., Bustos, P., Torrealba, D., Dixon, B., Soto, C., Conejeros, P., Gallardo, J.A., 2017. Coinfection takes its toll: Sea lice override the protective effects of vaccination against a bacterial pathogen in Atlantic salmon. Scientific Reports 7. https://doi.org/10.1038/s41598-017-18180-6

Greenland, S., Pearl, J., Robins, J.M, 1999. Causal diagrams for epidemiologic research. Epidemiology 10(1), 37-48. 
González, L., Robles, C., Cortez San Martín, M., 2016. Management issues regarding caligidosis treatment on salmon farms in Chile affected by infection salmon anaemia virus (ISAV), Piscirickettsia salmonis and Neoparamoeba perurans. Ocean \& Coastal Management 123, 74-83. https://doi.org/10.1016/j.ocecoaman.2016.02.002

Henriquez, P., Kaiser, M., Bohle, H., Bustos, P., Mancilla, M., 2016. Comprehensive antibiotic susceptibility profiling of Chilean Piscirickettsia salmonis field isolates. Journal of fish diseases 39, 441-448. https://doi.org/10.1111/jfd.12427

Hutchison, J., Mackenzie, C., Madin, B., Happold, J., Leslie, E., Zalcman, E., Meyer, A., Cameron, A., 2018. New approaches to aquatic and terrestrial animal surveillance: The potential for people and technology to transform epidemiology. Preventive Veterinary Medicine. https://doi.org/10.1016/j.prevetmed.2018.10.009

Inam, A., Adamowski, J., Halbe, J., Prasher, S., 2015. Using causal loop diagrams for the initialization of stakeholder engagement in soil salinity management in agricultural watersheds in developing countries: A case study in the Rechna Doab watershed, Pakistan. Journal of environmental management 152, 251-267.

Jakob, E., Stryhn, H., Yu, J., Medina, M.H., Rees, E.E., Sanchez, J., StHilaire, S., 2014. Epidemiology of Piscirickettsiosis on selected Atlantic salmon (Salmo salar) and rainbow trout (Oncorhynchus mykiss) salt water aquaculture farms in Chile. Aquaculture 433, 288-294.

Larenas, J.J., Contreras, J., Oyanedel, S., Morales, M.A., Smith, P., 1997. Efecto de la densidad poblacional y temperatura en truchas arco iris (Oncorhynchus mykiss) inoculadas con Piscirickettsia salmonis. Archivos de medicina veterinaria 29, 113-119.

Lenth, R., 2018. emmeans: Estimated Marginal Means, aka Least-Squares Means [WWW Document]. R package version 1.2.1. URL https://CRAN.Rproject.org/package $=$ emmeans

Lhorente, J.P., Gallardo, J.A., Villanueva, B., Carabaño, M.J., Neira, R., 2014. Disease Resistance in Atlantic Salmon (Salmo salar): Coinfection of the 
Intracellular Bacterial Pathogen Piscirickettsia salmonis and the Sea Louse Caligus rogercresseyi. PLOS

One

9,

e95397.

https://doi.org/10.1371/journal.pone.0095397

Lunestad, B.T., Goksøyr, J., 1990. Reduction in the antibacterial effect of oxytetracycline in sea water by complex formation with magnesium and calcium. Diseases of Aquatic Organisms 9, 67-72.

Maisey, K., Montero, R., Christodoulides, M., 2017. Vaccines for piscirickettsiosis (salmonid rickettsial septicaemia, SRS): the Chile perspective. Expert Review of Vaccines 16, 215-228.

Mardones, F.O., Paredes, F., Medina, M., Tello, A., Valdivia, V., Ibarra, R., Correa, J., Gelcich, S., 2018. Identification of research gaps for highly infectious diseases in aquaculture: The case of the endemic Piscirickettsia salmonis in the Chilean salmon farming industry. Aquaculture 482, 211-220. https://doi.org/10.1016/j.aquaculture.2017.09.048

Martinsen, B., Horsberg, T.E., Varma, K.J., Sams, R., 1993. Single dose pharmacokinetic study of florfenicol in Atlantic salmon (Salmo salar) in seawater at $11^{\circ} \mathrm{C}$. Aquaculture 112, 1-11. https://doi.org/10.1016/0044-8486(93)90153-P

Meyer, A, Burroughs, A, Sadler, R, Happold, J, Cowled, B, Mackenzie, C., Gallardo Lagno, AL, Cameron, A., 2019. Quantifying the effects of sea lice burden and lice bathing treatments on salmonid rickettsial septicaemia in commercial salmon and trout farms in Chile. Aquaculture 513, 734411.

Namdari, R., Abedini, S., Albright, L., Law, F.C.P., 1998. Tissue Distribution and Elimination of Oxytetracycline in Sea-Pen Cultured Chinook Salmon, Oncorhynchus tshawytscha, and Atlantic Salmon, Salmo salar, Following Medicated-Feed Treatment. Journal of Applied Aquaculture 8, 39-51. https://doi.org/10.1300/Jo28vo8no1_03

Norambuena-Subiabre, L., González, M.P., Contreras-Lynch, S., 2018. Oxytetracycline depletion and withdrawal time estimation following intraperitoneal administration in three species from Chilean salmon farming. Aquaculture Research 49, 593-602. https://doi.org/10.1111/are.13501 
Okocha, R.C., Olatoye, I.O., Adedeji, O.B., 2018. Food safety impacts of antimicrobial use and their residues in aquaculture. Public Health Reviews 39, 21. https://doi.org/10.1186/s40985-018-0099-2

Olsen, A.B., Melby, H.P., Speilberg, L., Evensen, Ø., Håstein, T., 1997. Piscirickettsia salmonis infection in Atlantic salmon Salmo salar in Norway epidemiological, pathological and microbiological findings. Diseases of Aquatic Organisms 31, 35-48. https://doi.org/10.3354/daoo31035

Pettersen, J.M., Rich, K.M., Jensen, B.B., Aunsmo, A., 2015. The economic benefits of disease triggered early harvest: a case study of pancreas disease in farmed Atlantic salmon from Norway. Preventive Veterinary Medicine 121 (3-4), https://doi.org/314-324. 10.1016/j.prevetmed.2015.08.003

Price, D., Stryhn, H., Sánchez, J., Ibarra, R., Tello, A., St-Hilaire, S., 2016. Retrospective analysis of antibiotic treatments against piscirickettsiosis in farmed Atlantic salmon Salmo salar in Chile. Diseases of Aquatic Organisms 118, 227-235.

Price, D., Sánchez, J., McClure, J., McConkey, S., Ibarra, R., St-Hilaire, S., 2018. Assessing concentration of antibiotics in tissue during oral treatments against piscirickettsiosis. Preventive Veterinary Medicine 156, 16-21.

Price, D., Sánchez, J., Ibarra, R., St-Hilaire, S., 2019. Variation in the concentration of antibiotics in tissue during oral antibiotic treatments in farmed salmonids. Aquaculture 498, 587-593.

R Core Team, 2018. R: A Language and Environment for Statistical Computing. R Foundation for Statistical Computing, Vienna, Austria. URL: https://www.r-project.org/.

Reed, M.S, 2008. Stakeholder participation for environmental management: a literature review. Biological conservation 141 (10): 2417-2431.

Rees, E.E., Ibarra, R., Medina, M., Sanchez, J., Jakob, E., Vanderstichel, R., St-Hilaire, S., 2014. Transmission of Piscirickettsia salmonis among salt water salmonid farms in Chile. Aquaculture 428-429, 189-194. https://doi.org/10.1016/j.aquaculture.2014.03.031

Rozas, M., Enriquez, R., 2014. Piscirickettsiosis and Piscirickettsia salmonis in fish: a review. Journal of fish diseases 37, 163-188. https://doi.org/10.1111/jfd.12211 
Samuelsen, O.B., Hjeltnes, B., Glette, J., 1998. Efficacy of Orally Administered Florfenicol in the Treatment of Furunculosis in Atlantic Salmon. Journal of Aquatic Animal Health 10, 56-61. https://doi.org/10.1577/15488667(1998)010<0056:EOOAFI >2.0.CO;2

Sernapesca, 2018a. Informe Sanitario de Salmonicultura en Centros Marinos: Año 2017. Servicio Nacional de Pesca y Acuicultura, Valparaíso, Chile.

Sernapesca, 2018b. Informe Sobre Uso de Antimicrobianos en la Salmonicultura Nacional: Año 2017. Servicio Nacional de Pesca y Acuicultura, Valparaíso, Chile.

Sernapesca, 2009. Resolución No 1449 de 2009, Establece medidas de manejo sanitario por área. Servicio Nacional de Pesca y Acuicultura, Valparaíso, Chile.

Smith, P., Niland, T., O’Domhnaill, F., O’Tuathaigh, G., Hiney, M., 1996. Influence of marine sediment and divalent cations on the activity of oxytetracycline against Listonella Anguillarum. Bull. Eur. Ass. Fish Pathol. 16, 54-57.

Talbot, C., Corneillie, S., Korsøen, Ø., 1999. Pattern of feed intake in four species of fish under commercial farming conditions: implications for feeding management. Aquaculture Research 30 (7), 509-518.

Watts, J.E.M., Schreier, H.J., Lanska, L., Hale, M.S., 2017. The Rising Tide of Antimicrobial Resistance in Aquaculture: Sources, Sinks and Solutions. Marine drugs 15. https://doi.org/10.3390/md15060158

Zuur, A.F., Ieno, E.N., Elphick, C.S., 2010. A protocol for data exploration to avoid common statistical problems. Methods in Ecology and Evolution 1, 3-14. https://doi.org/10.1111/j.2041-210X.2009.00001.x 


\section{Supplementary material}

Supplementary material 1 Causal web and list of hypotheses developed during the design phase of a study on the effectiveness of antimicrobial treatment of salmonid rickettsial septicaemia in commercial salmon and trout farms in Chile.

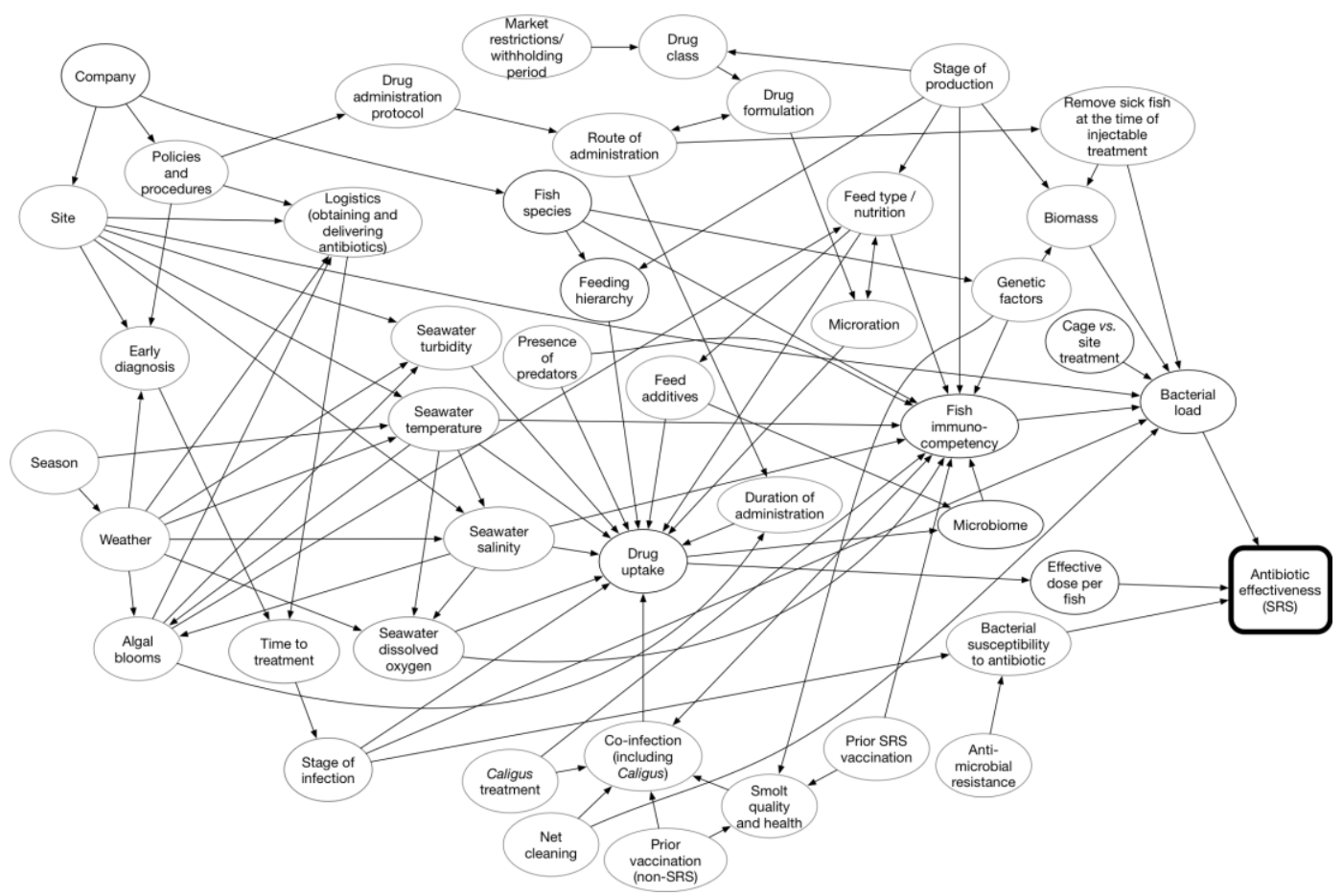

Figure Suppl 1.1 Causal web describing postulated links between explanatory variables and the effectiveness of antimicrobial treatment of SRS outbreaks. 


\begin{tabular}{ll}
\hline & $\begin{array}{l}\text { Studies having } \\
\text { directly or } \\
\text { indirectly } \\
\text { investigated this } \\
\text { hypothesis }\end{array}$
\end{tabular}

Hypotheses group 1: antimicrobial treatment factors

Certain antimicrobials (Price et al. 2016) Antimicrobials differ in terms of mode of action are more effective than (Henriquez et al. others in treating SRS 2016) outbreaks

(Mora 2010) on the pathogen and distribution of resistance against them. Flumequine and oxolinic acid are relatively old, bactericidal drugs with more resistance reported in $P$. salmonis than bacteriostatic drugs such as florfenicol and oxytetracycline. A previous study found a higher rate of failure of florfenicol over oxytetracycline treatments.

Antimicrobials are more effective if given by injection than infeed.

(Norambuena-

Subiabre, González, and Contreras-Lynch 2018)

Oral administration of None antimicrobials is more effective if the duration of treatment is greater is eliminated more slowly when administered by intraperitoneal injection. Besides, it is suspected that not all fish absorb the effective dose of drug when it is administered in-feed (as it depends on factors such as the fish appetite, their activity level and the feeding hierarchy).

A longer treatment would increase the probability that more fish ingest enough drug to reach the effective treatment dose.
A previous study suggested that oxytetracycline

Hypotheses group 2: fish-level factors

\begin{tabular}{lll}
\hline $\begin{array}{l}\text { The presence of other } \\
\text { infectious diseases } \\
\text { decreases the } \\
\text { effectiveness of } \\
\text { antimicrobial } \\
\text { treatment }\end{array}$ & $\begin{array}{l}\text { (Gaggero, Castro, } \\
\text { and Sandino 1995) }\end{array}$ & $\begin{array}{l}\text { Co-infection with other pathogens has been } \\
\text { proposed as a risk factor for infection. By } \\
\text { compromising the immunocompetency of the } \\
\text { fish, it may also affect the treatment } \\
\text { effectiveness. }\end{array}$ \\
\hline $\begin{array}{l}\text { Antimicrobial } \\
\text { treatment is less } \\
\text { effective if the sea lice } \\
\text { burden is high }\end{array}$ & (Lhorente et al. & $\begin{array}{l}\text { Previous studies showed that sea lice infestation } \\
\text { increased the susceptibility of the fish to } P . \\
\text { salmonis infection. It is suspected that sea lice } \\
\text { could also decrease the effectiveness of } \\
\text { treatment. }\end{array}$ \\
\hline $\begin{array}{l}\text { Antimicrobial } \\
\text { treatment is more } \\
\text { effective in smaller (or } \\
\text { younger) fish than in } \\
\text { larger (or older) fish }\end{array}$ & (Price et al. 2016) & $\begin{array}{l}\text { A previous study showed increased treatment } \\
\text { failure in larger fish for florfenicol. }\end{array}$ \\
\hline $\begin{array}{l}\text { Antimicrobial } \\
\text { treatment is more } \\
\text { effective when the } \\
\text { density is lower }\end{array}$ & (Larenas et al. & $\begin{array}{l}\text { A study in trout showed that mortality was } \\
\text { higher when the biomass density was higher. }\end{array}$ \\
\hline
\end{tabular}




\begin{tabular}{|c|c|c|}
\hline Hypothesis & $\begin{array}{l}\text { Studies having } \\
\text { directly or } \\
\text { indirectly } \\
\text { investigated this } \\
\text { hypothesis }\end{array}$ & Reasoning supporting this hypothesis \\
\hline $\begin{array}{l}\text { Antimicrobial } \\
\text { treatment is more } \\
\text { effective in production } \\
\text { cycles with higher } \\
\text { smolt quality }\end{array}$ & $\begin{array}{l}\text { (Yáñez et al. 2013) } \\
\text { (Jakob et al. 2014) } \\
\text { (Eggset et al. 1997) }\end{array}$ & $\begin{array}{l}\text { Smolt quality is suspected to influence the } \\
\text { resistance of the fish to disease in the sea water } \\
\text { phase. Genetics play a role in disease resistance, } \\
\text { but many other factors may contribute such as } \\
\text { transportation stress and sea water adaptation. } \\
\text { A previous study (which did not look at } \\
\text { antimicrobial treatment but at mortality during } \\
\text { SRS outbreaks) showed that larger smolt } \\
\text { (weight is often used a measure of smolt quality) } \\
\text { had lower SRS mortality. }\end{array}$ \\
\hline $\begin{array}{l}\text { Antimicrobial } \\
\text { treatment is more } \\
\text { effective when the last } \\
\text { SRS vaccination is } \\
\text { more recent }\end{array}$ & $\begin{array}{l}\text { (Jakob et al. 2014) } \\
\text { (Leal and } \\
\text { Woywood 2007) } \\
\text { (Marshall et al. } \\
\text { 2007) } \\
\text { (Tobar et al. 2011) }\end{array}$ & $\begin{array}{l}\text { There is evidence for a waning and variable } \\
\text { protective effect of vaccination, which can be } \\
\text { partly overcome by administering a booster at } \\
\text { sea. No study formally investigated the } \\
\text { relationship between SRS vaccination and } \\
\text { treatment so far. }\end{array}$ \\
\hline
\end{tabular}

Hypotheses group 3: management factors

\begin{tabular}{|c|c|c|}
\hline $\begin{array}{l}\text { Antimicrobial } \\
\text { treatment is more } \\
\text { effective if treatment } \\
\text { starts when SRS- } \\
\text { attributed mortality is } \\
\text { relatively low }\end{array}$ & (Price et al. 2016) & $\begin{array}{l}\text { A previous study showed that treatment was } \\
\text { more effective when administered while the } \\
\text { mortality was still low, presumably because it is } \\
\text { less effective in fish that are already in the } \\
\text { clinical phase of the disease. }\end{array}$ \\
\hline $\begin{array}{l}\text { Antimicrobial } \\
\text { treatment is more } \\
\text { effective if treatment } \\
\text { starts soon after the } \\
\text { SRS outbreak begins }\end{array}$ & None & $\begin{array}{l}\text { The time to treatment is correlated to the pre- } \\
\text { treatment mortality rate, which was shown to be } \\
\text { a significant risk factor for treatment success, } \\
\text { and is thus related to the hypothesis directly } \\
\text { above. However, the time to treatment may be } \\
\text { important in its own right and a useful } \\
\text { additional management factor, as outbreaks } \\
\text { with different behaviours (milder or more } \\
\text { severe) may reach critical mortality at different } \\
\text { times. }\end{array}$ \\
\hline $\begin{array}{l}\text { Antimicrobial } \\
\text { treatment is more } \\
\text { effective when applied } \\
\text { simultaneously to all } \\
\text { cages on a site }\end{array}$ & None & $\begin{array}{l}\text { Treating all the cages on a site may lower the } \\
\text { overall infection pressure and therefore increase } \\
\text { the effectiveness of treatment. }\end{array}$ \\
\hline $\begin{array}{l}\text { Antimicrobial } \\
\text { treatment is more } \\
\text { effective when the } \\
\text { within-cage variability } \\
\text { in fish weights is } \\
\text { smaller }\end{array}$ & (Price et al., 2018) & $\begin{array}{l}\text { Large within-cage variability may interfere with } \\
\text { drug dosage and feeding patterns, hereby } \\
\text { reducing the probability that more fish in the } \\
\text { cage reach therapeutic drug levels for a sufficient } \\
\text { duration. }\end{array}$ \\
\hline $\begin{array}{l}\text { Antimicrobial } \\
\text { treatment is more } \\
\text { effective when there } \\
\text { are fewer days of } \\
\text { interruption of }\end{array}$ & None & $\begin{array}{l}\text { Treatment interruptions may prevent drug } \\
\text { concentration to reach therapeutic levels for a } \\
\text { sufficient duration. Interruptions occur because } \\
\text { of uncontrolled factors such as storms. However, } \\
\text { improved management of drug stocks could be } \\
\text { implemented. }\end{array}$ \\
\hline
\end{tabular}




\begin{tabular}{|c|c|c|}
\hline Hypothesis & $\begin{array}{l}\text { Studies having } \\
\text { directly or } \\
\text { indirectly } \\
\text { investigated this } \\
\text { hypothesis }\end{array}$ & Reasoning supporting this hypothesis \\
\hline \multicolumn{3}{|l|}{$\begin{array}{l}\text { antimicrobial } \\
\text { administration }\end{array}$} \\
\hline \multicolumn{3}{|c|}{ Hypotheses group 4: environmental factors } \\
\hline $\begin{array}{l}\text { Antimicrobial } \\
\text { treatments are less } \\
\text { effective when sea } \\
\text { temperature is } \\
\text { warmer. This effect } \\
\text { might depend on the } \\
\text { treatment type. }\end{array}$ & $\begin{array}{l}\text { (Namdari et al. } \\
\text { 1998) } \\
\text { (Cusack, Groman, } \\
\text { and Jones 2002) } \\
\text { (Larenas et al. } \\
\text { 1997) } \\
\text { (Lannan and Fryer } \\
\text { 1994) } \\
\text { (Price et al., 2019) }\end{array}$ & $\begin{array}{l}\text { Two previous studies suggested that drug } \\
\text { elimination is faster when sea temperature is } \\
\text { warmer. Therefore, drug concentration may not } \\
\text { reach therapeutic levels for a sufficient duration } \\
\text { in warm water. However, it was also shown that } \\
\text { the survival of } P \text {. salmonis is negatively affected } \\
\text { by water temperature. Besides, fish may become } \\
\text { anorexic when the temperature drops to low } \\
\text { values, and this may affect oral treatment } \\
\text { effectiveness. Last, fluctuations in water } \\
\text { temperature have been proposed to be a risk } \\
\text { factor more than the temperature itself. } \\
\text { Although temperature may affect treatment } \\
\text { effectiveness in several ways, it is included as a } \\
\text { confounder only. }\end{array}$ \\
\hline $\begin{array}{l}\text { Oral antimicrobial } \\
\text { treatments are less } \\
\text { effective when sea } \\
\text { turbidity is higher }\end{array}$ & $\begin{array}{l}\text { (Branson and } \\
\text { Nieto Díaz-Munoz } \\
\text { 1991) }\end{array}$ & $\begin{array}{l}\text { An increase in water turbidity may both act as a } \\
\text { stressor on fish and reduce feed intake, and } \\
\text { hereby decrease treatment effectiveness. Also, it } \\
\text { was shown than proliferation of non-toxic algae } \\
\text { was a risk factor for SRS outbreaks. }\end{array}$ \\
\hline $\begin{array}{l}\text { Antimicrobial } \\
\text { treatment is less } \\
\text { effective when salinity } \\
\text { is higher }\end{array}$ & $\begin{array}{l}\text { (Gaggero, Castro, } \\
\text { and Sandino 1995) } \\
\text { (Lannan and Fryer } \\
\text { 1994) } \\
\text { (Bravo 1994) } \\
\text { (Lunestad and } \\
\text { Goksøyr 1990) }\end{array}$ & $\begin{array}{l}\text { Salinity is suspected to play a role, as outbreaks } \\
\text { mostly occur in salt water, although infection } \\
\text { with P. salmonis has been reported in fresh } \\
\text { water as well. Previous work showed that the } \\
\text { pathogen is rapidly inactivated in fresh water. A } \\
\text { previous study also showed reduced } \\
\text { effectiveness of oxytetracycline is seawater. }\end{array}$ \\
\hline $\begin{array}{l}\text { Antimicrobial } \\
\text { treatment is less } \\
\text { effective when } \\
\text { predator-related } \\
\text { mortality is higher }\end{array}$ & None & $\begin{array}{l}\text { As mentioned for water turbidity, an increase in } \\
\text { predator attacks may both act as a stressor on } \\
\text { fish and reduce feed intake, and hereby decrease } \\
\text { treatment effectiveness. }\end{array}$ \\
\hline $\begin{array}{l}\text { Antimicrobial } \\
\text { treatment is less } \\
\text { effective in the face of } \\
\text { higher infection } \\
\text { pressure from other } \\
\text { SRS-infected cages at } \\
\text { the same site }\end{array}$ & (Rees et al. 2014) & $\begin{array}{l}\text { A previous study showed positive spatial } \\
\text { correlation between SRS mortality on farms up } \\
\text { to } 10 \mathrm{~km} \text { apart (the study did not look at } \\
\text { antimicrobial treatment but at reports of SRS } \\
\text { mortality). By increasing the infection pressure } \\
\text { on the cage, infection in other cages of the same } \\
\text { site could decrease treatment effectiveness. }\end{array}$ \\
\hline $\begin{array}{l}\text { Antimicrobial } \\
\text { treatment is less } \\
\text { effective in the face of } \\
\text { higher infection } \\
\text { pressure from SRS- } \\
\text { infected sites within } \\
20 \mathrm{~km}\end{array}$ & (Rees et al. 2014) & $\begin{array}{l}\text { A previous study showed positive spatial } \\
\text { correlation between SRS mortality on farms up } \\
\text { to } 10 \text { km apart (the study did not look at } \\
\text { antimicrobial treatment but at reports of SRS } \\
\text { mortality). By increasing the infection pressure } \\
\text { on the cage, infection in neighbouring sites } \\
\text { could decrease treatment effectiveness. }\end{array}$ \\
\hline
\end{tabular}




\section{References for this supplementary material}

Branson, E J, and D Nieto Díaz-Munoz. 1991. "Description of a New Disease Condition Occurring in Farmed Coho Salmon, Oncorhynchus Kisutch (Walbaum), in South America." Journal of Fish Diseases 14 (2): 147-56. https://doi.org/10.1111/j.1365-2761.1991.tboo585.x.

Bravo, S. 1994. "Piscirickettsiosis in Freshwater." Bulletin of the European Association of Fish Pathologists 14 (4): 137-38.

Cusack, R Roland, David B Groman, and Simon R M Jones. 2002. "Rickettsial Infection in Farmed Atlantic Salmon in Eastern Canada." The Canadian Veterinary Journal.

Eggset, Guri, Atle Mortensen, Lill-Heidi Johansen, and Ann-Inger Sommer. 1997. "Susceptibility to Furunculosis, Cold Water Vibriosis, and Infectious Pancreatic Necrosis (IPN) in Post-Smolt Atlantic Salmon (Salmo Salar L.) as a Function of Smolt Status by Seawater Transfer." Aquaculture 158 (3): 179-91. https://doi.org/10.1016/Soo44-8486(97)oo178-6.

Gaggero, A, H Castro, and A M Sandino. 1995. "First Isolation of Piscirickettsia Salmonis from Coho Salmon, Oncorhynchus Kisutch (Walbaum), and Rainbow Trout, Oncorhynchus Mykiss (Walbaum), during the Freshwater Stage of Their Life Cycle." Journal of Fish Diseases 18 (3): 277-80. https://doi.org/10.1111/j.1365-2761.1995.tboo303.x.

Henriquez, P, M Kaiser, H Bohle, P Bustos, and M Mancilla. 2016. "Comprehensive Antibiotic Susceptibility Profiling of Chilean Piscirickettsia Salmonis Field Isolates." Journal of Fish Diseases 39 (4): 441-48. https://doi.org/10.1111/jfd.12427.

Jakob, Eva, Henrik Stryhn, Jenny Yu, Matias H Medina, Erin E Rees, Javier Sanchez, and Sophie St-Hilaire. 2014. "Epidemiology of Piscirickettsiosis on Selected Atlantic Salmon (Salmo Salar) and Rainbow Trout (Oncorhynchus Mykiss) Salt Water Aquaculture Farms in Chile." Aquaculture 433: 288-94. https://doi.org/10.1016/j.aquaculture.2014.06.018.

Lannan, C N, and J L Fryer. 1994. "Extracellular Survival of Piscirickettsia Salmonis." Journal of Fish Diseases 17 (5): 545-48. https://doi.org/10.1111/j.13652761.1994.tboo251.x. 
Larenas, J J, J Contreras, S Oyanedel, M A Morales, and P Smith. 1997. "Efecto de La Densidad Poblacional y Temperatura En Truchas Arco Iris (Oncorhynchus Mykiss) Inoculadas Con Piscirickettsia Salmonis.” Archivos de Medicina Veterinaria 29: 113-19.

Leal, J, and D Woywood. 2007. "Piscirickettsiosis En Chile: Avances y Perspectivas Para Su Control." Salmociencia 2: 34-42.

Lhorente, Jean Paul, José A Gallardo, Beatriz Villanueva, María J Carabaño, and Roberto Neira. 2014. "Disease Resistance in Atlantic Salmon (Salmo Salar): Coinfection of the Intracellular Bacterial Pathogen Piscirickettsia Salmonis and the Sea Louse Caligus Rogercresseyi." PLOS ONE 9 (4): 1-7. https://doi.org/10.1371/journal.pone.0095397.

Lunestad, B. T., and J. Goksøyr. 1990. "Reduction in the Antibacterial Effect of Oxytetracycline in Sea Water by Complex Formation with Magnesium and Calcium." Diseases of Aquatic Organisms 9 (1): 67-72.

Marshall, Sergio H, Pablo Conejeros, Marcela Zahr, Jorge Olivares, Fernando Gomez, Patricio Cataldo, and Vitalia Henriquez. 2007. "Immunological Characterization of a Bacterial Protein Isolated from Salmonid Fish Naturally Infected with Piscirickettsia Salmonis." Vaccine 25 (11): 2095-2102. https://doi.org/10.1016/j.vaccine.2006.11.035.

Mora, J. 2010. “Antibiogram Analyses Strains of Piscirickettsia Salmonis Isolated from Salmonid and Trout, Reared in the Region of Los Rios, Los Lagos and Aysen during 2007- 2008." Bachelor Veterinary Sciences Thesis. Universidad de Concepcion, Facultad de Ciencias Veterinarias, Chile.

Namdari, R, S Abedini, L Albright, and F C P Law. 1998. "Tissue Distribution and Elimination of Oxytetracycline in Sea-Pen Cultured Chinook Salmon, Oncorhynchus Tshawytscha, and Atlantic Salmon, Salmo Salar, Following Medicated-Feed Treatment." Journal of Applied Aquaculture 8 (1): 39-51. https://doi.org/10.1300/Jo28vo8no1_03.

Norambuena-Subiabre, Luis, Margarita P González, and Sergio ContrerasLynch. 2018. "Oxytetracycline Depletion and Withdrawal Time Estimation Following Intraperitoneal Administration in Three Species from Chilean Salmon 
Farming.” Aquaculture $\quad$ Research $49 \quad$ (2): 593-602. https://doi.org/10.1111/are.13501.

Price, D, J Sánchez, R Ibarra, and S St-Hilaire. 2019. "Variation in the concentration of antibiotics in tissue during oral antibiotic treatments in farmed salmonids." Aquaculture 498: 587-593.

Price, D, J Sánchez, J McClure, S McConkey, R Ibarra, and S St-Hilaire. 2018. "Assessing concentration of antibiotics in tissue during oral treatments against piscirickettsiosis." Preventive Veterinary Medicine 156: 16-21.

Price, D, H Stryhn, J Sánchez, R Ibarra, A Tello, and S St-Hilaire. 2016. "Retrospective Analysis of Antibiotic Treatments against Piscirickettsiosis in Farmed Atlantic Salmon Salmo Salar in Chile.” Diseases of Aquatic Organisms 118 (3): $227-35$.

Rees, Erin E, Rolando Ibarra, Matias Medina, Javier Sanchez, Eva Jakob, Raphael Vanderstichel, and Sophie St-Hilaire. 2014. "Transmission of Piscirickettsia Salmonis among Saltwater Salmonid Farms in Chile.” Aquaculture 428-429: 189-94. https://doi.org/10.1016/j.aquaculture.2014.03.031.

Tobar, Jaime A., Sofía Jerez, Mario Caruffo, Catalina Bravo, Francisco Contreras, Sergio A. Bucarey, and Moti Harel. 2011. "Oral Vaccination of Atlantic Salmon (Salmo Salar) against Salmonid Rickettsial Septicaemia.” Vaccine 29 (12): 2336-40. https://doi.org/10.1016/j.vaccine.2010.12.107.

Yáñez, José Manuel, Rama Bangera, Jean Paul Lhorente, Marcela Oyarzún, and Roberto Neira. 2013. "Quantitative Genetic Variation of Resistance against Piscirickettsia Salmonis in Atlantic Salmon (Salmo Salar).” Aquaculture 414-415. https://doi.org/10.1016/j.aquaculture.2013.08.009. 
Supplementary material 2 Selection and hypothesis support for models of antimicrobial effectiveness, using information-theoretic approach

Table Suppl 2.1 Selection and hypothesis support for models of antimicrobial effectiveness, using an information-theoretic approach, for Atlantic salmon production cycles. Models which contributed to the final weighted average are highlighted in grey.

\begin{tabular}{|c|c|c|c|c|}
\hline Model specification & $\mathbf{k}$ & AICc & $\triangle \mathrm{AICc}$ & Weight \\
\hline $\begin{array}{l}\text { Hypothesis groups } 2 \text { (fish), } 3 \text { (management) and } 4 \\
\text { (environment) }\end{array}$ & 40 & 43813 & $\mathrm{O}$ & 0.90 \\
\hline Hypothesis groups 3 (management) and 4 (environment) & 32 & 43818 & 4 & 0.10 \\
\hline $\begin{array}{l}\text { Hypothesis groups } 1 \text { (treatment), } 3 \text { (management) and } 4 \\
\text { (environment) }\end{array}$ & 49 & 43825 & 12 & 0.00 \\
\hline Maximal model & 61 & 43830 & 16 & 0.00 \\
\hline Hypothesis groups 1 (treatment) and 3 (management) & 42 & 44011 & 197 & 0.00 \\
\hline $\begin{array}{l}\text { Hypothesis groups } 1 \text { (treatment), } 2 \text { (fish) and } 3 \\
\text { (management) }\end{array}$ & 54 & 44013 & 200 & 0.00 \\
\hline Hypothesis groups 2 (fish) and 3 (management) & 37 & 44038 & 224 & 0.00 \\
\hline Hypothesis group 3 (management) & 29 & 44053 & 240 & 0.00 \\
\hline SVH: pre-treatment SRS mortality & 24 & 44319 & 506 & 0.00 \\
\hline $\begin{array}{l}\text { Hypothesis groups } 1 \text { (treatment), } 2 \text { (fish) and } 4 \\
\text { (environment) }\end{array}$ & 51 & 44542 & 729 & 0.00 \\
\hline Hypothesis groups 1 (treatment) and 4 (environment) & 39 & 44547 & 734 & 0.00 \\
\hline SVH: pre-treatment unknown mortality & 24 & 44605 & 792 & 0.00 \\
\hline Hypothesis groups 2 (fish) and 4 (environment) & 34 & 44608 & 794 & 0.00 \\
\hline Hypothesis group 4 (environment) & 26 & 44618 & 805 & 0.00 \\
\hline SVH: site infection pressure & 24 & 44640 & 827 & 0.00 \\
\hline $\begin{array}{l}\text { SVH: interaction between treatment type and time to } \\
\text { treatment }\end{array}$ & 32 & 44734 & 921 & 0.00 \\
\hline $\begin{array}{l}\text { SVH: interaction between treatment type and water } \\
\text { temperature }\end{array}$ & 32 & 44769 & 955 & 0.00 \\
\hline Hypothesis groups 1 (treatment) and 2 (fish) & 44 & 44777 & 963 & 0.00 \\
\hline $\begin{array}{l}\text { SVH: interaction between treatment type and treatment } \\
\text { duration }\end{array}$ & 32 & 44790 & 977 & 0.00 \\
\hline Hypothesis group 1 (treatment) & 32 & 44790 & 977 & 0.00 \\
\hline SVH: treatment type & 27 & 44814 & 1001 & 0.00 \\
\hline SVH: time to treatment & 24 & 44831 & 1018 & 0.00 \\
\hline SVH: biomass density & 24 & 44849 & 1036 & 0.00 \\
\hline Hypothesis group 2 (fish) & 31 & 44855 & 1042 & 0.00 \\
\hline SVH: water temperature & 24 & 44864 & 1051 & 0.00 \\
\hline SVH: pre-treatment site coverage & 24 & 44876 & 1062 & 0.00 \\
\hline SVH: time at sea & 24 & 44878 & 1065 & 0.00 \\
\hline SVH: treatment duration & 24 & 44883 & 1070 & 0.00 \\
\hline SVH: treatment continuity & 24 & 44888 & 1074 & 0.00 \\
\hline SVH: number of lice treatments & 24 & 44901 & 1087 & 0.00 \\
\hline
\end{tabular}




\begin{tabular}{lllll}
\hline Model specification & k & AICc & AAICc & Weight \\
\hline SVH: time since vaccine & 24 & 44901 & 1087 & 0.00 \\
Minimal model & 23 & 44901 & 1088 & 0.00 \\
SVH: area infection pressure & 24 & 44902 & 1088 & 0.00 \\
SVH: smolt mortality & 24 & 44902 & 1089 & 0.00 \\
SVH: smolt weight & 24 & 44902 & 1089 & 0.00 \\
SVH: post-treatment site coverage & 24 & 44902 & 1089 & 0.00 \\
SVH: time since lice treatment & 24 & 44903 & 1090 & 0.00 \\
SVH: mortality from other diseases & 24 & 44903 & 1090 & 0.00 \\
\hline
\end{tabular}

AICc $=$ bias-corrected AIC; $\triangle$ AICc $=$ AICc difference from the model with lowest AICc $\mathrm{k}=$ number of adjusted parameters; $\mathrm{SVH}=$ single variable hypothesis; weight = Akaike weight. Note: Models with non-zero weight are highlighted in grey.

Table Suppl 2.2 Selection and hypothesis support for models of antimicrobial effectiveness, using information-theoretic approach, for rainbow trout production cycles. Models which contributed to the final weighted average are highlighted in grey. Non-convergent models $(\mathrm{N}=3)$ are not included.

\begin{tabular}{|c|c|c|c|c|}
\hline Model specification & $\mathbf{k}$ & AICc & $\begin{array}{l}\Delta \text { AIC } \\
\text { c }\end{array}$ & $\begin{array}{l}\text { Weigh } \\
t\end{array}$ \\
\hline Maximal model & $\begin{array}{l}6 \\
0\end{array}$ & 17928 & O & 1.00 \\
\hline Hypothesis groups 1 (treatment), 2 (fish) and 3 (management) & 53 & 17952 & 24 & 0.00 \\
\hline $\begin{array}{l}\text { Hypothesis groups } 1 \text { (treatment), } 3 \text { (management) and } 4 \\
\text { (environment) }\end{array}$ & 49 & 17976 & 49 & 0.00 \\
\hline $\begin{array}{l}\text { Hypothesis groups } 2 \text { (fish), } 3 \text { (management) and } 4 \\
\text { (environment) }\end{array}$ & 39 & $\begin{array}{l}1800 \\
3\end{array}$ & 75 & 0.00 \\
\hline Hypothesis groups 1 (treatment) and 3 (management) & 42 & $\begin{array}{l}1800 \\
8\end{array}$ & 80 & 0.00 \\
\hline Hypothesis groups 2 (fish) and 3 (management) & 36 & 18023 & 96 & 0.00 \\
\hline Hypothesis groups 3 (management) and 4 (environment) & 32 & 18057 & 129 & 0.00 \\
\hline Hypothesis group 3 (management) & 29 & $\begin{array}{l}1808 \\
5\end{array}$ & 157 & 0.00 \\
\hline SVH: pre-treatment SRS mortality & 24 & 18106 & 178 & 0.00 \\
\hline Hypothesis groups 1 (treatment), 2 (fish) and 4 (environment) & 46 & 18127 & 199 & 0.00 \\
\hline Hypothesis groups 1 (treatment) and 2 (fish) & 43 & 18186 & 258 & 0.00 \\
\hline Hypothesis groups 1 (treatment) and 4 (environment) & 39 & 18211 & 284 & 0.00 \\
\hline Hypothesis groups 2 (fish) and 4 (environment) & 33 & $\begin{array}{l}1822 \\
0\end{array}$ & 292 & 0.00 \\
\hline Hypothesis group 2 (fish) & $\begin{array}{l}3 \\
0\end{array}$ & 18274 & 346 & 0.00 \\
\hline $\begin{array}{l}\text { SVH: interaction between treatment type and treatment } \\
\text { duration }\end{array}$ & $\begin{array}{l}2 \\
8\end{array}$ & 18294 & 366 & 0.00 \\
\hline Hypothesis group 1 (treatment) & $\begin{array}{l}2 \\
8\end{array}$ & 18294 & 366 & 0.00 \\
\hline
\end{tabular}




\begin{tabular}{lllll}
\hline Model specification & $\mathbf{k}$ & AICc & $\begin{array}{l}\Delta \text { AIC } \\
\mathbf{c}\end{array}$ & $\begin{array}{l}\text { Weigh } \\
\text { t }\end{array}$ \\
\hline SVH: interaction between treatment type and time to & 32 & 18299 & 371 & o.oo \\
treatment & 24 & 18314 & 386 & 0.oo \\
SVH: time since lice treatment & 26 & 18317 & 389 & 0.oo \\
Hypothesis group 4 (environment) & 2 & 18318 & 390 & 0.00 \\
SVH: interaction between treatment type and water & 8 & & & \\
temperature & 27 & 18321 & 393 & 0.00 \\
SVH: treatment type & 24 & 18327 & 399 & 0.00 \\
SVH: site infection pressure & 24 & 18359 & 431 & 0.00 \\
SVH: time to treatment & 24 & 18362 & 434 & 0.00 \\
SVH: treatment duration & 24 & 18365 & 437 & 0.00 \\
SVH: time at sea & 24 & 18371 & 443 & 0.00 \\
SVH: time since vaccine & 24 & 18385 & 457 & 0.00 \\
SVH: pre-treatment unknown mortality & 24 & 1838 & 460 & 0.00 \\
SVH: area infection pressure & & 8 & & \\
SVH: smolt mortality & 24 & 18391 & 463 & 0.00 \\
SVH: water temperature & 24 & 18393 & 465 & 0.00 \\
SVH: smolt weight & 24 & 18394 & 466 & 0.00 \\
Minimal model & 23 & 18399 & 471 & 0.00 \\
SVH: post-treatment site coverage & 24 & 18399 & 472 & 0.00 \\
SVH: mortality from other diseases & 24 & 18401 & 473 & 0.00 \\
SVH: biomass density & 24 & 18401 & 473 & 0.00 \\
\hline AICc: bias
\end{tabular}

$\overline{\mathrm{AICc}}=$ bias-corrected AIC; $\triangle \mathrm{AICc}=\mathrm{AICc}$ difference from the model with lowest AICc $; \mathrm{k}=$ number of adjusted parameters; SVH = single variable hypothesis; weight = Akaike weight. Note: Models with non-zero weight are highlighted in grey. 


\section{CHAPTER 3}

\section{Quantifying the effects of sea lice burden and}

lice bathing treatments on salmonid rickettsial septicaemia in commercial salmon and trout farms in Chile

Anne Meyera, Amy Burroughsa, Rohan Sadler ${ }^{a, b}$, Jonathan Happolda, Brendan Cowled $^{a}$, Catriona Mackenzie ${ }^{a}$, Alicia L. Gallardo Lagno ${ }^{c}$, Angus Cameron ${ }^{a}$

a Ausvet, 34 Thynne St, Bruce ACT 2617, Australia

b Mo89 School of Agriculture and Environment, The University of Western Australia, 35 Stirling Hwy, Crawley, WA 6008, Australia

${ }^{\mathrm{c}}$ Servicio Nacional de Pesca y Acuicultura, Victoria 2832, Valparaíso, Chile

Aquaculture 513 (2019) 734411

https://doi.org/10.1016/j.aquaculture.2019.734411 


\section{Abstract}

Salmonid rickettsial septicaemia (SRS) has caused significant losses in the Chilean salmonid aquaculture industry in the last two decades. While evidence suggests a strong association between sea lice burden and SRS severity, research to date has been conducted in tanks under controlled environmental conditions. Further, existing work does not account for the effect of the treatments used to control sea lice on SRS severity. This study measures the effect of lice burden, lice bathing treatments and the interaction between these two factors on SRS severity in salmonid aquaculture systems in Chile. Health and management data from nine commercial companies were combined with regulatory data to conduct a retrospective cage-level cohort study. Eight biologically plausible hypotheses were defined and investigated using an information-theoretic approach. The modelling approach was based on mixed-effect, negative binomial models of SRS-attributed mortality counts. A total of 6638 valid production cycles were included in the study, ranging from 01 January 2012 to 28 September 2018. A total of 35,864 cage-level observations were defined in two species: 28,529 in Atlantic salmon and 7335 in rainbow trout. Lice burden and rate of bath treatments were found individually to be risk factors for increased SRS-attributed mortality in both species. For Atlantic salmon, there was also a significant interaction between the levels of lice burden and rate of bath treatments so that increasing levels of one risk factor results in a dampening of the effect of the other factor. While these two factors were found to increase SRS mortality, much of the variability in mortality remained unexplained. Based on these findings, implications for lice management are discussed. The development of firm recommendations about optimal lice control programs should consider the findings of this study in conjunction with economic analysis. This study contributes to improved understanding of the complex epidemiology of SRS in the Chilean salmonid production system.

\section{Key words}

Aquaculture; epidemiology; salmonid rickettsial septicaemia; Atlantic salmon; rainbow trout; sea lice; retrospective study; Chile 


\section{Introduction}

Piscirickettsiosis, also called salmonid rickettsial septicaemia (SRS), is responsible for $95 \%$ of antimicrobial use at the seawater production stage in Chile (Sernapesca, 2017; Burridge et al., 2010). This endemic, bacterial disease does not respond well to either antibiotic treatment or vaccination (Jakob et al., 2014; Price et al., 2016; Rozas and Enriquez, 2014). Losses are heavily influenced by many factors, not all of which have been identified. Mounting evidence suggests that coinfection of salmonids with sea lice increases the severity of infection with Piscirickettsia salmonis, resulting in greater SRS mortality (Figueroa et al., 2017; Lhorente et al., 2014). Sea lice were previously shown to play a role in the epidemiology of other salmon diseases such as amoebic gill disease (Nowak et al., 2010) and infectious salmonid anaemia (Barker et al., 2019). Under controlled conditions, SRS mortality rates in Atlantic salmon (Salmo salar) co-infected with $P$. salmonis and the sea louse Caligus rogercresseyi were shown to be significantly higher than rates observed for fish without lice infestation (Figueroa et al., 2017; Lhorente et al., 2014). The detrimental effects of lice on fish physiology and skin integrity are thought to increase fish susceptibility to initial infection by $P$. salmonis, or if already infected, enhance disease progression and worsen disease outcomes (González et al., 2015; Tadiso et al., 2011).

Antiparasitic drugs administered in feed or drugs administered via immersion (i.e., bath) are two of the methods used to control lice in commercial aquaculture (González et al., 2016). The effectiveness of pharmacological treatments for sea lice may vary according to factors such as lice sensitivity to the chemical, and risk of re-infestation from neighbouring farms (Arriagada et al., 2017). The Chilean regulatory body for fisheries and aquaculture (Servicio Nacional de Pesca y Acuicultura, Sernapesca) implements health monitoring and control programs for $C$. rogercresseyi designed to maintain counts under a farmlevel average of three gravid female lice per fish (Sernapesca, 2015). Bath treatments usually involve concentrating fish in a smaller volume of water (Jimenez et al., 2018), which may stress the fish and increase pathogen transmission. Jakob et al. (2014) found a significant association between the number of sea lice treatments and SRS severity for rainbow trout. As the method 
of sea lice treatments was not specified in this work, and the analysis did not account for the magnitude of lice burden, the specific effects of bathing on SRS severity remain unknown.

In order to design integrated health management programs, both the benefits of reducing lice burden through bathing and the potential negative impacts of such treatment on the incidence and severity of other diseases should be accounted for. Ideally, such analysis should be conducted in commercial production settings, in order to account for the variability of conditions affecting salmon production that may not be observed in experimental studies. To this end, an integrated platform (Plataforma Integrada de Investigación Sanitaria para la Acuicultura Chilena, PIISAC) was developed to support epidemiological research of relevance to the Chilean aquaculture industry. The PIISAC platform provides an unprecedented capability to undertake research on risk factors for SRS at a scale that is not possible with traditional, resource-intensive methods of data collection (Hutchison et al., 2018). This paper presents a retrospective cohort study based on industry-generated data that aimed to i) measure the effect of lice burden on SRSattributed mortality in commercial aquaculture in Chile; and ii) investigate whether bathing treatments applied to reduce sea lice infestation increase SRSattributed mortality.

\section{Methods}

\subsection{Study design}

This retrospective cohort study investigated the role of sea lice infestation and bath treatments applied to control lice infestation as risk factors for SRS mortality in commercial salmonid production. Three biologically plausible hypotheses representing the nature of the association between lice burden, rate of bath treatments and SRS mortality risk during the observation period were identified based on discussion with stakeholders and existing literature:

- Fish with more lice have a greater risk of SRS mortality due to the negative physiological changes associated with infestation or the skin lesions caused by parasitism allowing a route of entry for P. salmonis. 
- Fish exposed to a higher rate of bath treatments for lice control have a greater risk of SRS mortality due to stress or increased opportunity for pathogen transmission caused by bathing conditions.

- The level of lice burden and the rate of bath treatments interact to influence the risk of SRS mortality. The interaction is likely to be complex due to biological and non-biological (e.g., regulatory requirements) factors. For this reason, no prior assumptions are made about the direction and nature of this interaction.

These biological hypotheses were represented by eight working hypotheses that were used in the analysis to measure the support for the biological hypotheses (Table 5).

Table 5 Description of the working hypotheses used in the analysis.

\begin{tabular}{|c|c|c|c|c|}
\hline \multirow[t]{2}{*}{$\begin{array}{l}\text { Hypothesis } \\
\text { identifier }\end{array}$} & \multirow[t]{2}{*}{ Hypothesis } & \multicolumn{2}{|c|}{$\begin{array}{l}\text { Presence and nature of } \\
\text { the association between } \\
\text { parameters and SRS } \\
\text { mortality }\end{array}$} & \multirow{2}{*}{$\begin{array}{l}\text { Interaction } \\
\text { between lice } \\
\text { burden and } \\
\text { rate of bath } \\
\text { treatments }\end{array}$} \\
\hline & & $\begin{array}{l}\text { Lice } \\
\text { burden }\end{array}$ & $\begin{array}{l}\text { Rate of bath } \\
\text { treatments }\end{array}$ & \\
\hline 1 & $\begin{array}{l}\text { Lice burden and the rate of } \\
\text { bath treatments for lice are } \\
\text { not associated with SRS } \\
\text { mortality }\end{array}$ & None & None & No \\
\hline 2 & $\begin{array}{l}\text { Lice burden is linearly } \\
\text { associated with SRS } \\
\text { mortality }\end{array}$ & Linear & None & No \\
\hline 3 & $\begin{array}{l}\text { The rate of bath treatments } \\
\text { for lice is linearly } \\
\text { associated with SRS } \\
\text { mortality }\end{array}$ & None & Linear & No \\
\hline 4 & $\begin{array}{l}\text { The rate of bath treatments } \\
\text { for lice is non-linearly } \\
\text { associated with SRS } \\
\text { mortality }\end{array}$ & None & Non-linear & No \\
\hline 5 & $\begin{array}{l}\text { Both the lice burden and } \\
\text { the rate of bath treatments } \\
\text { for lice are linearly } \\
\text { associated with SRS } \\
\text { mortality }\end{array}$ & Linear & Linear & No \\
\hline 6 & $\begin{array}{l}\text { Lice burden is linearly } \\
\text { associated with SRS }\end{array}$ & Linear & Non-linear & No \\
\hline
\end{tabular}


mortality and the rate of

bath treatments for lice is

non-linearly associated

with SRS mortality

Both the lice burden and

the rate of bath treatments

for lice are linearly

7

associated with SRS

mortality and there is an

Linear Linear Yes

interaction between both

these exposures

The lice burden is linearly

associated with SRS

mortality, the rate of bath

8

treatments for lice is non-

linearly associated with

Linear Non-linear Yes

SRS mortality and there is

an interaction between

both these exposures

\subsection{Setting}

In this study, only the seawater phase of salmonid production was considered as sea lice do not thrive in freshwater (González and Carvajal, 2003). In Chile, seawater production is performed in three regions: X (Los Lagos), XI (Aysén) and XII (Magallanes). Five salmonid species are produced: Atlantic salmon (Salmo salar), coho salmon (Oncorhynchus kisutch), rainbow trout (Oncorhynchus mykiss), King salmon (Oncorhynchus tshawytscha) and Pink salmon (Oncorhynchus gorbuscha), although the production of the two latter species is anecdotal. At the time of this study, 21 companies were operating in the country. The production is strongly clustered with fish stocked in seawater cages that are grouped within farms. Regulations define management areas within which farms are grouped based on their location (Sernapesca, 2009). Management areas may contain farms operated by different companies. Around 830 farms have produced at least one fish group since the deployment of the Information System for Aquaculture Management (Sistema de Información para la Fiscalización de Acuicultura, SIFA) database managed by Sernapesca, with an average of 300 farms active at any one time. 


\subsection{Study population and data sources}

Daily cage-level data were obtained from nine commercial aquaculture companies operating in the three regions where seawater production is performed. The data covered all seawater cages stocked with Atlantic salmon or rainbow trout between 01 January 2012 and 28 September 2018. These species are simply referred to as 'salmon' and 'trout' in the remainder of this manuscript. Additionally, sea lice counts were obtained from the SIFA database for these cages. All mentions of lice in this manuscript refer to C. rogercresseyi (Boxshall and Bravo, 2000).

The data in PISAC were provided voluntarily by participating companies, directly from the companies' routine management software systems. A full backup copy of each database was uploaded to secure cloud storage, leaving very little opportunity for manual interference with the original data. The data from each company were extracted from the relevant tables of their management software and compiled in a relational database, together with the SIFA data. Numeric values were inspected for biologically improbable values, and the measurement units were harmonised between data sources.

The epidemiological unit of interest was the cage-level production cycle, from stocking in a given seawater cage to harvest. For the purpose of this paper, the term 'production cycle' refers to a cage-level group of fish. The cage was the level at which sea lice counts and treatments were performed, and was the lowest level at which many variables were recorded. In addition, initial exploratory data analysis showed that the between-cage variance of sea lice counts was high, with about $40 \%$ of the counts being significantly different between cages, thus limiting the validity of using a farm-level average. The statistical unit for the analysis was a cage-level observation. A cage-level observation was initiated each time a sea lice count was performed on a seawater cage.

\subsection{Variables}

\subsubsection{Outcome variable}

The outcome of interest was the cage-level SRS mortality count during a 30day period following the sea lice count (hereafter, 'the observation period'). The 
observation period was set at 30 days, corresponding to approximately twice the hypothesized incubation period of SRS (Rozas and Enriquez, 2014; Smith et al., 2004). Also, it was consistent with the time required to observe a measurable difference in SRS mortality between lice-infested and lice-free fish (Figueroa et al., 2017; Lhorente et al., 2014).

During a production cycle, a single cage may have been selected for lice counting more than once. If the 30-day observation period for a given count event overlapped with subsequent count event(s), only the first cage-level observation was included in the analysis to avoid double counting (pseudo-counting) of the statistical units. To obtain complete 30-day cage-level observations and so avoid right-censoring of the data, observations that occurred less than 30 days before harvest were removed.

\subsubsection{Primary exposures}

The primary exposures of interest were the sea lice burden and the rate of bath treatments. The sea lice burden was defined as the mean number of lice per fish at the beginning of the observation period. The sea lice monitoring scheme of Sernapesca imposes regular sea lice counts in seawater cages. The frequency of counts was weekly for salmon and trout farms in high risk areas and monthly for all other farms. For each sampling, 10 fish were sampled from each of four cages (or all cages if the farm had less than four cages stocked). The cages were chosen at random at each sampling. The sea lice samplings began at a maximum of 30 days after the stocking of the first cage on the farm had been completed. Lice were counted by mutually exclusive life stages: juveniles (non-mobile chalimus), gravid females and other mobile adults (non-gravid adult females and adult males) (González and Carvajal, 2003). Exploratory data analysis was used to ascertain which lice stages to include in the lice burden exposure variable.

The rate of bath treatments was defined as the daily rate of bath treatments used to control lice. This value was calculated as the total number of bathing days divided by the duration in days from sea entry to the cage-level observation. Bath treatments used to control other infections and infestations were not considered in this study, as their occurrence during the seawater phase of the production is rare 
compared to the use of bath treatments to control sea lice. This variable gave a measure of the cumulative effect of bathing up until the time of the observation period. Based on the findings of Jakob et al. (2014), the possible non-linear association between the outcome and the rate of bath treatments was considered by including this exposure as linear and quadratic terms in the corresponding models.

\subsubsection{Other explanatory variables}

A number of risk factors susceptible to influence SRS mortality were identified from the scientific literature, through consultation with experts and from the results of previous studies conducted within the same project (Happold et al., 2020ba, 2020b; Hillman et al., 2020; Zalcman et al., 2021). These variables were included in the models as they may act as confounders: number of days since sea entry, average water temperature during the observation period (in degrees Celsius), average dissolved oxygen concentration during the observation period (in $\mathrm{mg} / \mathrm{L}$ ), latitude of the farm (in decimal degrees), calendar year at the start of observation period and neighbourhood infection pressure. The average temperature and oxygen values were calculated from daily records obtained for standardized values of water depth and time of day. The neighbourhood infection pressure was calculated as the weighted density average of the SRS mortality incidence at the beginning of the observation period in neighbouring farms. These calculations were based on a previously published methodology (Rees et al., 2014), where the weighting was inversely related to the seaway distances between farms. Farms were considered as neighbours when located within a $20-\mathrm{km}$ radius of the farm of interest, consistently with distances of pathogen dispersal considered in previous work (Rees et al., 2014; Salama and Murray, 2013, 2011). The seaway distance between farms was computed using a least-cost path algorithm implemented in Python by the scikit-image package'.

${ }^{1}$ http://scikit-image.org/docs/0.7.0/api/skimage.graph.mcp.html 


\subsection{Statistical methods}

A negative binomial model of the SRS-attributed mortality count measured during the observation period was used. The modelling adopted a generalised linear mixed effect regression framework using the lme 4 package (Bates et al., 2015), implemented in the R statistical environment, version 3.5.1 (R Core Team, 2018). The SRS-attributed mortality count was offset by the natural logarithm of the population size at the beginning of the observation period, effectively modelling the outcome as a mortality risk (Cameron and Trivedi, 2013). Explanatory variables were centred and scaled where appropriate. Salmon and trout data were modelled separately due to important differences in management as well as susceptibility to disease and ectoparasitism. Variables with a variance inflation factor larger than three indicating high collinearity should be removed to improve the coefficient estimation (Zuur et al., 2010). Adjustment for collinearity was not required in this study as all calculated variance inflation factors were lower than three. Model diagnostics included inspection of the residuals, fitted values and autocorrelation. Two and eight observations were associated with very large fitted and residual values in salmon and trout, respectively. The models were re-fitted without these data points to assess their influence. The resulting coefficient estimates and their standard errors did not noticeably vary. Consequently, the outlier data points were retained in the dataset.

Cage-level production cycle, farm and management area were included as nested random effects to control for clustering in the data given the hierarchical structure of farms and management factors. As data were available for only nine companies, a company factor was included as a fixed effect. An intercept-only and a minimal model were defined. The intercept-only model included only the random effects and the company fixed effect, while the minimal model included both the random effects and the potential confounders discussed above.

Consistent with an information-theoretic approach (Burnham and Anderson, 2002), eight statistical models were developed based on the working hypotheses. These models were obtained by adding the explanatory variable(s) corresponding to each hypothesis to the minimal model. The model for hypothesis 1 was effectively the minimal model, without primary exposures. The models were 
ranked according to their Akaike weight computed from their bias-corrected Akaike information criterion (AICc) (Akaike, 1974). The Akaike weights were then applied in a weighted average of the models, generating the final model from which model inferences were drawn. As models were weighted by their Akaike weight in the estimation of the final model, only models with a non-zero Akaike weight were effectively contributing to the final model's coefficients. Posterior marginal means and their respective confidence intervals were calculated from the model including all exposures, corresponding to hypothesis 8 , using the emmeans package in $\mathrm{R}$ (Lenth, 2018).

The final models showed a weak, order-1 autocorrelation within production cycles. The small number of observations per cycle (six on average) did not justify the use of an autocorrelation-specific model such as time series analysis. Few methods are available to fit generalized mixed effect models with an autocorrelation structure. The R functions glmmPQL and $g \operatorname{lmm} T M B$ (Brooks et al., 2017; Venables and Ripley, 2002) were trialled but failed to produce interpretable results. Other methods were at the development stage and could not be considered reliable, such as the lme4ord package. Finally, including the mortality during the previous week as a model parameter did not reduce the remaining autocorrelation in the residuals and led to relatively similar parameter estimates. Further, it removed the first observation for all cycles, which amounts to $16 \%$ of the entire dataset. Consequently, within-cycle clustering of the observation was only accounted for by the random effect for production cycle.

\section{Results}

\subsection{General description of the data}

The dataset available for this study ranged from o1 January 2012 to 28 September 2018 and included 4638 and 2000 valid cage-level production cycles in salmon and trout, respectively. Production cycles were distributed across 160 farms in 53 management areas. One company did not have any matching SIFA lice counts and was therefore excluded from the analysis. Of the eight remaining companies, all were growing trout and seven were growing salmon. A total of 35,864 cage-level observations were included in the analysis $(28,529$ in salmon and 
7335 in trout). For salmon, the maximum number of observations for a single cage within a production cycle was 18 , with a median of 6 . For trout, the maximum number of observations for a single cage within a production cycle was 11, with a median of 4 . The distribution of the outcome and primary exposure variables is shown in Table 2.

Table 6 Descriptive summary of the outcome and primary exposure variables in the dataset used for the analysis $(\mathrm{N}=35,864)$

\begin{tabular}{|c|c|c|c|c|c|c|c|c|}
\hline Species & Variable & Min. & Q1 & Median & Mean & Q3 & Max. & $\begin{array}{l}\text { \% of } \\
\text { zeroes }\end{array}$ \\
\hline \multirow{3}{*}{$\begin{array}{l}\text { Atlantic } \\
\text { salmon }\end{array}$} & $\begin{array}{l}\text { mean lice count per fish } \\
\text { (all stages) }\end{array}$ & 0.0 & 0.7 & 2.5 & 4.5 & 6.0 & 173.1 & 9 \\
\hline & $\begin{array}{l}\text { rate of bath treatments } \\
(\%)\end{array}$ & 0.0 & 0.0 & 0.0 & 1.4 & 1.9 & 19.3 & 55 \\
\hline & $\begin{array}{l}\text { SRS mortality risk } \\
\text { during the observation } \\
\text { period (\%) }\end{array}$ & 0.0 & 0.0 & 0.005 & 0.1 & 0.05 & 26.0 & 38 \\
\hline \multirow{3}{*}{$\begin{array}{l}\text { Rainbow } \\
\text { trout }\end{array}$} & $\begin{array}{l}\text { mean lice count per fish } \\
\text { (all stages) }\end{array}$ & 0.0 & 0.0 & 1.4 & $3 \cdot 3$ & 4.4 & 150.8 & 28 \\
\hline & $\begin{array}{l}\text { rate of bath treatments } \\
(\%)\end{array}$ & 0.0 & 0.0 & 0.0 & 0.7 & 0.6 & 21.5 & 74 \\
\hline & $\begin{array}{l}\text { SRS mortality risk } \\
\text { during the observation } \\
\text { period (\%) }\end{array}$ & 0.0 & 0.0 & 0.007 & 0.5 & 0.2 & 39.1 & 42 \\
\hline
\end{tabular}

Q1: first quartile, Q3: third quartile

There was a statistically significant, strong correlation within each pair of lice stages (juvenile, gravid females and mobile adults). Consequently, the three variables could not be included in the models at the same time. The univariate correlations between different lice stages and the SRS mortality risk were relatively similar (results not shown, Spearman's rank correlation coefficients between 0.22 and 0.32 depending on stage and species, $\mathrm{P}<0.01$ ). As the association between SRS mortality risk in the observation period and mean lice count appeared slightly stronger when accounting for all lice stages in the mean lice count, a variable indicating lice burden due to all lice stages was used in the multivariable models.

\subsection{Mixed effects model of SRS mortality risk in Atlantic salmon}

Only one model was supported by the data in salmon (Table Suppl 1.1): the full multivariable model including mean lice count, rate of bath treatments as a 
quadratic predictor and an interaction between mean lice count and rate of bath treatments (hypothesis 8). There was an AICc difference of at least 16 points between this model and any of the other models included in the analysis, suggesting that the best model provided a significantly better fit to the data. The distribution of the outcome variable showed that there was no SRS-attributable mortality in many of the cage-level observations (38\% and $42 \%$ of observations in salmon and trout, respectively). However, the AICc of an equivalent zero-inflated negative binomial model was not different from the AICc of the negative binomial model. As a rule of model parsimony, the model with the least number of parameters (negative binomial) was selected as the preferred model. The high number of observations with zero SRS mortality was well accounted for by the negative binomial model of over-dispersion.

Table 7 Adjusted risk ratios of SRS-attributed mortality based on model averaging for the Atlantic salmon observations $(\mathrm{N}=\mathbf{2 8 , 5 2 9})$.

\begin{tabular}{|c|c|c|c|c|c|}
\hline \multicolumn{2}{|l|}{ Variable } & Risk ratio & $\begin{array}{l}95 \% \text { CI } \\
\text { lower } \\
\text { bound }\end{array}$ & $\begin{array}{l}95 \% \mathrm{CI} \\
\text { upper } \\
\text { bound }\end{array}$ & $\begin{array}{l}\mathbf{P} \text { - } \\
\text { value }\end{array}$ \\
\hline \multicolumn{2}{|l|}{ mean lice count per fish } & $1.17^{\mathrm{b}}$ & 1.13 & 1.21 & $<0.01$ \\
\hline \multicolumn{2}{|l|}{ rate of bath treatments (linear term) } & 1.92 & 1.72 & 2.15 & $<0.01$ \\
\hline \multicolumn{2}{|l|}{ rate of bath treatments (quadratic term) } & 0.60 & 0.55 & 0.66 & $<0.01$ \\
\hline \multicolumn{2}{|c|}{ mean lice count per fish $\mathrm{x}$ rate of bath treatments } & 0.93 & 0.90 & 0.96 & $<0.01$ \\
\hline \multicolumn{2}{|l|}{ latitude of the farm ${ }^{a}$} & 2.30 & 1.66 & 3.19 & $<0.01$ \\
\hline \multicolumn{2}{|l|}{ average water temperature $^{\mathrm{a}}$} & 158.74 & 112.75 & 223.50 & $<0.01$ \\
\hline \multicolumn{2}{|l|}{ average dissolved oxygen concentration ${ }^{\text {a }}$} & 0.90 & 0.87 & 0.94 & $<0.01$ \\
\hline \multicolumn{2}{|l|}{ neighbourhood infection pressure ${ }^{\mathrm{a}}$} & 1.26 & 1.21 & 1.32 & $<0.01$ \\
\hline \multicolumn{2}{|l|}{ number of days since sea entry ${ }^{a}$} & 2.94 & 2.82 & 3.06 & $<0.01$ \\
\hline \multirow{7}{*}{ calendar year } & 2012 & reference & & & \\
\hline & 2013 & 1.60 & 1.34 & 1.91 & $<0.01$ \\
\hline & 2014 & 1.75 & 1.44 & 2.13 & $<0.01$ \\
\hline & 2015 & 5.54 & 4.56 & 6.74 & $<0.01$ \\
\hline & 2016 & 2.41 & 1.95 & 2.96 & $<0.01$ \\
\hline & 2017 & 2.78 & 2.26 & 3.42 & $<0.01$ \\
\hline & 2018 & $5 \cdot 35$ & 4.20 & 6.81 & $<0.01$ \\
\hline
\end{tabular}

a Parameter estimates of continuous variables are presented for the scaled variables. 
${ }^{\mathrm{b}}$ The parameter estimates presented in this table were obtained through an average of the component model estimates, weighted by the respective Akaike weights of each model. Due to distribution of the Akaike weight in this species, the average model effectively corresponds to the best model.

$\mathrm{CI}=$ confidence interval.

All the primary exposures, interaction term and confounding variables included in the most supported model had a statistically significant association with the outcome. In particular, the mean lice count per fish had a statistically significant, positive association with the SRS mortality risk during the observation period (Table 3). There was a statistically significant quadratic relationship between the rate of bath treatments for lice and the SRS mortality risk during the observation period. There was a positive association for the linear term and a negative association for the quadratic term. These associations indicate that as the rate of bath treatments increases, the SRS mortality risk during the observation period initially increases. For higher rates of bath treatments, this is associated with a reduction in the rate of increase in SRS mortality risk and eventually a decrease in the SRS mortality risk.

The SRS mortality risk during the observation period increased with an increase in latitude, an increase in seawater temperature, a decrease in oxygen levels, an increase of the neighbourhood infection pressure and an increased duration at sea (Table 3).

The conditional $R^{2}$ estimate for fixed terms in the most supported model was $17 \%$. The residual variance was reduced by $12 \%$ when moving from the interceptonly model including the random effects to the most supported model. The variance partition coefficients showed that the primary exposures captured some of the variance observed at management area-level compared to the minimal model without primary exposures (hypothesis 1). A third of the unexplained variance in the most supported model was captured by the farm random effect. The management area random effect captured $20 \%$ of the unexplained variance, and the company and cage random effects captured around $14 \%$ of the variance each, indicating substantial clustering of the variance within the management structure. The coefficient estimates for each management area are presented as Figure Suppl 2.1 . 


\subsection{Mixed effects model of SRS mortality risk in rainbow trout}

All models including the rate of bath treatments had some support from the data for trout (Table Suppl 1.2). Among these, the models also including the mean lice count (hypotheses 5, 6, 7 and 8) were more supported than those which did not (hypotheses 3 and 4). The AICc differences between these models were relatively small (up to 6 points).

Table 8 Adjusted risk ratios of SRS-attributed mortality based on model averaging for the rainbow trout observations $(\mathrm{N}=7335)$.

\begin{tabular}{|c|c|c|c|c|c|}
\hline \multicolumn{2}{|l|}{ Variable } & Risk ratio & $\begin{array}{l}95 \% \\
\text { CI } \\
\text { lower } \\
\text { bound } \\
\end{array}$ & $\begin{array}{l}95 \% \\
\text { CI } \\
\text { upper } \\
\text { bound } \\
\end{array}$ & $\boldsymbol{P}$ \\
\hline \multicolumn{2}{|l|}{ mean lice count per fish ${ }^{\mathrm{c}}$} & $1.16^{\mathrm{b}}$ & 1.03 & 1.31 & 0.01 \\
\hline \multicolumn{2}{|l|}{ rate of bath treatments (linear term) $\mathrm{c}$} & 1.51 & 1.19 & 1.93 & $<0.01$ \\
\hline \multicolumn{2}{|l|}{ rate of bath treatments (quadratic term) } & 0.95 & 0.78 & 1.16 & 0.62 \\
\hline \multicolumn{2}{|c|}{ mean lice count per fish $\mathrm{x}$ rate of bath treatments } & 0.99 & 0.94 & 1.03 & 0.50 \\
\hline \multicolumn{2}{|c|}{ latitude of the farm ${ }^{a}$} & 0.83 & 0.40 & 1.71 & 0.61 \\
\hline \multicolumn{2}{|l|}{ average water temperature ${ }^{\mathrm{a}, \mathrm{c}}$} & 140.14 & 70.44 & 278.82 & $<0.01$ \\
\hline \multicolumn{2}{|l|}{ average dissolved oxygen concentration ${ }^{\mathrm{a}, \mathrm{c}}$} & 0.74 & 0.68 & 0.82 & $<0.01$ \\
\hline \multicolumn{2}{|l|}{ neighbourhood infection pressure ${ }^{\mathrm{a}, \mathrm{c}}$} & 1.39 & 1.24 & 1.56 & $<0.01$ \\
\hline \multicolumn{2}{|l|}{ number of days since sea entry $a, c$} & 18.63 & 17.01 & 20.40 & $<0.01$ \\
\hline \multirow{7}{*}{ calendar year $^{\mathrm{c}}$} & 2012 & reference & & & \\
\hline & 2013 & 0.64 & 0.45 & 0.91 & 0.01 \\
\hline & 2014 & 1.50 & 1.05 & 2.15 & 0.03 \\
\hline & 2015 & 0.43 & 0.30 & 0.63 & $<0.01$ \\
\hline & 2016 & 1.10 & 0.72 & 1.68 & 0.66 \\
\hline & 2017 & 0.77 & 0.49 & 1.23 & 0.27 \\
\hline & 2018 & 1.62 & 0.85 & 3.08 & 0.14 \\
\hline
\end{tabular}

a Parameter estimates of continuous variables are presented for the scaled variables.

${ }^{\mathrm{b}}$ The parameter estimates presented in this table were obtained through an average of the component model estimates, weighted by the respective Akaike weights of each model.

${ }^{c}$ Variables that had a statistically significant $\mathrm{P}$ value $(\mathrm{P}<0.05)$.

$\mathrm{CI}=$ confidence interval.

There was a statistically significant association between the mean lice count and the SRS mortality risk in the averaged model (Table 8). There was a positive, 
linear relationship between the rate of bath treatments and the SRS mortality risk during the observation period. Neither the quadratic effect for the rate of bath treatments nor the interaction term between mean lice count and rate of bath treatments were statistically significant.

The effects of all the confounding variables besides the farm latitude were statistically significant. The SRS mortality risk increased with an increase in seawater temperature, a decrease in oxygen levels, an increase in the neighbourhood infection pressure and an increased duration at sea (Table 8).

The conditional $R^{2}$ estimate for the supported models was around $32 \%$. The net reduction in residual variance was $26 \%$ when moving from the intercept-only model including the random effects to the most supported model. The inclusion of the fixed effects captured all the management area-level variability. In the most supported model, most of the variance resided at company level (80\%), while $15 \%$ was captured by the farm-level random effect.

\subsection{Posterior marginal means}

In cages that were not bathed, or cages that were bathed at a rate of up to $3 \%$ of production days, an increase in mean lice count was associated with a small but significant increase in SRS mortality risk in both species (Figure 3). For instance, the SRS mortality risk during the observation period increased between $5 \%$ and $10 \%$ in relative terms when increasing the average number of lice per fish from zero to three, and between $4 \%$ and $7 \%$ when increasing the average number of lice per fish from three to five. In cages bathed at a rate of $5 \%$ of the production days or more, the differences between SRS mortality values for different mean lice counts were no longer significant. 

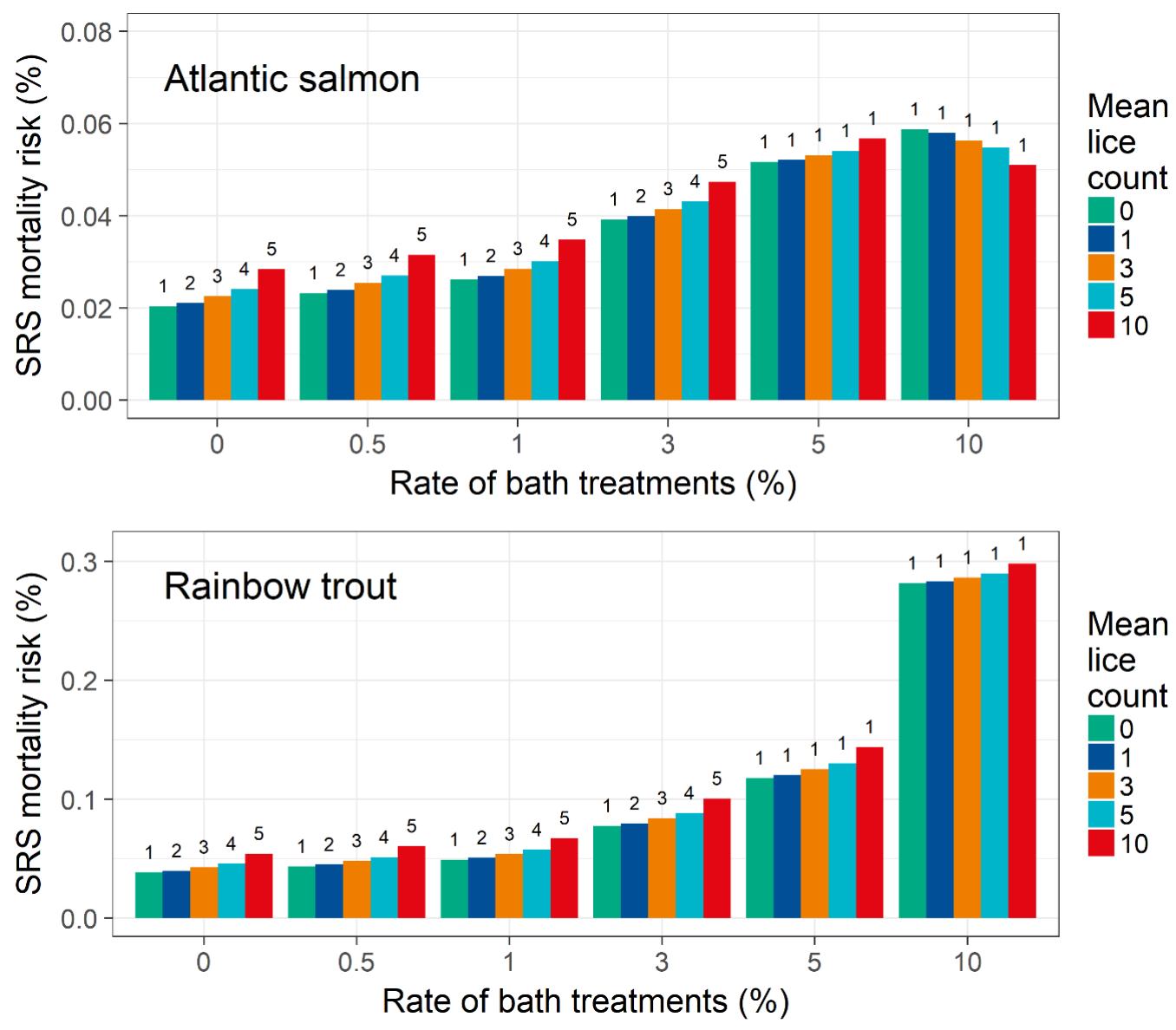

Figure 3 Posterior marginal means and comparisons of the effect of lice burden on the observed SRS mortality risk during the observation period for different rates of bath treatments in Atlantic salmon (upper panel) and rainbow trout (lower panel). Different superscripts assigned to the lice burden values indicate significantly different SRS mortality risks during observation periods for a given rate of bath treatments (multiple comparisons with Tukey adjustment).

An increase in the rate of bath treatments was associated with a significant increase in SRS mortality risk in both species (Figure 4). However, this association was no longer significant for rates of bath treatments of $5 \%$ and higher in salmon. Cages never treated by baths had $18 \%$ to $22 \%$ lower SRS mortality risk during the observation period than cages treated every 3 months (rate of bath treatments 
around 1\%). Cages treated every 3 months had a $30 \%$ to $37 \%$ lower SRS mortality than cages treated monthly (rate of bath treatments around 3\%).
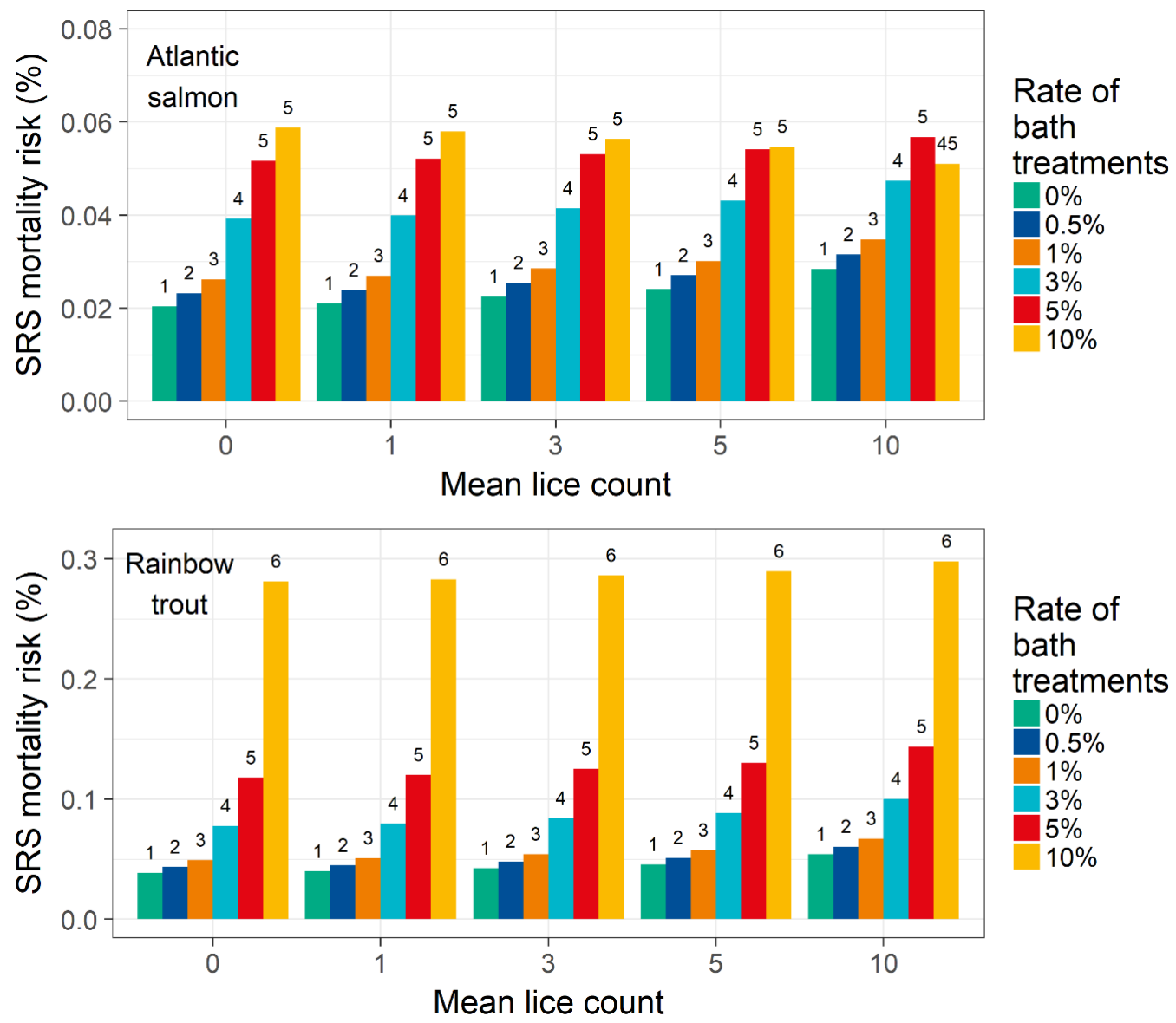

Figure 4 Posterior marginal means and comparisons of the effect of the rate of bath treatments on the observed SRS mortality risk during the observation period for different values of lice burden in Atlantic salmon (upper panel) and rainbow trout (lower panel). Different superscripts assigned to the values of rate of bath treatments indicate significantly different SRS mortality risks during observation periods for a given lice burden (multiple comparisons with Tukey adjustment). 


\section{Discussion}

Knowing the extent to which co-morbid conditions and management practices influence SRS severity is critical to the design of an integrated health strategy that minimises loss and antimicrobial use associated with SRS. Research to date has assessed the influence of lice burden on SRS severity separately to the influence of lice treatments (Figueroa et al., 2017; Lhorente et al., 2014). In this study, it was considered that these two exposures need to be accounted for simultaneously, given the complex relationship whereby lice burden influences the amount of lice treatments and vice versa. The effect of lice burden and lice bathing treatments on SRS severity was estimated in two species, Atlantic salmon and rainbow trout, using routinely generated industry data. Results showed that cages with higher mean lice counts or more frequent bath treatments had a significantly higher SRS mortality risk in the 30 days following the lice count.

These results support those of controlled tank trials that found higher SRS mortality rates in salmon infested with lice compared to lice-free fish (Figueroa et al., 2017; Lhorente et al., 2014). The lice burden in these controlled experiments was much greater than the mean lice counts observed under commercial conditions in our study population. These experimental studies showed a significant effect of lice burden on SRS mortality rate for lice counts ranging from 44 to 88 copepodites per fish. Our results indicate that relatively small lice burdens may also have a negative effect on fish survival when infected with $P$. salmonis. In our study, the majority (75\%) of cage-observations had a cage average of 6 lice per fish or lower, which was identified as the threshold above which fish physiology was adversely affected by González et al. (2015). Note that lice burden was measured as a cage-level average; there will be fish in the cage with higher and lower lice counts.

Higher rates of bath treatments were associated with a greater SRS mortality risk during the observation period in both species. In Atlantic salmon, the differences were not significant for cages bathed $5 \%$ of production days or more often. In rainbow trout, the differences were significant for all rates of bath treatments. These results support those of Jakob et al. (2014) who found a quadratic relationship between the number of lice treatments and the average SRS 
mortality risk during outbreaks in trout. However, the association was not significant for salmon production cycles. In their study, the authors used a smaller dataset for salmon (252 cages compared to 4,638 cages in our study) and the method of lice treatment was not specified. It is likely that our study provided a greater power to detect the association between lice treatments (specifically bathing) and SRS mortality risk. A previous study using the same data source (Happold et al., 2020a) found a significant negative association between number of lice treatments and SRS mortality risk during outbreaks in salmon and a significant positive association in trout. Importantly, the method of lice treatment was not specified in that earlier work and the predictor used was the number of treatments. The results of the current study suggest that SRS mortality risk increases with the proportion of production days where treatment was administered before the observation period rather than with the total number of treatment days. Previous work has showed that stress had significant physiological effects on fish that may affect immunocompetency (Barton, 2002). Bathing may increase stress levels in fish and, consequently, increase the fish susceptibility to infectious diseases. González et al. (2016) detected a similar association between bath treatments and mortality for two other main salmonid diseases (amoebic gill disease and infectious salmonid anaemia). In addition, increased fish density has been associated with increased SRS mortality in experimental conditions (Larenas et al., 1997). By temporarily increasing the fish density, it would be plausible that bathing may also increase pathogen transmission through more frequent fish contact.

The interaction between mean lice count and rate of bath treatments influenced the effect of each exposure on SRS mortality risk in salmon (but not in trout). The risk ratio was 0.9, indicating that as one of the exposures (lice burden or rate of bath treatments) increases, the effect of the other exposure decreases. For instance, when the lice burden increases, the increase in SRS mortality associated with higher rates of bath treatments slowly decreases. For higher lice burdens, the negative effects of bath treatments may be overcome by the positive effects associated with the reduction in lice burden. It is worth noting that results for high rates of bath treatments $(>3 \%)$ had a greater degree of uncertainty due to 
the limited amount of data for these values in both species and should be interpreted with caution. Also, the time since bathing to the period of SRS mortality measurement may have been a confounding factor in this complex relationship.

For both salmon and trout, the results show that lice bathing treatments may adversely affect fish survival during SRS mortality episodes. Lice control is important in the context of $P$. salmonis coinfection, but it is also essential to maintain animal welfare, reduce losses directly attributable to sea lice infestation and also to reduce the prevalence of other coinfections associated with $C$. rogercresseyi (Figueroa et al., 2017). Therefore, considering a reduction of the rate of bath treatments to that required to manage lice burden is recommended based on the results presented here. Alternative strategies should be explored to manage the trade-off between the reduction in SRS severity associated with maintaining lice counts below a defined threshold and the increase in SRS severity associated with increasing the rate of bath treatments to a level necessary to achieve this desired threshold. A threshold for lice counts may be based on physiological thresholds (González et al., 2015), optimal thresholds calculated using bioeconomic modelling, or regulatory requirements. Such threshold should ideally consider both the short-term effect of lice burden and bath treatments, as shown in this study, but also integrate these effects across the entire production cycle to provide producers with economically relevant measures. Consideration is also due to the potential circulation of sea lice between native wild fish and farmed salmon and its impacts. This is an important issue in some salmon farming systems (Marty et al., 2010) but is less studied in Chile (Sepúlveda et al., 2004), probably in relation with the absence of native salmonids in the study area (Pascual and Ciancio, 2007).

In addition to adjusting the bathing frequency, it is important to optimize the efficiency of bath treatments. This may involve ensuring the correct therapeutic dose is administered and employing strategies such as synchronisation of bathing with neighbouring farms (Arriagada et al., 2017). Where possible, bathing conditions may be altered to reduce potential stress and enhanced pathogen transmission (e.g. minimise density of fish). However, maximum bathing efficiency should be maintained, for instance by ensuring a sufficient treatment duration (Jimenez et al., 2018). Lice control via bathing may be minimised by 
supplementing or replacing with non-immersive options such as long acting infeed treatments (Poley et al., 2018), targeted fallowing, and innovative methods that minimize or avoid exposure to parasites (e.g., growing fish in closed floating cages (Nilsen et al., 2017)). Last, recent research providing producers with a tool to predict the abundance of sea lice is also of importance in this context (St-Hilaire et al., 2018). Such a tool may support decision-making concerning fish stocking and sea lice treatments, in order to minimize both the sea lice burden and the intensity of treatments.

This study has provided further evidence to support the following variables as factors reducing fish survival during episodes of SRS: higher latitudes, higher daily mean seawater temperature, lower daily mean oxygen levels, higher neighbourhood infection pressure and longer duration at sea. The year 2012 was set as the reference year for this study, and all other years were associated with higher SRS mortality in salmon. On the other hand, years 2013 to 2017 were associated with lower SRS mortality in trout, while the mortality was exceptionally high in 2018. Some variables such as temperature were associated with very large risk ratios (140 and 158 for trout and salmon, respectively). This may be because SRS mortality at low daily mean temperatures is minimal, and therefore the linear association is associated with a very large slope. It would be useful to explore these associations in a non-linear regression framework, to better describe the impact of these factors on the outcome and overcome the limitations of linear models. In the case of temperature, the association might involve a sharp slope for low to medium temperatures followed by a plateau where there is no further additional effect of increasing temperature.

It is important to note that the inclusion of the lice burden and rate of bath treatments did not increase the explanatory power of the models, compared to the minimal model. Sea lice burdens vary spatially, while rates of bath treatments are strongly dependent on company and farm practices. Therefore, it is possible that these two variables captured some of the variability that was previously associated to one or more of the random effects. This is supported by the reduction in the variance at management area level observed between hypotheses 1 and 8 in salmon. Although the conditional $R^{2}$ did not change overall, the inclusions of these 
primary exposures modified the distribution of the variance between random and fixed effects. In addition, the variables included in the minimal model (describing potential confounders as well as variables related to hierarchical clustering in the data) only explained about 17 and $32 \%$ of the total variability in the SRS mortality outcome, in salmon and trout, respectively. This finding is consistent with the findings of our previous study (Happold et al., 2020a), which showed that although several variables were associated with mortality after treatment for SRS, the effect of each was relatively small. This highlights the large variability in SRS incidence, and perhaps the existence of other factors with a major influence on SRS mortality that are as yet unaccounted for. The statistically significant coefficient estimate for latitude in salmon suggests that such factors are likely to be spatially distributed. In addition, some management areas performed significantly better or worse than average for salmon (Figure Suppl 2.1), while management area was not a significant predictor for trout. It would be useful to investigate the characteristics of management areas which may explain the observed variations in SRS mortality.

Although important confounders were accounted for to the best of our knowledge and data availability, it is possible that unaccounted-for variables could influence the relationships between lice burden, bath treatments and SRS mortality risk in ways that were not considered in this study. Also, this study was conducted soon after the PIISAC research platform was developed. At this time, only nine of the 21 companies operating in Chile were participants in this platform, and these companies may not be representative of the industry as a whole. For this reason, the results cannot readily be extrapolated to the entire industry. Last, the results presented here are related to two of the major salmonid species farmed in Chile, but do not cover either coho salmon or less common species such as Chinook salmon. Exploratory data analysis showed that coho salmon cages overall had small numbers of lice, with little variability, and were not subjected to bathing treatments. In addition, previous studies have demonstrated the low susceptibility of coho salmon to C. rogercresseyi infestation (Bravo, 2003; Hamilton-West et al., 2012; Yatabe et al., 2011). Consequently, coho salmon production cycles were not analysed in this study. 
This study did not enable us to identify which of the individual lice stages (juvenile, gravid females or mobile adults) most affected SRS mortality. Exploratory analysis showed high correlation between different lice stages, precluding their simultaneous inclusion in the models (Zuur et al., 2010). After obtaining the final model, the variable for total lice count was replaced by variables for each of the individual lice stage counts. A comparison of the four resulting models using their AICc showed overwhelming data support for the model including the total lice count over the models including individual lice stages. This was observed for both salmon and trout. A comparison of the three models containing the juvenile, gravid females and mobile adult counts, respectively, showed more or less equal Akaike weights among them. This suggests that none of the individual lice stages provides a better explanation of SRS-attributed mortality. Previous research showed that adult stages had the largest impact on fish physiology (González et al., 2015) and would be the most likely stages to transmit disease (Oelckers et al., 2014). Due to the high correlation between the counts of different lice stages, the statistical model framework used in this study did not allow identification of the lice stage that has most influence on SRS mortality. Further research should investigate this question using different methods. However, it is likely that retrospective studies will not allow unequivocal identification of causal links between any of the individual life stages and SRSattributed mortality. In addition, the accuracy of sea lice counts and classification of life stages are likely to be observer-dependent (Elmoslemany et al., 2013) and may be a source of error in such studies.

Potential sources of error in this study include misclassification of SRSattributed mortality, bias associated with selection of cages for lice counting, and bias associated with using regulatory datasets for lice counts. Misclassification may occur as fish dying from SRS may not present any visible clinical signs, or only present non-specific signs (Rozas and Enriquez, 2014). The available data did not allow determination of the level of misclassification of mortality categories. It is also possible that misclassification of mortality may be associated with the primary exposures, introducing differential bias in the results. Although random selection of cages of lice counting was specified, the methods of selection used on-farm are 
unknown and may be subject to selection bias. Last, regulatory consequences of high lice burdens may have provided a disincentive to report the full extent of lice counts. Underreporting could have biased our results towards the null hypothesis.

\section{Conclusion}

This study confirmed that the presence of sea lice affects survival of salmonids infected with $P$. salmonis and demonstrated that the bath treatments used to control lice may themselves contribute to greater SRS severity. Importantly, these results relate to management decisions or practices and indicate practical, actionable ways in which the losses associated with SRS could be minimised. Thus, this study contributes to demonstrating the value of making use of company production data and data sharing between stakeholders. Firm recommendations about optimal lice control programs should consider the findings of this study in conjunction with economic analysis. Future work may focus on the evaluation of economic outcomes, and the development of decision support tools based on the economically optimal ways to control sea lice infestation. 


\section{Acknowledgments}

The authors gratefully acknowledge the enthusiasm and vision shown by the companies who contributed data to this study: AquaChile, Australis Seafoods, Blumar Seafoods, Camanchaca, Multiexport Foods, Salmones Antartica, Salmones Aysén, Salmones Magallanes and Ventisqueros. Other companies have contributed greatly to the discussions about risk factors and hypotheses. We thank representatives from SalmonChile for their technical insights, and contributions to meetings and workshops. Berta Contreras (Conecta $\mathrm{SpA}$ ) has been invaluable in providing a link between Ausvet and the salmon aquaculture industry in Chile. Finally, we acknowledge the tireless efforts of many people at Sernapesca, who have supported this and other PGSA projects.

\section{Funding}

This study was carried out under the framework of the 'Program for Aquaculture Sanitary Management' (PGSA), a project executed by the Chilean National Fisheries and Aquaculture Service (Sernapesca), with public and private financing from the Ministry of the Economy, Development and Tourism and the Chilean Salmon Industry Association (SalmonChile). 


\section{References}

Akaike, H., 1974. A new look at the statistical model identification. IEEE Trans. Autom. Control 19, 716-723. https://doi.org/10.1109/TAC.1974.1100705

Arriagada, G., Stryhn, H., Sanchez, J., Vanderstichel, R., Campistó, J.L., Rees, E.E., Ibarra, R., St-Hilaire, S., 2017. Evaluating the effect of synchronized sea lice treatments in Chile. Prev. Vet. Med. 136, 1-10. https://doi.org/10.1016/j.prevetmed.2016.11.011

Barker, S.E., Bricknell, I.R., Covello, J., Purcell, S., Fast, M.D., Wolters, W., Bouchard, D.A., 2019. Sea lice, Lepeophtheirus salmonis (Krøyer 1837), infected Atlantic salmon (Salmo salar L.) are more susceptible to infectious salmon anemia virus. PLOS ONE 14, e0209178. https://doi.org/10.1371/journal.pone.0209178

Barton, B.A., 2002. Stress in fishes: a diversity of responses with particular reference to changes in circulating corticosteroids. Integr. Comp. Biol. 42, 517525. https://doi.org/10.1093/icb/42.3.517

Bates, D., Mächler, M., Bolker, B., Walker, S., 2015. Fitting Linear MixedEffects Models Using lme4. J. Stat. Softw. Artic. 67, 1-48. https://doi.org/10.18637/jss.v067.io1

Boxshall, G., Bravo, S., 2000. On the identity of the common Caligus (Copepoda: Siphonostomatoida: Caligidae) from salmonid netpen systems in southern Chile. Contrib. Zool. 69, 137-146.

Bravo, S., 2003. Sea lice in Chilean salmon farms. Bull. Eur. Assoc. Fish Pathol. 23, 197-200.

Brooks, M., Kristensen, K., van Bethem, K., Magnusson, A., Berg, C., Nielsen, A., Skaug, H., Maechler, M., Bolker, B., 2017. glmmTMB Balances Speed and Flexibility Among Packages for Zero-inflated Generalized Linear Mixed Modeling. R J. 9, 378-400.

Burnham, K., Anderson, D., 2002. Model selection and multimodel inference: a practical information-theoretic approach, 2nd edition. Springer, New York.

Burridge, L., Weis, J.S., Cabello, F., Pizarro, J., Bostick, K., 2010. Chemical use in salmon aquaculture: A review of current practices and possible 
environmental

effects.

Aquaculture

306 ,

$7-23$.

https://doi.org/10.1016/j.aquaculture.2010.05.020

Cameron, A., Trivedi, P., 2013. Regression Analysis of Count Data, 2nd edition. ed. Cambridge University Press, United-Kingdom.

Elmoslemany, A., Whyte, S.K., Revie, C.W., Hammell, K.L., 2013. Sea lice monitoring on Atlantic salmon farms in New Brunswick, Canada: comparing audit and farm staff counts. J. Fish Dis. 36, 241-247. https://doi.org/10.1111/jfd.12051

Figueroa, C., Bustos, P., Torrealba, D., Dixon, B., Soto, C., Conejeros, P., Gallardo, J.A., 2017. Coinfection takes its toll: Sea lice override the protective effects of vaccination against a bacterial pathogen in Atlantic salmon. Sci. Rep. 7. https://doi.org/10.1038/s41598-017-18180-6

González, L., Carvajal, J., 2003. Life cycle of Caligus rogercresseyi, (Copepoda: Caligidae) parasite of Chilean reared salmonids. Aquaculture 220, 101-117. https://doi.org/10.1016/Soo44-8486(02)00512-4

González, L., Robles, C., Cortez San Martín, M., 2016. Management issues regarding caligidosis treatment on salmon farms in Chile affected by infection salmon anaemia virus (ISAV), Piscirickettsia salmonis and Neoparamoeba perurans. Ocean $\quad$ Coast. $\quad$ Manag. $\quad 123, \quad 74-83$. https://doi.org/10.1016/j.ocecoaman.2016.02.002

González, M., Marín, S.L., Vargas-Chacoff, L., 2015. Effects of Caligus rogercresseyi (Boxshall and Bravo, 2000) infestation on physiological response of host Salmo salar (Linnaeus 1758): Establishing physiological thresholds. Aquaculture 438, 47-54. https://doi.org/10.1016/j.aquaculture.2014.12.039

Hamilton-West, C., Arriagada, G., Yatabe, T., Valdés, P., Hervé-Claude, L.P., Urcelay, S., 2012. Epidemiological description of the sea lice (Caligus rogercresseyi) situation in southern Chile in August 2007. Prev. Vet. Med. 104, 341-345. https://doi.org/10.1016/j.prevetmed.2011.12.002

Happold, J., Meyer, A., Sadler, R., Cowled, B., Mackenzie, C., Gallardo Lagno, A., Cameron, A., 2020b. Effectiveness of antimicrobial treatment of salmonid rickettsial septicaemia in commercial salmon and trout farms in Chile. Aquaculture 525, 735323. 
Happold, J., Sadler, R., Meyer, A., Cowled, B., Mackenzie, C., Gallardo Lagno, A., Cameron, A., 202ob. Effectiveness of vaccination for the control of salmonid rickettsial septicaemia in commercial salmon and trout farms in Chile. Aquaculture 520, 734968.

Hillman, A., Zalcman, E., Burroughs, A., Meyer, A., Mackenzie, C., Sadler, R., Stevenson, M., Ward, M., Gallardo Lagno, A., Happold, J., Cameron, A., Cowled, B., 2020. Use of regulatory data to describe and identify risk factors for salmonid rickettsial septicaemia in Chile, 2011-2017. Aquaculture 526, 735324.

Hutchison, J., Mackenzie, C., Madin, B., Happold, J., Leslie, E., Zalcman, E., Meyer, A., Cameron, A., 2018. New approaches to aquatic and terrestrial animal surveillance: The potential for people and technology to transform epidemiology. Prev. Vet. Med. https://doi.org/10.1016/j.prevetmed.2018.10.009

Jakob, E., Stryhn, H., Yu, J., Medina, M.H., Rees, E.E., Sanchez, J., StHilaire, S., 2014. Epidemiology of Piscirickettsiosis on selected Atlantic salmon (Salmo salar) and rainbow trout (Oncorhynchus mykiss) salt water aquaculture farms in Chile. Aquaculture 433, 288-294. https://doi.org/10.1016/j.aquaculture.2014.06.018

Jimenez, D.F., Ibarra, R., Artacho, P., Primus, A.E., Tello, A., 2018. Prolonging Azamethiphos bath increases the effectiveness of field treatments against Caligus rogercresseyi in Atlantic salmon in Chile (Salmo salar). Aquaculture 493, 186-191. https://doi.org/10.1016/j.aquaculture.2018.04.034

Larenas, J.J., Contreras, J., Oyanedel, S., Morales, M.A., Smith, P., 1997. Efecto de la densidad poblacional y temperatura en truchas arco iris (Oncorhynchus mykiss) inoculadas con Piscirickettsia salmonis. Arch. Med. Vet. $29,113-119$.

Lenth, R., 2018. emmeans: Estimated Marginal Means, aka Least-Squares Means. $\mathrm{R}$ Package Version 121. URL: https://CRAN.Rproject.org/package=emmeans

Lhorente, J.P., Gallardo, J.A., Villanueva, B., Carabaño, M.J., Neira, R., 2014. Disease Resistance in Atlantic Salmon (Salmo salar): Coinfection of the Intracellular Bacterial Pathogen Piscirickettsia salmonis and the Sea Louse Caligus 
rogercresseyi.

https://doi.org/10.1371/journal.pone.0095397

Marty, G.D., Saksida, S.M., Quinn, T.J., 2010. Relationship of farm salmon, sea lice, and wild salmon populations. Proc. Natl. Acad. Sci. 107, 22599-22604. https://doi.org/10.1073/pnas.1009573108

Nilsen, A., Nielsen, K.V., Biering, E., Bergheim, A., 2017. Effective protection against sea lice during the production of Atlantic salmon in floating enclosures. Aquaculture 466, 41-50. https://doi.org/10.1016/j.aquaculture.2016.09.009

Nowak, B.F., Bryan, J., Jones, S.R.M., 2010. Do salmon lice, Lepeophtheirus salmonis, have a role in the epidemiology of amoebic gill disease caused by Neoparamoeba perurans? J. Fish Dis. 33, 683-687. https://doi.org/10.1111/j.1365-2761.2010.01158.x

Oelckers, K., Vike, S., Duesund, H., Gonzalez, J., Wadsworth, S., Nylund, A., 2014. Caligus rogercresseyi as a potential vector for transmission of Infectious Salmon Anaemia (ISA) virus in Chile. Aquaculture 420-421, 126-132. https://doi.org/10.1016/j.aquaculture.2013.10.016

Pascual, M.A., Ciancio, J.E., 2007. Chapter 18 - Introduced anadromous salmonids in Patagonia: risks, uses, and a conservation paradox, in: Ecological and Genetic Implications of Aquaculture Activities. Springer, Dordrecht, The Netherlands, p. 537.

Poley, J.D., Braden, L.M., Messmer, A.M., Igboeli, O.O., Whyte, S.K., Macdonald, A., Rodriguez, J., Gameiro, M., Rufener, L., Bouvier, J., Wadowska, D.W., Koop, B.F., Hosking, B.C., Fast, M.D., 2018. High level efficacy of lufenuron against sea lice (Lepeophtheirus salmonis) linked to rapid impact on moulting processes. Int. J. Parasitol. Drugs Drug Resist. 8, 174-188. https://doi.org/10.1016/j.ijpddr.2018.02.007

Price, D., Stryhn, H., Sánchez, J., Ibarra, R., Tello, A., St-Hilaire, S., 2016. Retrospective analysis of antibiotic treatments against piscirickettsiosis in farmed Atlantic salmon Salmo salar in Chile. Dis. Aquat. Organ. 118, 227-235.

R Core Team, 2018. R: A Language and Environment for Statistical Computing. R Foundation for Statistical Computing, Vienna, Austria. URL: http://www.R-project.org/ 
Rees, E.E., Ibarra, R., Medina, M., Sanchez, J., Jakob, E., Vanderstichel, R., St-Hilaire, S., 2014. Transmission of Piscirickettsia salmonis among salt water salmonid farms in Chile. Aquaculture 428-429, 189-194. https://doi.org/10.1016/j.aquaculture.2014.03.031

Rozas, M., Enriquez, R., 2014. Piscirickettsiosis and Piscirickettsia salmonis in fish: a review. J. Fish Dis. 37, 163-188. https://doi.org/10.1111/jfd.12211

Salama, N., Murray, A.G., 2013. A comparison of modelling approaches to assess the transmission of pathogens between Scottish fish farms: The role of hydrodynamics and site biomass. Prev. Vet. Med., Special Issue: SVEPM 2012 The cutting-edge of animal disease control in a global environment 108, 285-293. https://doi.org/10.1016/j.prevetmed.2012.11.005

Salama, N., Murray, A.G., 2011. Farm size as a factor in hydrodynamic transmission of pathogens in aquaculture fish production. Aquac. Environ. Interact. 2, 61-74. https://doi.org/10.3354/aeiooo30

Sepúlveda, F., Marı́n, S.L., Carvajal, J., 2004. Metazoan parasites in wild fish and farmed salmon from aquaculture sites in southern Chile. Aquaculture 235, 89-100. https://doi.org/10.1016/j.aquaculture.2003.09.015

Sernapesca, 2017. Informe Sobre Uso de Antimicrobianos en la Salmonicultura Nacional. Servicio Nacional de Pesca y Acuicultura, Valparaíso, Chile.

URL: www.sernapesca.cl/sites/default/files/informe_sobre_uso_de_antimicrobianos _2017_o.pdf

Sernapesca, 2009. Resolución No. 1449 de 2009, Establece medidas de manejo sanitario por área. Servicio Nacional de Pesca y Acuicultura, Valparaíso, Chile.

Sernapesca, 2015. Resolución No. 013 de 2015, Establece Programa Sanitario específico de vigilancia y control de Caligidosis: PSEVC-Caligidosis. Servicio Nacional de Pesca y Acuicultura, Valparaíso, Chile.

Smith, P.A., Rojas, M.E., Guajardo, A., Contreras, J., Morales, M.A., Larenas, J., 2004. Experimental infection of coho salmon Oncorhynchus kisutch by exposure of skin, gills and intestine with Piscirickettsia salmonis. Dis. Aquat. Organ. 61, 53-57. https://doi.org/10.3354/daoo61053 
St-Hilaire, S., Patanasatienkul, T., Yu, J., Kristoffersen, A.B., Stryhn, H., Revie, C.W., Ibarra, R., Tello, A., McEwan, G., 2018. Tool for predicting Caligus rogercresseyi abundance on salt water salmon farms in Chile. Prev. Vet. Med. 158, 122-128. https://doi.org/10.1016/j.prevetmed.2018.08.001

Tadiso, T.M., Krasnov, A., Skugor, S., Afanasyev, S., Hordvik, I., Nilsen, F., 2011. Gene expression analyses of immune responses in Atlantic salmon during early stages of infection by salmon louse (Lepeophtheirus salmonis) revealed biphasic responses coinciding with the copepod-chalimus transition. BMC Genomics 12, 141. https://doi.org/10.1186/1471-2164-12-141

Venables, W., Ripley, B., 2002. Modern Applied Statistics with S, Fourth edition. ed. Springer, New York, USA.

Yatabe, T., Arriagada, G., Hamilton-West, C., Urcelay, S., 2011. Risk factor analysis for sea lice, Caligus rogercresseyi, levels in farmed salmonids in southern Chile. J. Fish Dis. 34, 345-354. https://doi.org/10.1111/j.1365-2761.2011.01238.x

Zalcman, E., Burroughs, A., Meyer, A., Mackenzie, C., Sadler, R., Stevenson, M., Ward, M., Gallardo Lagno, A., Happold, J., Cameron, A., Cowled, B., 2021. Sea lice infestation of salmonids in Chile between 2011 and 2017: Use of regulatory data to describe characteristics and identify risk factors. Aquaculture 530, 735752.

Zuur, A.F., Ieno, E.N., Elphick, C.S., 2010. A protocol for data exploration to avoid common statistical problems. Methods Ecol. Evol. 1, 3-14. https://doi.org/10.1111/j.2041-210X.2009.00001.x 


\section{Supplementary material}

Supplementary material 1 Selection and hypothesis support for models of SRS mortality, using an information-theoretic approach.

Table Suppl 1.1 Atlantic salmon models

\begin{tabular}{lllll}
\hline Corresponding working hypothesis & $\mathbf{k}$ & AICc & $\boldsymbol{\Delta A I C c}$ & Weight \\
\hline Hypothesis 8 & 26 & 197733 & $\mathrm{o}$ & $\mathbf{1 . 0 0}$ \\
\hline Hypothesis 6 & 25 & 197750 & 16 & 0.00 \\
\hline Hypothesis 4 & 24 & 197799 & 66 & 0.00 \\
\hline Hypothesis 7 & 25 & 197812 & 79 & 0.00 \\
\hline Hypothesis 5 & 24 & 197827 & 93 & 0.00 \\
\hline Hypothesis 2 & 23 & 197830 & 97 & 0.00 \\
\hline Hypothesis 3 & 23 & 197880 & 147 & 0.00 \\
\hline Hypothesis 1 & 22 & 197884 & 151 & 0.00 \\
\hline
\end{tabular}

k: number of adjusted parameters; AICc: bias-corrected Akaike information criterion; $\triangle \mathrm{AICc}$ : AICc difference with the model with lowest AICc

Table Suppl 1.2 Rainbow trout models

\begin{tabular}{lllll}
\hline Corresponding working hypothesis & $\mathbf{k}$ & AICc & $\boldsymbol{\Delta A I C c}$ & Weight \\
\hline Hypothesis 5 & 25 & 60709 & 0 & 0.32 \\
\hline Hypothesis 7 & 26 & 60710 & 1 & 0.28 \\
\hline Hypothesis 6 & 26 & 60710 & 1 & 0.20 \\
\hline Hypothesis 8 & 27 & 60711 & 2 & 0.16 \\
\hline Hypothesis 3 & 24 & 60714 & 5 & 0.02 \\
\hline Hypothesis 4 & 25 & 60715 & 6 & 0.02 \\
\hline Hypothesis 2 & 24 & 60726 & 17 & 0.00 \\
\hline Hypothesis 1 & 23 & 60734 & 25 & 0.00 \\
\hline
\end{tabular}

k: number of adjusted parameters; AICc: bias-corrected Akaike information criterion; $\triangle$ AICc: AICc difference with the model with lowest AICc 
Supplementary material 2 Random effect coefficients for the barrio variable in Atlantic salmon observations.

Figure Suppl 2.1 Random effect coefficients for the barrio variable in Atlantic salmon observations: most-likely estimate and $95 \%$ confidence interval

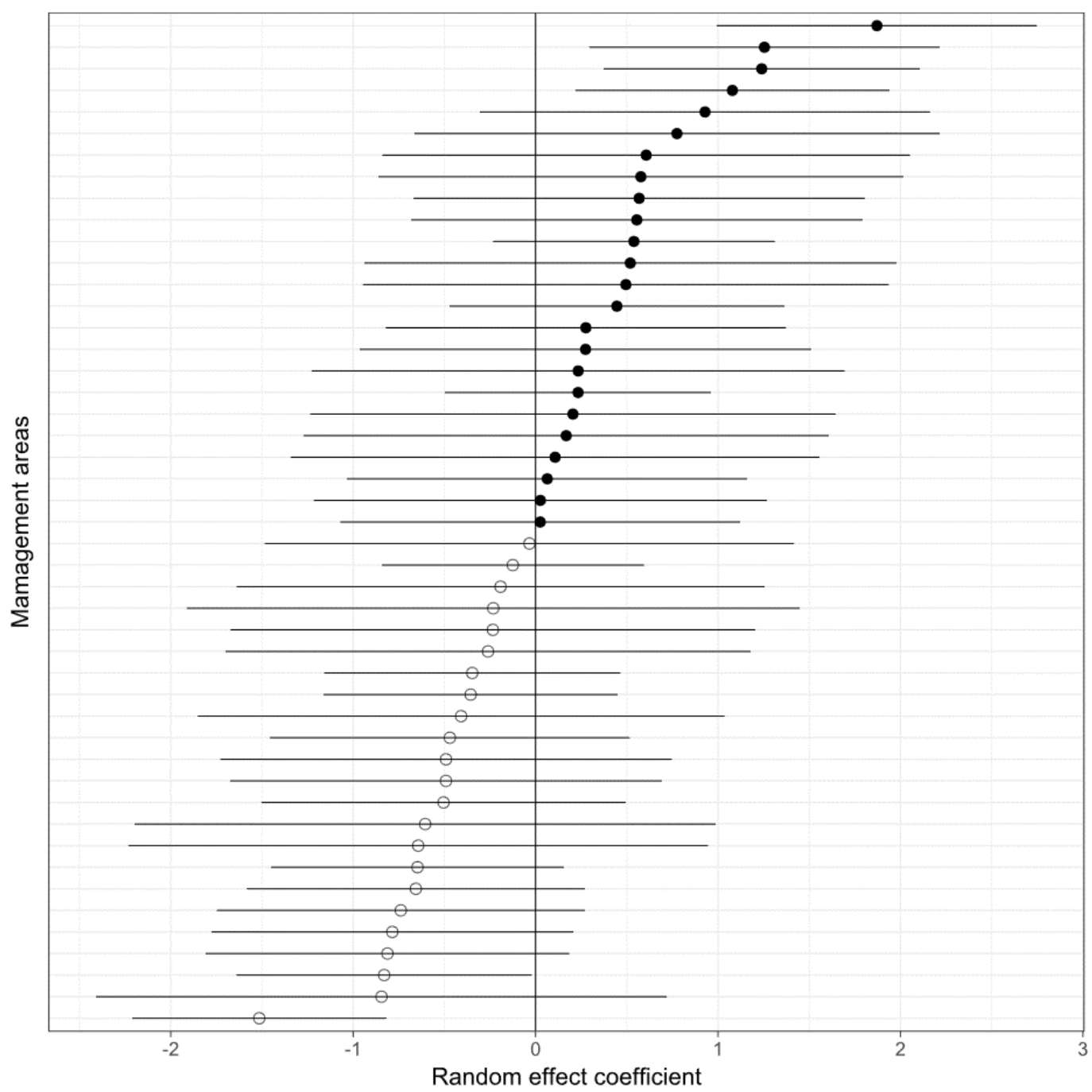




\section{CHAPTER 4}

\section{Is between-farm water-borne pathogen dissemination an important driver in the epidemiology of salmonid rickettsial septicaemia in Chile?}

Anne Meyera, Rohan Sadlerb,c, Melanie Bannister-Tyrrellb, Alicia L. Gallardo Lagno $^{\text {, }}$ Arjan Stegemane, Angus Camerona,b

a Ausvet Europe, 3 rue Camille Jordan, 69001 Lyon, France

b Ausvet, 5 Shuffrey Street, Fremantle, Western Australia, Australia

c The University of Western Australia, Mo89 School of Agriculture and Environment, 35 Stirling Hwy, Crawley, WA 6008, Australia

d Servicio Nacional de Pesca y Acuicultura, Victoria 2832, Valparaíso, Chile

e Utrecht University, Department of Farm Animal Health, 3512 JE Utrecht, the Netherlands 


\section{Abstract}

Although the bacterium Piscirickettsia salmonis has been detected in many salmon-producing countries around the world, losses caused by salmonid rickettsial septicaemia (SRS) are mostly occurring in the Chilean aquaculture industry. Horizontal transmission of SRS between salmonid farms was suggested, based on the existence of spatiotemporal correlation in the level of disease between neighbouring sea farms. However, it remains unclear to which extent betweenfarm water-borne pathogen dissemination is important in the epidemiology of SRS in Chile. Such information is critical to assess the level of risk of transmission of SRS from one farm to another at different mortality incidence levels and to apply appropriate and cost-effective mitigation measures. In this study, we used weekly SRS mortality data from all salmonid farms in the Los Lagos region between January 2012 and September 2018 to model the spatiotemporal autocorrelation in the SRS-attributed mortality in the study area. A generalized additive regression modelling framework was adopted, using a linear functional component to model the influence of other farms on the target farm. Several nested statistical models were built to compare the significance of different covariates. Predicted values of SRS mortality on the target farm, conditional on different distance, time lag and mortality values from the source farms were estimated from the best model. The results showed that there was a statistically significant association between the weekly mortality incidence at source farms and the mortality incidence at target farms during the same week and during the previous weeks. This study did not provide evidence that the spatiotemporal correlation observed in SRS mortality may be due to water-borne pathogen dissemination between farms and alternative explanatory mechanisms should be investigated. It remains possible that the patterns of lagged correlation observed between source and target farm mortality may be due to a model artefact. In addition, there was no evidence of a threshold effect above which farms pose a substantially larger health risk to their neighbours. Stronger evidence for or against between-farm transmission of $P$. salmonis may be obtained by different methods. 


\section{Key words}

Salmonid rickettsial septicaemia; Atlantic salmon; rainbow trout; retrospective study; spatial correlation 


\section{Introduction}

Salmonid rickettsial septicaemia (SRS) is an infectious disease caused by the bacterium Piscirickettsia salmonis. The disease was first identified in Chile in coho salmon farms in 1989 (Bravo and Campos 1989), and has since caused substantial losses to the industry in all salmonid species. Although smolt stocks are diseasefree at sea entry, a previous study of regulatory data showed that about $80 \%$ of production batches will be diagnosed with SRS during the sea production phase (Hillman et al. 2020). The occurrence of horizontal transmission between farms has been suggested in Chile for SRS and other pathogens, as well as for ectoparasites such as sea lice (Rees et al. 2014; Kristoffersen et al. 2013; Price et al. 2017; Arriagada et al. 2017). These suggestions were based on detecting spatiotemporal correlation in the level of disease or infestation between neighbouring sea farms, a phenomenon also called 'infection pressure' by some authors. However, the distances between sites and the site densities for which this correlation poses a substantial health risk have not been characterized. In addition, it remains unclear whether the available evidence of spatiotemporal correlation between farms is due to direct horizontal transmission between farms or to infection by a common environmental reservoir of $P$. salmonis. In the latter case, the SRS mortality on neighbouring farms would be correlated due to such farms sharing similar environmental and spatial characteristics. Under the hypothesis of horizontal transmission between farms, the pathogen circulation could be mediated by a vector or occur via bacteria suspended in the flowing saltwater column. The latter would be possible given the extended survival time of $P$. salmonis in salt water, which can be up to 50 days (Olivares and Marshall 2010). In addition, the role of wildlife reservoirs is unclear as $P$. salmonis has been identified in native fish species in Chile (Contreras-Lynch et al. 2015).

Comprehensive management of SRS outbreaks requires direct application of control measures in affected farms to limit the local transmission of SRS and hence reduce mortality within a farm. Moreover, control measures should effectively mitigate the risk of SRS spreading from one farm to other farms. The Chilean National Fisheries and Aquaculture Service (Servicio Nacional de Pesca y Acuicultura, Sernapesca) sets regulatory thresholds for SRS mortality incidence 
rates that, if exceeded, trigger mandatory responses to control outbreaks of SRS and hence reduce the risk of transmission to nearby farms. These regulations rely on the assumption that the infectivity of a farm for neighbouring farms is correlated with the mortality incidence on the infected farm. However, the level of risk of transmission of SRS from one farm to another at different mortality incidence thresholds is yet to be characterised for the Chilean salmon farming industry.

This study was the fifth in a series of epidemiological studies to examine risk factors for SRS and evaluate the effectiveness of interventions to control the disease (Happold, Meyer, et al. 2020; Happold, Sadler, et al. 2020; Hillman et al. 2020; Meyer et al. 2019). This work aimed to generate information that supports Sernapesca in evaluating the current regulatory threshold for on-farm interventions (Sernapesca 2012). Our specific objective in this work was to examine the plausibility of the hypothesis that spatiotemporal correlation of SRS mortality between farms in Chile is caused by water-borne pathogen dissemination between farms.

\section{Material and methods}

\subsection{Study population}

The study population comprised all seawater farms and farm-level production cycles included in the data provided by Sernapesca between January 2012 and September 2018, in the Los Lagos region of Chile where a large proportion of the saltwater rearing of salmonids occurs (Sernapesca, personal communication). The unit of analysis was the farm-level weekly observation, hereafter referred to as 'farm-week'.

\subsection{Data sources}

Weekly, farm-level mortality reports were obtained from the Sistema de Información para la Fiscalización de Acuicultura (SIFA) database. The SIFA database was deployed at the end of 2010 and contains complete data since January 2012 based on mandatory mortality reporting by all salmonid production companies. The mortality data used in this study were based on mortality 
categories as reported in the SIFA database, rather than laboratory-confirmed disease cases.

\subsection{Statistical regression model}

\subsubsection{Primary outcome}

The outcome variable was the SRS-attributed mortality count for each farmweek observation in the study area. Here we considered the mortality incidence in a given region as a single variable. The spatiotemporal autocorrelation of this variable was considered as the primary exposure. More specifically, we included two separate model terms to account for autocorrelation: the SRS-attributed mortality incidence on other farms at different distances and time lags (primary exposure) and the temporal autocorrelation at the same farm.

\subsubsection{Primary exposure variable}

The primary exposure variable was the SRS-attributed mortality incidence on the 50 closest active farms ('source farms') around the farm on which the mortality was measured ('target farm'), during a window of time prior to the week of interest. This variable effectively modelled the spatially and temporally lagged autocorrelation of the outcome variable.

In a previous study on SRS in Chile where authors investigated several between-farm distances up to $20 \mathrm{~km}$, the model with the lowest Akaike information criterion (AIC) included spatial influence between farms distant by up to $10 \mathrm{~km}$ (Rees et al. 2014). Here, the source farms were located at distances up to $150 \mathrm{~km}$, allowing the model to reveal any spatiotemporal autocorrelation, regardless of the underlying mechanism of such correlation. The source farms were limited to the 50 closest farms for computational reasons.

In this work, we used a varying coefficient model (Hastie and Tibshirani 1993) that allowed mortality on a given farm to vary as a smooth function of mortality located at different distances and temporal lags from this farm. The influence of the source farms on the SRS-attributed mortality count at target farm $i$ during week $t$ was modelled using a linear functional (Ramsay and Silverman 2006; Wood 2017) of the following form: 


$$
\sum_{j \neq i, k} F\left(d_{i, j}, k, \text { mort }_{j, t-k}\right)
$$

with $j$ the indices of the active farms within a 300-km radius of farm $i, d_{i, \mathrm{j}}$ the sea-way distance between farms $i$ and $j, k$ between o and 10 weeks, mort $_{j, t-k}$ the mortality at farm $j$ during week $t-k$, and $F$ a spline function estimated from the data. The mortality at farm $j$ during week $t-k$ was measured as an incidence rate in the full model, i.e., as the mortality incidence count during that week divided by the number of fish present at the beginning of the week. In an alternative model (see explanations below), the mortality at farm $j$ during week $t-k$ was measured as an incidence count. In addition to the linear functional term, the model was riskadjusted for the other risk factors observed at each farm and within-farm autocorrelation, as described below.

\subsubsection{Other explanatory variables}

The autocorrelation model was adjusted for other risk factors, given the large variability between different farms and different production cycles, and in order to account for possible confounding. Seven risk factors identified as important from previous studies conducted by the authors or published results from other research groups were included in the models.

The fish-level factors included in the model were the fish species, the time since sea entry in degree-days, and the mortality from other infectious causes during the week of observation. Two predictors were included to capture temporal trends: the number of days since the first observation in the dataset (January $2^{\text {nd }}$, 2012) to account for broad scale temporal trends such as variations between years, and the day of the year was included to account for potential seasonal trends. Lastly, we included the average sea water temperature during the week of observation, which was the only available variable related to environmental conditions with low rates of missing data. The farm latitude was included to account for other unmeasured environmental and spatial variations. 


\subsubsection{Statistical methods}

The weekly SRS-attributed mortality incidence count data was treated as a negative binomial response to account for overdispersion in the counts. These counts were offset by the natural logarithm of the number of fish present at the beginning of the week. A generalized additive regression modelling framework was adopted, and implemented through the mgcv package (Wood 2017) available within the R statistical computing environment (R Core Team 2019).

The linear functional component of the model that included time lag, distance and SRS-attributed mortality incidence observed at other farms was modelled via a tensor product smooth (Wood 2017). Other explanatory variables were included either as linear effects or as spline smooth effects (thin plate regression splines) (Wood 2017), based on initial data exploration. Continuously valued explanatory variables were centred and scaled.

Clustering of the farm-week records within company, farm and production cycle was considered when building the models. Different methods for including random effects for company, farm and production cycle, and a stricter temporal within-farm autoregression structure, were trialled but were not computationally feasible to implement given the large size of the dataset $(\approx 49$, o0o farm-week records). Ultimately, the random effects were included in the model as spline smooth effects, which are treated as penalized regression terms, an estimation method equivalent to that of conventional random effects (Wood 2004). In short, the coefficients associated with the model matrix component are assumed i.i.d. normal, with unknown variance to be estimated. The within-farm autocorrelation terms of lag order 1 and 2 were modelled as linear regression terms, again for ease of implementation. These terms correspond to the mortality on the same farm during the last and before-last weeks before the observation week. Exploratory analysis showed that the within-farm autocorrelation for larger temporal lags (>2) was not significant. 


\subsubsection{Model selection}

Consistent with the information theoretic approach (Burnham and Anderson 2002), eight nested statistical models were built to compare the significance of different covariates. The full model included all the covariates described in the above sections. In three other models, some variables were not included, namely the spatiotemporal autocorrelation term, the latitude effect and the farm and company effects. The maximum lag of the spatiotemporal correlation was changed from 10 to 4 and 15 weeks in two other models, respectively. Last, a model based on the Euclidean distances rather than the seaway distances was also built, as well as a model using the mortality incidence count on source farms rather than the incidence rate (Table 1).

Once fitted to the observed data, the eight statistical models were ranked according to their AIC and Akaike weights (Akaike 1974). Models with an AIC difference greater than ten points from the model with the lowest AIC were considered to be substantially less supported by the data than the highest-ranking model (Burnham and Anderson 2002; Wagenmakers and Farrell 2004).

Table 1. Characteristics of each statistical model

\begin{tabular}{cl}
\hline Statistical model identifier & Model characteristics \\
\hline 1 (null model) & No spatiotemporal autocorrelation terms. \\
\hline 2 (full model) & $\begin{array}{l}\text { Spatiotemporal autocorrelation estimated with } \\
\text { a lag between o and 10 weeks. }\end{array}$ \\
\hline 3 & Farm and company effects not included. \\
\hline 4 & $\begin{array}{l}\text { Spatiotemporal autocorrelation estimated with } \\
\text { a lag up to 15 weeks rather than 10 weeks. }\end{array}$ \\
\hline 5 & $\begin{array}{l}\text { Spatiotemporal autocorrelation estimated with } \\
\text { a lag up to 4 weeks rather than 10 weeks. }\end{array}$ \\
\hline 6 & $\begin{array}{l}\text { Spatiotemporal autocorrelation estimated } \\
\text { using Euclidean distances rather than sea-way } \\
\text { distances. }\end{array}$ \\
\hline 7 & \begin{tabular}{l} 
Latitude effect not included. \\
\hline 8
\end{tabular} \\
\hline & $\begin{array}{l}\text { Mortality on source farms estimated as an } \\
\text { incidence count rather than an incidence rate. }\end{array}$ \\
\hline
\end{tabular}




\subsection{Distance calculations}

The sea-way distance between farms was computed using a least-cost path algorithm implemented in Python by the scikit-image package ${ }^{2}$. A raster map of the region of interest, with a cell resolution of $0.003^{\circ}$, was used. Resistance values of one for seawater pixels and of one million for land pixels were selected to prevent the optimal route from crossing land pixels. The routing algorithm was applied to each pair of farms available in the dataset. Both the sea-way distance and the Euclidean (straight-line) distance were recorded for each pair.

\subsection{Interpretation of the results}

Partial effects were obtained from the most supported model for a range of time lag, distance and source farm mortality values. We obtained the partial effects for the influence of a single source farm on the target farm, although the models were fitted by considering the influence of the 50 closest source farms. In addition, the concepts of source and target farms are used here for clarity, but it is important to note that the linear functional term considers an undirected spatiotemporal correlation. The partial effects displayed in Figures $2 a$ and $2 b$ indicate the direction and intensity of the correlation between the mortality on source and target farms, at different values of time lag, distance and source farm mortality.

Then, predicted values of SRS mortality on the source farm were obtained considering the influence of SRS mortality on the 50 closest source farms, distributed as per the average neighbourhood configuration in the dataset. Continuous and categorical fixed effect values were set to the dataset mean or reference category, respectively. The within-farm autocorrelation terms were set to o. This allowed us to compare the changes attributable to the spatiotemporal correlation in time and space, all other factors remaining equal (Figure 3).

\section{Results}

Sea farms in the Los Lagos region reported a total of 49,724 farm-week records between January $2^{\text {nd }}, 2012$ and September $24^{\text {th }}, 2018$. Species farmed

${ }^{2}$ http://scikit-image.org/docs/0.7.0/api/skimage.graph.mcp.html 
during that period were rainbow trout, Atlantic salmon, coho salmon, King salmon and pink salmon. There were only very few records for the two latter species, and they were removed before analysis. The number of fish present each week on the farm and the average sea temperature were missing from $1.2 \%$ and $25 \%$ of the records, respectively. These values were approximated using the previous and following weekly records where possible. A total of 48,791 complete farm-week records (1,010 production cycles) were retained for this analysis. These records originated from 334 farms (Figure 1).

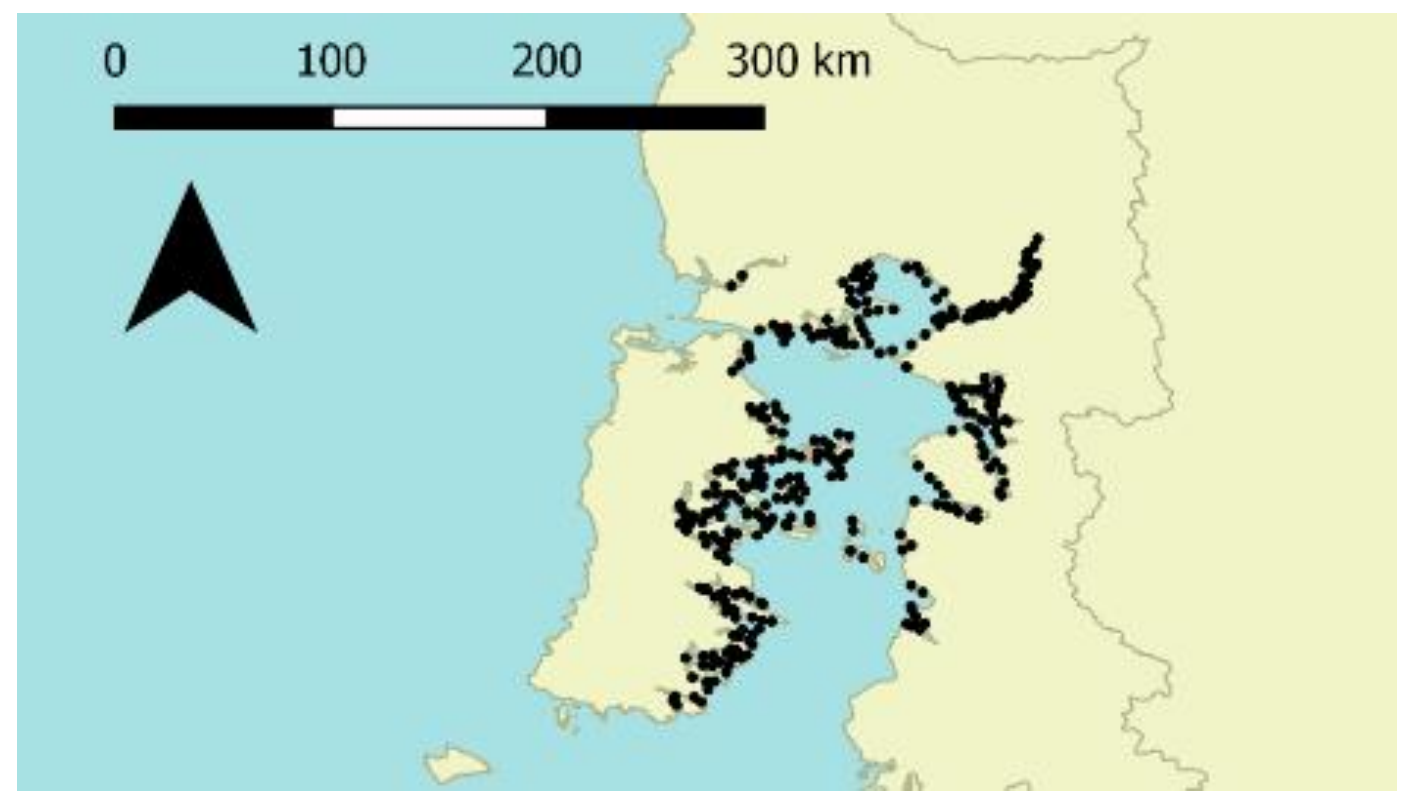

Figure 1. Location of the 334 farms for which data were available, in the Los Lagos region of Chile.

The best-fitting statistical model according to the Akaike weight was model 7, which was the model based on mortality incidence rates on source farms during the previous 10 weeks, without the latitude effect (Table 2). There was only a small difference with the full model (model 2). These 2 models performed better than the model based on Euclidean distances (model 6), the model including lags up to 15 weeks (model 4) and the model based on SRS mortality incidence counts on source farms (model 8), with AIC differences larger than 200 points. The models including no spatiotemporal correlation and only 4 weeks of lagged mortalities 
(models 1 and 5) had the highest AIC values. The spatiotemporal correlation in SRS mortality was statistically significant in all models where it appeared (Table 3).

Table 2. Statistical model ranking based on the observed data.

\begin{tabular}{cllll}
\hline Statistical model identifier & No. of parameters & AIC & $\Delta$ AIC & Akaike weight \\
\hline 7 & 1,007 & 394,303 & 0 & 0.97 \\
\hline 2 & 1,007 & 394,310 & 7 & 0.03 \\
\hline 3 & 997 & 394,351 & 48 & 0.00 \\
\hline 6 & 997 & 394,520 & 217 & 0.00 \\
\hline 4 & 993 & 394,572 & 269 & 0.00 \\
\hline 8 & 1,004 & 394,673 & 370 & 0.00 \\
\hline 5 & 1,003 & 394,820 & 517 & 0.00 \\
\hline 1 & 967 & 396,295 & 1,992 & 0.00 \\
\hline
\end{tabular}

However, the partial effect of a single source farm on SRS mortality was small in all models (see estimates from best model in Figure 2a). There were small variations of this effect with distance, time lag and mortality on the source farm, which are described below for the best fitting model (model 7) but were similar for model 2. There was no correlation between the mortality on source and target farms for a wide range of parameters. Within a small time lag ( $\leq 3$ weeks), there was a negative correlation for very high values of mortality (above 1\%) when the distance between the source and target farms was small (up to $10 \mathrm{~km}$ ). There was also a negative correlation for very high values of mortality for farms located at long distances $(\geq 80 \mathrm{~km})$, with medium time lags between 2 and 8 weeks. For farms located at medium distances ( 20 to $50 \mathrm{~km}$ ), there was a positive correlation for very high values of mortality. For longer time lags ( $\geq 8$ weeks), there was a positive correlation across the range of mortality levels at short and medium distances (up to $25 \mathrm{~km}$ ). At long time lags, there was also a strong positive correlation for very high values of mortality (above $1 \%$ ) at very long distances (above $100 \mathrm{~km}$ ). Although model 4 only ranked $5^{\text {th }}$ in our study, the partial effect plots from this model are presented in Figure $2 b$ to illustrate the effect of considering time lags up to 15 weeks. In model 4 , the large correlation values mentioned above for long and time lags distances were not observed. Other correlation patterns were similar between models 4 and 7 . 


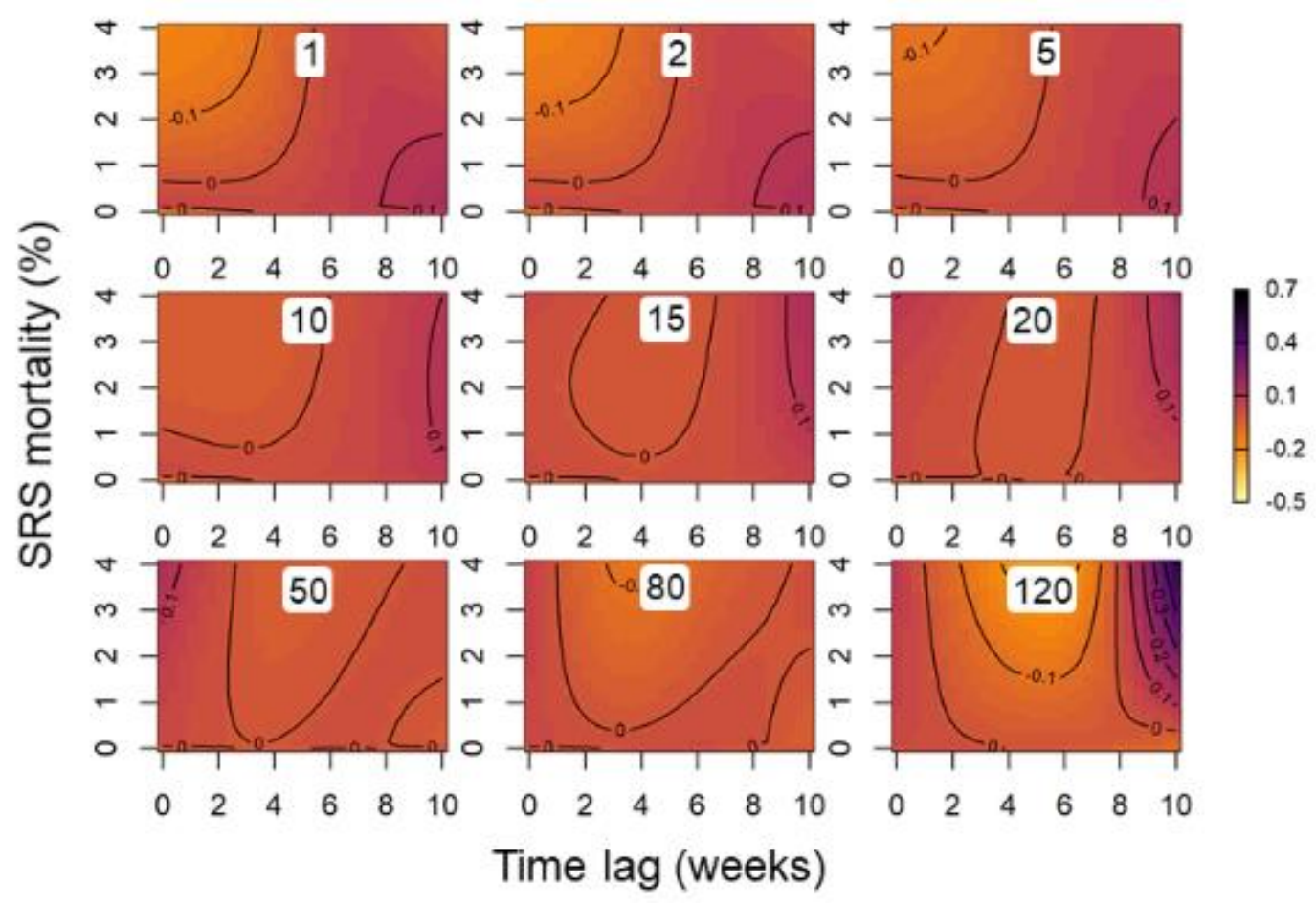

Yellow tones correspond to the lowest values while purple tones correspond to the highest values. The $y$-axis corresponds to increasing levels of mortality on the source farm. The $x$-axis corresponds to an increasing time lag between the mortality observations on the source and target farms. The panels correspond to increasing distances between the source and target farms, as indicated by the numbers (in $\mathrm{km}$ ) in the white boxes.

Figure 2a. Partial effect of the SRS mortality of the source farm on the SRS mortality on the target farm, conditional on different distance and time lag values, obtained from model 7. 


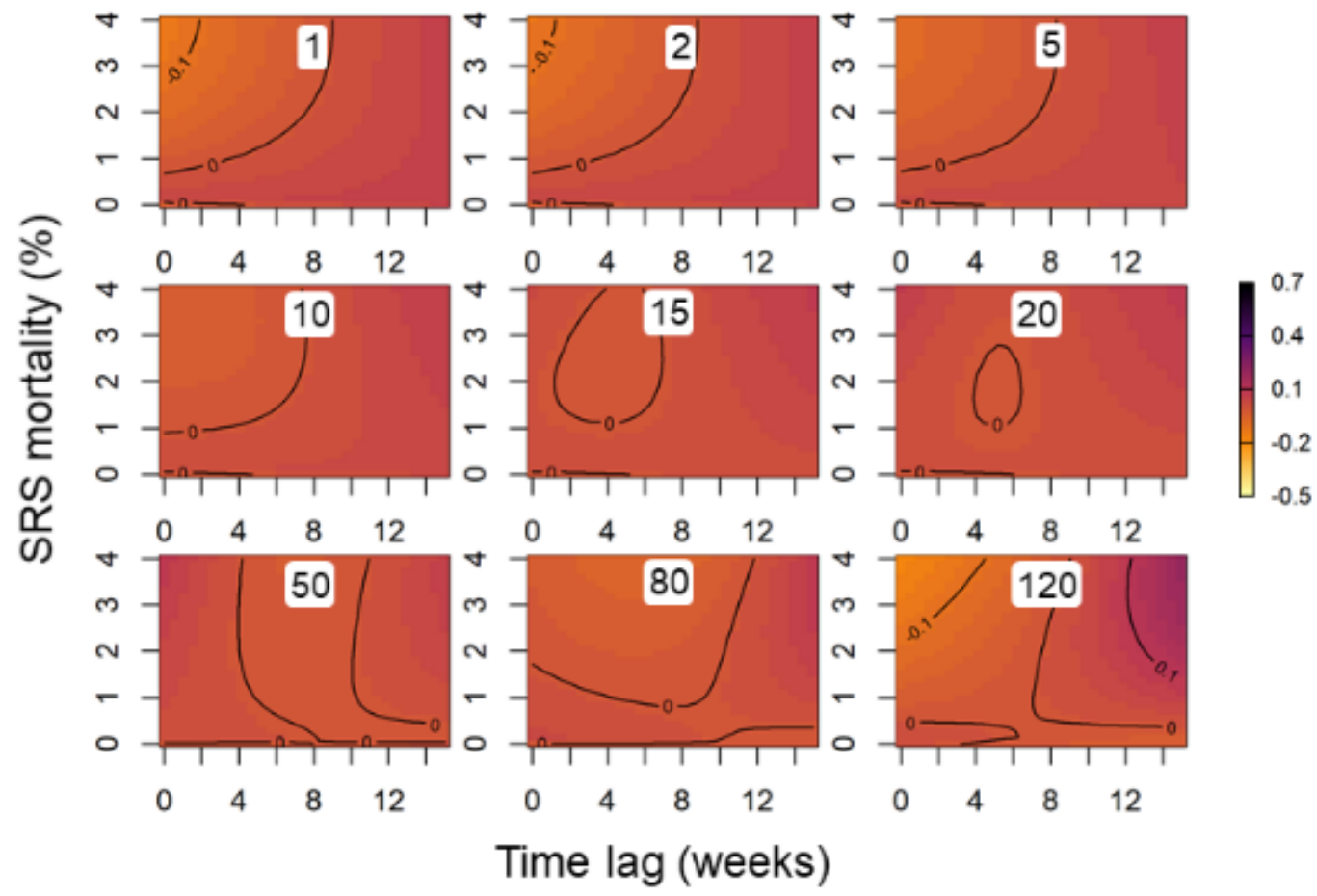

Yellow tones correspond to the lowest values while purple tones correspond to the highest values. The $y$-axis corresponds to increasing levels of mortality on the source farm. The $\mathrm{x}$-axis corresponds to an increasing time lag between the mortality observations on the source and target farms. The panels correspond to increasing distances between the source and target farms, as indicated by the numbers (in $\mathrm{km}$ ) in the white boxes.

Figure $2 \mathrm{~b}$. Partial effect of the SRS mortality of the source farm on the SRS mortality on the target farm, conditional on different distance and time lag values, obtained from model 4 .

While the partial effects showed significant spatiotemporal autocorrelation, the influence of a single infected source farm on predicted values of mortality on the target farm was negligible regardless of the time lag and source farm mortality considered (Figure 3). The mortality on the target farm remained lower than $0.0001 \%$ after 3 weeks and increased to $0.0002 \%$ after 9 weeks. Predicted values were higher when 10 to 20 of the source farms were infected, remaining under $0.005 \%$. When all neighbour farms were infected for 9 weeks, the mortality on the target farm increased to up to $0.2 \%$. The standard errors for all predicted values 
were large and the confidence intervals included o. The effect of the level of mortality on infected source farms was not statistically significant.

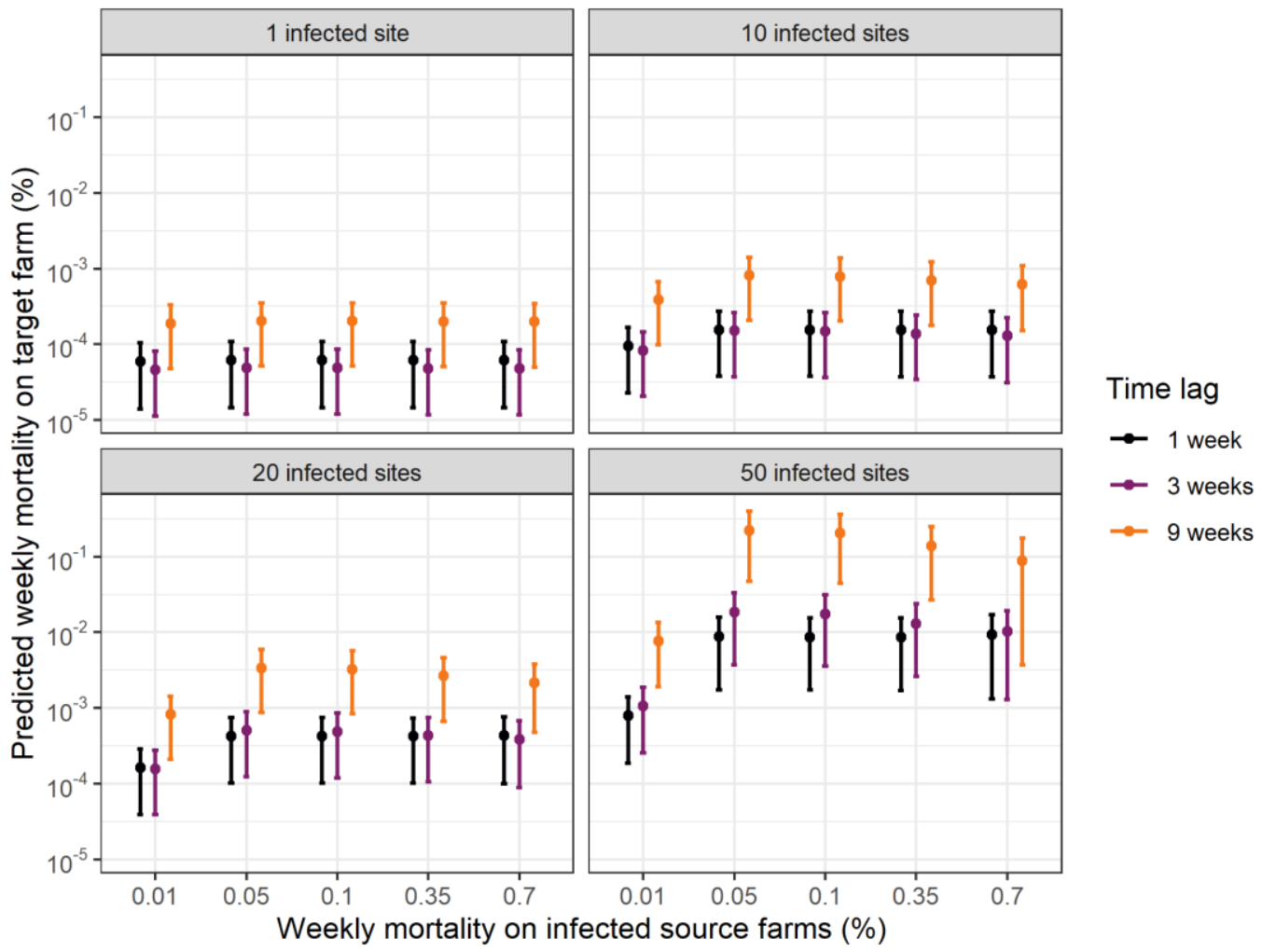

Distances were set to represent the average neighbourhood configuration in the region. The different line colours represent the cumulative time lag of SRS mortality on the source farms (for example, 3 indicates that we considered the mortality on the target farm after 3 weeks of SRS mortality on the source farms). The panels represent the number of source farms which declare SRS mortality at the level indicated on the x-axis. The error bars represent the standard error of the predicted values. The predicted values were obtained from model 7 and are plotted on a log scale.

Figure 3. Predicted values of SRS mortality of the target farm according to the SRS mortality on the neighbour source farms.

In the most supported model, SRS mortality was positively associated with the mortality on the same farm during the previous week and two weeks before the observation (Table 3). Weekly SRS mortality was also positively associated with time since sea entry, sea temperature, mortality from other infectious causes. There were significant long- and short-term temporal trends (Supplementary 
material, Figures 1 and 2). Mortality in coho salmon was significantly lower than in Atlantic salmon, and there was no difference between Atlantic salmon and rainbow trout.

Table 3. Coefficient estimates from the best statistical model. edf: estimated degrees of freedom. Estimates for continuous variables are provided for the scaled variables.

\begin{tabular}{lllll}
\hline Parametric coefficients & Estimate & Standard error & t-value & p-value \\
\hline Intercept & -12.61 & 0.19 & -65.42 & $<0.01$ \\
\hline Autocorrelation with lag 1 & 4.15 & 0.06 & 73.99 & $<0.01$ \\
\hline Autocorrelation with lag 2 & 0.30 & 0.05 & 6.21 & $<0.01$ \\
\hline Time since sea entry & $<0.01$ & $<0.01$ & 56.10 & $<0.01$ \\
\hline Sea temperature & 0.18 & 0.03 & 6.75 & $<0.01$ \\
\hline Mortality from other infectious causes & 0.55 & 0.07 & 7.68 & $<0.01$ \\
\hline Species (reference: Atlantic salmon) & 1 (reference) & & \\
\hline coho salmon & -1.75 & 0.20 & -8.84 & $<0.01$ \\
\hline Rainbow trout & -0.03 & 0.23 & -0.14 & 0.89 \\
\hline Smooth terms & edf & & F- & p-value \\
& & & 88.01 & $<0.01$ \\
\hline Linear functional term & 42.86 & & 145.68 & $<0.01$ \\
\hline Long term temporal trend & 3.00 & & 718.74 & $<0.01$ \\
\hline Seasonal trend & 1.98 & & &
\end{tabular}

\section{Discussion}

This study considered the spatiotemporal correlation of SRS mortality in commercial salmonid farms in southern Chile. The results showed that there was a statistically significant association between the weekly mortality incidence at source farms and the mortality incidence at target farms during the same week and during the previous weeks. The ranking of different model formulae provided additional information on this spatiotemporal correlation in SRS mortality. First, including the spatiotemporal correlation term for time lags of up to 10 weeks substantially improved the model fit compared to the model excluding this term, or including only 4 weeks of lagged mortalities. Extending the correlation term to longer time lags (up to 15 weeks rather than 10) did not provide additional benefits in terms of model fit. The time lag considered between mortality on source and target farms is an important factor to consider when interpreting the model results 
(see more detailed interpretation below). Under the hypothesis of water-borne pathogen dissemination of $P$. salmonis from a source farm, a substantial time lag is expected before observing an increase in SRS mortality on the target farm. This period can be divided in two: a period of dissemination of bacteria from the source to the target farm and the period before substantial SRS mortality is observed on the target farm. These durations may be affected by many factors, such as the level of shedding of bacteria on the source farm, hydrodynamic parameters, the incubation period of SRS and within-farm disease dynamics.

The exclusion of the latitude effect (model 7) did not substantially modify the fit to the data (small AIC difference with model 2), nor did it modify the spatiotemporal patterns of predicted values (data not shown). Consequently, we considered that the latitude effect was not unduly capturing the variability due to spatiotemporal autocorrelation in the response in the full model. Previous analyses showed that SRS mortality was influenced by the site latitude in Atlantic salmon (Happold, Meyer, et al. 2020). The present results suggest that the association with latitude may be due to local correlation in mortality between sites. It is also plausible that our results differ because the model was fitted for the Los Lagos region only. Within the region, there was a smaller range of variations along the North-South direction.

Interpretation of the partial effects showed local, positive correlation between the mortality on source and target farms within a radius of 20 to $50 \mathrm{~km}$, instantaneously and for time lags of up to 2 weeks. As the incubation period of SRS is assumed to be at least 2 weeks (Rozas and Enriquez 2014; Smith et al. 2004), such spatial correlation with time lags inferior or equal to the incubation period is unlikely to be explained by water-borne pathogen dissemination between the source and target farms. Alternative mechanisms such as infection by a common (e.g., environmental) reservoir of $P$. salmonis or sharing similar local environmental characteristics that trigger the expression of SRS mortality on already-infected farms may explain the observed correlation in neighbouring farms for small time lags. Local, positive correlation, on sites up to $25 \mathrm{~km}$ apart, also occurred for longer time lags, from 7 to 8 weeks onwards. This pattern could be consistent with water-borne pathogen dissemination having occurred between 
the source and target farms. The longer time lags observed in this case are biologically plausible, as they could reflect a combination of the incubation period of the disease at fish-level and the time for the disease to result in observable levels of fish mortality on a newly infected farm. Published descriptive parameters of the within-farm transmission of SRS were not available at the time of writing. Finally, the positive correlation observed over long distances $(\geq 100 \mathrm{~km})$ may be associated with multiple disease foci, distributed over the entire study area. These foci of SRS mortality may appear correlated, while actually occurring in parallel without any epidemiological link between them. In addition to between-farm correlation, model results showed temporal, within-farm autocorrelation in mortality, with positive coefficients for 1-week and 2-week lags. These terms represented the within-farm dynamics of the disease, including transmission both between fish and between pens.

In this paper, we used a spline-based model. Others have studied spatiotemporal correlation of animal diseases using kernel-based methods (e.g. Boender et al. 2007; Gubbins et al. 2018; Ypma et al. 2013). Both methods are based on arbitrary values for the 'smoothing' parameter (i.e., bandwidth or degrees of freedom). The spline-based method was chosen in this work as it better allowed for the inclusion of multiple risk factors within the GAM framework, such as seasonality with a cyclic spline. No readily usable framework for kernel-based multivariate GAM estimation was found at the time of this study. In addition, the spline-based GAM framework allowed for the use of continuous mortality data rather than dichotomizing the data according to arbitrary rules. The choice of kernel type is a critical step in kernel-based methods, and may have a significant impact on the outcome, as shown in Gubbins et al. (2018). Other methods used to study spatial correlation of infectious animal disease outbreaks include the spacetime K function (Vergne, Gogin, and Pfeiffer 2017). It is worth noting that any such method may only be used to assess whether spatiotemporal correlation has a substantial effect on the distribution of the cases, and that these studies do not assess whether farm-to-farm transmission is the main cause of such correlation.

A potential caveat of the spline-based method is harmonic behaviour. Higher values observed at the upper extremity of the range of time lags may be due to a 
model artefact rather than representing biological processes. Such oscillations may have occurred for large time lags in model 7 and did not appear in the model using longer time lags (model 4). Harmonic behaviour may also explain the negative correlations observed for some of the parameter combinations, which are unlikely to be biologically plausible. Oscillations in the spline functions may be a consequence of the harmonic behaviour of the smoothing process, as demonstrated by previous authors (Bowman and Azzalini 1997; Wüst et al. 2017). In addition, it is worth noting that the uncertainty associated with the smooth effect was large, which leads to the necessity of interpreting the shape of the surfaces carefully.

An important limitation of this study is the use of on-farm mortality classification data as the only form of SRS diagnosis. We were unable to determine the sensitivity and specificity of the classification process of fish mortalities. These indicators may depend on the qualifications and experience of farm personnel as well as previous SRS laboratory diagnoses for the fish group. Classification inaccuracies may have affected our results, by misestimating the level of SRS mortality on the source or target farms. The data used in this study could be improved by including results from farm-level or area-level laboratory diagnosis of SRS.

Our model results suggest a small dose-response effect where increasing SRS mortality on the source farms (up to $0.05 \%$ ) resulted in increasing mortality predicted values on target farms. However, this response was not statistically significant and only appeared when a very large proportion of the neighbouring farms were affected. The infection pressure from a few farms in the neighbourhood, even with very high SRS mortality and at short distances did not increase the mortality on the target farm. Overall, the mortality on source farms did not explain a substantial proportion of the variance in the SRS mortality on the farms included in our dataset. Hence, this study does not provide evidence that the spatiotemporal correlation observed in SRS mortality could be due to water-borne pathogen dissemination between farms. Although the pathogen may abundantly disperse in the sea environment of infected farms, our models do not support a substantial effect of this dissemination in causing mortality in neighbour farms. 
Overall, the models provide evidence in favour of alternative explanations of the mechanisms behind spatiotemporal correlations. Confounding effects due to unaccounted-for factors that influence SRS mortality on neighbouring farms simultaneously or with a certain time lag include various biotic and abiotic factors. The results presented here highlight the complex epidemiology of $P$. salmonis infection in salmonid farms.

Previous modelling work showed that larger sea farms were at higher risk of transmitting disease to their neighbours, due to the higher intensity of pathogen shedding (Salama and Murray 2011). Our full model based on SRS mortality rates on source farms (model 2) provided a significantly better fit to the data than the alternative model using mortality counts instead (model 8), with a large AIC difference. This result is surprising, as it was expected that the number of fish dying from SRS (representing a combination of the level of mortality on the source farm and the farm size) would provide a better estimation of the farm-level infectivity and pathogen shedding. Other variables which could be of interest are the stocking density, the number and size of cages and the production stage on the source farms. However, the effect of these variables could not be studied here, as the models did not converge when including more than three variables in the linear functional terms (time lag, distance and source farm mortality). The importance of SRS mortality rates is consistent with Chilean regulatory thresholds for intervention, which are based on weekly mortality rates rather than counts. However, there was no evidence in our study of a threshold effect above which farms poses a substantially larger health risk to their neighbours.

It is important to note that models based on seaway distances performed better than the model based on Euclidean distances. A spatial study of pancreas disease using a hydrodynamic model in Norway showed that the infection pressure for this disease was best modelled by a variable based on water contact and the fish biomass on infectious sites (Viljugrein et al. 2009). An infection pressure variable based on seaway distances and including the number of fish at infectious sites was an acceptable alternative. Stronger evidence for or against between-farm transmission of $P$. salmonis may be obtained by building and assessing the predictive power of mathematical models of pathogen spread. A large range of 
methods are available, depending on the spatiotemporal scale of interest for instance (Parry, Sadler, and Kriticos 2013). Existing models of pathogen spread in aquaculture demonstrated the importance of including hydrodynamic features of the study area (Salama and Murray 2013, 2011; Viljugrein et al. 2009). Little published work on hydrodynamic features is currently available to support such modelling work in our study area. Local parameters for currents and tidal amplitude were reported in a few studies in the Los Lagos and Aysén regions (Atkinson et al. 2002; Aiken 2008; Shaffer et al. 1999; Figueroa and Moffat 2000; Sobarzo et al. 2018). Although the Peru-Chile current system affects the general area (Karstensen and Ulloa 2019), sea farms in the Los Lagos region are located in protected channels, fjords and bays rather than in open water. These farms are less likely to be affected by large-scale oceanic conditions than by local water flows. Such water flows follow complex patterns created by tidal movements, residual currents, freshwater inputs, oceanographic features and local topography (Sobarzo et al. 2018). The development of a mathematical model of SRS spread including hydrodynamic parameters would be expected to provide a substantial contribution to explaining spatiotemporal patterns of SRS mortality in Chile (Steven et al. 2019). Such work could build on previous hydrodynamic modelling for other diseases, such as the work on infectious salmon anaemia presented by Olivares et al. (2015), which was based on the Regional Oceanic Modelling System (Shchepetkin and McWilliams 2005).

In addition, whole-genome sequencing has proven useful in identifying disease transmission patterns in various situations where traditional contact tracing was not conclusive (Crispell et al. 2017; Kao et al. 2014; Walker et al. 2014; Gardy et al. 2011). Molecular techniques could contribute to clarifying SRS transmission routes in Chilean salmon farms, by characterising the P. salmonis isolates identified on different farms and assessing the genetic distance between them. Further research on these topics would contribute to close some important knowledge gaps related to SRS (Mardones et al. 2018) and support the development of more evidence-based policy. In the meantime, the evidence currently available is not strong enough to base all regulatory disease management efforts on the hypothesis of water-borne between-farm transmission. A broader 
approach to risk management is recommended, with different mitigation measures addressing the potential spread mechanisms.

\section{Acknowledgments}

The authors acknowledge the tireless efforts of many people at the Chilean National Fisheries and Aquaculture Service (Sernapesca), who have supported this project. We thank representatives from the Chilean Salmon Industry Association (SalmonChile) for their technical insights, and contributions to meetings and workshops. Berta Contreras (Conecta $\mathrm{SpA}$ ) has been invaluable in providing a link between the authors and the salmon aquaculture industry in Chile. Last, we are grateful to Prof. Sophie St-Hilaire for helpful insights and advice during the preparation of this manuscript.

\section{Funding}

This study was partly carried out under the framework of the Program for Aquaculture Sanitary Management (PGSA, program number FIE-2015-Vo14), a project executed by Sernapesca, with public and private financing from the Ministry of the Economy, Development and Tourism and SalmonChile. 


\section{References}

Aiken, C. M. 2008. "Barotropic Tides of the Chilean Inland Sea and Their Sensitivity to Basin Geometry." Journal of Geophysical Research 113 (C8). https://doi.org/10.1029/2007JC004593.

Akaike, H. 1974. “A New Look at the Statistical Model Identification.” IEEE $\begin{array}{lllll}\text { Transactions on Automatic Control } 19 & \text { (6): 716-723. }\end{array}$ https://doi.org/10.1109/TAC.1974.1100705.

Arriagada, G., H. Stryhn, J. Sanchez, R. Vanderstichel, J. L. Campistó, E. E. Rees, R. Ibarra, and S. St-Hilaire. 2017. "Evaluating the Effect of Synchronized Sea Lice Treatments in Chile." Preventive Veterinary Medicine 136 (January): 1-10. https://doi.org/10.1016/j.prevetmed.2016.11.011.

Atkinson, Larry P., Arnoldo Valle-Levinson, Dante Figueroa, Ricardo De PolHolz, Victor A. Gallardo, Wolfgang Schneider, Jose L. Blanco, and Mike Schmidt. 2002. "Oceanographic Observations in Chilean Coastal Waters between Valdivia and Concepción.” Journal of Geophysical Research: Oceans 107 (C7): 18-1-18-13. https://doi.org/10.1029/2001JCooo991.

Boender, Gert Jan, Thomas J. Hagenaars, Annemarie Bouma, Gonnie Nodelijk, Armin R. W. Elbers, Mart C. M. de Jong, and Michiel van Boven. 2007. "Risk Maps for the Spread of Highly Pathogenic Avian Influenza in Poultry." PLOS Computational Biology 3 (4): e71. https://doi.org/10.1371/journal.pcbi.0030071.

Bowman, AW, and A Azzalini. 1997. Applied Smoothing Techniques for Data Analysis. Oxford Statistical Science Series 18. Oxford, UK: Oxford University Press.

Bravo, S, and M Campos. 1989. "Coho Salmon Syndrome in Chile.” FHS/AFS Newsletter 17: 3.

Burnham, KP, and DR Anderson. 2002. Model Selection and Multimodel Inference: A Practical Information-Theoretic Approach, 2nd Edition. Springer, New York.

Contreras-Lynch, Sergio, Paola Olmos, Augusto Vargas, Jaime Figueroa, Roxana González-Stegmaier, Ricardo Enríquez, and Alex Romero. 2015. "Identification and Genetic Characterization of Piscirickettsia Salmonis in Native 
Fish from Southern Chile." Diseases of Aquatic Organisms 115 (3): 233-44. https://doi.org/10.3354/daoo2892.

Crispell, Joseph, Ruth N. Zadoks, Simon R. Harris, Brent Paterson, Desmond M. Collins, Geoffrey W. de-Lisle, Paul Livingstone, et al. 2017. "Using Whole Genome Sequencing to Investigate Transmission in a Multi-Host System: Bovine Tuberculosis in New Zealand.” BMC Genomics 18 (1): 180. https://doi.org/10.1186/s12864-017-3569-x.

Figueroa, Dante, and Carlos Moffat. 2000. "On the Influence of Topography in the Induction of Coastal Upwelling along the Chilean Coast." Geophysical Research Letters 27 (23): 3905-8. https://doi.org/10.1029/1999GL011302.

Gardy, Jennifer L., James C. Johnston, Shannan J. Ho Sui, Victoria J. Cook, Lena Shah, Elizabeth Brodkin, Shirley Rempel, et al. 2011. "Whole-Genome Sequencing and Social-Network Analysis of a Tuberculosis Outbreak." New England Journal of $\quad$ Medicine $364 \quad$ (8): $730-39$. https://doi.org/10.1056/NEJMoa1003176.

Gubbins, Simon, Arjan Stegeman, Eyal Klement, Ledi Pite, Alessandro Broglia, and José Cortiñas Abrahantes. 2018. "Inferences about the Transmission of Lumpy Skin Disease Virus between Herds from Outbreaks in Albania in 2016.” Preventive Veterinary Medicine, December. https://doi.org/10.1016/j.prevetmed.2018.12.008.

Happold, J, A Meyer, R Sadler, B Cowled, C Mackenzie, AL Gallardo Lagno, and A Cameron. 2020. "Effectiveness of Antimicrobial Treatment of Salmonid Rickettsial Septicaemia in Commercial Salmon and Trout Farms in Chile." Aquaculture 525: 735323. https://doi.org/doi.org/10.1016/j.aquaculture.2020.735323.

Happold, J, R Sadler, A Meyer, B Cowled, C Mackenzie, AL Gallardo Lagno, and A Cameron. 2020. "Effectiveness of Vaccination for the Control of Salmonid Rickettsial Septicaemia in Commercial Salmon and Trout Farms in Chile.” Aquaculture 520: 734968. https://doi.org/10.1016/j.aquaculture.2020.734968.

Hastie, T, and R Tibshirani. 1993. "Varying-Coefficient Models." Journal of the Royal Statistical Society, Series B 55: 757-96. 
Hillman, A, E Zalcman, A Burroughs, A Meyer, C Mackenzie, R Sadler, M Stevenson, et al. 2020. "Use of Regulatory Data to Describe and Identify Risk Factors for Salmonid Rickettsial Septicaemia in Chile, 2011-2017.” Aquaculture 526: 735324. https://doi.org/doi.org/10.1016/j.aquaculture.2020.735324.

Kao, Rowland R., Daniel T. Haydon, Samantha J. Lycett, and Pablo R. Murcia. 2014. "Supersize Me: How Whole-Genome Sequencing and Big Data Are Transforming Epidemiology.” Trends in Microbiology, Special Issue: Omics: Fulfilling the Promise, 22 (5): 282-91. https://doi.org/10.1016/j.tim.2014.02.011.

Karstensen, Johannes, and Osvaldo Ulloa. 2019. "Peru-Chile Current System.” In Encyclopedia of Ocean Sciences (Third Edition), edited by J. Kirk Cochran, Henry J. Bokuniewicz, and Patricia L. Yager, 3:437-44. Oxford: Academic Press. https://doi.org/10.1016/B978-0-12-409548-9.11335-1.

Kristoffersen, A. B., E. E. Rees, H. Stryhn, R. Ibarra, J. -L. Campisto, C. W. Revie, and S. St-Hilaire. 2013. "Understanding Sources of Sea Lice for Salmon Farms in Chile." Preventive Veterinary Medicine 111 (1): 165-75. https://doi.org/10.1016/j.prevetmed.2013.03.015.

Mardones, Fernando O, Felipe Paredes, Matías Medina, Alfredo Tello, Victor Valdivia, Rolando Ibarra, Juan Correa, and Stefan Gelcich. 2018. "Identification of Research Gaps for Highly Infectious Diseases in Aquaculture: The Case of the Endemic Piscirickettsia Salmonis in the Chilean Salmon Farming Industry." Aquaculture 482: 211-220. https://doi.org/10.1016/j.aquaculture.2017.09.048.

Meyer, A, Burroughs, A, Sadler, R, Happold, J, Cowled, B, C Mackenzie, Gallardo Lagno, AL, and A Cameron. 2019. "Quantifying the Effects of Sea Lice Burden and Lice Bathing Treatments on Salmonid Rickettsial Septicaemia in Commercial Salmon and Trout Farms in Chile." Aquaculture 513: 734411. https://doi.org/10.1016/j.aquaculture.2019.734411.

Olivares, Gonzalo, H. H. Sepúlveda, and B. Yannicelli. 2015. "Definition of Sanitary Boundaries to Prevent ISAv Spread between Salmon Farms in Southern Chile Based on Numerical Simulations of Currents." Estuarine, Coastal and Shelf Science 158 (June): 31-39. https://doi.org/10.1016/j.ecss.2015.02.013.

Olivares, J., and S. H. Marshall. 2010. "Determination of Minimal Concentration of Piscirickettsia Salmonis in Water Columns to Establish a 
Fallowing Period in Salmon Farms.” Journal of Fish Diseases 33 (3): 261-66. https://doi.org/10.1111/j.1365-2761.2009.01119.x.

Parry, H. R., R. J. Sadler, and D. J. Kriticos. 2013. "Practical Guidelines for Modelling Post-Entry Spread in Invasion Ecology.” NeoBiota, no. No.18: 41-66.

Price, Derek, Rolando Ibarra, Javier Sánchez, and Sophie St-Hilaire. 2017. "A Retrospective Assessment of the Effect of Fallowing on Piscirickettsiosis in Chile.” Aquaculture 473 (April): $400-406$. https://doi.org/10.1016/j.aquaculture.2017.02.034.

R Core Team, 2019. R: A Language and Environment for Statistical Computing. R Foundation for Statistical Computing, Vienna, Austria. URL: https://www.r-project.org/.

Ramsay, JO, and BW Silverman. 2006. Functional Data Analysis. 2nd ed. Springer Series in Statistics. New Yor, USA: Springer.

Rees, Erin E, Rolando Ibarra, Matias Medina, Javier Sanchez, Eva Jakob, Raphael Vanderstichel, and Sophie St-Hilaire. 2014. "Transmission of Piscirickettsia Salmonis among Salt Water Salmonid Farms in Chile.” Aquaculture 428-429: 189-194. https://doi.org/10.1016/j.aquaculture.2014.03.031.

Rozas, M, and R Enriquez. 2014. "Piscirickettsiosis and Piscirickettsia Salmonis in Fish: A Review." Journal of Fish Diseases 37 (3): 163-188. https://doi.org/10.1111/jfd.12211.

Salama, N, and A. G. Murray. 2011. "Farm Size as a Factor in Hydrodynamic Transmission of Pathogens in Aquaculture Fish Production.” Aquaculture Environment Interactions 2 (1): 61-74. https://doi.org/10.3354/aeiooo30.

Salama, N, and A. G. Murray. 2013. "A Comparison of Modelling Approaches to Assess the Transmission of Pathogens between Scottish Fish Farms: The Role of Hydrodynamics and Site Biomass." Preventive Veterinary Medicine, Special Issue: SVEPM 2012 - The cutting-edge of animal disease control in a global environment, 108 (4): 285-93. https://doi.org/10.1016/j.prevetmed.2012.11.005.

Sernapesca. 2012. "Establece Programa Sanitario Específico de Vigilancia y Control de Piscirickettsiosis: PSEVC- Piscirickettsiosis. Resolución Exenta N. 3.174, 28/12/2012." Servicio Nacional de Pesca y Acuicultura. 
Shaffer, Gary, Samuel Hormazabal, Oscar Pizarro, and Sergio Salinas. 1999. "Seasonal and Interannual Variability of Currents and Temperature off Central Chile.” Journal of Geophysical Research: Oceans 104 (C12): 29951-61. https://doi.org/10.1029/1999JC900253.

Shchepetkin, Alexander F., and James C. McWilliams. 2005. “The Regional Oceanic Modeling System (ROMS): A Split-Explicit, Free-Surface, TopographyFollowing-Coordinate Oceanic Model." Ocean Modelling 9 (4): 347-404. https://doi.org/10.1016/j.ocemod.2004.08.002.

Smith, P. A., M. E. Rojas, A. Guajardo, J. Contreras, M. A. Morales, and J. Larenas. 2004. "Experimental Infection of Coho Salmon Oncorhynchus Kisutch by Exposure of Skin, Gills and Intestine with Piscirickettsia Salmonis.” Diseases of Aquatic Organisms 61 (1-2): 53-57. https://doi.org/10.3354/daoo61053.

Sobarzo, Marcus, Luis Bravo, Claudio Iturra, Alfredo Troncoso, Roberto Riquelme, Patricio Campos, and Cristian Agurto. 2018. "Hydrodynamics of a Channel Occupied by the Aquaculture Industry in Southern Chile: Implications for Connectivity between Farms." Aquaculture Environment Interactions 10 (July): 291-307. https://doi.org/10.3354/aeioo268.

Steven, Andrew D. L., Santosh Aryal, Patricio Bernal, Francisco Bravo, Rodrigo H. Bustamante, Scott Condie, Jeffrey M. Dambacher, et al. 2019. "SIMA Austral: An Operational Information System for Managing the Chilean Aquaculture Industry with International Application.” Journal of Operational Oceanography o (o): 1-18. https://doi.org/10.1080/1755876X.2019.1636606.

Vergne, T., A. Gogin, and D. U. Pfeiffer. 2017. "Statistical Exploration of Local Transmission Routes for African Swine Fever in Pigs in the Russian Federation, 2007-2014." Transboundary and Emerging Diseases 64 (2): 504-12. https://doi.org/10.1111/tbed.12391.

Viljugrein, H, A Staalstrøm, J Molvær, Ha Urke, and Pa Jansen. 2009. "Integration of Hydrodynamics into a Statistical Model on the Spread of Pancreas Disease (PD) in Salmon Farming." Diseases of Aquatic Organisms 88 (December): 35-44. https://doi.org/10.3354/daoo2151. 
Wagenmakers, Eric-Jan, and Simon Farrell. 2004. "AIC Model Selection Using Akaike Weights.” Psychonomic Bulletin \& Review 11 (1): 192-96. https://doi.org/10.3758/BFo3206482.

Walker, Timothy M, Maeve K Lalor, Agnieszka Broda, Luisa Saldana Ortega, Marcus Morgan, Lynne Parker, Sheila Churchill, et al. 2014. "Assessment of Mycobacterium Tuberculosis Transmission in Oxfordshire, UK, 2007-12, with Whole Pathogen Genome Sequences: An Observational Study." The Lancet Respiratory Medicine 2 (4): 285-92. https://doi.org/10.1016/S22132600(14)70027-X.

Wood, Simon N. 2004. "Stable and Efficient Multiple Smoothing Parameter Estimation for Generalized Additive Models.” Journal of the American Statistical Association 99 (467): 673-86. https://doi.org/10.1198/016214504000000980.

Wood, S.N. 2017. Generalized Additive Models: An Introduction with R. 2nd ed. Chapman and Hall/CRC. https://cran.rproject.org/web/packages/mgcv/citation.html.

Wüst, Sabine, Verena Wendt, Ricarda Linz, and Michael Bittner. 2017. "Smoothing Data Series by Means of Cubic Splines: Quality of Approximation and Introduction of a Repeating Spline Approach." Atmospheric Measurement Techniques 10 (9): 3453-62. https://doi.org/10.5194/amt-10-3453-2017.

Ypma, Rolf J. F., Marcel Jonges, Arnaud Bataille, Arjan Stegeman, Guus Koch, Michiel van Boven, Marion Koopmans, W. Marijn van Ballegooijen, and Jacco Wallinga. 2013. "Genetic Data Provide Evidence for Wind-Mediated Transmission of Highly Pathogenic Avian Influenza." The Journal of Infectious Diseases 207 (5): 730-35. https://doi.org/10.1093/infdis/jis757. 


\section{Supplementary material}

Supplementary material 1. Additional results obtained from the most supported statistical model of weekly SRS mortality on target farms.

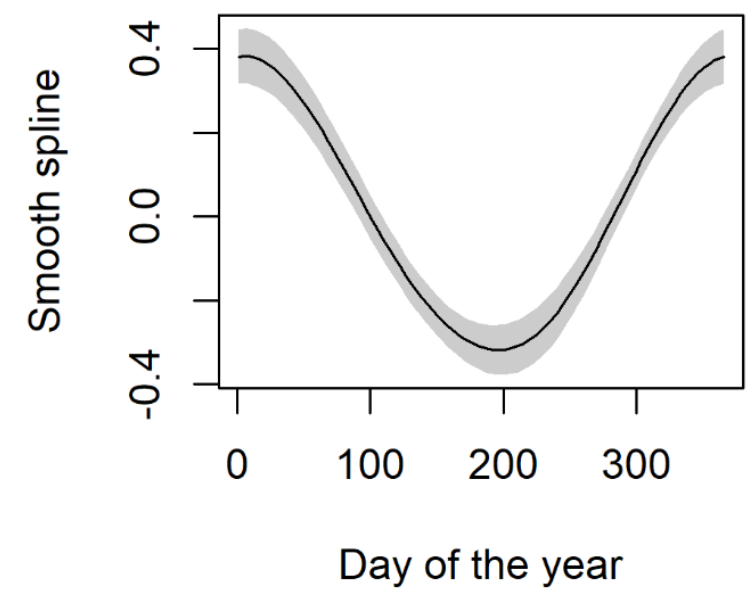

Figure Suppl 1. Partial effect of the time since the first observation on the SRS mortality on the target farm, equivalent to the long-term temporal trend in SRS mortality.

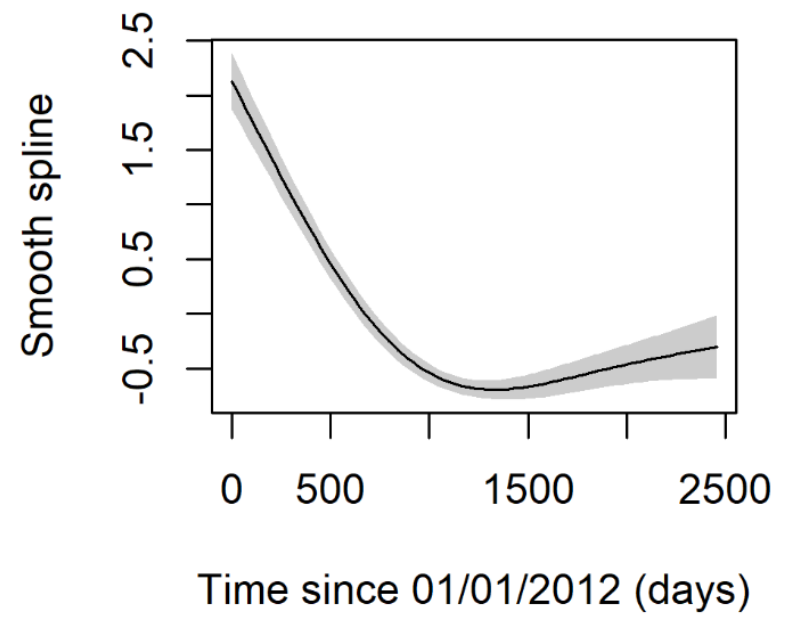

Figure Suppl 2. Partial effect of the day of the year on the SRS mortality on the target farm, equivalent to the seasonal trend in SRS mortality. 


\section{CHAPTER 5}

\section{Barriers to the adoption of a fish health data integration initiative in the Chilean salmonid production}

Anne Meyera ${ }^{\mathrm{a}}$, Melanie Bannister-Tyrrell ${ }^{\mathrm{b}}$, Catriona Mackenzie ${ }^{\mathrm{a}, \mathrm{b}}$, Arjan Stegeman ${ }^{\mathrm{c}}$, Angus Cameron ${ }^{\mathrm{a}, \mathrm{b}}$

a Ausvet Europe, 69001 Lyon, France

b Ausvet, Fremantle WA, 6160, Australia

c Utrecht University, Department of Farm Animal Health, 3512 JE Utrecht, the Netherlands

Computers and Electronics in Agriculture 179 (2020) 105853

https://doi.org/10.1016/j.compag.2020.105853 


\section{Abstract}

The fish production, health and management data routinely collected on aquaculture farms represent a significant resource that could better support epidemiological research than traditional surveys and other studies. To this aim, a collaborative data integration platform was developed in late 2017 with the Chilean salmon and trout production industry (an initiative named 'Plataforma Integrada de Investigación Sanitaria para la Acuicultura', PIISAC). Initially supported through a joint government-industry program, it was planned that the PIISAC initiative would transition towards ongoing industry ownership and governance in 2019. However, this transition did not occur, due to lack of industry support. In this qualitative study, we used semi-structured key informant interviews to explore the perspective of stakeholders on the implementation of PIISAC and identify barriers to sustained adoption. An inductive, semantic thematic analysis was conducted. While informants reported that the platform was valuable for the industry, they also identified many concerns and barriers. These elements were grouped under two main themes, i.e., factors related to the environment for the data integration platform, and issues linked to the project implementation. Within the first main theme, sub-themes included competitive advantages, privacy concerns, and lack of trust between stakeholders and towards third parties. Regarding the project implementation, the identified factors included project attributes such as relative advantage, complexity and observability, as well as participation-related factors such as the critical mass. These factors were consistent with established theory on diffusion of innovations. Additional findings include that in-country presence is critical to support and maintain participation, and that effective communication is equally important as robust design principles to overcome existing perceptions and barriers to participation. The findings of this study can inform the design of future successful and sustainable partnerships. Our work emphasizes the need to conduct targeted consultations during the design stage of such initiatives, to identify context-specific challenges related to the environment and the stakeholders. These consultations are critical to inform the implementation plan and better address the needs of the participants. 


\section{Key words}

Data integration; public-private partnership; thematic analysis; aquaculture; stakeholder 


\section{Introduction}

Chile was the fourth largest finfish producer worldwide in 2016, with a production of over 700 thousand tonnes (FAO 2018), most of which being salmon and trout. Most salmonid farms in Chile are operated by large companies operating farms in different regions or multinational companies. Collectively, the routine fish production, health and management data gathered on farms (e.g., records concerning movements of fish groups, weight gain and variability, mortality, veterinary treatments, feed distribution) form a comprehensive and complex picture of what is happening day-to-day on these farms. Such data also includes much of the variability in management systems adopted and environmental conditions encountered by salmonid producers in the country. Collaborative efforts are required to create national information systems to support health research in both public and animal health. However, most of animal health initiatives to date were developed at the instigation of non-industry stakeholders such as authorities or research institutes. Examples abound, from early systems such as the National Swedish animal disease recording system (Emanuelson 1988), surveillance systems for companion animal health (O’Neill 2012; McGreevy et al. 2017), to cloud-based systems such as Indonesia's integrated animal health information system (Hutchison et al. 2018). A few initiatives of collaborative data integration and analysis have been described within the agriculture sector, for instance in the United States (Shekhar et al. 2017; Stubb 2016) and in Switzerland (Faverjon et al. 2019). In the aquaculture sector, two initiatives were identified in Norway, the AquaCloud platform for improving sea lice management (Hoel 2018) and the fish health module in BarentsWatch (https://www.barentswatch.no). These types of initiatives are likely to become more common in agriculture and aquaculture with (i) the increasing availability of real-time data from precision farming technologies, both in terrestrial animal production (Berckmans 2014) and aquaculture (Føre et al. 2018; O’Donncha and Grant 2019), and (ii) the increasing recognition of the value of public-private partnerships in the veterinary domain (OIE 2019).

A collaborative platform where producers regularly contribute routine data would support ongoing research in fish health in Chile and could facilitate the 
provision of data to third parties such as the Chilean regulatory body for fisheries and aquaculture (Servicio Nacional de Pesca y Acuicultura, Sernapesca) and the Chilean salmon farming association (SalmonChile). In late 2017, a project was commissioned by Chilean stakeholders to build an integrated platform for epidemiological research in the Chilean aquaculture industry ('Plataforma Integrada de Investigación Sanitaria para la Acuicultura', PIISAC). This approach was complementary to another approach commissioned by the Chilean government in the aquaculture sector, the 'Sistema Integrado de Manejo para la Acuicultura Austral de Chile' (SIMA), a recently deployed information and modelling platform (Steven et al. 2019). The SIMA platform uses regulatory databases as well as publicly available data (e.g., climate, weather, remote sensing) to support better policy and management decisions. At the time when the development of PIISAC started, 21 aquaculture companies were operating commercial salmon and trout sea farms in Chile. Consultations with the industry to develop the PIISAC collaborative platform started in January 2018, with the first companies providing data in April 2018. By the end of the government-executed project in December 2018, 10 companies were participating and three epidemiological risk factor studies based on the PIISAC data had been completed (Happold, Meyer, et al. 2020; Happold, Sadler, et al. 2020; Meyer et al. 2019). The PIISAC initiative showed that an operational platform could be set-up and populated during the project duration (December 2017 - December 2018). During that period, the development and maintenance of the platform as well as the recruitment of companies was entirely funded by the government, through a joint government-industry program ('Programa para la gestión sanitaria en la Acuicultura', PGSA). However, after the end of the project, the proposed transition towards industry ownership, governance and funding of the platform has proven difficult and PIISAC was discontinued in September 2019. The research question investigated in this study can be formulated as follows: how can a public-private data integration initiative transition into a sustainable industry program? We analysed the case of PIISAC to identify factors which may affect the sustainability of such initiatives and inform the design of successful future partnerships. 


\section{Methods}

A qualitative study was designed to explore the perspective of stakeholders on the implementation of PIISAC. Data were collected via semi-structured individual interviews of informants selected from relevant stakeholder groups. In this section, we first present key features of the platform that are useful to interpret the results of this study, then report the study methodology according to the COREQ guidelines (Tong, Sainsbury, and Craig 2007).

\subsection{Key features of the platform}

The PIISAC initiative was based on a people-centred approach to animal health surveillance previously presented in a discussion paper (Hutchison et al. 2018). The purpose of the platform was to integrate data across multiple companies in order to answer research questions that could not be answered by examining a single company's data alone. The platform was based on data integration in a secure environment, with controlled access to the data by authorized participants, rather than data sharing between companies. Thus, companies could not access data from other companies but could visualize data summaries and de-identified results from the analyses conducted for specific purposes, maintaining each individual company's commercial privacy and respecting antitrust legislation (Decree Law no. 211 from 1973 and subsequent amendments and rulings). The platform was designed as a flexible and comprehensive data source that could be used to conduct observational epidemiological studies to answer fish health questions prioritized by the industry. In addition to this long-term goal, the short-term goal of the platform was to provide rapid access to their own data to companies, via an online interface. Data from production databases were integrated using automated algorithms. This process was designed to avoid the need for manual data extraction by company personnel, in contrast with current systems for reporting to government authorities and existing data service providers. 


\subsection{Research team}

The research team jointly developed the semi-structured interview guide (Supplementary material), while the interviews were conducted by a native Chilean Spanish speaker (NR). Some of the authors had previously worked with the informants during the implementation of PISAC, while NR had not been involved in the implementation.

\subsection{Study design}

\subsubsection{Informant selection}

Veterinary staff or technical managers (fish health and production) were selected from the following groups, using a purposive sampling strategy (Robinson 2014; Gentles et al. 2015): salmon producing companies who actively participated in PIISAC ('participating companies'), salmon producing companies who did not actively participate in PIISAC, and third-party stakeholders (Sernapesca and SalmonChile). To increase the validity of the results across the industry, we aimed at interviewing one informant from each company as well as one informant from Sernapesca and one from SalmonChile. The informants were approached by email and telephone to arrange for an interview. As four companies did not reply to our requests, and on two occasions we interviewed two informants from the same company, we conducted a total of 20 interviews. All informants except one were men, and they had between 10 and 30 years of experience in the aquaculture industry or regulatory area.

\subsubsection{Data collection}

Roger's diffusion theory, initially published in 1962, proposed a framework to understand the diffusion process of new ideas and innovations in a social system (Rogers 2003). We used the five stages of the diffusion theory (knowledge, persuasion, decision, implementation, confirmation) to develop and structure the semi-structured interview guide used in the present study. The interview guide was slightly refined after the first two interviews. The interviews were conducted between January and April 2020, either in person $(n=13)$ or using a teleconference 
tool $(n=7)$. The interviews were conducted at the workplace, in a location that prevented the conversation being overheard, and were audio recorded.

\subsection{Data analysis}

The interview records were transcribed and translated into English by NR before being imported in RQDA (Huang 2018), a package in the R environment ( $R$ Core Team 2019) for analysis. An inductive, semantic thematic analysis was conducted by the first author, following the approach described by (Braun and Clarke 2006, 2014). In the coding stage, the interview materials were read carefully, and each individual idea in relation to the research question was identified and marked ('code'). Then, themes and sub-themes were derived from the data itself, via an iterative and systematic process of reviewing, summarizing and cross-checking the codes previously identified. The sub-themes described in this work cover the ideas identified in the interview materials in an exhaustive manner, while the narrative provides indications of the differences and similarities between the informants.

\subsection{Ethics}

A study information sheet was provided to each informant prior to the start of the interview as well as a short video explaining the reasons for conducting the interviews. Then, they were informed that they were free to withdraw consent at any time and given an opportunity to ask questions regarding the study or their participation. Finally, consent to participate was obtained and documented via signing a written consent form. This study was approved by the ScienceGeosciences Ethics Review Board of Utrecht University under the reference number DGK L-19302.

\section{Results}

Two main themes were identified in the interview materials when exploring the research question. These two themes were divided into 19 sub-themes (Table 9) which are presented in more details in the sections below. 
Table 9. Set of themes and sub-themes identified in semi-structured interviews of key informants in the Chilean salmonid production industry $(\mathrm{N}=20)$.

\begin{tabular}{|c|c|}
\hline $\begin{array}{l}\text { A difficult environment for a data } \\
\text { integration platform }\end{array}$ & $\begin{array}{l}\text { Issues linked to the project } \\
\text { implementation }\end{array}$ \\
\hline $\begin{array}{l}\text { - } \text { Existing data management systems } \\
\text { - Cre considered good } \\
\text { - } \text { Role of the antitrust laws } \\
\text { - Generic climate of distrust } \\
\text { - Concerns related to data privacy } \\
\text { - Collaboration within the industry is } \\
\text { - Iifficult } \\
\text { - } \text { Comportance of competitive advantages } \\
\text { - } \text { relationship } \\
\text { Competing priorities in } 2018\end{array}$ & $\begin{array}{l}\text { - } \text { Results did not meet expectations } \\
\text { - } \text { Quality of the data and analyses } \\
\text { - } \text { PIISAC as a foreign initiative } \\
\text { - } \quad \text { Insufficient knowledge of the } \\
\text { - } \quad \text { Lack of understanding regarding } \\
\text { - Privacy and security } \\
\text { - Project timeline was too short } \\
\text { - } \text { factor participation as a critical } \\
\text { - } \text { dynamics } \\
\text { Data integration requires joint efforts }\end{array}$ \\
\hline
\end{tabular}

\subsection{A difficult environment for a data integration platform}

The first theme gathers a number of issues related to the Chilean aquaculture industry and its operating environment that were discussed by the informants as obstacles to the initial uptake of PIISAC.

3.1.1.Existing data management systems are considered good

Decision-makers in the surveyed companies inform their fish health related decisions with a combination of results from internal analyses, expertise and historical knowledge from technical personnel and outputs obtained from external data service providers. Most companies' information management systems (IMS) in terms of fish health data are based on a combination of tools. These tools include commercial production software, spreadsheets and other tools storing fish health data. Substantial improvements in data management and analysis over the years were reported during the interviews, leading to improved support for decision making. Most informants felt that their company's IMS meets their information needs for fish health management: "I really do not see any area that we need that the tool does not comply with" (interview 03). However, several informants reported that there was room for improvement, such as a lack of data analysis tools 
in existing IMS. Some reported that they would benefit from a more user-friendly access to and better visualization of company production and health data, with fewer manual inputs and more integration. Several informants felt that more consolidation of existing data is needed to better support decision making: "this industry has way too much data, but very little information" (interview 16).

\subsubsection{Crowded market for data services}

A few organizations (private companies and the industry association) currently provide data consolidation services as well as benchmarking tools to producers, leading to a crowded market for data services available to the industry. In this context, several informants saw PIISAC as a service in competition with existing data service providers. Some informants highlighted that the results from PIISAC studies were similar to those obtained from other data service providers. Those providers were generally deemed as delivering good value and concrete outputs in terms of information to assist with fish health management, complementing information available in-house via the company's IMS. Some of these data service providers have been working with the industry for a long time, gaining substantial experience with the industry's data and expectations. In this context, PIISAC was seen as a new player providing competing services, without the advantage of local contextual experience. Talking about an existing data service provider, one informant said that it "is like a competitor for [PISAC], has more years of experience and knows the work better and does similar things" (interview 02).

\subsubsection{Role of the antitrust laws}

Antitrust regulation was repeatedly highlighted as one of the major obstacles to the integration of fish health data within the industry. Restrictions on the amount and variety of data that can be shared by producers affect existing data service providers and most projects involving some form of data exchange. One of the options to maintain compliance with these regulations is to delay the publication of consolidated reports containing results related to production. This strategy, used by some providers, reduces the value of the information for ongoing 
decision making. The informants raised the lack of clarity of antitrust regulations and existing jurisprudence regarding the exchange of data related to fish health as an important issue. Informants reported receiving competing advice from lawyers, who recommend a more conservative attitude, and from other services or individuals, who advise that fish health data does not fall under antitrust restrictions. This lack of clarity around legal boundaries and interpretation of the law, as well as past accusations of collusion against some industry players, created a climate of fear around the subject of exchanging fish health data. Informants evoked the risk of being accused of collusion as an important reason for the producers' reluctance to participate in PIISAC in particular, and for the cautious attitude of the industry to publicly discuss practices in general.

\subsubsection{Generic climate of distrust}

One informant said about Chileans that "it is in our nature not to trust" (interview 01). Many informants described a general atmosphere of distrust within the Chilean industry, affecting all stakeholders for different reasons: between companies, with government services and with third parties. Third parties, academic bodies, government and NGOs were sometimes perceived as potential adversaries due to past use of industry data resulting in negative consequences for producers. Such past events seem to have anchored the climate of distrust faced by PIISAC and other related projects: "one never knows how this will be used against you" (interview 01). One informant said that in the wake of these events, "today the attitude towards information [sharing] is not so open" (interview 14) than it was previously. Several informants reported that obtaining the participation of companies in research projects was notoriously difficult in Chile. The issue of distrust regarding sharing fish health data with a third party appeared to have been a critical factor for deciding whether to participate in PIISAC.

\subsubsection{Concerns related to data privacy}

The element of distrust described above appeared particularly focussed on the issue of data privacy. Although this issue has affected many industry-level projects in the past, most informants reported that the industry is increasingly 
favourable to data integration initiatives. Despite these changes, most informants reported a cautious attitude of companies where their production and health data are concerned. Perceived or potential issues around data confidentiality and privacy were reported as one of the major obstacles to data exchange across the industry. Distrust that strict confidentiality would be adequately maintained during the project was a key reason for companies not participating in PIISAC. For example, one informant mentioned that they had a strong interest in the project but preferred to observe its implementation from the outside for this reason. Another one expressed that they knew from the start that the project could not succeed for the very reason that companies would need to share data. A few informants felt that automatically copying the fish production and health data from source was less acceptable that manually sharing a subset of these data. However, attitudes toward data sharing were varied among the informants. One informant challenged the need for fish production and health data to be kept confidential and that these data are "the heart of the company" (interview 10). Another contrasted the claim of companies to have "nothing to hide" (interview 15) with the strong reluctance to share information. In their opinion, some companies "believe [they] have the latest technology, the latest secrets, but that is not so" (interview 13).

\subsubsection{Collaboration within the industry is difficult}

Informants expressed diverse views on attitudes to collaboration within the industry. Most agreed that it was a complex issue, with views ranging from the Chilean industry "is one of the most collaborative in the world in the area of aquaculture" (interview o9) to "the Chilean industry isn't as open [towards collaboration] as one would think" (interview 01). In general, it appeared that the companies were historically not very transparent about their data and practices and reluctant to collaborate. These attitudes were reported to have changed over time, in particular since the infectious salmon anaemia crisis starting in 2007. This crisis triggered an evolution in practices, as companies realized the need for more collective actions. Although data privacy remains critical, as discussed above, the industry became more open to sharing information. The decreasing number of companies operating in the country (from 21 in 2018 to 18 in 2019) was suggested 
as a facilitating factor in the collaborative process. Another factor is the increasing recognition of the value of research and development activities. While investing in such activities may not be accessible individually for small companies, it may be more cost-effective collectively. Last, companies are increasingly recognizing that they are "carrying out [their] activities on a shared national good" (interview o8) and that the long-term sustainability of these activities depend on industry-wide collaboration.

The extent and impact of these changes to date differed according to different informants. Issues that may remain relevant to date include a general lack of communication and dialogue within the industry and a reluctance to change and innovate. Several informants considered that there is still insufficient collaboration within the industry and that this negatively affects areas such as disease preparedness and early warning. Some mentioned that participation in collaborative projects is a critical issue in Chile but that this issue is not openly discussed within the industry. Others highlighted that there are some recent examples of successful collaborative initiatives in Chile as well as informal collaboration, which demonstrate the improvements achieved over the past few years. The attitudes reported by the informants were very diverse. While some companies appear more likely to choose to work independently only, others are very supportive of collaborative initiatives, with intermediary attitudes being also widespread.

\subsubsection{Importance of competitive advantages}

The reluctance towards collaborative initiatives discussed in the previous section also appeared to relate to the competitiveness within the industry: "there is an issue of competitiveness, of how we do things versus how the rest does them" (interview 15). One informant noted that advancing together as an industry may result in levelling up the competitive advantages of some of the participating companies. The gains from a collaborative initiative benefit the industry as a whole and participating companies individually, but these individual benefits may vary by company. In such situations, the cost-benefit analysis of participating in a collaborative initiative is not necessarily positive. Such balance depends on the 
respective weight given to individual company interests versus interests for the industry as a whole. In this regard, a condition for participation is that the project's objectives are "in alignment with [the company's] interests" (interview 04). A few informants thought that even in the absence of direct individual company benefits, companies should show the example by participating. In their opinion, all companies would ultimately benefit, and a long-term vision should prevail.

Some informants strongly associated the concept of analysing integrated data with the loss of the specificity of individual farm sites, in terms of local management, personnel and environmental conditions. The availability of tailored information was highly valued, as it allowed "taking into account [their] own realities at each sea site and its environment” (interview 12) in the decision-making process. In a few cases, this attitude was linked to the company being different from the rest of the industry, in terms of practices, the geographical distribution of sites or the choice of salmonid species, for instance. The benefits of data integration appeared smaller for these companies due to these distinguishing characteristics, influencing their decision to participate.

Informants largely agreed that most initiatives in the Chilean industry, including PIISAC, face similar problems when it comes to securing participation. The absence of an industry body representing the entire industry was cited as an issue for such industry-wide initiatives. As there is currently no pathway for collective decision making, transversal projects must secure participation individually, a difficult process as discussed in these two sections. Consequently, some informants reported that they felt their companies were disconnected from the rest of the industry.

\subsubsection{Complex industry-government relationship}

Many informants reported an underlying distrust in industry-government relationships. Some government measures were deemed as not science-based, and others as harmful to businesses. In addition, informants argued that government initiatives tend to lag behind situations of concern, and not address current problems in a timely manner. As such, industry-led initiatives were judged more useful and appropriate than government ones. Several informants considered that 
the government did not consult the producers enough when developing policy or that government policies were too repressive. As a result, the current relationship between government and industry appeared tense and complex. This climate of suspicion and distrust was deemed to affect participation in governmentsupported initiatives such as the program to which PIISAC belonged. This may have created distrust in the project, due to the concern that government may obtain access to the data provided by participating companies. Even if confidentiality were maintained, one informant expressed suspicions that the project outputs may be used to develop additional regulations that would burden the industry.

By contrast, several informants reported that the industry-government relationship had vastly improved over time. As mentioned previously regarding within-industry dynamics, the infectious salmon anaemia crisis had fostered improvements in the government-industry working relationship as well. While past government initiatives had not been highly valued by industry, the recent industry-government partnership, including PIISAC, had shown significant improvement in that area. Voluntary government initiatives using incentives were deemed more successful than compulsory programs associated with sanctions. In this context, several possible effects of the industry-government relationship on participation in PIISAC were reported by informants. Some reported that the participation of government services can make initiatives more robust and give them additional credit, especially in the public opinion, while others thought it was an obstacle. Two informants reported that they "felt forced to participate at first" (interview 19) due to the involvement of the government. Another informant considered that Chilean companies tend to participate only when obliged to, contrasting it to the attitude in some other countries were companies "act on [their] own responsibility" (interview 18).

\subsubsection{Competing priorities in 2018}

Several informants from companies which did not participate in PIISAC reported that this was mainly due to competing priorities at the time. At the individual level, company employees are solicited by many internal and external demands, such as internal IMS enhancements and projects such as PIISAC, which 
they prioritize for action. At the company level, several merging and selling operations were under negotiation or implementation in 2018. These activities were cited by several informants as preventing participation in PIISAC, either due to unclear strategies at the time or to the ongoing transfers of decision-making power. Last, at the industry level, adjustments in practices and management required to meet regulatory changes around the time of PIISAC implementation were also mentioned as a competing priority.

The topics covered in this theme summarize the obstacles faced by the project that were related to the context and environment of its implementation. The second theme gathers issues reported by informants related to the PIISAC project itself that affected its long-term sustainability.

\subsection{Issues linked to the project implementation}

Most informants reported supporting the project at the beginning of its implementation but felt that their interest faded over time. Reasons for initial support included the potential of PIISAC to provide additional benefits over existing tools, hope that the industry coverage would be higher than that of existing services, interest in gaining new knowledge regarding the management of $P$. salmonis and sea lice on farms, assurances provided about data security aspects as well as an approach that appeared different from previous initiatives. In this section, we analysed the possible issues which may have led to this drop in the initial level of support.

\subsubsection{Results did not meet expectations}

Although informants reported high initial expectations from PIISAC, most considered that the epidemiological risk factor studies based on the PIISAC data (hereafter referred to as 'studies') obtained by the end of 2018 had not met those expectations. Two different reasons were suggested by informants: some thought that there were inconsistencies between the studies' results and existing knowledge within their companies or the industry in general. On the other hand, the majority of informants thought that the results were not novel and that they did not contribute additional information to what was already known in the industry: "the 
answers that we got were obvious answers. We already knew that" (interview 11). Most informants reported frustration with the results, as they felt that these results did not provide applicable solutions to the industry for the main issue at hand ( $P$. salmonis). However, a few informants considered that the studies' results were interesting as they provided evidence to support existing informal knowledge. This disappointment with the studies was reported as the key reason for companies discontinuing their support to PIISAC. The staff from participating companies were not convinced that this tool would help them improve their own fish health management and therefore that it justified further support and investment. One informant summarized their concern as "there was no benefit in the future use of the platform" (interview 17). Several informants said that the participating companies did not perceive additional benefits from using PIISAC compared with existing data service providers, resulting in drop-out at the end of 2018.

\subsubsection{Quality of the data and analyses}

Many informants expressed doubts regarding the quality and accuracy of the study results because they felt that the data verification and cleaning process had not been adequate. Consequently, they did not trust the validity of the input data used in the studies. "Without fixing these data, we aren't going anywhere" (interview 04). Some informants were confident that there was potential in PIISAC to provide more robust results in a following phase, given that the first studies were conducted over a short time frame. The lack of data standardisation existing across the industry was cited as a key issue affecting the data verification and cleaning process. This may have affected the nomenclature of veterinary products such as vaccines for example. Some informants considered that the complexity of the data and the diversity in data recording practices had not been sufficiently taken into account in the studies. In addition, some informants did not fully understand or agree with the analytical methodology used in PIISAC's studies. Last, some informants reported that including economic aspects in the analyses would have substantially increased the usefulness of the results for decision making. 
A couple of informants reported that they did not "consider [costs] as a barrier" (interview 11) or that "maybe this cost was worth it" (interview 19). However, several others mentioned the cost of participation in PIISAC from 2019 onwards as a reason for the drop-off of participating companies. They considered that the cost-benefit analysis was not in favour of ongoing support due to the low perceived benefits once participation became associated with a fee. One informant felt that scientists in general tend to present research outputs in terms of their scientific value, with a lesser emphasis on presenting the expected "impact translated into numbers" showing the economic benefits (interview 13).

\subsubsection{PIISAC as a foreign initiative}

Several informants reported that language and geographic distance had acted as barriers during the implementation of PIISAC. They felt that the use of translation services was insufficient to develop effective communication and understanding by all stakeholders involved. The concerns related to sharing data with a third party (see above) were amplified by the facts that this third party was not a Chilean company and that the data would be stored outside of Chile. This was deemed by informants to have raised too much uncertainty regarding data security and confidentiality. One informant felt that such a project "has to have presence, office, servers here, based in Chile" (interview 16).

The project team being based abroad, some informants reported that there were insufficient in-person interactions to allow for solid trust building and obtaining full industry support. One informant said that "there was lacking a little promotion and initiative from their side to promote the platform more" (interview 14). Some informants raised the importance of a previous working relationship with the team proposing such an initiative as well as a solid track record of implementing such initiatives. 
Some informants considered that the project team did not spend enough time understanding the industry's dynamics and analysing the needs of the companies before developing PIISAC. One informant felt that this was a common feature of government-initiated efforts, which should be "a little more inclusive" (interview 07) instead. Another informant reported that the platform collated lots of data but "lack[ed] direction in getting the best value out of it" (interview 15). They suggested that a more active participation of companies in the analyses would have provided such direction.

While informants reported that the project team had expertise in terms of epidemiology and statistical analysis, several informants considered that the project team lacked local expertise in terms of practices and products to assist with the data verification and cleaning process as well as the interpretation of results. Close interaction between the producers and the data service providers was reported as key to support and improve the data integration process. For instance, the company's technicians and veterinarians can provide additional key information that is not recorded in the fish health and production database and can substantially affect the interpretation of these records.

\subsubsection{Lack of understanding regarding privacy and security}

As detailed under the first theme, data security and confidentiality were a key concern among the companies. It appeared that some of the informants did not trust that the data transfer and analysis process used in PIISAC would meet these objectives. A few informants also mentioned a lack of understanding around the proposed security and privacy-related aspects of the project. One informant was concerned about the uncertainty around the future use of the datasets. Another informant said that the industry needed more clarity on what would happen to PIISAC after the project, its future objectives and also what would potentially be made public in time. Overall, these elements may have amplified the initial distrust around sharing data with a third party, as reported by this informant: "when you 
don't understand the mechanism very well [...], there will always be a certain amount of doubt” (interview 05).

\subsubsection{Project timeline was too short}

An informant referred to a previous large collaborative initiative on sea lice in Norway, which lasted more than six years, to highlight that such initiatives require long-term efforts. Many informants mentioned the project timeline as one of the key challenges for PIISAC. They reported that data integration, standardization, validation and epidemiological analysis were time-consuming tasks, and that, consequently, the 12-month funding of PIISAC was too short. One informant said that PIISAC was still at an early stage by December 2018, "it was too new" (interview 06). For this reason, the potential of the platform to provide industry benefits had not been realized yet by the time that financial commitment was sought from the companies: "given the time it took for the companies to start participating, we were not able to obtain all of the information and to analyse all of the information" (interview 13). Some informants regretted that the project had not delivered a fully functional online user interface by the end of 2018. One informant said that this interface could have helped people to demonstrate the usefulness of PIISAC within their own companies to stimulate ongoing participation.

Given more time, several informants thought that PIISAC would have been able to integrate a broader range of data, produce more and better analytical results, as well as become integrated as a new tool in the companies' existing processes. In addition, one informant mentioned that the participating companies "did not know how to organize themselves in establishing guidance for a platform like this" (interview 17). Several informants suggested that the government should have provided support for a second phase to enable these issues to be resolved. They considered that once PIISAC would have had demonstrated the benefits that it can provide, the industry would have been much more likely to endorse the ongoing costs. 
The recruitment of companies was also a time-consuming activity. Some of the informants reported that their companies had not been able to join, as by the time they had dealt with other priorities or obtained high-level authorizations, the project was closing: "we were left at the stage of trying to join and transfer our information" (interview 15). One informant considered that the participation in PIISAC increased at too slow a pace, generating doubts for the remaining companies and causing the initiative to significantly lose momentum. Informants felt that participation had influenced the success of the platform in two ways. First, the quality, robustness and validity of the results were influenced by the number of companies which data were included. A higher level of participation would have allowed the results to better represent the industry reality. Second, informants felt that a high level of participation would have decreased the perceived risks related to confidentiality of the shared information.

Overall, the level of participation in PIISAC was mentioned by many informants as a key factor. Several informants initially expected that this level would be rather high, given that it was free for the duration of the project: "it was another opportunity of integrating data in the industry where there was more participation than what [existing data service providers] had" (interview 02). An initiative which would gather the entire industry would have much higher chances of being sustainable according to the informants. Such an initiative would have a distinct advantage over existing data service providers and other initiatives, which lack complete coverage: "these tools are the correct ones, or they contribute a lot. What happens is that the representativity is not what you want" (interview 12).

\subsubsection{Considering internal company dynamics}

Several informants mentioned that while veterinarians and fish health managers are generally aware of the value of industry-wide information to support decision making, general managers give more weight to data privacy concerns and economic benefits of participation than technical employees. While technical staff can champion the project within their own team and contribute to the decision 
outcome, some informants believed that the efforts of the project team to convince the decision-makers directly had not been sufficient: "it needed a little more convincing" (interview 10). Last, some informants reported that a company's decision to participate might rely on only one person who would be strongly supporting or rejecting participation.

3.2.10. Data integration requires joint efforts

Finally, several informants considered that the success of data integration initiatives requires joint efforts from all parties, and that participation does not only rely on providing data but also contributing substantial staff time to the initiative. One informant felt that this time (in workshops, for instance) would have helped to design the studies and outputs that the companies really wanted. Another informant said that many participating companies "didn't take the project seriously" (interview 13). Others reported some unrealistic expectations on the industry side, "they believe that science solves problems immediately, but these are very different timelines" (interview 10). The expectations of quick results were deemed as damaging for the platform, as they did not allow for the research to occur and created impatience. Last, a few informants thought that the project lacked a strong in-country leader (or leaders) to drive the implementation of the platform: "you have to have someone behind it to make things happen" (interview 20). It was suggested that the appointment of a spokesperson by the industry would have facilitated the communication between the stakeholders, including platform implementer, industry and others such as government, and coordinate their involvement.

\section{Discussion}

This study analysed the possible reasons why an industry-based data integration platform to support epidemiological research in farmed salmonids in Chile was not sustainable. The interviews, conducted after the end of the project, provided valuable insights into the perspectives and decision-making processes of key stakeholders. Informants generally saw data integration as a worthwhile activity, expressed the need for more data analysis to support decision making, and 
considered that working collectively as an industry would make the production more sustainable in time. However, they also highlighted many issues and concerns, which were categorized under two broad themes during the analysis. The first theme gathered aspects related to the industry context, while the second dealt with issues identified by the informants in relation to the project itself. It is important that the lessons learned from this study can be considered when designing future data integration initiatives, to increase the likelihood of long-term adoption and support of these initiatives by stakeholders.

Although industry collaboration in Chile started as early as the late $1980 \mathrm{~s}$ with the creation of SalmonChile, none of the initiatives to date has gathered all the producers at once. The industry association gathered 11 producers as of 2020 (SalmonChile 2020), suggesting the difficulty to foster industry-wide collaboration in Chile. Thus, the platform appeared to have been implemented in a difficult environment, which may have explained the moderate uptake of the platform during the first year (50\% of the companies). Many of the barriers to data integration identified in our study were similar to those previously identified in the public health sector (van Panhuis et al. 2014), suggesting that these barriers are not specific to the aquaculture sector. Commercial interests, privacy concerns and general lack of trust between stakeholders and towards third parties are critical challenges to overcome for collaborative efforts. Unfair competition and misuse or monetization of data are recognized as potential risks from data integration initiatives, for instance, in agriculture (Maru et al. 2018). In addition, the complexity of data governance in commercial settings was identified as one of the major challenges for big data in agriculture (Weersink et al. 2018).

While informants generally reported that the platform was valuable for the industry, many felt that it needed further work to be considered as a tool with longterm potential. The concerns of the informants in relation to the results from PIISAC studies were diverse. Some valued the results as they provided evidence to confirm or dispute existing knowledge, but many felt that the results did not meet their expectations. This is critical, as new initiatives such as PIISAC need to compete for attention and resources with existing data service providers. In addition to the longer-term research outputs, PIISAC also intended to provide 
companies with user-friendly access to and visualization of their own data, in nearreal time, via an online interface. Although existing information management systems provide some analytical capacity to support everyday decision-making, informants expressed the need for improved use of data for health management on a routine basis within companies. Further development of the interface would have likely been beneficial, as it would have provided more immediate benefits in comparison with the perhaps less tangible benefits of larger-scale epidemiological studies for company staff concerned by everyday challenges. The present study highlights the opportunity for targeted solutions which would complement existing information management systems in processing data into information. In summary, most of the informants in this study were not convinced that the expected benefits justified the costs involved by participation by the end of the first year. This view is likely to have been important in the decision of participating companies not to continue their support to PIISAC in 2019.

Many of the findings presented in this study demonstrated a gap between the way in which the platform was designed to address known challenges and stakeholder concerns and informants' perceptions of these concerns. For instance, all communication materials were translated in Spanish, while a simultaneous translation service was used during workshops. Despite these efforts, participants reported that language was a barrier in the project. Other areas where a mismatch between design principles and participant perceptions was noted include respect of the antitrust laws and data security, access and confidentiality. We were not able to determine whether the measures to address these issues in PIISAC were inadequate in their design or implementation, whether the measures taken were not effectively communicated, or whether the project duration was not sufficient to build the required trust. This is a key lesson for future initiatives, as efforts towards project design alone are not sufficient, and communication efforts and the development of trust are equally important to counterbalance existing perceptions and cultural values.

The constraints and limitations of the 'project' framework and implementation schedule have been long recognized in the domain of international development (Chambers 1995; Craig and Porter 1997). A key lesson from 
international development which can be extended to the present commercial settings is the need to create space for the ideas of stakeholders to allow for sustainable participation. There is a large body of literature relating to best practices for stakeholder engagement in fields other than international development, for instance in relation to animal health (Allepuz et al. 2017) and environmental management (Reed 2008). In our study, stakeholder engagement appeared to have been the most important factor influencing the outcome of the initiative. Challenges associated with participation in PIISAC were similar to challenges identified for stakeholder participation in an evaluation of strategies for improving the management of fisheries in the US (Goethel et al. 2019). Some of the challenges identified by these authors are establishing and maintaining trust, unfamiliarity with analytical approaches and translation of results to workable solutions. Our study emphasizes the need for in-country presence in such projects to help overcome these challenges and lead the participant recruitment process. Such a key, labour-intensive role is critical for maintaining continuity in participation and should be a core component of the project plan.

Research in the diffusion process of interactive media in the late $1980 \mathrm{os}$ proposed the concept of "critical mass" (Markus 1987). The adoption of an innovation related to communication is slow until the number of users exceeds this critical mass, after which the adoption process becomes self-sustaining. This property was used by Markus (1987) to explain the increased vulnerability of new systems in the early stages of implementation. In the case of PIISAC, this selfsustaining process can be linked to two features. First, the benefits of collaboration were perceived as more likely to be realized once broad participation in the initiative was secured. Second, the perceived risks, for instance related to data privacy, were perceived as inversely correlated to the number of participants. For these reasons, the broad adoption of such an initiative starts with the early participation of some companies, called "innovators" in diffusion theory (Rogers 2003), who are less risk-averse than their peers. Roger's diffusion theory has been widely used in many disciplines (Haider and Kreps 2004), for instance in the medical research literature to help understand the adoption of telehealth (Helitzer et al. 2003; Spaulding et al. 2005; Walker and Whetton 2002; Brooks et al. 2012). 
The theory identifies four main areas which interact in influencing the adoption of an innovation (Rogers 2003): the social system in which it is deployed, the attributes of the innovation itself, time and communication. In our study, the industry environment was explored in the first theme, while the attributes of the project were explored in the second theme. The effects of time and communication were closely linked to the project implementation itself and were therefore grouped with the project attributes when structuring the results. Within each theme, identifying the sub-themes from the data itself allowed us to better represent the similarities and differences between the codes identified in our dataset. The specific elements discussed by Rogers (2003) regarding the social system, the stages of the diffusion process and communication networks were not well adapted to analyse and interpret the PIISAC data, given that the participants were companies rather than individuals. This difference substantially affected the adoption process and the way decisions were made. However, the issues linked to the project implementation (see above) appear to closely reflect the attributes required for successful diffusion of innovations, i.e., relative advantage, compatibility, complexity, trialability and observability, as well as the critical mass factor. In addition, the stages of the diffusion process provided a useful framework for structuring the interviews.

Lessons learned from this study can improve the design of future data integration initiatives in the field of fish production as well as other commercial animal production where digital information management systems are used (i.e., poultry, pigs and dairy). As this study was conducted in one particular country and industry, it is expected that the importance of these challenges may vary in other settings. While collaborative initiatives appear to be welcomed by the industry, high-quality outputs should be delivered rapidly to maintain interest, such as practical solutions that may be directly used to improve fish health on farms. Substantial in-country presence is recommended to build and maintain trust with the stakeholders. Clarity regarding data management, privacy and ownership is key to establish this trust. The time to obtain formal agreement and set up the data integration process should not be under-estimated. To this effect, key executive 
staff in charge of decision-making must be targeted in addition to technical, veterinary and research staff.

For future initiatives, context-specific challenges related to the environment and the stakeholders may be identified by conducting targeted consultations during the design stage of the partnership. These consultations allow the design of a suitable implementation plan to better overcome barriers and address the needs of the participants. Such consultations are critical to ensure the long-term participation of the stakeholders and the sustainability of the initiative, as shown by the results of this study.

\section{Acknowledgments}

The authors acknowledge the staff from the Chilean National Fisheries and Aquaculture Service (Sernapesca), representatives from the Chilean Salmon Industry Association (SalmonChile) and the companies for supporting this project. We are grateful to all our informants for their contribution and to Nancy Rose for the interviews and translation of the interview materials.

\section{Funding}

Between December 2017 and December 2018, the PIISAC initiative was developed within a project that was part of the Programa para la gestión sanitaria en la Acuicultura supporting research into salmonid rickettsial septicaemia and sea lice in the salmon industry in Chile. It was jointly funded by the Chilean government (Ministry of the Economy Training and Tourism), the Chilean salmon producers' association (SalmonChile). The interviews conducted for the present study were funded by Ausvet Europe. 


\section{References}

Allepuz, Alberto, Katinka De Balogh, Ryan Aguanno, Martin Heilmann, and Daniel Beltran-Alcrudo. 2017. "Review of Participatory Epidemiology Practices in Animal Health (1980-2015) and Future Practice Directions." PloS One 12 (1): e0169198.

Berckmans, D. 2014. "Precision Livestock Farming Technologies for Welfare Management in Intensive Livestock Systems." Revue Scientifique et Technique de l'OIE 33 (1): 189-96. https://doi.org/10.20506/rst.33.1.2273.

Braun, Virginia, and Victoria Clarke. 2006. "Using Thematic Analysis in Psychology." Qualitative Research in Psychology 3 (2): 77-101. https://doi.org/10.1191/1478088706qpo63oa.

Braun, Virginia, and Victoria Clarke. 2014. "What Can 'Thematic Analysis' Offer Health and Wellbeing Researchers?” International Journal of Qualitative Studies on Health and Well-Being 9 (October). https://doi.org/10.3402/qhw.v9.26152.

Brooks, Elizabeth, Spero M. Manson, Byron Bair, Nancy Dailey, and Jay H. Shore. 2012. "The Diffusion of Telehealth in Rural American Indian Communities: A Retrospective Survey of Key Stakeholders." Telemedicine Journal and E-Health 18 (1): 60-66. https://doi.org/10.1089/tmj.2011.0076.

Chambers, Robert. 1995. "Poverty and Livelihoods: Whose Reality Counts?" Environment and Urbanization 7 (1): 173-204.

Craig, David, and Doug Porter. 1997. "Framing Participation: Development Projects, Professionals, and Organisations.” In Development and Patronage Selected Articles from Development in Practice, p50-57. Oxford, UK: Oxfam (UK and Ireland).

Emanuelson, U. 1988. "The National Swedish Animal Disease Recording System." Acta Veterinaria Scandinavica. Supplementum 84: 262-64.

FAO. 2018. "The State of World Fisheries and Aquaculture 2018 - Meeting the Sustainable Development Goals." Food and Agriculture Organization of the United Nations, Rome, Italy.

Faverjon, Céline, Abraham Bernstein, Rolf Grütter, Christina Nathues, Heiko Nathues, Cristina Sarasua, Martin Sterchi, Maria-Elena Vargas, and John 
Berezowski. 2019. "A Transdisciplinary Approach Supporting the Implementation of a Big Data Project in Livestock Production: An Example From the Swiss Pig Production Industry." Frontiers in Veterinary Science 6. https://doi.org/10.3389/fvets.2019.00215.

Føre, Martin, Kevin Frank, Tomas Norton, Eirik Svendsen, Jo Arve Alfredsen, Tim Dempster, Harkaitz Eguiraun, et al. 2018. "Precision Fish Farming: A New Framework to Improve Production in Aquaculture." Biosystems Engineering, Advances in the Engineering of Sensor-based Monitoring and Management Systems for Precision Livestock Farming, 173 (September): 176-93. https://doi.org/10.1016/j.biosystemseng.2017.10.014.

Gentles, Stephen J, Cathy Charles, Jenny Ploeg, and K Ann McKibbon. 2015. "Sampling in Qualitative Research: Insights from an Overview of the Methods Literature" 20 (11): 1772-89.

Goethel, Daniel R, Sean M Lucey, Aaron M Berger, Sarah K Gaichas, Melissa A Karp, Patrick D Lynch, John F Walter III, Jonathan J Deroba, Shana Miller, and Michael J Wilberg. 2019. "Closing the Feedback Loop: On Stakeholder Participation in Management Strategy Evaluation.” Canadian Journal of Fisheries and Aquatic Sciences 76 (10): 1895-1913.

Haider, Muhiuddin, and Gary L Kreps. 2004. "Forty Years of Diffusion of Innovations: Utility and Value in Public Health." Journal of Health Communication 9 (S1): 3-11.

Happold, J, A Meyer, R Sadler, B Cowled, C Mackenzie, AL Gallardo Lagno, and A Cameron. 2020. "Effectiveness of Antimicrobial Treatment of Salmonid Rickettsial Septicaemia in Commercial Salmon and Trout Farms in Chile.” Aquaculture 525:

735323 . https://doi.org/doi.org/10.1016/j.aquaculture.2020.735323.

Happold, J, R Sadler, A Meyer, B Cowled, C Mackenzie, AL Gallardo Lagno, and A Cameron. 2020. "Effectiveness of Vaccination for the Control of Salmonid Rickettsial Septicaemia in Commercial Salmon and Trout Farms in Chile." Aquaculture 520: 734968. https://doi.org/10.1016/j.aquaculture.2020.734968.

Helitzer, Deborah, Debra Heath, Kristine Maltrud, Eileen Sullivan, and Dale Alverson. 2003. "Assessing or Predicting Adoption of Telehealth Using the 
Diffusion of Innovations Theory: A Practical Example from a Rural Program in New Mexico." Telemedicine Journal and E-Health 9 (2): 179-87. https://doi.org/10.1089/153056203766437516.

Hoel, T. 2018. "Data Science Helps Norway's Fish Farmers Keep Salmon Populations Healthy." IBM Cloud Computing News - Big Data (blog). September 17, 2018. https://www.ibm.com/blogs/cloud-computing/2018/o9/17/datascience-norway-fish-farmers/.

Huang, Ronggui. 2018. RQDA: R-Based Qualitative Data Analysis. http://rqda.r-forge.r-project.org. Accessed January 15, 2020.

Hutchison, Jennifer, Catriona Mackenzie, Ben Madin, Jonathan Happold, Edwina Leslie, Emma Zalcman, Anne Meyer, and Angus Cameron. 2018. "New Approaches to Aquatic and Terrestrial Animal Surveillance: The Potential for People and Technology to Transform Epidemiology." Preventive Veterinary Medicine, October. https://doi.org/10.1016/j.prevetmed.2018.10.009.

Markus, ML. 1987. "Toward a 'Critical Mass' Theory of Interactive Media: Universal Access, Interdependence and Diffusion." Communication Research 14 (5): 491-511. https://doi.org/10.1177/009365087014005003.

Maru, Ajit, Dan Berne, Jeremy De Beer, Peter G Ballantyne, Valeria Pesce, Stephen Kalyesubula, Nicolene Fourie, Chris Addison, Anneliza Collett, and Juanita Chavez. 2018. "Digital and Data-Driven Agriculture: Harnessing the Power of Data for Smallholders.” White Paper. Global Forum on Agricultural Research and Innovation.

McGreevy, Paul, Peter Thomson, Navneet K Dhand, David Raubenheimer, Sophie Masters, Caroline S Mansfield, Timothy Baldwin, et al. 2017. "VetCompass Australia: A National Big Data Collection System for Veterinary Science.” Animals 7 (10): 74 .

Meyer, A, Burroughs, A, Sadler, R, Happold, J, Cowled, B, C Mackenzie, Gallardo Lagno, AL, and A Cameron. 2019. "Quantifying the Effects of Sea Lice Burden and Lice Bathing Treatments on Salmonid Rickettsial Septicaemia in Commercial Salmon and Trout Farms in Chile.” Aquaculture 513: 734411. https://doi.org/10.1016/j.aquaculture.2019.734411. 
O’Donncha, Fearghal, and Jon Grant. 2019. "Precision Aquaculture.” IEEE Internet of Things Magazine 2 (4): 26-30. https://doi.org/10.1109/IOTM.0001.1900033.

OIE. 2019. "The OIE PPP Handbook: Guidelines for Public-Private Partnerships in the Veterinary Domain.” Paris, France: World Organisation for Animal Health. https://www.oie.int/publicprivatepartnerships/ppp/en/Handbook_en.html.

O’Neill, DG. 2012. "VetCompass Clinical Data Points the Way Forward." Veterinary Ireland Journal 2 (7): 353-356.

Panhuis, Willem G. van, Proma Paul, Claudia Emerson, John Grefenstette, Richard Wilder, Abraham J. Herbst, David Heymann, and Donald S. Burke. 2014. "A Systematic Review of Barriers to Data Sharing in Public Health." BMC Public Health 14 (1): 1144. https://doi.org/10.1186/1471-2458-14-1144.

R Core Team. 2019. R: A Language and Environment for Statistical Computing. $\mathrm{R}$ Foundation for Statistical Computing, Vienna, Austria. https://www.r-project.org/.

Reed, Mark S. 2008. "Stakeholder Participation for Environmental Management: A Literature Review.” Biological Conservation 141 (10): 2417-31. https://doi.org/10.1016/j.biocon.2008.07.014.

Robinson, Oliver C. 2014. "Sampling in Interview-Based Qualitative Research: A Theoretical and Practical Guide." Qualitative Research in Psychology 11 (1): 25-41. https://doi.org/10.1080/14780887.2013.801543.

Rogers, Everett M. 2003. Diffusion of Innovations. 5th edition. Simon and Schuster.

SalmonChile. 2020. "Quiénes Somos: Socios." 2020. https://www.salmonchile.cl.

Shekhar, Shashi, Patrick Schnable, David LeBauer, Katherine Baylis, and KV Waal. 2017. "Agriculture Big Data (AgBD) Challenges and Opportunities from Farm to Table: A Midwest Big Data Hub Community Whitepaper." White Paper for the US National Institute of Food and Agriculture.

Spaulding, Ryan J., Tracy Russo, David J. Cook, and Gary C. Doolittle. 2005. "Diffusion Theory and Telemedicine Adoption by Kansas Health-Care Providers: 
Critical Factors in Telemedicine Adoption for Improved Patient Access.” Journal of Telemedicine and Telecare 11 Suppl 1: 107-9. https://doi.org/10.1258/1357633054461903.

Steven, Andrew D. L., Santosh Aryal, Patricio Bernal, Francisco Bravo, Rodrigo H. Bustamante, Scott Condie, Jeffrey M. Dambacher, et al. 2019. "SIMA Austral: An Operational Information System for Managing the Chilean Aquaculture Industry with International Application.” Journal of Operational Oceanography o (o): 1-18. https://doi.org/10.1080/1755876X.2019.16366o6.

Stubb, Megan. 2016. "Big Data in US Agriculture.” Congressional Research Service Washington, DC.

Tong, Allison, Peter Sainsbury, and Jonathan Craig. 2007. "Consolidated Criteria for Reporting Qualitative Research (COREQ): A 32-Item Checklist for Interviews and Focus Groups." International Journal for Quality in Health Care 19 (6): 349-57. https://doi.org/10.1093/intqhc/mzmo42.

Walker, Judi, and Sue Whetton. 2002. "The Diffusion of Innovation: Factors Influencing the Uptake of Telehealth.” Journal of Telemedicine and Telecare 8 Suppl 3 (6): 73-75. https://doi.org/10.1258/13576330260440934.

Weersink, Alfons, Evan Fraser, David Pannell, Emily Duncan, and Sarah Rotz. 2018. "Opportunities and Challenges for Big Data in Agricultural and Environmental Analysis.” Annual Review of Resource Economics 10 (1): 19-37. https://doi.org/10.1146/annurev-resource-100516-053654. 


\section{Supplementary material}

Supplementary material 1: interview guide

Study title: Adoption of a novel data integration tool within the Chilean salmon industry

Lead researcher: Anne Meyer

Interviewer: Nancy Rose

Suggested questions and comments are in normal font font while instructions for the interviewer are in italic font.

\section{Introduction}

Thank you for agreeing to participate in this interview. We are interested in finding out your views on what might have influenced the adoption of an integrated industry data platform which was developed in 2018 through the PGSA program. You may or may not remember about the PIISAC Research Platform. Some in the industry were more involved than others, so, first, I am going to show you a short video and an information sheet about the work to help you remember it. Then I would like to get your formal consent to participate in the interview.

Play the introductory video to the participant. Hand out the information sheet. Once the interviewee has read it, ask whether they have any questions about the study or the interview. Answer any questions they may have.

For specific questions about the PIISAC Research Platform that you cannot directly answer (e.g., why was PIISAC shut down or what is Ausvet's future role?), please note these down. Then, send the questions to us as soon as possible (with details of who asked them and any contextual information you think useful) and assure the participant that we will respond to them promptly. 
I would like to assure you again that the privacy of your responses will always be maintained. If you agree with this, let us both sign the consent form.

Sign the two copies of the consent forms (pages 2 and 3) and have the participant do the same. Leave Pages 1 and 2 with them and keep Page 3 for our records.

I would like to clarify my role in the study. I have been involved in workshops as an interpreter, and now I am talking with you. However, I did not have any role in the design or implementation of PIISAC. Now, let us start the interview. Are you still OK if I record this interview?

Make sure that the conversation cannot be overheard by other people. Turn on the voice recording device.

\section{Interview topics}

This guide only represents the main themes to be discussed with the interviewee. Example prompts are provided as examples. Non-leading and general prompts may also be used, such as "Can you please tell me a little bit more about that?" or "What else do you remember?"

\section{Interview topic 1: Need for a platform}

First, I want to talk about fish health-related data and how it is managed, analysed and used. How does your company manage and use its fish health data?

What do you think of your current data management system in terms of how well it is able to help you and others with health-related decision making?

Prompts: how helpful is the system when making decision about treatments or understanding disease patterns for example?

How could the current data management system be improved to allow you to use and analyse data better? 
What specific issues and challenges have you or your company encountered with existing tools?

What needs in terms of fish health data management are not currently met by existing tools?

Interview topic 2: Initiatives in the industry

According to you, what is the general attitude in the Chilean industry towards collaborative initiatives?

What do you think is the general attitude in the Chilean industry towards initiatives from the government?

In your view, what is the general attitude in the Chilean industry towards research initiatives?

Interview topic 3: Data integration

What do you understand by the term 'data integration'?

What tools or programs related to integrating fish health data within the industry are you aware of?

What do you think are the benefits of integration of fish-health data?

What do you think are the obstacles and barriers to integration of fish-health data?

What issues and challenges have you or your organization encountered with existing tools or systems which integrate fish-health data? 
Before we look at more specific aspects, can you tell me about what involvement you had with PIISAC?

How did you first become aware of the PIISAC Research Platform?

How did you feel about the availability and quality of information provided by Ausvet and others about the Research Platform?

What did you think of the PIISAC project at the beginning of the implementation (early 2018)?

How did your impressions and opinions change by the end of the project (early 2019)?

What did you think of the way that Ausvet introduced the Research Platform during the workshops?

What did you think of the way that Ausvet informed you about the Platform via emails, Whatsapp and website posts?

Which mode of communication used to keep in touch with you was most effective?

How responsive was Ausvet to queries about the Research Platform?

Interview topic 5: Initial adoption of PIISAC

In this section, I am going to ask you questions about the initial participation in PIISAC, during 2018, when it was funded by the PGSA program.

In your opinion, were there benefits of using the PIISAC Research Platform? 
If 'yes': can you tell more about these benefits?

Prompts: Think of both private and public good benefits.

Were there benefits that you expected from the platform but did not feel were realized by it?

If 'yes': can you tell more about these?

Companies only: Which reasons were taken into consideration by your company to participate or not participate in PIISAC?

In your opinion, were there any challenges or disadvantages of using the PIISAC Research Platform?

If 'yes': can you tell more about these?

Companies only: Were there any constraints or challenges not related to PIISAC itself that influenced the decision of your company to participate or not participate?

Non-company interviewee: According to you, which other constraints or challenges influenced the decision of the companies to participate or not participate in PIISAC?

Interview topic 6: Transition to industry ownership

In this section, we will talk about the attempts to transition PIISAC to an ongoing, industry-led and funded research platform after the PGSA funding ended.

Did your company support the continued use of PIISAC in the industry after December 2018?

According to you, what were the reasons that influenced this decision?

What did you think about your company's decision? 
In your opinion, what were the reasons that the platform did not get more buy-in from the rest of the industry at the end of the PGSA funding?

What other business or management models could have been tried to support the continued use of the Research Platform?

\section{$\underline{\text { Conclusion }}$}

Do you have any additional comments or impressions you would like to share with me?

Thank you very much for your time and the information you shared today. Now, turn off the voice recording device. 


\section{CHAPTER 6}

\section{Current status of veterinary epidemiological research in two species regarding the FAIR guiding principles}

Anne Meyer ${ }^{\mathrm{a}}$, Céline Faverjon ${ }^{\mathrm{a}}$, Miel Hostens ${ }^{\mathrm{b}}$, Arjan Stegeman ${ }^{\mathrm{b}}$, Angus Cameron ${ }^{\mathrm{a}}$

a Ausvet Europe, 69001 Lyon, France

b Utrecht University, Department of Farm Animal Health, 3512 JE Utrecht, the Netherlands

Manuscript submitted for publication to Scientific Data (January 2021) 


\begin{abstract}
The FAIR principles proposed in 2016 have set the path towards reusability of research data objects. In this work, we present a systematic review of the FAIRness of datasets associated with peer-reviewed articles in veterinary epidemiology research, specifically looking at salmonids and dairy cattle. In this study, we considered the differences in practices between molecular epidemiology, the branch of epidemiology using genetic sequences of pathogens and hosts to describe disease patterns, and non-molecular epidemiology. A total of 152 articles were included in the assessment. Consistent with previous assessments conducted in other disciplines, our results showed that most datasets used in non-molecular epidemiological studies were not available (i.e., neither findable nor accessible). Data availability was much higher for molecular epidemiology papers, in line with a strong repository base available to scientists in this discipline. The available data objects generally scored favourably for Findable, Accessible and Reusable indicators, but Interoperability was more problematic. The latter may require specific skills in data management which are not yet broadly available in the epidemiology community.
\end{abstract}

\title{
Key words
}

Veterinary epidemiology, FAIR, data access, salmonids, dairy cattle 


\section{Introduction}

The FAIR (Findable, Accessible, Interoperable, Reusable) guiding principles were first published in 2016, providing a foundation to support increased of scientific data (Wilkinson et al., 2016). Mons et al. (2017) highlighted that FAIR is a continuum, which they represented with six levels, from "re-useless data" to "FAIR data with open access and functionally linked". The ultimate goal of this set of principles is for research objects (such as datasets) to be rendered reusable and increasingly reused. A number of articles on the topic of FAIR principles, from the original group of authors and others have been published since 2017. Jacobsen et al. (2019) described some of the challenges and opportunities for implementation of each of the FAIR principles, while Thompson et al. (2019) outlined the tools and technologies that are already available to support the adoption of FAIR data management, as well as the functionalities which are still lacking in that respect. Such resources enable scientific communities to identify existing solutions before considering developing their own.

There is however little visibility on the progress achieved by researchers in specific disciplines since the publication of the FAIR foundational paper. At the time of writing, very few published evaluations of FAIRness in publications and datasets were found in the literature. Van Reisen et al. (2020) reviewed the implementation of the FAIR principles reported in 100 randomly selected academic journal articles citing the foundational FAIR paper. They point out that life sciences represent the vast majority of the implementation, with 95 of the selected papers related to this discipline and a very limited representation (5 papers) of the other disciplines such as social science, humanities and other sciences. As supplementary materials to their publication on FAIR metric development, Wilkinson et al. (2018) also provided evaluation results for ten digital resources, as example application of these metrics. In addition, two reviews on application of FAIR principles, in Europe and Africa respectively, have been published recently, gathering large scale initiatives which are representing important steps to optimise data management and stewardship, and therefore, strive towards more FAIRness (van Reisen et al., 2019; Wittenburg et al., 2019). These reviews highlighted initiatives in humanities, environmental science, 
materials science and digital health, but none in many other sectors, such as veterinary research.

The importance of veterinary research in general, and especially veterinary epidemiology, has been better acknowledged since the beginning of the COVID-19 pandemic. Managing and improving animal health is not only critical to provide a secure access to safe animal-sourced foods, but also as a key component of the global health ecosystem. The purpose of the work presented in this manuscript is to fill the current gap of knowledge about the adoption of FAIR principles in this discipline. Our study is based on a systematic review of the FAIRness of datasets associated with peer-reviewed articles relating veterinary epidemiology research and published since 2017. The objectives are (i) to assess the state of FAIRness in this discipline, currently and over the past few years, and (ii) to explore how veterinary epidemiology research could move towards more re-usability, in line with the goal of the FAIR principles.

Many tools for evaluating the FAIRness of digital resources are available, in the form of questionnaires. Some of these tools were reviewed in peer-reviewed publications (de Miranda Azevedo and Dumontier, 2019; Thompson et al., 2019), while others are referenced in online repositories such as the FAIRassist (2019) and Research Data Alliance (2019) repositories. Wilkinson et al. (2018) in particular have proposed a framework and a first set of metrics developed for the evaluation of FAIRness. The authors subsequently proposed a second set of metrics, called maturity indicators, after including community feedback regarding the first set and gaining a better understanding on how data generators, managers and users were addressing FAIR principles (Wilkinson et al., 2019). These maturity indicators are registered by FAIRsharing (www.fairsharing.org), an online register of metadata standards to allow scientists to use frameworks which have been thoroughly documented. In the present manuscript, we applied the maturity indicators and tools proposed by these authors to conduct our evaluations. This framework intends to evaluate the overall maturity of an approach by assessing the FAIR maturity indicators separately and identifying specific points that can be improved, rather than evaluating the resource with a summary score of FAIRness: "FAIRness is not a competition, rather, FAIRness refers to a maturation process 
where digital objects are rendered increasingly self-descriptive to the machine" (Wilkinson et al., 2019).

Given the diversity found in the animal production sector in terms of species, further definition of the scope of this study is required. Aquaculture is an increasingly important provider of animal protein worldwide (FAO, 2018). There are dozens of diseases which affect the economic sustainability of aquaculture enterprises (Lafferty et al., 2015) and may be of concern regarding public health (Sapkota et al., 2008). In this context, epidemiological studies provide key tools to better understand the complex systems in which fish and other aquatic species are produced (Stentiford et al., 2017), by looking at the variations in disease risk in populations and considering the interplay between host, pathogen and environment factors. Epidemiological research to improve aquatic health management, and salmonid health in particular, emerged as a discipline in the early 2000s and is still growing (Brun, 2019; Subasinghe, 2005). Salmonids (including several salmon and trout species) are an important group in seawater fish production globally, with over 3 million tons produced in 2016 (FAO, 2018), and also an interesting group for the present work given the increasingly common use of data routinely generated by commercial producers for research. Such data are likely to be considered as confidential information, due to animal health and production data revealing production practices, adding another layer of complexity in terms of FAIRness. Given the growing importance of this sector, this study focuses on the current state of FAIRness in salmonid epidemiology.

In contrast, milk and dairy products are contributing to a much larger proportion of food produced from animals worldwide than fish (Speedy, 2003), making dairy cattle one of the major livestock production systems. However, there are increasing concerns about the impact of terrestrial livestock production systems on the environment and on climate change. It is estimated that $15 \%$ of human-induced emissions of greenhouse gases worldwide are attributable to livestock production, with a large proportion of these emissions due to ruminants (Gerber et al., 2013). Nonetheless, ruminants, and dairy cattle in particular, remain critical in many ecosystems given their unique ability to convert feedstuffs with little nutritional value for humans into high-quality protein (Broderick, 2018). In 
this context, epidemiological research in dairy cattle is a long-established discipline, as improving animal health is key to optimise yields and thus make the most of available resources. Given the importance of dairy cattle in epidemiological research, we chose to compare our snapshot of the state of FAIRness in salmonid epidemiological research with a similar snapshot in this species to address the two study objectives stated above. In this work, molecular epidemiology research, the branch of epidemiology using genetic sequences of pathogens or hosts to describe disease patterns, was considered separately from other branches of epidemiology, given the differences in the types of data that are collected and analysed in these disciplines.

\section{Methods}

The methods used for this systematic review are reported in accordance with the PRISMA statement (Moher et al., 2009). A literature search was conducted to identify all peer-reviewed publications related to epidemiological research in salmonid production published between January $1^{\text {st }}, 2017$ to October $18^{\text {th }}, 2020$. We searched scientific literature referenced in three electronic databases: Scopus, Web of Science and PubMed. For the salmonid dataset, we used the following keywords: (epidemiology) AND (salmon OR trout) AND (aquaculture). The documents retrieved were imported into a desktop reference management system for screening, eligibility assessment and further analysis. All titles, abstracts and key words were screened to select the results relevant to our study, i.e., articles related to epidemiological research in salmonid production. All farmed salmonid species were included (e.g., Atlantic salmon, coho salmon, rainbow trout). We excluded (i) studies in other disciplines (clinical reports, molecular biology, proteomics, bacteriology, microbiology, parasitology3, phylogenetics, physiology, food safety, economics, welfare), (ii) studies not conducted in farmed salmonids (wild salmonids, other species) and (iii) documents other than peer-reviewed publications (e.g., conference papers). Three additional articles were removed at

\footnotetext{
${ }^{3}$ papers looking at epidemiology-related aspects of sea lice were retained due to high relevance of this
}

species for the aquaculture sector. 
the full-text review stage (see below) as they were discussion papers and therefore not based on any formal dataset.

A similar literature search was conducted for epidemiological research in dairy cattle, with the same parameters. Given the large number of database results, only titles and key words were screened to select the relevant results. Abstracts were reviewed only when the title and key words did not provide sufficient information. The same exclusion criteria (i) to (iii) were used, except that (ii) were studies not conducted in dairy cattle (e.g., dairy goats). Additional exclusion criteria were (iv) articles which were not available in English and (v) molecular epidemiology papers. The latter were not considered for inclusion, as the comparison between salmonids and dairy cattle focused on studies in nonmolecular epidemiology. Given the large number of eligible results for dairy (739 articles), we used random sampling to select full-text articles which were reviewed for data availability. The sampling was stratified by publication year (2017 to 2020), with the number of dairy papers selected each year matching the number of available salmonid papers for that year. A pseudo-random number generation function in Microsoft Excel was used for this purpose.

The full text of all articles selected for inclusion was then reviewed and assessed, along with any supplementary materials and information available on the publisher's Web page for the article. Relevant information for our study (DOI, publication year, species, country, title, type of work and information regarding nature and availability of datasets) was extracted and tabulated. The nature of the data used in the study was classified as commercial (i.e., data collected and managed by commercial producers for their own purposes) or non-commercial data (i.e., data provided by public agencies and industry bodies, data collected from the literature and data collected on purpose for the study such as experimental data or farm survey data). For salmonids, given the very different nature of datasets between disciplines, molecular epidemiology papers were assessed separately from non-molecular epidemiology papers.

Raw data were considered 'available' when they were provided in the manuscript's main text, as supplementary materials or in an online repository. Data available upon request to the authors were not considered as available in this 
study. Data considered as raw data in this assessment were non-aggregated data, provided at the level to which they were collected (i.e., excluding any summary data). For mathematical modelling studies (simulation studies), the model inputs and parameter values were considered as the raw data for the purpose of this assessment, not the model outputs such as simulation results for example. The rationale for identifying 'available' datasets in this first stage was that these data are potentially findable and accessible outside of the research team which produced them. In some cases, all the data required to reproduce the results may have been provided in the manuscript itself (either in the text or as tables in the article). Such data could not be evaluated for FAIRness as they did not form a distinct digital resource from the article itself. Therefore, they were excluded from the next stage of the assessment described in the next paragraph.

The information required to assess FAIRness was then extracted for each digital resource identified as available. Furthermore, information about the online repositories used to deposit datasets by the articles' authors was obtained from the Registry of Research Data Repositories (www.re3data.org). A list of 13 FAIR maturity indicators relevant for our work was compiled based on the indicators proposed by Wilkinson et al. (2019, 2018) (Table 1). Maturity indicators should be applied to a single digital resource, and therefore the target resource must be defined clearly, as some of the principles apply to both the data and the associated metadata (Wilkinson et al., 2016). Here, the resources we evaluated were the datasets associated with each paper and identified during the first steps of the work. For molecular epidemiology papers, the datasets of interest were those containing genetic data rather than the sample or isolate data. While the authors of this framework have used a binary scoring system (pass or fail) in their maturity indicator tests (w3id.org/AmIFAIR), we felt that some resources presented some maturity regarding a certain indicator while not entirely meeting the requirement. Therefore, resources were assessed with a 3 -level scoring system, according to whether they fully met, partially met or did not meet the requirements for each indicator.

The assessment of articles and datasets described above was conducted by the first author (AM), while a parallel assessment of $10 \%$ of the items included in 
the study was conducted by one of the co-authors (CF). Results were compared and assessment criteria adjusted and re-evaluated in light of the identified points of discordance.

Table 1 List of 13 FAIRness maturity indicators evaluated in this study, based on the framework proposed by Wilkinson et al. $(2019,2018)$. The indicator identifiers are the same as the corresponding guiding principle identifiers for simplicity. For ease of reference, the colours in maturity levels are the same used in the Results section.

\begin{tabular}{llll}
\hline Indicator identifier & $\begin{array}{l}\text { Indicator } \\
\text { name }\end{array}$ & Indicator description & $\begin{array}{l}\text { Maturity } \\
\text { levels }\end{array}$ \\
\hline F1.1 & $\begin{array}{l}\text { Identifier } \\
\text { uniqueness }\end{array}$ & $\begin{array}{l}\text { Whether there is a scheme to } \\
\text { uniquely identify the digital } \\
\text { resource }\end{array}$ & $\begin{array}{l}\text { Indicator is not } \\
\text { met }\end{array}$ \\
\hline F1.2 & $\begin{array}{l}\text { Identifier } \\
\text { persistence }\end{array}$ & $\begin{array}{l}\text { Whether there is a policy or } \\
\text { scheme which ensures the } \\
\text { persistence of the digital } \\
\text { resource identifier }\end{array}$ & $\begin{array}{l}\text { Indicator is not } \\
\text { met }\end{array}$ \\
\hline F2 & $\begin{array}{l}\text { Data are } \\
\text { described with } \\
\text { metadata }\end{array}$ & $\begin{array}{l}\text { Whether metadata } \\
\text { corresponding to the digital } \\
\text { resource are available }\end{array}$ & Indicator is met \\
\hline F3 & $\begin{array}{l}\text { Resource } \\
\text { identifier in } \\
\text { metadata }\end{array}$ & $\begin{array}{l}\text { Whether the metadata contains } \\
\text { the unique identifier for the } \\
\text { digital resource }\end{array}$ & $\begin{array}{l}\text { Indicator is not } \\
\text { met }\end{array}$ \\
\hline met
\end{tabular}


representation in the digital resource. This

language indicator was assessed in terms

of the format of the data.
Indicator is partially met: the resource is in a structured, non-proprietary, editable format (e.g., CSV, XML)

Indicator is met (language used is cited and documented)

Whether the digital resource uses formal and shared vocabularies (ontologies) for knowledge representation, which are
themselves terms from open, I2 Use of FAIR community-accepted vocabularies published in an appropriate knowledge-exchange format.

Indicator is not met

\begin{tabular}{l} 
Indicator is \\
partially met: \\
the vocabularies \\
used in the \\
resource are \\
documented \\
Indicator is met \\
Indicator is not \\
met \\
\hline Indicator is met
\end{tabular}

Indicator is not met

\section{Use of} Whether the digital resource or its metadata contain relationships with third-party data, with an explicit and useful semantic meaning
R1.1

Accessible usage license
Whether there is a license document for the digital resource and the ability to retrieve those documents
Indicator is partially met: elements concerning the conditions for reuse, copying or distributing the resource are available but no formal license can be found

Indicator is met

Whether the digital resource content is associated with Indicator is not met provenance information associated with the data, covering at least: (i) who Indicator is met

$\begin{array}{ll}\text { R1.2 } & \begin{array}{l}\text { Detailed } \\ \text { provenance }\end{array}\end{array}$

R1.3 produced the data and when, and (ii) why and how the data was produced (context and relevance of the data). The availability of such information in the digital resource itself or its metadata was evaluated, not in the content of the associated article

Whether the digital resource is listed by a recognized body as
Indicator is not met 
${ }^{1}$ as per (Wilkinson et al., 2016).

\section{Results}

\subsection{Data availability in salmonid research}

The literature search yielded 147 and 98 results for salmon and trout, respectively. The flow diagram of the identification, screening and inclusion of results is included in Supplementary File 1. The review process led to the inclusion of 91 articles on various epidemiological topics in salmonid production in this study (the full reference list is provided in Supplementary File 2). The selected articles presented data from 16 individual countries, with an important representation from Norway, Chile and Canada, as well as global data and grouped data from North America, Latin America and Europe (Figure 1, left panel).

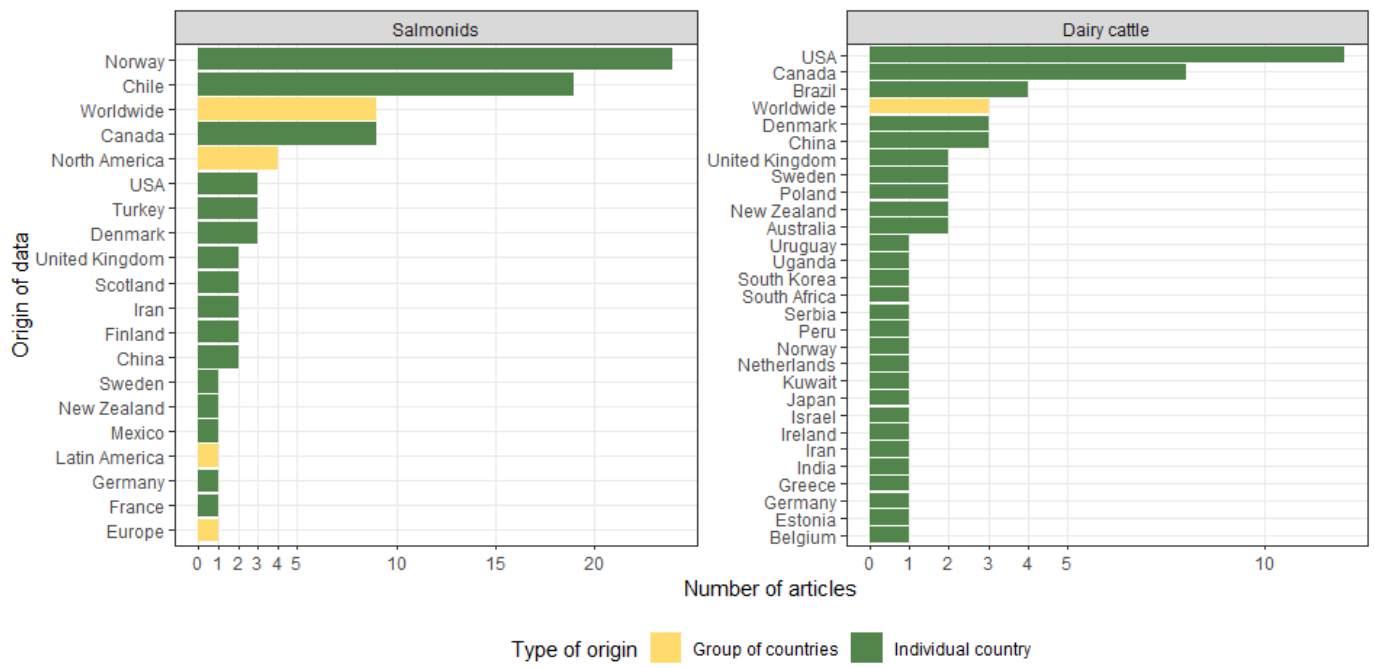

Figure 1 Distribution of the articles related to epidemiology research selected in this review by country of origin and species $(\mathrm{N}=152)$.

The assessment of the full texts, supplementary materials and article pages on the publisher websites showed that for 55 out of the 91 papers, the raw data 
supporting the work were not provided within the article, via its supplementary materials or in an online repository (Figure 2). Raw data were available for $80 \%$ of the molecular epidemiology papers (24 out of 30 ) and $20 \%$ of the papers in other epidemiology sub-disciplines (12 out of 61). In addition, authors stated that raw data were available upon request in 3 out of the 55 papers for which they were not directly provided.
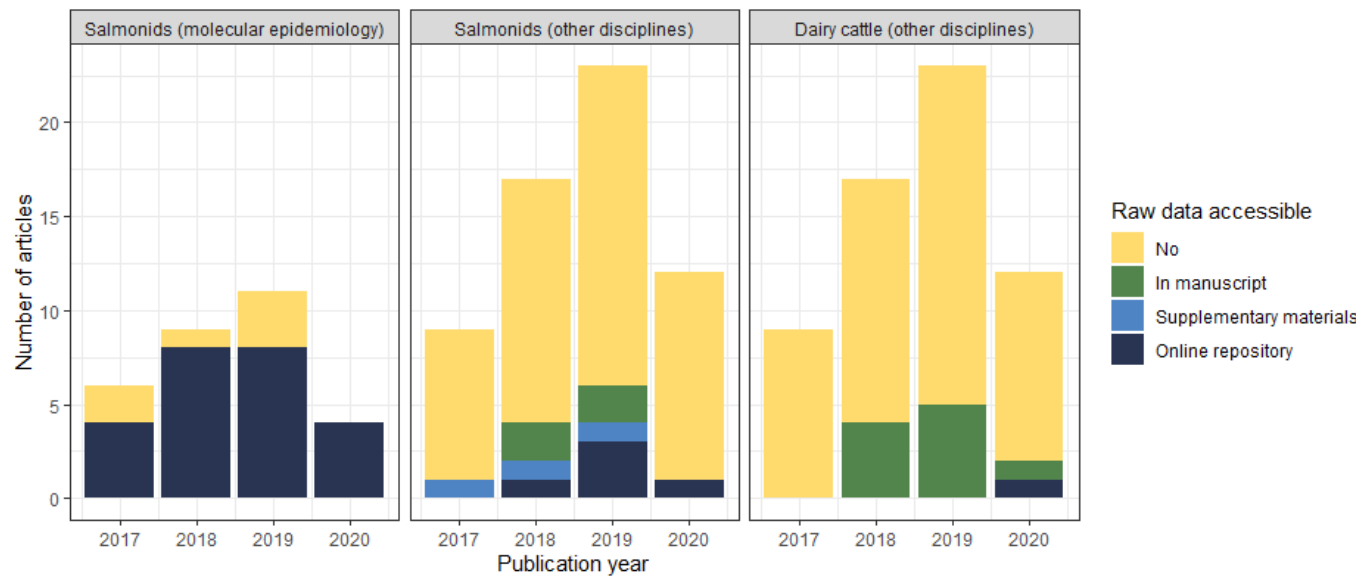

Figure 2

Distribution of the articles selected in this review according to publication year, species, discipline and accessibility of raw data $(\mathrm{N}=152)$. Note that 2020 publications were assessed until October 18th only. For the molecular epidemiology papers, the raw data referred to in this figure are the molecular data.

For the 24 molecular epidemiology papers with raw data classified as available, genetic data were uploaded in specific-purpose repositories: GenBank (19 papers), NCBI's Sequence Read Archive (4), PubMLST (3) and the European Nucleotide Archive (2), or in a generic-purpose repository (FigShare, 2 papers). The sum of the numbers in brackets is larger than 24 as six papers deposited data in two repositories. Genetic data were not available for the six remaining papers. Epidemiological data on the isolates or samples were also provided in two thirds of molecular epidemiology papers (21 out of 30). Such data were generally shared as tables within the manuscript itself (14 papers), and/or as supplementary materials (either as PDF tables, 3 papers, or Word tables, 5 papers). Isolate data were shared 
in a MicroReact project for one paper and could be downloaded as a tab-separated file.

For the 12 papers in other epidemiology sub-disciplines for which raw data were available, these were deposited in an online repository in 5 cases: a genericpurpose repository (Mendeley Data, Dryad) or institutional repositories (Marine Data BC and Norwegian Marine Data Centre). In the other cases, the raw data were shared in the manuscript itself as tables (4 papers), as supplementary materials (either as PDF tables, 1 paper, or Excel file, 2 papers). For two of these papers, it appeared that only part of the data used to conduct the work was made available. Last, ten of the 61 non-molecular epidemiology papers used commercial data, but raw data were available for only one of these ten papers.

\subsection{Data availability in dairy cattle research}

At the end of the eligibility and inclusion steps (see flow chart in Supplementary File 1), a total of 61 papers concerning epidemiology research in dairy production were randomly selected and assessed for data availability. A third of the papers related to Canada or USA (20 papers out of 61), while the remainder originated from 26 other countries or were based on worldwide data (3 papers) (Figure 1, right panel). The assessment of dairy papers showed that raw data were available for $18 \%$ of them (11 out of 61 ) (Figure 2). In ten of those, the raw data were provided within the manuscript. Raw data were deposited in a genericpurpose repository for the remaining paper (Scholars Portal Dataverse). In addition, authors stated that raw data were available upon request in 3 out of the 50 papers for which they were not directly provided. Four of the 61 dairy cattle papers used commercial data, but raw data were not available for any of these four papers.

\subsection{Data availability statements}

The 152 articles assessed in this part of the study were published in 60 different journals. Among those, 17 included a formal data availability statement either as a dedicated section in the manuscript or as a supplementary item (Figure 3). Such statements were introduced during the study period in some of the journals most represented by the selected articles, such as Aquaculture, Journal of 
Fish Diseases and Preventive Veterinary Medicine. These additional sections may be named "Availability of data and materials", "Data access", "Data accessibility", "Data availability", "Data profile", "Data summary" or "Research data for this article". Among papers not related to molecular epidemiology, data availability statements were provided in 6 and 10 of the dairy and salmonid articles, respectively. In salmonid papers, the statements mentioned that the study datasets were available upon request ( 2 papers), that authors did not have permission to share them (1 paper), that the data had been deposited in an online repository (4 papers), or that "all relevant data are within the paper and its Supporting Information files" (or similar, 3 papers). In two of the three latter papers, the raw data did not appear to be available despite the statement. In dairy papers, the statements mentioned that study datasets were available upon request (3 papers), that authors did not have permission to share them (2 papers), or that the data had been deposited in an online repository (1 paper).

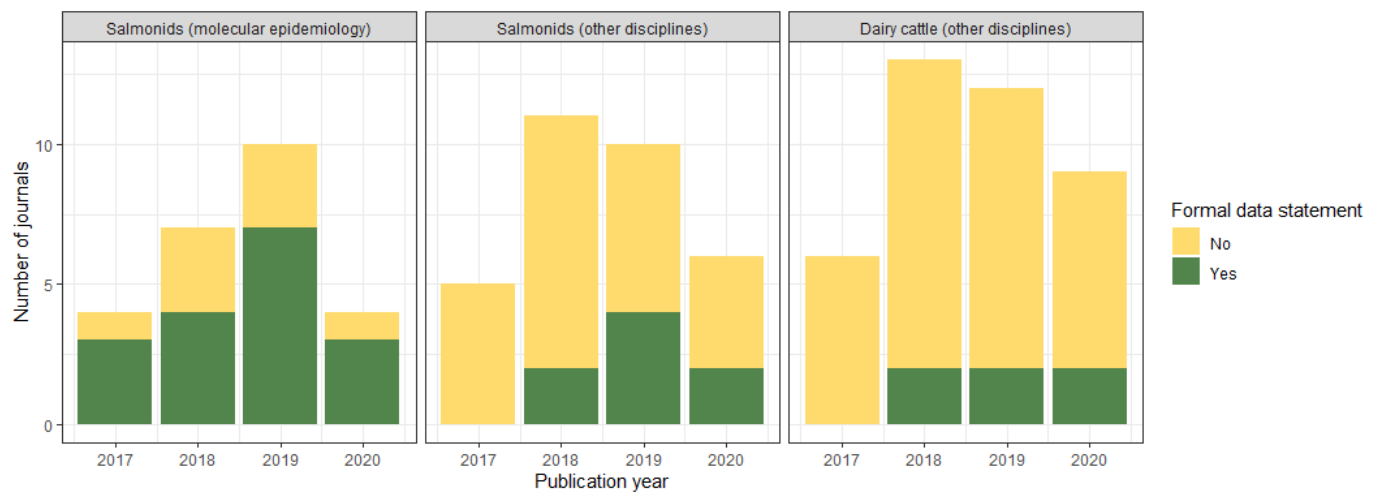

Figure 3 Presence of a data availability statement in the journals $(\mathrm{N}=62)$ publishing the articles selected in this review according to publication year and species. Some individual journals may appear in more than one year, species or discipline. Note that 2020 publications were assessed until October 18 th only.

\subsection{FAIRness assessment}

Evaluation results for 13 maturity indicators of the available datasets are presented in Table 2 (papers on molecular epidemiology) and Table 3 (other papers). A number of papers provided the data used in the study within the 
manuscript itself (text or tables) (Figure 2), including 4 and 10 papers on salmonids and dairy cattle, respectively. Those datasets were not evaluated for FAIRness as they do not form a distinct digital resource from the article itself.

Molecular digital resources were almost always identified by a globally unique identifier defined by the repository, but this identifier was generally not persistent (F1). Most resources were associated with metadata including the data identifier (F2 and $\mathrm{F}_{3}$ ) and provenance information (R1.2). All resources were indexed by a search engine (F4) and accessible via an open, free protocol (A1) but the persistence of the metadata should the resource become unavailable was not guaranteed (A2). No resources used a formal knowledge representation language, but all were provided in standardized formats, such as GenBank data (I1). Most used FAIR vocabularies (I2) and about half were linked to other relevant resources (I3). Clear license conditions were not often provided (R1.1), given that several common repositories such as GenBank state that the repository managers "cannot provide comment or unrestricted permission concerning the use of the information contained in the molecular databases" or similar. All repositories but one were certified or listed as trusted in known community schemes (R1.3). The digital resources evaluated here originated from a range of 12 individual countries and from two multi-country studies. 
epidemiology of salmonids. Dark, medium and pale shades of orange indicate that a given maturity indicator was met, partially met and not met, respectively. The grey boxes corresponds to a resource which could not be evaluated given that the dataset accession number was invalid. $\mathrm{N}$ corresponds to the number of articles with a given combination of indicator.

\begin{tabular}{ll}
\hline \multicolumn{2}{l}{ Maturity indicator assessment } \\
\hline 3 \\
\hline 2
\end{tabular}

Within non-molecular datasets, most digital resources were identified by a globally unique and persistent identifier, generally a Digital Object Identifier (F1). Six out of nine resources were associated with metadata including the data identifier (F2 and F3) while most had provenance information (R1.2) and were indexed in a search engine ( $\left.\mathrm{F}_{4}\right)$. Accessibility indicators were similar to those observed above for molecular data (A1, A2). No resources used a formal knowledge representation language and only two were provided in editable, non-proprietary format (I1). No resources used standardized vocabularies, and only two provided some documentation regarding the vocabularies used (I2). None were linked to 
other relevant resources (I3). Clear license conditions were always provided (R1.1) and five datasets were deposited in repositories certified or listed as trusted in known community schemes (R1.3). The nine digital resources which were evaluated originated from a range of countries: Canada (two datasets), Finland (one dataset), Mexico (one dataset), Norway (two datasets) and USA (one dataset) or from multi-country studies (two datasets).

Table 3 Evaluation of FAIRness for nine datasets accompanying articles in non-molecular epidemiology papers. Eight papers concerned salmonids and one dairy cattle (the latter is marked with an asterisk). Dark, medium and pale shades of orange indicate that a given maturity indicator was met, partially met and not met, respectively.

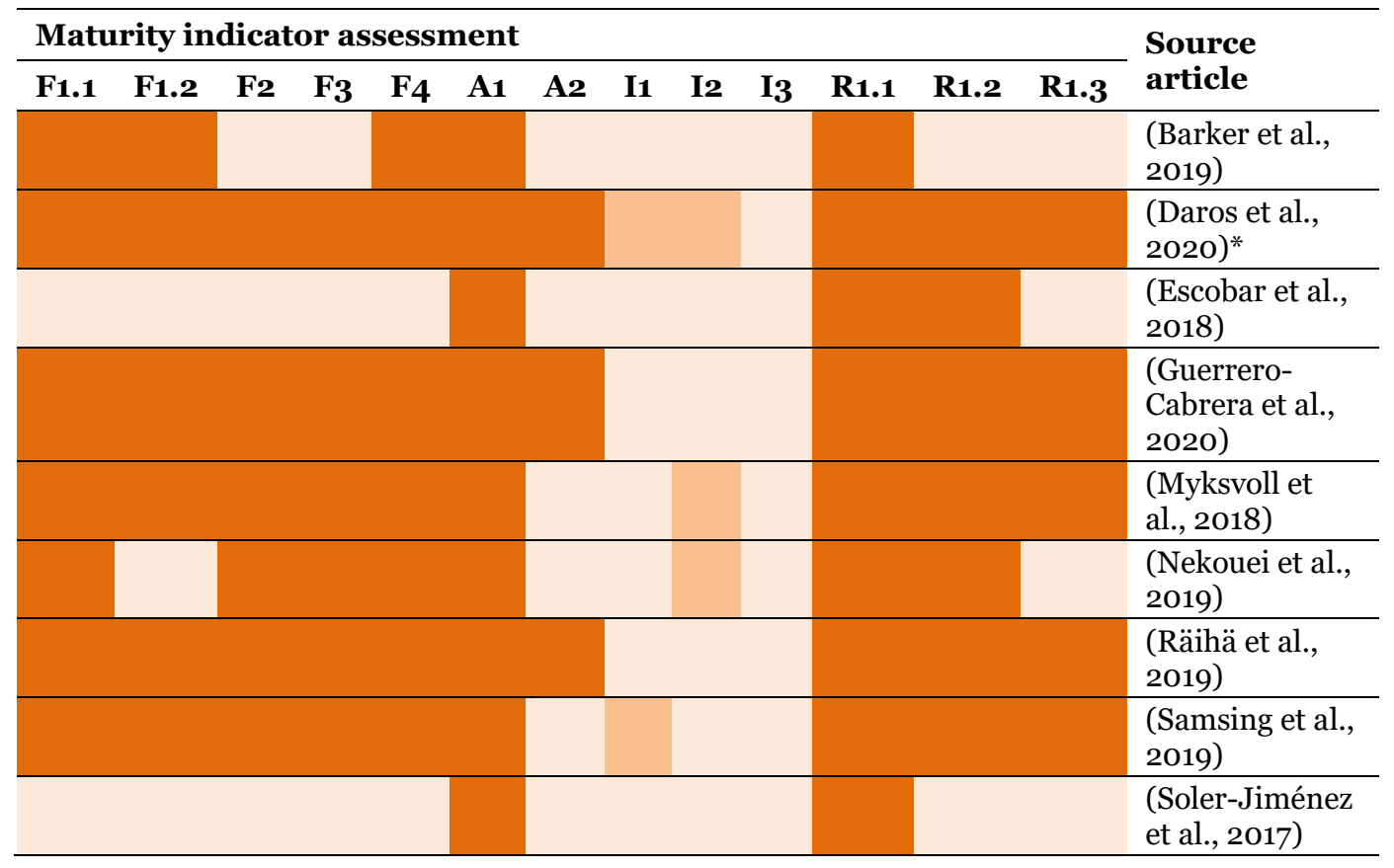

Finally, the data sources for the nine non-molecular epidemiological digital resources evaluated in this section were databases from government agencies (e.g., the Directorate of Fisheries in Norway (Myksvoll et al., 2018) and the Aquatic Health Committee of Oaxaca in Mexico (Guerrero-Cabrera et al., 2020)) or international agencies (e.g., European Community Reference Laboratory for Fish 
Diseases (Escobar et al., 2018)), data from the published literature or data specifically generated for the purpose of the study. The dataset made available by Soler-Jiménez et al. (2017) in their literature review was the only dataset from a commercial source. However, this dataset was not collected specifically for the purpose of the study described in this publication. The authors were able to obtain mortality, environmental and management data from a group of fish producers in Mexico in the context of another study, which could not be identified in peerreviewed sources at the time of writing. The dataset contained a few hundreds of farm-level records of several variables, without associated farm identifiers.

\section{Discussion}

Most datasets used in non-molecular epidemiological studies were not findable, or "re-useless" as characterised by Mons et al. (2017). These authors estimated that $80 \%$ of datasets in science belonged to this category. Our assessment suggests that the proportion in veterinary epidemiology is at least as high for the two species included in this work. In addition, no clear trend of improvement was observed over the past four years. Data availability was much higher for molecular epidemiology papers, with $80 \%$ of the articles assessed depositing genetic data in online repositories. The low proportion of raw data provided as distinct digital resources in non-molecular epidemiology publications means that only few datasets could be assessed in terms of FAIR maturity indicators in this study (nine out of 122 articles assessed). Of note, our assessment considered whether all the raw data used to produce the results were available for a given paper, but we did not try to reproduce any of the results as this was out of scope of the present study. Such additional assessment may allow the identification of papers for which some of the data required to reproduce the results were not available.

For articles with no raw data or, more rarely, data shared within the manuscript itself, the absence of separate data objects means that the FAIR assessment could not be conducted. Although these data may be reusable as they are both findable and accessible by researchers, and associated with provenance information and other metadata, their format (not directly searchable and 
editable) does not make them interoperable. In addition, they are neither machinefindable nor machine-accessible. Such considerations also apply to the data shared in supplementary files assessed in this study. For supplementary materials, metadata may not be readily available (F2), although researchers may manually find relevant information in the article, and these resources sometimes do not have a unique resource identifier (F1), although some journals associated a dedicated DOI to each supplementary item. Supplementary materials were not searchable in search engines, as the article itself is the object that is indexed ( $\left.\mathrm{F}_{4}\right)$. Although providing raw data as supplementary materials does not make datasets FAIR, it is a common and practical way for researchers to respond to the increasingly pressing requests to make data available. It could be argued that there is little difference between sharing raw data in a manuscript table or in a supplementary material table and that treating them differently is arbitrary. However, a criterion for what constitutes raw data had to be established for the specific purpose of this study. In accordance with the FAIR framework which focuses on digital objects, we chose to only assess the FAIRness of raw data which were provided as separate digital resources, as described in the Methods section.

While the number of papers for which the raw data were available was similar between salmonid and dairy cattle in non-molecular epidemiology (12 and 11, out of 61, respectively), datasets were made available as individual digital resources more often by salmonid researchers than by dairy researchers ( 8 and 1 datasets, respectively). It was not possible to compare the FAIR maturity indicators between the two species given the small sample size and they are discussed here together. Across disciplines and without considering the case of supplementary material datasets which was already discussed above, the FAIRness assessment showed that most resources were uniquely identified, although persistence of these identifiers was generally not provided for molecular datasets (F1). Indicators F2, F3 and R1.2 were often met, with some metadata provided for the digital resource, along with the data identifier and provenance information. The persistence of the metadata should the data objects be removed was generally not guaranteed regardless of the repository considered. Importantly, all data objects were discoverable by webbased search engines (F4) and freely accessible via an open protocol (A1). 
While the available objects generally scored favourably for Findable, Accessible and Reusable indicators, Interoperability was more problematic. The datasets identified in our study were not using a "formal, accessible, shared, and broadly applicable language for knowledge representation" as per the definition of the I1 indicator (Wilkinson et al., 2016). In non-molecular epidemiology, datasets were often shared as Excel files, with little to no documentation of the content of the different data fields, and no linked objects could be identified. Much progress remains possible on the I1, I2 and I3 indicators for these resources. Examples of existing resources which may be used to improve Interoperability in epidemiological research are the AGROVOC vocabulary developed and managed by the Food and Agriculture Organization (http://www.fao.org/agrovoc/) and the SNOVET systematized nomenclature for veterinary medicine (Palotay, 1983). By contrast, standardized formats (e.g., XML) and vocabularies are used in the National Centre for Biotechnology Information (NCBI)'s databases considered in this study for molecular datasets (GenBank and Sequence Read Archive) (23 out of 30 datasets). As the I1 maturity indicator is not associated with an agreed list of what constitutes a valid language for knowledge representation for a given discipline, there is room for interpretation by the person performing the assessment in terms of defining their scoring system. As such, the scoring system used in the present study may not be valid for another study or discipline. It is important to recognize that, as the coding of molecular data is universal, it is much easier to achieve interoperability for such datasets, as shown by the good scores achieved on this indicator compared to non-molecular epidemiology. In addition, the digital archiving of such data is concentrated by a few stakeholders as NCBI is collaborating with other large repositories such as DNA DataBank of Japan and the European Nucleotide Archive, making it practical for the interested researcher to find related data, even if they are not explicitly linked (I3). Molecular epidemiology papers were also frequently providing epidemiological data (isolate or sample data) in a tabular format (70\% of papers). Such data, which can be considered as raw data or as metadata for the genetic data, are critical to support reusability. Although inferior to the availability of genetic data (80\%), the availability of epidemiological data was substantially higher than that observed in non-molecular 
papers. Finally, frequent re-use of published genetic sequences by other researchers is observed in the literature, showing the progress made in this discipline compared with other disciplines. In summary, the relatively consistent structure of molecular datasets, the availability of appropriate repositories, and the existing demand for data re-use are some of the factors which may explain the differences in data availability observed between molecular and non-molecular papers in our study.

Meeting indicators related to the Findable, Accessible and Reusable principles is likely possible for researchers who do not have specific skills in data management. On the other hand, interoperability appears to be a more complex objective. The process of migrating the Pathogen-Host Interaction Database, in plant sciences, to a FAIR-compliant form (Rodríguez-Iglesias et al., 2016) illustrates that the data transformation required to apply machine-readable standards for knowledge representation require specialist knowledge in this area. This may be an obstacle for both funders and scientists who may not readily understand the concepts or have the skills required for effective data preparation, management and long-term preservation (Houtkoop et al., 2018; Tenopir et al., 2015, 2011). In this regard, more systematic data management training is needed in graduate programmes, both to develop awareness around open science and FAIRness and to teach specific skills required to reach these goals. Meanwhile, researchers may already take simple measures to increase the interoperability of their datasets. For example, documenting the content of tabular data in a systematic manner, indicating the content, type and unit of each data field is an accessible step for rendering datasets self-descriptive, short of using knowledge representation languages and FAIR vocabularies. Units and conditions of measurement are critical for the re-use of quantitative data. In the case of 'oxygen' levels in fish cages, one needs to know the type and unit of the measurement (e.g., oxygen saturation in \%, oxygen concentration in $\mathrm{mg} / \mathrm{L}$ ) as well as the depth and temperature of the measurement to allow for correct interpretation.

No comparable assessments of FAIRness in publications were found in the literature but the subjects of data sharing and open data in research have been abundantly documented. A strong contrast is observed between willingness to 
share research data expressed by scientists and availability of datasets in practice. Survey respondents often declare willingness to share at least some data publicly (around 80\% of them depending on the discipline and study) (Tenopir et al., 2020, 2018). Recent studies looking at the proportion of published work for which datasets were publicly available showed relatively low levels of availability: $8 \%$ in geoscience flux research (Dai et al., 2018), less than 10\% in psychology research (Houtkoop et al., 2018), 14\% in morphology research (Hipsley and Sherratt, 2019) and $18 \%$ in biomedical research (Wallach et al., 2018). Even in biomedical journals with a full data sharing policy for randomized controlled trials, a review found that only 17 out of 37 eligible articles satisfied the definition for data availability (Naudet et al., 2018). Our present findings are consistent with these observations. Despite the plethora of published literature on the topic of data sharing and the growing availability of technological solutions, the evolution of practices and attitudes remains slow. In this regard, as our study was conducted only four years after the principles were formally published, it is not surprising that no significant changes were observed yet. These results will provide a baseline measure for future evaluations aiming at identifying longer-term changes.

Regardless, some scientific disciplines are significantly ahead in terms of data sharing, for example in genomics (Byrd, 2020), as confirmed in the present study for molecular epidemiology in animal species. In other disciplines, barriers to making research datasets available have been explored (Dallmeier-Tiessen et al., 2014; Houtkoop et al., 2018; Perrier et al., 2020; Tenopir et al., 2020) and some of the factors which can positively impact data sharing have been identified (Kim and Burns, 2015; Schmidt et al., 2016; Vines et al., 2013). Top-down pressure, in the form of strong encouragement or policies of mandatory sharing, from funding bodies and journal publishers appears to be highly effective. For measurable progress, such policies and requirements must not remain theoretical but need to be verified in practice. Data management plans indicating how FAIR principles will be applied are an increasingly common requirement from research funding organisations (Bloemers and Montesanti, 2019; EC, 2018).

In the animal production sector in particular, data provided for research by stakeholders may be considered as confidential information, due to animal health 
and production data revealing production practices as well as representing commercial assets and competitive advantages. Fourteen of the 122 non-molecular epidemiology papers reviewed in this study were based on commercial data, including four in dairy cattle and ten in salmonids. The availability of raw data was very low for these potentially sensitive commercial production data (only one of the fourteen papers made the raw data publicly available). It is reasonable to assume that raw data provided by commercial producers are even more concerned by privacy issues than datasets collected by other means. In such cases, researchers are subjected to conflicting needs, with transparency, reproducibility and reusability on one side, and data confidentiality on the other side. Our results suggest that researchers may have more room to make datasets available when they collected these data from third-party sources, such as government databases holding data submitted by industry for regulatory purposes (for example the study by Myksvoll et al. (2018)). Sourcing research data from third-party data integration initiatives may allow the generation of epidemiological datasets which are easier to share publicly, due to pre-existing data sharing agreements with the industry. An example of such initiative found during this review is Fish-iTrends, a sea lice data management system administered by the Atlantic Veterinary College in Canada (Gautam et al., 2017). Another example in salmonids is the attempt to set up a data integration platform described by Meyer et al. (2020). The use of animal production commercial data for research can significantly increase access to quality data with excellent coverage in time and space of the populations of interest, as shown by studies included in this work such as analyses conducted in the Chile salmonid industry (Happold et al., 2020a, 2020b) and in the Canadian dairy industry (Haine et al., 2017). The confidentiality level required for these datasets as well as barriers to data sharing related to competitiveness and antitrust regulation aspects suggest that there could be a fundamental incompatibility between the principles of open-access data and the use of commercial data for research. However, progress towards more FAIRness does not require the datasets to be made open access. The four first levels presented by Mons et al. (2017) are compatible with access-restricted datasets. Data integration systems such as those proposed above may allow progress to be made towards improved FAIRness. For 
example, authors making datasets findable and their metadata findable, accessible, interoperable and reusable would reach the fourth of these levels, "FAIR data with restricted access". This would better enable other researchers to assess which digital resources could potentially be useful to them and express their interest in reusing such datasets. Negotiations regarding the conditions for access, such as the appropriate type of license, could then be undertaken between interested parties. This would represent significant progress from the "re-useless data" stage where most of the datasets assessed in the present study were found.

Finally, our assessment showed that molecular datasets appear relatively compliant with machine readability, while this was generally not the case for the nine non-molecular available datasets. Thus, machine readability remains uncommon for non-molecular epidemiological data, especially as these nine datasets only made up for a small proportion of the 61 studies initially identified. The approach proposed by Wilkinson et al. (2019) puts emphasis on machine readability: "detecting and validating behaviours of digital objects that make them machine-readable and reusable". Given the relative novelty of FAIRness implementation in veterinary epidemiology, it is not surprising that only few resources were standardized for machine readability, while most provide humanreadable content. In addition, the FAIRness assessments strictly focus on the digital object itself, and therefore do not assess other aspects of compliance with generic data management good practices, such as data curation and governance. The salmonid data platforms used in some of the studies (Gautam et al., 2017; Happold et al., 2020a, 2020b) show the progress made by producers and data users to explore new ways of managing data, which require data curation and governance aspects to be defined in a collaborative manner. The FAIR principles also do not consider discipline-specific attributes which may be considered critical. For instance, some authors proposed an extension of the FAIR principles to better address the reproducibility and privacy protection challenges encountered in health research (Holub et al., 2018). There are no standard indicators available to assess the additional aspects, and they were not considered within the scope of this study. Last, FAIRness assessments may also be applied to model code objects, when these are shared by their authors. Although we did not specifically address 
this aspect in the present work, we noted that none of the fourteen mathematical modelling studies provided access to such model objects.

In conclusion, we recommend that the FAIR framework is progressively integrated in the routine workflow of researchers in veterinary epidemiology, starting with more education, training and communication. Furthermore, the barriers to reach the goals of data re-usability which have been set for a few years should be identified by discipline. This would allow the design and implementation of interventions to overcome these barriers. Last, we suggest a stepwise approach to improving the FAIRness of research data, in which the first step would be to make a large proportion of datasets and their metadata findable as digital resources. 


\section{References}

Adamek, M., Hellmann, J., Flamm, A., Teitge, F., Vendramin, N., Fey, D., Riße, K., Blakey, F., Rimstad, E., Steinhagen, D., 2019. Detection of piscine orthoreoviruses (PRV-1 and PRV-3) in Atlantic salmon and rainbow trout farmed in Germany. Transbound. Emerg. Dis. 66, 14-21. https://doi.org/10.1111/tbed.13018

Aslam, M.L., Robledo, D., Krasnov, A., Moghadam, H.K., Hillestad, B., Houston, R.D., Baranski, M., Boison, S., Robinson, N.A., 2020. Quantitative trait loci and genes associated with salmonid alphavirus load in Atlantic salmon: implications for pancreas disease resistance and tolerance. Sci. Rep. 10. https://doi.org/10.1038/s41598-020-67405-8

Barker, S.E., Bricknell, I.R., Covello, J., Purcell, S., Fast, M.D., Wolters, W., Bouchard, D.A., 2019. Sea lice, Lepeophtheirus salmonis (Krøyer 1837), infected Atlantic salmon (Salmo salar L.) are more susceptible to infectious salmon anemia virus. PLOS ONE 14, e0209178. https://doi.org/10.1371/journal.pone.0209178

Bayliss, S.C., Verner-Jeffreys, D.W., Ryder, D., Suarez, R., Ramirez, R., Romero, J., Pascoe, B., Sheppard, S.K., Godoy, M., Feil, E.J., 2018. Genomic epidemiology of the commercially important pathogen Renibacterium salmoninarum within the Chilean salmon industry. Microb. Genomics 4. https://doi.org/10.1099/mgen.0.000201

Bloemers, M., Montesanti, A., 2019. The FAIR Funding Model: Providing a Framework for Research Funders to Drive the Transition toward FAIR Data Management and Stewardship Practices. Data Intell. 2, 171-180. https://doi.org/10.1162/dint_a_ooo39

Broderick, G.A., 2018. Review: Optimizing ruminant conversion of feed protein to human food protein. animal 12, 1722-1734. https://doi.org/10.1017/S1751731117002592

Brosnahan, C.L., Munday, J.S., Ha, H.J., Preece, M., Jones, J.B., 2019. New Zealand rickettsia-like organism (NZ-RLO) and Tenacibaculum maritimum: Distribution and phylogeny in farmed Chinook salmon (Oncorhynchus tshawytscha). J. Fish Dis. 42, 85-95. https://doi.org/10.1111/jfd.12909 
Brun, E., 2019. Epidemiology - an important tool for a sustainable $\begin{array}{llllll}\text { aquaculture future. } & \text { Prev. } & \text { Vet. } & \text { Med. } & 167, & 158 .\end{array}$ https://doi.org/10.1016/j.prevetmed.2019.03.015

Büyükekiz, A.G., Altun, S., Hansen, E.F., Satıcıŏlu, I.B., Duman, M., Markussen, T., Rimstad, E., 2018. Infectious pancreatic necrosis virus (IPNV) serotype $\mathrm{Sp}$ is prevalent in Turkish rainbow trout farms. J. Fish Dis. 41, 95-104. https://doi.org/10.1111/jfd.12675

Byrd, J.B., 2020. Responsible, practical genomic data sharing that accelerates research. Nat. Rev. Genet. 21, 615-629. https://doi.org/10.1038/s41576-020-0257-5

Dai, S.-Q., Li, H., Xiong, J., Ma, J., Guo, H.-Q., Xiao, X., Zhao, B., 2018. Assessing the Extent and Impact of Online Data Sharing in Eddy Covariance Flux Research. J. Geophys. Res. Biogeosciences 123, 129-137. https://doi.org/10.1002/2017JGo04277

Dallmeier-Tiessen, S., Darby, R., Gitmans, K., Lambert, S., Matthews, B., Mele, S., Suhonen, J., Wilson, M., 2014. Enabling Sharing and Reuse of Scientific Data. New Rev. Inf. Netw. 19, 16-43. https://doi.org/10.1080/13614576.2014.883936

Daros, R.R., Eriksson, H.K., Weary, D.M., von Keyserlingk, M.A.G., 2020. The relationship between transition period diseases and lameness, feeding time, and body condition during the dry period. J. DAIRY Sci. 103, 649-665. https://doi.org/10.3168/jds.2019-16975

de Miranda Azevedo, R., Dumontier, M., 2019. Considerations for the Conduction and Interpretation of FAIRness Evaluations. Data Intell. 2, 285-292. https://doi.org/10.1162/dint_a_0o051

Du, X., Bayliss, S.C., Feil, E.J., Liu, Y., Wang, C., Zhang, G., Zhou, D., Wei, D., Tang, N., Leclercq, S.O., Feng, J., 2019. Real time monitoring of Aeromonas salmonicida evolution in response to successive antibiotic therapies in a commercial fish farm. Environ. Microbiol. 21, 1113-1123. https://doi.org/10.1111/1462-2920.14531

Duman, M., Altun, S., Cengiz, M., Saticioglu, I.B., Buyukekiz, A.G., Sahinturk, P., 2017. Genotyping and antimicrobial resistance genes of Yersinia 
ruckeri isolates from rainbow trout farms. Dis. Aquat. Organ. 125, 31-44. https://doi.org/10.3354/daoo3132

Duman, M., Buyukekiz, A.G., Saticioglu, I.B., Cengiz, M., Sahinturk, P., Altun, S., 2020. Epidemiology, genotypic diversity, and antimicrobial resistance of Lactococcus garvieae in farmed rainbow trout (Oncorhynchus mykiss). Iran. J. Fish. Sci. 19, 1-18. https://doi.org/10.22092/ijfs.2018.117609

EC, 2018. Final Report and Action Plan from the European Commission Expert Group on FAIR Data: Turning Fair into Reality. European Commission, Brussels, Belgium.

Escobar, L.E., Escobar-Dodero, J., Phelps, N.B.D., 2018. Infectious disease in fish: global risk of viral hemorrhagic septicemia virus. Rev. Fish Biol. Fish. 28, 637-655. https://doi.org/10.1007/s1116o-018-9524-3

FAIRassist, 2019. Help you discover resources to measure and improve FAIRness. [WWW Document]. URL https://fairassist.org/ (accessed 10.18.20).

FAO, 2018. The State of World Fisheries and Aquaculture 2018 - Meeting the sustainable development goals. Food Agric. Organ. U. N. Rome Italy.

Gallagher, M.D., Karlsen, M., Petterson, E., Haugland, O., Matejusova, I., Macqueen, D.J., 2020. Genome sequencing of $\mathrm{SAV}_{3}$ reveals repeated seeding events of viral strains in norwegian aquaculture. Front. Microbiol. 11. https://doi.org/10.3389/fmicb.2020.00740

Gautam, R., Vanderstichel, R., Boerlage, A.S., Revie, C.W., Hammell, K.L., 2017. Effect of timing of count events on estimates of sea lice abundance and interpretation of effectiveness following bath treatments. J. Fish Dis. 40, 367-375. https://doi.org/10.1111/jfd.12519

Gerber, P., Steinfeld, H., Henderson, B., Mottet, A., Opio, C., Dijkman, J., Falcucci, A., Tempio, G., 2013. Tackling climate change through livestock: a global assessment of emissions and mitigation opportunities. Food and Agriculture Organization of the United Nations, Rome, Italy.

Guerrero-Cabrera, L., Luna Olivera, B.C., Villavicencio-Pulido, J.G., Ortiz Luna, R.J., 2020. Proximity and density of neighboring farms and water supply, as risk factors for bacteriosis: A case study of spatial risk analysis in tilapia and 
rainbow trout farms of Oaxaca, Mexico. Aquaculture 520, 734955. https://doi.org/10.1016/j.aquaculture.2020.734955

Haine, D., Delgado, H., Cue, R., Sewalem, A., Wade, K., Lacroix, R., Lefebvre, D., Arsenault, J., Bouchard, É., Dubuc, J., 2017. Culling from the herd's perspective-Exploring herd-level management factors and culling rates in Québec dairy herds. Prev. Vet. Med. 147, 132-141. https://doi.org/10.1016/j.prevetmed.2017.08.020

Happold, J., Meyer, A., Sadler, R., Cowled, B., Mackenzie, C., Gallardo Lagno, A., Cameron, A., 2020a. Effectiveness of antimicrobial treatment of salmonid rickettsial septicaemia in commercial salmon and trout farms in Chile. Aquaculture 525 ,

735323.

https://doi.org/doi.org/10.1016/j.aquaculture.2020.735323

Happold, J., Sadler, R., Meyer, A., Cowled, B., Mackenzie, C., Gallardo Lagno, A., Cameron, A., 2020b. Effectiveness of vaccination for the control of salmonid rickettsial septicaemia in commercial salmon and trout farms in Chile. Aquaculture 520, 734968. https://doi.org/10.1016/j.aquaculture.2020.734968

Hipsley, C.A., Sherratt, E., 2019. Psychology, not technology, is our biggest challenge to open digital morphology data. Sci. Data 6, 41. https://doi.org/10.1038/s41597-019-0047-o

Holub, P., Kohlmayer, F., Prasser, F., Mayrhofer, M.Th., Schlünder, I., Martin, G.M., Casati, S., Koumakis, L., Wutte, A., Kozera, Ł., Strapagiel, D., Anton, G., Zanetti, G., Sezerman, O.U., Mendy, M., Valík, D., Lavitrano, M., Dagher, G., Zatloukal, K., van Ommen, G.B., Litton, J.-E., 2018. Enhancing Reuse of Data and Biological Material in Medical Research: From FAIR to FAIR-Health. Biopreservation Biobanking 16, 97-105. https://doi.org/10.1089/bio.2017.0110

Houtkoop, B.L., Chambers, C., Macleod, M., Bishop, D.V.M., Nichols, T.E., Wagenmakers, E.-J., 2018. Data Sharing in Psychology: A Survey on Barriers and Preconditions, Data Sharing in Psychology: A Survey on Barriers and Preconditions. Adv. Methods Pract. Psychol. Sci. 1, 70-85. https://doi.org/10.1177/2515245917751886

Isla, A., Saldarriaga-Córdoba, M., Fuentes, D.E., Albornoz, R., Haussmann, D., Mancilla-Schulz, J., Martínez, A., Figueroa, J., Avendaño-Herrera, R., Yáñez, 
A., 2019. Multilocus sequence typing detects new Piscirickettsia salmonis hybrid genogroup in Chilean fish farms: Evidence for genetic diversity and population structure. J. Fish Dis. 42, 721-737. https://doi.org/10.1111/jfd.12976

Jacobsen, A., de Miranda Azevedo, R., Juty, N., Batista, D., Coles, S., Cornet, R., Courtot, M., Crosas, M., Dumontier, M., Evelo, C.T., Goble, C., Guizzardi, G., Hansen, K.K., Hasnain, A., Hettne, K., Heringa, J., Hooft, R.W.W., Imming, M., Jeffery, K.G., Kaliyaperumal, R., Kersloot, M.G., Kirkpatrick, C.R., Kuhn, T., Labastida, I., Magagna, B., McQuilton, P., Meyers, N., Montesanti, A., van Reisen, M., Rocca-Serra, P., Pergl, R., Sansone, S.-A., da Silva Santos, L.O.B., Schneider, J., Strawn, G., Thompson, M., Waagmeester, A., Weigel, T., Wilkinson, M.D., Willighagen, E.L., Wittenburg, P., Roos, M., Mons, B., Schultes, E., 2019. FAIR Principles: Interpretations and Implementation Considerations. Data Intell. 2, 1029. https://doi.org/10.1162/dint_r_ooo24

Jalali, S.A.H., Mohammadinezhad, R., Mohammadi, A., Latifian, M.H., Talebi, M., Soleimanin-Zad, S., Golkar, P., Hemmatzadeh, F., 2019. Molecular evolution and selection pressure analysis of infectious hematopoietic necrosis virus (IHNV) revealed the origin and phylogenetic relationship of Iranian isolates in recent epidemics in Iran. Virology 535, 45-58. https://doi.org/10.1016/j.virol.2019.06.012

Jia, P., Breyta, R.B., Li, Q., Qian, X., Wu, B., Zheng, W., Wen, Z., Liu, Y., Kurath, G., Hua, Q., Jin, N., Liu, H., 2018. Insight into infectious hematopoietic necrosis virus (IHNV) in Chinese rainbow trout aquaculture from virus isolated from 7 provinces in 2010-2014. Aquaculture 496, 239-246. https://doi.org/10.1016/j.aquaculture.2018.06.062

Johnson-Mackinnon, J.C., Crosbie, P.B.B., Karlsbakk, E., Marcos-Lopez, M., Paley, R., Nowak, B.F., Bridle, A.R., 2019. Multilocus Sequence Typing (MLST) and Random Polymorphic DNA (RAPD) Comparisons of Geographic Isolates of Neoparamoeba perurans, the Causative Agent of Amoebic Gill Disease. Pathog. Basel Switz. 8. https://doi.org/10.3390/pathogens8040244

Karlsen, C., Ottem, K.F., Brevik, Ø.J., Davey, M., Sørum, H., Winther-Larsen, H.C., 2017. The environmental and host-associated bacterial microbiota of Arctic 
seawater-farmed Atlantic salmon with ulcerative disorders. J. Fish Dis. 40, 16451663. https://doi.org/10.1111/jfd.12632

Kibenge, M.J.T., Wang, Y., Gayeski, N., Morton, A., Beardslee, K., McMillan, B., Kibenge, F.S.B., 2019. Piscine orthoreovirus sequences in escaped farmed Atlantic salmon in Washington and British Columbia. Virol. J. 16, 41. https://doi.org/10.1186/s12985-019-1148-2

Kim, Y., Burns, C.S., 2015. Norms of data sharing in biological sciences: The roles of metadata, data repository, and journal and funding requirements: J. Inf. Sci. https://doi.org/10.1177/0165551515592098

Kristoffersen, A.B., Devold, M., Aspehaug, V., Gjelstenli, O., Breck, O., Bang Jensen, B., 2018. Molecular tracing confirms that infection with infectious pancreatic necrosis virus follows the smolt from hatchery to grow-out farm. J. Fish Dis. 41, 1601-1607. https://doi.org/10.1111/jfd.12844

la Bastide, P.Y. de, Naumann, C., Hintz, W.E., 2018. Assessment of intraspecific variability in Saprolegnia parasitica populations of aquaculture facilities in British Columbia, Canada. Dis. Aquat. Organ. 128, 235-248. https://doi.org/10.3354/daoo3224

Lafferty, K.D., Harvell, C.D., Conrad, J.M., Friedman, C.S., Kent, M.L., Kuris, A.M., Powell, E.N., Rondeau, D., Saksida, S.M., 2015. Infectious Diseases Affect Marine Fisheries and Aquaculture Economics. Annu. Rev. Mar. Sci. 7, 471-496. https://doi.org/10.1146/annurev-marine-010814-015646

Loch, T.P., Faisal, M., 2018. Flavobacteria colonizing the early life stages of hatchery-incubated Chinook salmon Oncorhynchus tshawytscha (Walbaum 1792) are markedly diverse. J. Fish Dis. 41, 829-845. https://doi.org/10.1111/jfd.12795

Meyer, A., Bannister-Tyrrell, M., Mackenzie, C., Stegeman, A., Cameron, A., 2020. Barriers to the adoption of a fish health data integration initiative in the Chilean salmonid production. Comput. Electron. Agric. 179, 105853. https://doi.org/10.1016/j.compag.2020.105853

Moher, D., Liberati, A., Tetzlaff, J., Altman, D.G., 2009. Preferred Reporting Items for Systematic Reviews and Meta-Analyses: The PRISMA Statement. J. Clin. Epidemiol. 62, 1006-1012. https://doi.org/10.1016/j.jclinepi.2009.06.005 
Mons, B., Neylon, C., Velterop, J., Dumontier, M., da Silva Santos, L.O.B., Wilkinson, M.D., 2017. Cloudy, increasingly FAIR; revisiting the FAIR Data guiding principles for the European Open Science Cloud. Inf. Serv. Use 37, 49-56. https://doi.org/10.3233/ISU-170824

Myksvoll, M.S., Sandvik, A.D., Albretsen, J., Asplin, L., Johnsen, I.A., Karlsen, Ø., Kristensen, N.M., Melsom, A., Skardhamar, J., Ådlandsvik, B., 2018. Evaluation of a national operational salmon lice monitoring system-From physics to fish. PloS One 13, e0201338. https://doi.org/10.1371/journal.pone.0201338

Naudet, F., Sakarovitch, C., Janiaud, P., Cristea, I., Fanelli, D., Moher, D., Ioannidis, J.P.A., 2018. Data sharing and reanalysis of randomized controlled trials in leading biomedical journals with a full data sharing policy: survey of studies published in The BMJ and PLOS Medicine. BMJ 360. https://doi.org/10.1136/bmj.k40o

Nekouei, O., Vanderstichel, R., Kaukinen, K.H., Thakur, K., Ming, T., Patterson, D.A., Trudel, M., Neville, C., Miller, K.M., 2019. Comparison of infectious agents detected from hatchery and wild juvenile Coho salmon in British Columbia, 2008-2018. PloS One 14, e0221956. https://doi.org/10.1371/journal.pone.0221956

Palotay, J.L., 1983. Snomed-Snovet: An information system for comparative medicine. Med. Inform. (Lond.)

8 $17-21$. https://doi.org/10.3109/14639238309010917

Perrier, L., Blondal, E., MacDonald, H., 2020. The views, perspectives, and experiences of academic researchers with data sharing and reuse: A metasynthesis. PLOS ONE 15 , eo229182. https://doi.org/10.1371/journal.pone.0229182

Räihä, V., Sundberg, L.-R., Ashrafi, R., Hyvärinen, P., Karvonen, A., 2019. Rearing background and exposure environment together explain higher survival of aquaculture fish during a bacterial outbreak. J. Appl. Ecol. 56, 1741-1750. https://doi.org/10.1111/1365-2664.13393

Research Data Alliance, 2019. Results of an Analysis of Existing FAIR Assessment Tools [WWW Document]. URL https://www.rd- 
alliance.org/group/fair-data-maturity-model-wg/outcomes/results-analysisexisting-fair-assessment-tools (accessed 10.18.20).

Rodríguez, F.H., Flores-Mara, R., Yoshida, G.M., Barría, A., Jedlicki, A.M., Lhorente, J.P., Reyes-López, F., Yáñez, J.M., 2019. Genome-Wide Association Analysis for Resistance to Infectious Pancreatic Necrosis Virus Identifies Candidate Genes Involved in Viral Replication and Immune Response in Rainbow Trout (Oncorhynchus mykiss). G3 Bethesda Md 9, 2897-2904. https://doi.org/10.1534/g3.119.400463

Rodríguez-Iglesias, A., Rodríguez-González, A., Irvine, A.G., Sesma, A., Urban, M., Hammond-Kosack, K.E., Wilkinson, M.D., 2016. Publishing FAIR Data: An Exemplar Methodology Utilizing PHI-Base. Front. Plant Sci. 7. https://doi.org/10.3389/fpls.2016.00641

Samsing, F., Johnsen, I., Treml, E.A., Dempster, T., 2019. Identifying "firebreaks" to fragment dispersal networks of a marine parasite. Int. J. Parasitol. 49, 277-286. https://doi.org/10.1016/j.ijpara.2018.11.005

Sapkota, A., Sapkota, A.R., Kucharski, M., Burke, J., McKenzie, S., Walker, P., Lawrence, R., 2008. Aquaculture practices and potential human health risks: Current knowledge and future priorities. Environ. Int. 34, 1215-1226. https://doi.org/10.1016/j.envint.2008.04.009

Schmidt, B., Gemeinholzer, B., Treloar, A., 2016. Open Data in Global Environmental Research: The Belmont Forum's Open Data Survey. PLOS ONE 11, e0146695. https://doi.org/10.1371/journal.pone.0146695

Småge, S.B., Brevik, Ø.J., Frisch, K., Watanabe, K., Duesund, H., Nylund, A., 2017. Concurrent jellyfish blooms and tenacibaculosis outbreaks in Northern Norwegian Atlantic salmon (Salmo salar) farms. PloS One 12, e0187476. https://doi.org/10.1371/journal.pone.0187476

Söderlund, R., Hakhverdyan, M., Aspan, A., Jansson, E., 2018. Genome analysis provides insights into the epidemiology of infection with flavobacterium psychrophilum among farmed salmonid fish in Sweden. Microb. Genomics 4. https://doi.org/10.1099/mgen.o.000241 
Soler-Jiménez, L.C., Paredes-Trujillo, A.I., Vidal-Martínez, V.M., 2017. Helminth parasites of finfish commercial aquaculture in Latin America. J. Helminthol. 91, 110-136. https://doi.org/10.1017/Soo22149X1600o833

Sørensen, J., Vendramin, N., Priess, C., Kannimuthu, D., Henriksen, N.H., Iburg, T.M., Olesen, N.J., Cuenca, A., 2020. Emergence and Spread of Piscine orthoreovirus Genotype 3. Pathog. Basel Switz. 9. https://doi.org/10.3390/pathogens9100823

Speedy, A.W., 2003. Global Production and Consumption of Animal Source Foods. J. Nutr. 133, 4048S-4053S. https://doi.org/10.1093/jn/133.11.4048S

Stentiford, G.D., Sritunyalucksana, K., Flegel, T.W., Williams, B.A.P., Withyachumnarnkul, B., Itsathitphaisarn, O., Bass, D., 2017. New Paradigms to Help Solve the Global Aquaculture Disease Crisis. PLOS Pathog. 13, e100616o. https://doi.org/10.1371/journal.ppat.1006160

Subasinghe, R.P., 2005. Epidemiological approach to aquatic animal health management: opportunities and challenges for developing countries to increase aquatic production through aquaculture. Prev. Vet. Med. 67, 117-124. https://doi.org/10.1016/j.prevetmed.2004.11.004

Tenopir, C., Allard, S., Douglass, K., Aydinoglu, A.U., Wu, L., Read, E., Manoff, M., Frame, M., 2011. Data Sharing by Scientists: Practices and Perceptions. PLOS ONE 6, e21101. https://doi.org/10.1371/journal.pone.0021101

Tenopir, C., Christian, L., Allard, S., Borycz, J., 2018. Research Data Sharing: Practices and Attitudes of Geophysicists. Earth Space Sci. 5, 891-902. https://doi.org/10.1029/2018EA000461

Tenopir, C., Dalton, E.D., Allard, S., Frame, M., Pjesivac, I., Birch, B., Pollock, D., Dorsett, K., 2015. Changes in Data Sharing and Data Reuse Practices and Perceptions among Scientists Worldwide. PLOS ONE 10, e0134826. https://doi.org/10.1371/journal.pone.0134826

Tenopir, C., Rice, N.M., Allard, S., Baird, L., Borycz, J., Christian, L., Grant, B., Olendorf, R., Sandusky, R.J., 2020. Data sharing, management, use, and reuse: Practices and perceptions of scientists worldwide. PLOS ONE 15, e0229003. https://doi.org/10.1371/journal.pone.0229003 
Terceti, M.S., Vences, A., Matanza, X.M., Dalsgaard, I., Pedersen, K., Osorio, C.R., 2018. Molecular Epidemiology of Photobacterium damselae subsp damselae Outbreaks in Marine Rainbow Trout Farms Reveals Extensive Horizontal Gene Transfer and High Genetic Diversity. Front. Microbiol. 9. https://doi.org/10.3389/fmicb.2018.02155

Thompson, M., Burger, K., Kaliyaperumal, R., Roos, M., da Silva Santos, L.O.B., 2019. Making FAIR Easy with FAIR Tools: From Creolization to Convergence. Data Intell. 2, 87-95. https://doi.org/10.1162/dint_a_ooo31

van Reisen, M., Stokmanks, M., Basajja, M., Ong'ayo, A., Kirkpatrick, C., Mons, B., 2020. Towards the tipping point of FAIR implementation. Data Intell. 2, 264-275. https://doi.org/10.1162/dint_a_ooo49

van Reisen, M., Stokmans, M., Mawere, M., Basajja, M., Ong'ayo, A.O., Nakazibwe, P., Kirkpatrick, C., Chindoza, K., 2019. FAIR Practices in Africa. Data Intell. 2, 246-256. https://doi.org/10.1162/dint_a_ooo47

Vennerström, P., Välimäki, E., Lyytikäinen, T., Hautaniemi, M., Vidgren, G., Koski, P., Virtala, A.-M., 2017. Viral haemorrhagic septicaemia virus (VHSV Id) infections are detected more consistently using syndromic vs. active surveillance. Dis. Aquat. Organ. 126, 111-123. https://doi.org/10.3354/daoo3161

Vines, T.H., Andrew, R.L., Bock, D.G., Franklin, M.T., Gilbert, K.J., Kane, N.C., Moore, J.-S., Moyers, B.T., Renaut, S., Rennison, D.J., Veen, T., Yeaman, S., 2013. Mandated data archiving greatly improves access to research data. FASEB J. 27, 1304-1308. https://doi.org/10.1096/fj.12-218164

Wallach, J.D., Boyack, K.W., Ioannidis, J.P.A., 2018. Reproducible research practices, transparency, and open access data in the biomedical literature, 20152017. PLOS Biol. 16, e2006930. https://doi.org/10.1371/journal.pbio.2006930

Wilkinson, M.D., Dumontier, M., Aalbersberg, Ij.J., Appleton, G., Axton, M., Baak, A., Blomberg, N., Boiten, J.-W., da Silva Santos, L.B., Bourne, P.E., Bouwman, J., Brookes, A.J., Clark, T., Crosas, M., Dillo, I., Dumon, O., Edmunds, S., Evelo, C.T., Finkers, R., Gonzalez-Beltran, A., Gray, A.J.G., Groth, P., Goble, C., Grethe, J.S., Heringa, J., 't Hoen, P.A.C., Hooft, R., Kuhn, T., Kok, R., Kok, J., Lusher, S.J., Martone, M.E., Mons, A., Packer, A.L., Persson, B., Rocca-Serra, P., Roos, M., van Schaik, R., Sansone, S.-A., Schultes, E., Sengstag, T., Slater, T., 
Strawn, G., Swertz, M.A., Thompson, M., van der Lei, J., van Mulligen, E., Velterop, J., Waagmeester, A., Wittenburg, P., Wolstencroft, K., Zhao, J., Mons, B., 2016. The FAIR Guiding Principles for scientific data management and stewardship. Sci. Data 3, 160018. https://doi.org/10.1038/sdata.2016.18

Wilkinson, M.D., Dumontier, M., Sansone, S.-A., Bonino da Silva Santos, L.O., Prieto, M., Batista, D., McQuilton, P., Kuhn, T., Rocca-Serra, P., Crosas, M., Schultes, E., 2019. Evaluating FAIR maturity through a scalable, automated, $\begin{array}{lllll}\text { community-governed framework. Sci. } & \text { Data } & 6, & 174 .\end{array}$ https://doi.org/10.1038/s41597-019-0184-5

Wilkinson, M.D., Sansone, S.-A., Schultes, E., Doorn, P., Bonino da Silva Santos, L.O., Dumontier, M., 2018. A design framework and exemplar metrics for FAIRness. Sci. Data 5, 180118. https://doi.org/10.1038/sdata.2018.118

Wittenburg, P., Lautenschlager, M., Thiemann, H., Baldauf, C., Trilsbeek, P., 2019. FAIR Practices in Europe. Data Intell. 2, 257-263. https://doi.org/10.1162/dint_a_00048 


\section{Supplementary information}

\section{Supplementary file 1 Literature search flow diagrams}

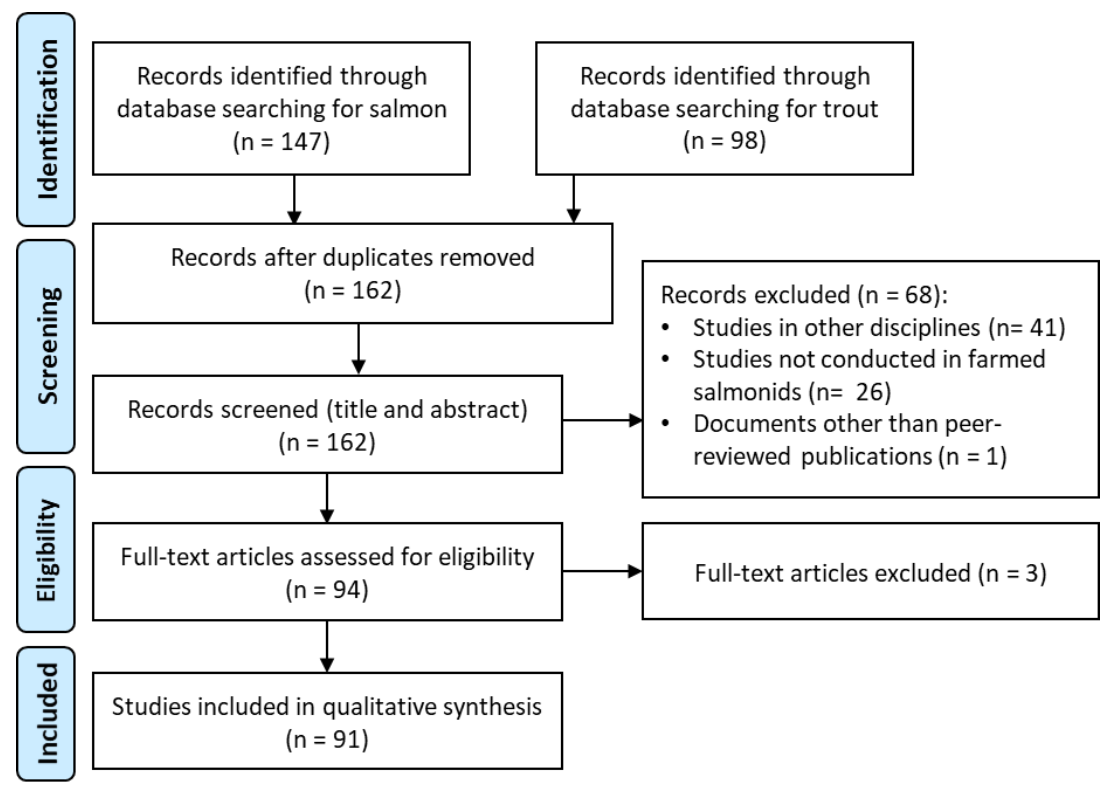


Figure S1. PRISMA flow diagram of the literature search for salmonids.

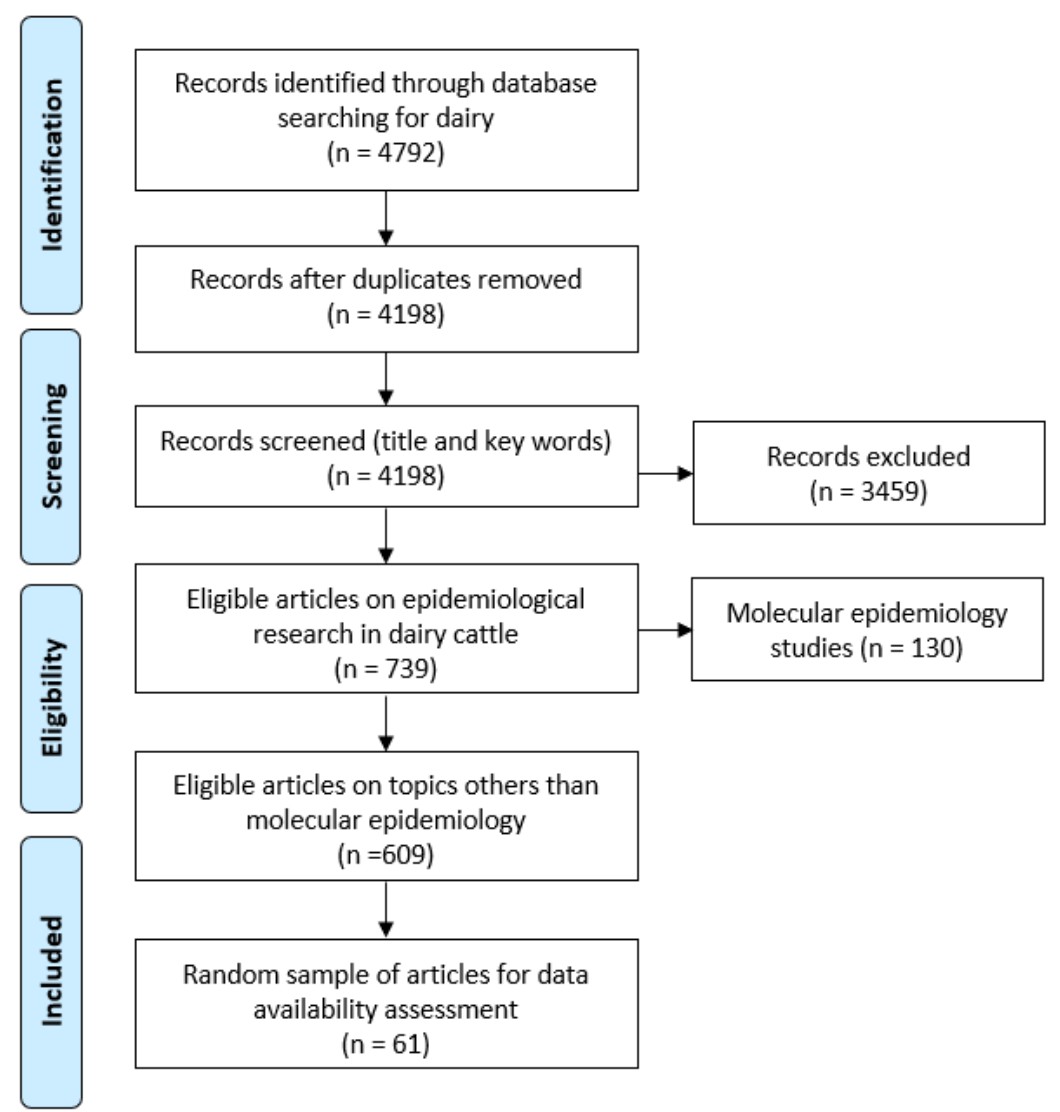

Figure S2. PRISMA flow diagram of the literature search for dairy cattle. 
Adamek, M., Hellmann, J., Flamm, A., Teitge, F., Vendramin, N., Fey, D., Riße, K., Blakey, F., Rimstad, E., Steinhagen, D., 2019. Detection of piscine orthoreoviruses (PRV-1 and PRV-3) in Atlantic salmon and rainbow trout farmed in Germany. Transbound. Emerg. Dis. 66, 14-21. https://doi.org/10.1111/tbed.13018

Adams, A.E., Lombard, J.E., Fossler, C.P., Román-Muñiz, I.N., Kopral, C.A., 2017. Associations between housing and management practices and the prevalence of lameness, hock lesions, and thin cows on US dairy operations. J. DAIRY Sci. 100, 2119-2136. https://doi.org/10.3168/jds.2016-11517

Aldrin, M., Jansen, P.A., Stryhn, H., 2019. A partly stage-structured model for the abundance of salmon lice in salmonid farms. Epidemics 26, 9-22. https://doi.org/10.1016/j.epidem.2018.08.001

Al-Mouqatea, S., Alkhamis, M., Akbar, B., Ali, A., Al-Aqeel, H., Bin-Heji, A., Razzaque, M., Alvarez, J., Perez, A., 2018. Bayesian estimation of ELISA and gamma interferon test accuracy for the detection of bovine tuberculosis in caudal fold test-negative dairy cattle in Kuwait. J. Vet. Diagn. Investig. Off. Publ. Am. Assoc. Vet. Lab. Diagn. Inc 30, 468-470. https://doi.org/10.1177/1040638718759574

Amirpour Haredasht, S., Tavornpanich, S., Jansen, M.D., Lyngstad, T.M., Yatabe, T., Brun, E., Martínez-López, B., 2019. A stochastic network-based model to simulate the spread of pancreas disease (PD) in the Norwegian salmon industry based on the observed vessel movements and seaway distance between marine $\begin{array}{lllll}\text { farms. } & \text { Prev. } & \text { Vet. } & \text { Med. } & 167,\end{array}$ https://doi.org/10.1016/j.prevetmed.2018.05.019

Anstey, I., Quigley, B.L., Polkinghorne, A., Jelocnik, M., 2019. Chlamydial infection and on-farm risk factors in dairy cattle herds in South East Queensland. Aust. Vet. J. 97, 505-508. https://doi.org/10.1111/avj.12879

Arriagada, G., Hamilton-West, C., Nekouei, O., Foerster, C., Müller, A., Lara, M., Gallardo-Escárate, C., 2019. Caligus rogercresseyi infestation is associated with Piscirickettsia salmonis-attributed mortalities in farmed salmonids in Chile. Prev. Vet. Med. 171, 104771. https://doi.org/10.1016/j.prevetmed.2019.104771 
Arriagada, G., Sanchez, J., Stryhn, H., Vanderstichel, R., Campistó, J.L., Ibarra, R., St-Hilaire, S., 2018. A multivariable assessment of the spatio-temporal distribution of pyrethroids performance on the sea lice Caligus rogercresseyi in Chile. Spat. Spatio-Temporal Epidemiol. 26, 1-13. https://doi.org/10.1016/j.sste.2018.04.004

Aslam, M.L., Robledo, D., Krasnov, A., Moghadam, H.K., Hillestad, B., Houston, R.D., Baranski, M., Boison, S., Robinson, N.A., 2020. Quantitative trait loci and genes associated with salmonid alphavirus load in Atlantic salmon: implications for pancreas disease resistance and tolerance. Sci. Rep. 10. https://doi.org/10.1038/s41598-020-67405-8

Bang Jensen, B., Nylund, S., Svendsen, J.C., Ski, P.-M.R., Takle, H., 2019. Indications for a vertical transmission pathway of piscine myocarditis virus in Atlantic salmon (Salmo salar L.). J. Fish Dis. 42, 825-833. https://doi.org/10.1111/jfd.12990

Bang Jensen, B., Qviller, L., Toft, N., 2020. Spatio-temporal variations in mortality during the seawater production phase of Atlantic salmon (Salmo salar) in Norway. J. Fish Dis. 43, 445-457. https://doi.org/10.1111/jfd.13142

Barker, S.E., Bricknell, I.R., Covello, J., Purcell, S., Fast, M.D., Wolters, W., Bouchard, D.A., 2019. Sea lice, Lepeophtheirus salmonis (Krøyer 1837), infected Atlantic salmon (Salmo salar L.) are more susceptible to infectious salmon anemia virus. PLOS ONE 14, e0209178. https://doi.org/10.1371/journal.pone.0209178

Bayliss, S.C., Verner-Jeffreys, D.W., Bartie, K.L., Aanensen, D.M., Sheppard, S.K., Adams, A., Feil, E.J., 2017. The Promise of Whole Genome Pathogen Sequencing for the Molecular Epidemiology of Emerging Aquaculture Pathogens. Front. Microbiol. 8, 121. https://doi.org/10.3389/fmicb.2017.00121

Bayliss, S.C., Verner-Jeffreys, D.W., Ryder, D., Suarez, R., Ramirez, R., Romero, J., Pascoe, B., Sheppard, S.K., Godoy, M., Feil, E.J., 2018. Genomic epidemiology of the commercially important pathogen Renibacterium salmoninarum within the Chilean salmon industry. Microb. Genomics 4. https://doi.org/10.1099/mgen.0.000201

Beaver, A., Meagher, R.K., von Keyserlingk, M.A.G., Weary, D.M., 2019. Invited review: A systematic review of the effects of early separation on dairy cow 
and calf health. J. DAIRY Sci. 102, 5784-5810. https://doi.org/10.3168/jds.201815603

Biemans, F., Bijma, P., Boots, N.M., de Jong, M.C.M., 2018. Digital Dermatitis in dairy cattle: The contribution of different disease classes to transmission. Epidemics 23 , $76-84$. https://doi.org/10.1016/j.epidem.2017.12.007

Blandford, M.I., Taylor-Brown, A., Schlacher, T.A., Nowak, B., Polkinghorne, A., 2018. Epitheliocystis in fish: An emerging aquaculture disease with a global impact. Transbound. Emerg. Dis. 65, 1436-1446. https://doi.org/10.1111/tbed.12908

Boerlage, A.S., Ashby, A., Herrero, A., Reeves, A., Gunn, G.J., Rodger, H.D., 2020. Epidemiology of marine gill diseases in Atlantic salmon (Salmo salar) aquaculture: a review. Rev. Aquac. https://doi.org/10.1111/raq.12426

Boerlage, A.S., Elghafghuf, A., Stryhn, H., Sanchez, J., Hammell, K.L., 2018. Risk factors associated with time to first clinical case of Bacterial Kidney Disease (BKD) in farmed Atlantic Salmon (Salmo salar L.) in New Brunswick, Canada. Prev. Vet. Med. 149, 98-106. https://doi.org/10.1016/j.prevetmed.2017.11.014

Boerlage, A.S., Stryhn, H., Armstrong, B., Hammell, K.L., 2019. A 2-stage hierarchical interrupted time-series analysis to quantify the long-term effect of subclinical bacterial kidney disease on performance of farmed Atlantic salmon $\begin{array}{lllllll}\text { (Salmo } & \text { salar } & \text { L.). } & \text { Prev. } & \text { Vet. Med. 172, } & 104776 .\end{array}$ https://doi.org/10.1016/j.prevetmed.2019.104776

Boerlage, A.S., Stryhn, H., Sanchez, J., Hammell, K.L., 2017. Case definition for clinical and subclinical bacterial kidney disease (BKD) in Atlantic Salmon (Salmo salar L.) in New Brunswick, Canada. J. Fish Dis. 40, 395-409. https://doi.org/10.1111/jfd.12521

Borges, I.A., McCollum, A.M., Mehal, J.M., Haberling, D., Dutra, L.A.L., Vieira, F.N., Andrade, L.A.O., Kroon, E.G., Holman, R.C., Reynolds, M.G., Trindade, G.S., 2017. Dairy production practices and associated risks for bovine vaccinia exposure in cattle, Brazil. New Microbes New Infect. 20, 43-50. https://doi.org/10.1016/j.nmni.2017.08.004 
Bravo, F., Sidhu, J.P.S., Bernal, P., Bustamante, R.H., Condie, S., Gorton, B., Herzfeld, M., Jimenez, D., Mardones, F.O., Rizwi, F., Steven, A.D.L., 2020. Hydrodynamic connectivity, water temperature, and salinity are major drivers of piscirickettsiosis prevalence and transmission among salmonid farms in Chile. Aquac. Environ. Interact. 12, 263-279. https://doi.org/10.3354/aeioo368

Brosnahan, C.L., Munday, J.S., Ha, H.J., Preece, M., Jones, J.B., 2019. New Zealand rickettsia-like organism (NZ-RLO) and Tenacibaculum maritimum: Distribution and phylogeny in farmed Chinook salmon (Oncorhynchus tshawytscha). J. Fish Dis. 42, 85-95. https://doi.org/10.1111/jfd.12909

Buczinski, S., Borris, M.E., Dubuc, J., 2018. Herd-level prevalence of the ultrasonographic lung lesions associated with bovine respiratory disease and related environmental risk factors. J. DAIRY Sci. 101, 2423-2432. https://doi.org/10.3168/jds.2017-13459

Büyükekiz, A.G., Altun, S., Hansen, E.F., Satıcıŏlu, I.B., Duman, M., Markussen, T., Rimstad, E., 2018. Infectious pancreatic necrosis virus (IPNV) serotype Sp is prevalent in Turkish rainbow trout farms. J. Fish Dis. 41, 95-104. https://doi.org/10.1111/jfd.12675

Chatziprodromidou, I.P., Apostolou, T., 2018. Diagnostic accuracy of enzyme-linked immunosorbent assay (ELISA) and immunoblot (IB) for the detection of antibodies against Neospora caninum in milk from dairy cows. Epidemiol. Infect. 146, 577-583. https://doi.org/10.1017/So950268817002916

Chung, J.J., Rayburn, M.C., Chigerwe, M., 2019. Randomized controlled clinical trial on the effect of oral immunoglobulin supplementation on neonatal dairy calves with diarrhea. J. Vet. Intern. Med. 33, 1807-1813. https://doi.org/10.1111/jvim.15538

Corbett, C.S., de Jong, M.C.M., Orsel, K., De Buck, J., Barkema, H.W., 2019. Quantifying transmission of Mycobacterium avium subsp. paratuberculosis among group-housed dairy calves. Vet. Res. 50, 6o. https://doi.org/10.1186/s13567-0190678-3

Cruvinel, L.B., Nicaretta, J.E., Bastos, T.S.A., Couto, L.F.M., Dos Santos, J.B., Zapa, D.M.B., Cavalcante, A.S.A., Cruz, B.C., Borges, D.G.L., Borges, F.A., Soares, V.E., Lopes, W.D.Z., 2018. Eimeria species in dairy and beef cattle of different ages 
in Goiás state, Brazil. Rev. Bras. Parasitol. Vet. 27, 169-176. https://doi.org/10.1590/S1984-296120180038

Cummings, K.J., Virkler, P.D., Wagner, B., Lussier, E.A., Thompson, B.S., 2018. Herd-level prevalence of Salmonella Dublin among New York dairy farms based on antibody testing of bulk tank milk. ZOONOSES PUBLIC Health 65, 10031007. https://doi.org/10.1111/zph.12523

Cvetojevic, D., Milicevic, V., Kureljusic, B., Savic, B., 2018. Seroprevalence of Neospora caninum in dairy cows in Belgrade city area, Serbia. J. Hell. Vet. Med. Soc. 69, 979-983. https://doi.org/10.12681/jhvms.18026

Dalen, G., Rachah, A., Nørstebø, H., Schukken, Y.H., Reksen, O., 2019. Dynamics of somatic cell count patterns as a proxy for transmission of mastitis pathogens. J. DAIRY Sci. 102, 11349-11358. https://doi.org/10.3168/jds.201916847

Daros, R.R., Eriksson, H.K., Weary, D.M., von Keyserlingk, M.A.G., 2020. The relationship between transition period diseases and lameness, feeding time, and body condition during the dry period. J. DAIRY Sci. 103, 649-665. https://doi.org/10.3168/jds.2019-16975

Deikun, L.L., Habing, G.G., Quigley, J.D., Proudfoot, K.L., 2020. Health and growth of veal calves provided a fatty acid supplement and a dry teat. J. DAIRY Sci. 103, 4633-4642. https://doi.org/10.3168/jds.2019-17240

Deperasinska, I., Schulz, P., Siwicki, A.K., 2018. Salmonid alphavirus (SAV). J. Vet. Res. 62, 1-6. https://doi.org/10.2478/jvetres-2018-0001

Dessen, J.-E., Mørkøre, T., Bildøy, J.I., Johnsen, S.N., Poppe, L.T., Hatlen, B., Thomassen, M.S., Rørvik, K.-A., 2019. Increased dietary protein-to-lipid ratio improves survival during naturally occurring pancreas disease in Atlantic salmon, Salmo salar L. J. Fish Dis. 42, 21-34. https://doi.org/10.1111/jfd.12904

Dolecheck, K.A., Overton, M.W., Mark, T.B., Bewley, J.M., 2019. Use of a stochastic simulation model to estimate the cost per case of digital dermatitis, sole ulcer, and white line disease by parity group and incidence timing. J. DAIRY Sci. 102, 715-730. https://doi.org/10.3168/jds.2018-14901

Douphrate, D.I., Fethke, N.B., Nonnenmann, M.W., Rodriguez, A., Gimeno Ruiz de Porras, D., 2019. Reliability of observational- and machine-based teat 
hygiene scoring methodologies. J. DAIRY Sci. 102, 7494-7502. https://doi.org/10.3168/jds.2019-16351

Du, X., Bayliss, S.C., Feil, E.J., Liu, Y., Wang, C., Zhang, G., Zhou, D., Wei, D., Tang, N., Leclercq, S.O., Feng, J., 2019. Real time monitoring of Aeromonas salmonicida evolution in response to successive antibiotic therapies in a commercial fish farm. Environ. Microbiol. 21, 1113-1123. https://doi.org/10.1111/1462-2920.14531

Dubuc, J., 2017. Short communication: Diagnostic performance of on-farm bacteriological culture systems for identification of uterine Escherichia coli in postpartum dairy cows. J. DAIRY Sci. 100, 3079-3082. https://doi.org/10.3168/jds.2016-12315

Duman, M., Altun, S., Cengiz, M., Saticioglu, I.B., Buyukekiz, A.G., Sahinturk, P., 2017. Genotyping and antimicrobial resistance genes of Yersinia ruckeri isolates from rainbow trout farms. Dis. Aquat. Organ. 125, 31-44. https://doi.org/10.3354/daoo3132

Duman, M., Buyukekiz, A.G., Saticioglu, I.B., Cengiz, M., Sahinturk, P., Altun, S., 2020. Epidemiology, genotypic diversity, and antimicrobial resistance of Lactococcus garvieae in farmed rainbow trout (Oncorhynchus mykiss). Iran. J. Fish. Sci. 19, 1-18. https://doi.org/10.22092/ijfs.2018.117609

Ekman, L., Nyman, A.-K., Landin, H., Magnusson, U., Waller, K.P., 2018a. Mild and severe udder cleft dermatitis-Prevalence and risk factors in Swedish dairy herds. J. DAIRY Sci. 101, 556-571. https://doi.org/10.3168/jds.2017-13133

Ekman, L., Nyman, A.-K., Landin, H., Persson Waller, K., 2018b. Hock lesions in dairy cows in freestall herds: A cross-sectional study of prevalence and risk factors. ACTA Vet. Scand. 6o. https://doi.org/10.1186/s13028-018-0401-9

Ellis, J., DeLong, K.L., Lambert, D.M., Schexnayder, S., Krawczel, P., Oliver, S., 2020. Analysis of closed versus operating dairies in the southeastern United States. J. DAIRY Sci. 103, 5148-5161. https://doi.org/10.3168/jds.2019-17516

Escobar, L.E., Escobar-Dodero, J., Phelps, N.B.D., 2018. Infectious disease in fish: global risk of viral hemorrhagic septicemia virus. Rev. Fish Biol. Fish. 28, 637-655. https://doi.org/10.1007/s11160-018-9524-3 
Escobar-Dodero, J., Kinsley, A., Perez, A.M., Ibarra, R., Tello, A., Monti, G., Mardones, F.O., 2019. Risk factors for infectious pancreatic necrosis in farmed Chilean Atlantic salmon (Salmo salar L.) from 2010 to 2013. Prev. Vet. Med. 167, 182-189. https://doi.org/10.1016/j.prevetmed.2018.04.016

Esmaeili, S., Mohabati Mobarez, A., Khalili, M., Mostafavi, E., 2019. High prevalence and risk factors of Coxiella burnetii in milk of dairy animals with a history of abortion in Iran. Comp. Immunol. Microbiol. Infect. Dis. 63, 127-130. https://doi.org/10.1016/j.cimid.2019.01.015

Esser, N.M., Su, H., Coblentz, W.K., Akins, M.S., Kieke, B.A., Martin, N.P., Borchardt, M.A., Jokela, W.E., 2019. Efficacy of recycled sand or organic solids as bedding sources for lactating cows housed in freestalls. J. DAIRY Sci. 102, 66826698. https://doi.org/10.3168/jds.2018-15851

Estevez, R.A., Mardones, F.O., Alamos, F., Arriagada, G., Carey, J., Corre, C., Escobar-Dodero, J., Gaete, A., Gallardo, A., Ibarra, R., Ortiz, C., Rozas-Serri, M., Sandoval, O., Santana, J., Gelcich, S., 2019. Eliciting expert judgements to estimate risk and protective factors for Piscirickettsiosis in Chilean salmon farming. AQUACULTURE 507 , $402-410$. https://doi.org/10.1016/j.aquaculture.2019.04.028

Faisal, M., Loch, T.P., Shavalier, M., VanDeuren, M.G., Standish, I., Winters, A., Glenney, G., Aho, J., Wolgamood, M., VanAmberg, J., Eisch, E., Whelan, G.E., 2019. Resurgence of Salmonid Herpesvirus-3 Infection (Epizootic Epitheliotropic Disease) in Hatchery-Propagated Lake Trout in Michigan. J. Aquat. Anim. Health 31, 31-45. https://doi.org/10.1002/aah.10051

Feist, S.W., Thrush, M.A., Dunn, P., Bateman, K., Peeler, E.J., 2019. The aquatic animal pandemic crisis. Rev. Sci. Tech. Int. Off. Epizoot. 38, 437-457. https://doi.org/10.20506/rst.38.2.2997

Fraslin, C., Brard-Fudulea, S., D’Ambrosio, J., Bestin, A., Charles, M., Haffray, P., Quillet, E., Phocas, F., 2019. Rainbow trout resistance to bacterial cold water disease: two new quantitative trait loci identified after a natural disease outbreak on a French farm. Anim. Genet. 50, 293-297. https://doi.org/10.1111/age.12777 
Gaete-Carrasco, A., Rosenfeld, C., Gallardo, A., 2019. Epidemiological analysis of the active surveillance programme for Piscirickettsia salmonis of the National Fisheries and Aquaculture Service of Chile. Rev. Sci. Tech. Int. Off. Epizoot. 38, 823-849. https://doi.org/10.20506/rst.38.3.3029

Gallagher, M.D., Karlsen, M., Petterson, E., Haugland, O., Matejusova, I., Macqueen, D.J., 2020. Genome sequencing of $\mathrm{SAV}_{3}$ reveals repeated seeding events of viral strains in norwegian aquaculture. Front. Microbiol. 11. https://doi.org/10.3389/fmicb.2020.00740

Gao, Y., Cao, J., Zhang, S., Zhang, Q., Sun, D., 2018. Short communication: Heritability estimates for susceptibility to Mycobacterium avium ssp. paratuberculosis infection in Chinese Holstein cattle. J. DAIRY Sci. 101, 72747279. https://doi.org/10.3168/jds.2017-13264

Garseth, A.H., Fritsvold, C., Svendsen, J.C., Bang Jensen, B., Mikalsen, A.B., 2018. Cardiomyopathy syndrome in Atlantic salmon Salmo salar L.: A review of the current state of knowledge. J. Fish Dis. 41, 11-26. https://doi.org/10.1111/jfd.12735

Gautam, R., Price, D., Revie, C.W., Gardner, I.A., Vanderstichel, R., Gustafson, L., Klotins, K., Beattie, M., 2018. Connectivity-based risk ranking of infectious salmon anaemia virus (ISAv) outbreaks for targeted surveillance planning in Canada and the USA. Prev. Vet. Med. 159, 92-98. https://doi.org/10.1016/j.prevetmed.2018.09.001

Gautam, R., Vanderstichel, R., Boerlage, A.S., Revie, C.W., Hammell, K.L., 2017a. Effect of timing of count events on estimates of sea lice abundance and interpretation of effectiveness following bath treatments. J. Fish Dis. 40, 367-375. https://doi.org/10.1111/jfd.12519

Gautam, R., Vanderstichel, R., Boerlage, A.S., Revie, C.W., Hammell, K.L., 2017b. Evaluating bath treatment effectiveness in the control of sea lice burdens on Atlantic salmon in New Brunswick, Canada. J. Fish Dis. 40, 895-905. https://doi.org/10.1111/jfd.12569

Gislason, H., 2018. Statistical modelling of sea lice count data from salmon farms in the Faroe Islands. J. Fish Dis. 41, 973-993. https://doi.org/10.1111/jfd.12742 
Gohary, K., LeBlanc, S.J., 2018. Cost of retained fetal membranes for dairy herds in the United States. JAVMA-J. Am. Vet. Med. Assoc. 252, 1485-1489. https://doi.org/doi.org/10.246o/javma.252.12.1485

Gomez, D.E., Arroyo, L.G., Poljak, Z., Viel, L., Weese, J.S., 2017. Detection of bovine coronavirus in healthy and diarrheic dairy calves. J. Vet. Intern. Med. 31, 1884-1891. https://doi.org/10.1111/jvim.14811

Goto, A., Takahara, K., Sugiura, T., Oikawa, S., Katamato, H., Nakada, K., 2019. Association of postpartum diseases occurring within 60 days after calving with productivity and reproductive performance in dairy cows in Fukuoka: A cowlevel, retrospective cohort study. J. Vet. Med. Sci. 81, 1055-1062. https://doi.org/10.1292/jvms.18-0384

Guarracino, M., Qviller, L., Lillehaug, A., 2018. Evaluation of aquaculture management zones as a control measure for salmon lice in Norway. Dis. Aquat. Organ. 130, 1-9. https://doi.org/10.3354/daoo3254

Guerrero-Cabrera, L., Luna Olivera, B.C., Villavicencio-Pulido, J.G., Ortiz Luna, R.J., 2020. Proximity and density of neighboring farms and water supply, as risk factors for bacteriosis: A case study of spatial risk analysis in tilapia and rainbow trout farms of Oaxaca, Mexico. Aquaculture 520, 734955. https://doi.org/10.1016/j.aquaculture.2020.734955

Guimarães, F.F., Manzi, M.P., Joaquim, S.F., Richini-Pereira, V.B., Langoni, H., 2017. Short communication: Outbreak of methicillin-resistant Staphylococcus aureus (MRSA)-associated mastitis in a closed dairy herd. J. DAIRY Sci. 100, 726730. https://doi.org/10.3168/jds.2016-11700

Gussmann, M., Steeneveld, W., Kirkeby, C., Hogeveen, H., Farre, M., Halasa, T., 2019. Economic and epidemiological impact of different intervention strategies for subclinical and clinical mastitis. Prev. Vet. Med. 166, 78-85. https://doi.org/10.1016/j.prevetmed.2019.03.001

Haine, D., Delgado, H., Cue, R., Sewalem, A., Wade, K., Lacroix, R., Lefebvre, D., Arsenault, J., Bouchard, É., Dubuc, J., 2017. Culling from the herd's perspective-Exploring herd-level management factors and culling rates in Québec dairy herds. Prev. Vet. Med. 147, 132-141. https://doi.org/10.1016/j.prevetmed.2017.08.020 
Happold, J., Meyer, A., Sadler, R., Cowled, B., Mackenzie, C., Gallardo Lagno, A., Cameron, A., 2020a. Effectiveness of antimicrobial treatment of salmonid rickettsial septicaemia in commercial salmon and trout farms in Chile. Aquaculture 525 ,

735323.

https://doi.org/doi.org/10.1016/j.aquaculture.2020.735323

Happold, J., Sadler, R., Meyer, A., Cowled, B., Mackenzie, C., Gallardo Lagno, A., Cameron, A., 202ob. Effectiveness of vaccination for the control of salmonid rickettsial septicaemia in commercial salmon and trout farms in Chile. Aquaculture 520, 734968. https://doi.org/10.1016/j.aquaculture.2020.734968

Hayer, S.S., VanderWaal, K., Ranjan, R., Biswal, J.K., Subramaniam, S., Mohapatra, J.K., Sharma, G.K., Rout, M., Dash, B.B., Das, B., Prusty, B.R., Sharma, A.K., Stenfeldt, C., Perez, A., Delgado, A.H., Sharma, M.K., Rodriguez, L.L., Pattnaik, B., Arzt, J., 2018. Foot-and-mouth disease virus transmission dynamics and persistence in a herd of vaccinated dairy cattle in India. Transbound. Emerg. Dis. 65, e404-e415. https://doi.org/10.1111/tbed.12774

Hellebø, A., Stene, A., Aspehaug, V., 2017. PCR survey for Paramoeba perurans in fauna, environmental samples and fish associated with marine farming sites for Atlantic salmon (Salmo salar L.). J. Fish Dis. 40, 661-670. https://doi.org/10.1111/jfd.12546

Hillman, A., Zalcman, E., Burroughs, A., Meyer, A., Mackenzie, C., Sadler, R., Stevenson, M., Ward, M., Gallardo Lagno, A., Happold, J., Cameron, A., Cowled, B., 2020. Use of regulatory data to describe and identify risk factors for salmonid rickettsial septicaemia in Chile, 2011-2017. Aquaculture 526, 735324. https://doi.org/doi.org/10.1016/j.aquaculture.2020.735324

Isla, A., Saldarriaga-Córdoba, M., Fuentes, D.E., Albornoz, R., Haussmann, D., Mancilla-Schulz, J., Martínez, A., Figueroa, J., Avendaño-Herrera, R., Yáñez, A., 2019. Multilocus sequence typing detects new Piscirickettsia salmonis hybrid genogroup in Chilean fish farms: Evidence for genetic diversity and population structure. J. Fish Dis. 42, 721-737. https://doi.org/10.1111/jfd.12976

Jagielski, T., Krukowski, H., Bochniarz, M., Piech, T., Roeske, K., Bakuła, Z., Wlazło, Ł., Woch, P., 2019. Prevalence of Prototheca spp. on dairy farms in Poland 
- a cross-country study. Microb. Biotechnol. 12, 556-566. https://doi.org/10.1111/1751-7915.13394

Jalali, S.A.H., Mohammadinezhad, R., Mohammadi, A., Latifian, M.H., Talebi, M., Soleimanin-Zad, S., Golkar, P., Hemmatzadeh, F., 2019. Molecular evolution and selection pressure analysis of infectious hematopoietic necrosis virus (IHNV) revealed the origin and phylogenetic relationship of Iranian isolates in recent epidemics in Iran. Virology 535, 45-58. https://doi.org/10.1016/j.virol.2019.06.012

Jamali, H., Barkema, H.W., Jacques, M., Lavallée-Bourget, E.-M., Malouin, F., Saini, V., Stryhn, H., Dufour, S., 2018. Invited review: Incidence, risk factors, and effects of clinical mastitis recurrence in dairy cows. J. DAIRY Sci. 101, 47294746. https://doi.org/10.3168/jds.2017-13730

Jansen, M.D., Bang Jensen, B., McLoughlin, M.F., Rodger, H.D., Taksdal, T., Sindre, H., Graham, D.A., Lillehaug, A., 2017. The epidemiology of pancreas disease in salmonid aquaculture: a summary of the current state of knowledge. J. Fish Dis. 40, 141-155. https://doi.org/10.1111/jfd.12478

Jansen, M.D., Guarracino, M., Carson, M., Modahl, I., Taksdal, T., Sindre, H., Brun, E., Tavornpanich, S., 2019. Field evaluation of diagnostic test sensitivity and specificity for salmonid alphavirus (SAV) infection and pancreas disease (PD) in farmed atlantic salmon (salmo salar 1.) in norway using bayesian latent class analysis. Front. Vet. Sci. 6. https://doi.org/10.3389/fvets.2019.00419

Janssen, K., Komen, H., Saatkamp, H.W., de Jong, M.C.M., Bijma, P., 2018. Derivation of the economic value of $\mathrm{R}(\mathrm{o})$ for macroparasitic diseases and application to sea lice in salmon. Genet. Sel. Evol. GSE 50, 47. https://doi.org/10.1186/s12711-018-0418-6

Jia, P., Breyta, R.B., Li, Q., Qian, X., Wu, B., Zheng, W., Wen, Z., Liu, Y., Kurath, G., Hua, Q., Jin, N., Liu, H., 2018. Insight into infectious hematopoietic necrosis virus (IHNV) in Chinese rainbow trout aquaculture from virus isolated from 7 provinces in 2010-2014. Aquaculture 496, 239-246. https://doi.org/10.1016/j.aquaculture.2018.06.062

Johnsen, I.A., Stien, L.H., Sandvik, A.D., Asplin, L., Oppedal, F., 2020. Optimal estimation of lice release from aquaculture based on ambient 
$\begin{array}{lllll}\text { temperatures. } & \text { Aquac. } & \text { Environ. } & \text { Interact. } & 12,\end{array}$ https://doi.org/10.3354/aeioo358

Johnson-Mackinnon, J.C., Crosbie, P.B.B., Karlsbakk, E., Marcos-Lopez, M., Paley, R., Nowak, B.F., Bridle, A.R., 2019. Multilocus Sequence Typing (MLST) and Random Polymorphic DNA (RAPD) Comparisons of Geographic Isolates of Neoparamoeba perurans, the Causative Agent of Amoebic Gill Disease. Pathog. Basel Switz. 8. https://doi.org/10.3390/pathogens8040244

Jones, A.E., Munro, L.A., Green, D.M., Morgan, K.L., Murray, A.G., Norman, R., Ryder, D., Salama, N.K.G., Taylor, N.G.H., Thrush, M.A., Wallace, I.S., Sharkey, K.J., 2019. The contact structure of Great Britain's salmon and trout aquaculture industry. Epidemics 28, 100342. https://doi.org/10.1016/j.epidem.2019.05.001

Jones, S.R.M., Long, A., MacWilliams, C., Polinski, M., Garver, K., 2020. Factors associated with severity of naturally occurring piscirickettsiosis in netpenand tank-reared juvenile Atlantic salmon at a research aquarium in western Canada. J. Fish Dis. 43, 49-55. https://doi.org/10.1111/jfd.13102

Karami, A.M., Bani, A., Pourkazemi, M., Ghasemi, M., Kania, P.W., Buchmann, K., 2018. Comparative susceptibilities and immune reactions of wild and cultured populations of Caspian trout Salmo trutta caspius to VHSV. Dis. Aquat. Organ. 128, 187-201. https://doi.org/10.3354/daoo3231

Karlsen, C., Ottem, K.F., Brevik, Ø.J., Davey, M., Sørum, H., Winther-Larsen, H.C., 2017. The environmental and host-associated bacterial microbiota of Arctic seawater-farmed Atlantic salmon with ulcerative disorders. J. Fish Dis. 40, 16451663. https://doi.org/10.1111/jfd.12632

Karzis, J., Petzer, I.-M., Donkin, E.F., Naidoo, V., 2018. Proactive udder health management in South Africa and monitoring of antibiotic resistance of Staphylococcus aureus; in dairy herds from 2001 to 2010. J. S. Afr. Vet. Assoc. 89, e1-e8. https://doi.org/10.4102/jsava.v89io.1490

Kelley, J.M., Rathinasamy, V., Elliott, T.P., Rawlin, G., Beddoe, T., Stevenson, M.A., Spithill, T.W., 2020. Determination of the prevalence and intensity of Fasciola hepatica infection in dairy cattle from six irrigation regions of Victoria, South-eastern Australia, further identifying significant triclabendazole 
resistance on three properties. Vet. Parasitol. 277, 109019. https://doi.org/10.1016/j.vetpar.2019.109019

Kelly, E., McAloon, C.G., O’Grady, L., Duane, M., Somers, J.R., Beltman, M.E., 2020. Cow-level risk factors for reproductive tract disease diagnosed by 2 methods in pasture-grazed dairy cattle in Ireland. J. DAIRY Sci. 103, 737-749. https://doi.org/10.3168/jds.2019-17064

Kibenge, M.J.T., Wang, Y., Gayeski, N., Morton, A., Beardslee, K., McMillan, B., Kibenge, F.S.B., 2019. Piscine orthoreovirus sequences in escaped farmed Atlantic salmon in Washington and British Columbia. Virol. J. 16, 41. https://doi.org/10.1186/s12985-019-1148-2

Knupp, C., Wiens, G.D., Faisal, M., Call, D.R., Cain, K.D., Nicolas, P., Van Vliet, D., Yamashita, C., Ferguson, J.A., Meuninck, D., Hsu, H.-M., Baker, B.B., Shen, L., Loch, T.P., 2019. Large-Scale Analysis of Flavobacterium psychrophilum Multilocus Sequence Typing Genotypes Recovered from North American Salmonids Indicates that both Newly Identified and Recurrent Clonal Complexes Are Associated with Disease. Appl. Environ. Microbiol. 85. https://doi.org/10.1128/AEM.02305-18

Kristoffersen, A.B., Devold, M., Aspehaug, V., Gjelstenli, O., Breck, O., Bang Jensen, B., 2018. Molecular tracing confirms that infection with infectious pancreatic necrosis virus follows the smolt from hatchery to grow-out farm. J. Fish Dis. 41, 1601-1607. https://doi.org/10.1111/jfd.12844

la Bastide, P.Y. de, Naumann, C., Hintz, W.E., 2018. Assessment of intraspecific variability in Saprolegnia parasitica populations of aquaculture facilities in British Columbia, Canada. Dis. Aquat. Organ. 128, 235-248. https://doi.org/10.3354/daoo3224

Lillehaug, A., Børnes, C., Grave, K., 2018. A pharmaco-epidemiological study of antibacterial treatments and bacterial diseases in Norwegian aquaculture from 2011 to 2016. Dis. Aquat. Organ. 128, 117-125. https://doi.org/10.3354/daoo3219

Lipkens, Z., Piepers, S., De Visscher, A., De Vliegher, S., 2019. Evaluation of test-day milk somatic cell count information to predict intramammary infection with major pathogens in dairy cattle at drying off. J. DAIRY Sci. 102, 4309-4321. https://doi.org/10.3168/jds.2018-15642 
Liu, H., Li, S., Meng, L., Dong, L., Zhao, S., Lan, X., Wang, J., Zheng, N., 2017. Prevalence, antimicrobial susceptibility, and molecular characterization of Staphylococcus aureus isolated from dairy herds in northern China. J. DAIRY Sci. 100, 8796-8803. https://doi.org/10.3168/jds.2017-13370

Loch, T.P., Faisal, M., 2018. Flavobacteria colonizing the early life stages of hatchery-incubated Chinook salmon Oncorhynchus tshawytscha (Walbaum 1792) are markedly diverse. J. Fish Dis. 41, 829-845. https://doi.org/10.1111/jfd.12795

Macchi, M.V., Suanes, A., Salaberry, X., Fernandez, F., Piaggio, J., Gil, A.D., 2020. Epidemiological study of neosporosis in Uruguayan dairy herds. Prev. Vet. Med. 179. https://doi.org/10.1016/j.prevetmed.2020.105022

MacKinnon, B., Jones, P., Hawkins, L., Dohoo, I., Stryhn, H., Vanderstichel, R., St-Hilaire, S., 2019. The epidemiology of skin ulcers in saltwater reared Atlantic salmon (Salmo salar) in Atlantic Canada. Aquaculture 501, 230-238. https://doi.org/10.1016/j.aquaculture.2018.11.035

Mahendran, S.A., Booth, R., Beekhuis, L., Manning, A., Blackmore, T., Vanhoudt, A., Bell, N., 2017. Assessing the effects of weekly preweaning health scores on dairy calf mortality and productivity parameters: cohort study. Vet. Rec. 181, 196. https://doi.org/10.1136/vr.104197

Mancilla-Schulz, J., Marín, S.L., Molinet, C., 2019. Dynamics of Caligus rogercresseyi (Boxshall \& Bravo, 2000) in farmed Atlantic salmon (Salmo salar) in southern Chile: Are we controlling sea lice? J. Fish Dis. 42, 357-369. https://doi.org/10.1111/jfd.12931

Mardones, F.O., Paredes, F., Medina, M., Tello, A., Valdivia, V., Ibarra, R., Correa, J., Gelcich, S., 2018. Identification of research gaps for highly infectious diseases in aquaculture: The case of the endemic Piscirickettsia salmonis in the Chilean salmon farming industry. Aquaculture 482, 211-220. https://doi.org/10.1016/j.aquaculture.2017.09.048

Medeiros, T.N.S., Lorenzetti, E., Massi, R.P., Alfieri, A.F., Alfieri, A.A., 2020. Neonatal diarrhea and rotavirus A infection in beef and dairy calves, Brazil, 20062015 [Diarreia neonatal e infecção por rotavírus A em bezerros de corte e leite, Brasil, 2006-2015]. Pesqui. Vet. Bras. 40, 7-11. https://doi.org/10.1590/16785150-PVB-5919 
Meyer, A, Burroughs, A, Sadler, R, Happold, J, Cowled, B, Mackenzie, C., Gallardo Lagno, AL, Cameron, A., 2019. Quantifying the effects of sea lice burden and lice bathing treatments on salmonid rickettsial septicaemia in commercial salmon and trout farms in Chile. Aquaculture 513, 734411. https://doi.org/10.1016/j.aquaculture.2019.734411

Meyer, A., Sadler, R., Bannister-Tyrrell, M., Gallardo Lagno, AL, Stegeman, A., Cameron, A., 2020. Is between-farm water-borne pathogen dissemination an important driver in the epidemiology of salmonid rickettsial septicaemia in Chile? Aquaculture 530, 735751. https://doi.org/10.1016/j.aquaculture.2020.735751

Milne, M.G., Graham, J., Allen, A., McCormick, C., Presho, E., Skuce, R., Byrne, A.W., 2019. Variation in Mycobacterium bovis genetic richness suggests that inwards cattle movements are a more important source of infection in beef herds than in dairy herds. BMC Microbiol. 19. https://doi.org/10.1186/s12866019-1530-7

Miranda, C.D., Godoy, F.A., Lee, M.R., 2018. Current Status of the Use of Antibiotics and the Antimicrobial Resistance in the Chilean Salmon Farms. Front. Microbiol. 9, 1284. https://doi.org/10.3389/fmicb.2018.01284

Miyama, T., Byaruhanga, J., Okamura, I., Nagahata, H., Murata, R., Mwebembezi, W., Muramatsu, Y., Makita, K., 2020. Prevalence of sub-clinical mastitis and its association with milking practices in an intensive dairy production region of Uganda. J. Vet. Med. Sci. 82, 488-493. https://doi.org/10.1292/jvms.190588

Mullin, B.R., Reyda, F.B., 2020. High Prevalence of the Copepod Salmincola californiensis in Steelhead Trout in Lake Ontario Following its Recent Invasion. J. Parasitol. 106, 198-200.

Myksvoll, M.S., Sandvik, A.D., Albretsen, J., Asplin, L., Johnsen, I.A., Karlsen, Ø., Kristensen, N.M., Melsom, A., Skardhamar, J., Ådlandsvik, B., 2018. Evaluation of a national operational salmon lice monitoring system-From physics to fish. PloS One 13, e0201338. https://doi.org/10.1371/journal.pone.0201338

Nekouei, O., Vanderstichel, R., Kaukinen, K.H., Thakur, K., Ming, T., Patterson, D.A., Trudel, M., Neville, C., Miller, K.M., 2019. Comparison of infectious agents detected from hatchery and wild juvenile Coho salmon in British 
Columbia, 2008-2018. PloS One 14, e0221956. https://doi.org/10.1371/journal.pone.0221956

Ngo, T.P.H., Bartie, K.L., Thompson, K.D., Verner-Jeffreys, D.W., Hoare, R., Adams, A., 2017. Genetic and serological diversity of Flavobacterium psychrophilum isolates from salmonids in United Kingdom. Vet. Microbiol. 201, 216-224. https://doi.org/10.1016/j.vetmic.2017.01.032

Olsen, A.B., Gulla, S., Steinum, T., Colquhoun, D.J., Nilsen, H.K., Duchaud, E., 2017. Multilocus sequence analysis reveals extensive genetic variety within Tenacibaculum spp. associated with ulcers in sea-farmed fish in Norway. Vet. Microbiol. 205, 39-45. https://doi.org/10.1016/j.vetmic.2017.04.028

Otten, N.D., Toft, N., Thomsen, P.T., Houe, H., 2019. Evaluation of the performance of register data as indicators for dairy herds with high lameness prevalence. ACTA Vet. Scand. 61, 49. https://doi.org/10.1186/s13028-019-0484-y

Pajdak-Czaus, J., Platt-Samoraj, A., Szweda, W., Siwicki, A.K., TerechMajewska, E., 2019. Yersinia ruckeri-A threat not only to rainbow trout. Aquac. Res. 50, 3083-3096. https://doi.org/10.1111/are.14274

Pantoja, J.C.F., Correia, L.B.N., Rossi, R.S., Latosinski, G.S., 2020. Association between teat-end hyperkeratosis and mastitis in dairy cows: A

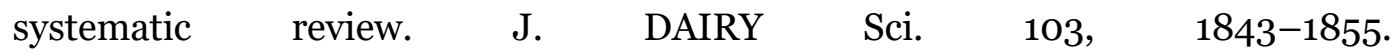
https://doi.org/10.3168/jds.2019-16811

Park, H.-S., Moon, D.C., Hyun, B.-H., Lim, S.-K., 2019. Short communication: Occurrence and persistence of Prototheca zopfii in dairy herds of Korea. J. DAIRY Sci. 102, 2539-2543. https://doi.org/10.3168/jds.2018-14979

Peruzzi, S., Puvanendran, V., Riesen, G., Seim, R.R., Hagen, Ø., MartínezLlorens, S., Falk-Petersen, I.-B., Fernandes, J.M.O., Jobling, M., 2018. Growth and development of skeletal anomalies in diploid and triploid Atlantic salmon (Salmo salar) fed phosphorus-rich diets with fish meal and hydrolyzed fish protein. PloS One 13, e0194340. https://doi.org/10.1371/journal.pone.0194340

Petersen, M.B., Wawegama, N.K., Denwood, M., Markham, P.F., Browning, G.F., Nielsen, L.R., 2018. Mycoplasma bovis antibody dynamics in naturally exposed dairy calves according to two diagnostic tests. BMC Vet. Res. 14. https://doi.org/10.1186/s12917-018-1574-1 
Price, D., Ibarra, R., Sánchez, J., St-Hilaire, S., 2017. A retrospective assessment of the effect of fallowing on piscirickettsiosis in Chile. Aquaculture 473, 400-406. https://doi.org/10.1016/j.aquaculture.2017.02.034

Räihä, V., Sundberg, L.-R., Ashrafi, R., Hyvärinen, P., Karvonen, A., 2019. Rearing background and exposure environment together explain higher survival of aquaculture fish during a bacterial outbreak. J. Appl. Ecol. 56, 1741-1750. https://doi.org/10.1111/1365-2664.13393

Reimus, K., Orro, T., Emanuelson, U., Viltrop, A., Mõtus, K., 2018. On-farm mortality and related risk factors in Estonian dairy cows. Prev. Vet. Med. 155, 5360. https://doi.org/10.1016/j.prevetmed.2018.04.006

Rodríguez, F.H., Flores-Mara, R., Yoshida, G.M., Barría, A., Jedlicki, A.M., Lhorente, J.P., Reyes-López, F., Yáñez, J.M., 2019. Genome-Wide Association Analysis for Resistance to Infectious Pancreatic Necrosis Virus Identifies Candidate Genes Involved in Viral Replication and Immune Response in Rainbow Trout (Oncorhynchus mykiss). G3 Bethesda Md 9, 2897-2904. https://doi.org/10.1534/g3.119.400463

Røsæg, M.V., Garseth, Å.H., Brynildsrud, O.B., Jansen, M.D., 2019. Pancreas disease caused by Salmonid alphavirus subtype 2 reduces growth and feed conversion in farmed Atlantic salmon. Prev. Vet. Med. 169, 104699. https://doi.org/10.1016/j.prevetmed.2019.104699

Rosaeg, M.V., Rimstad, E., Guttvik, A., Skjelstad, B., Bendiksen, E.A., Garseth, A.H., 2019. Effect of pancreas disease caused by SAV 2 on protein and fat digestion in Atlantic salmon. J. FISH Dis. 42, 97-108. https://doi.org/10.1111/jfd.12914

Rypuła, K., Płoneczka-Janeczko, K., Czopowicz, M., Klimowicz-Bodys, M.D., Shabunin, S., Siegwalt, G., 2020. Occurrence of BVDV Infection and the Presence of Potential Risk Factors in Dairy Cattle Herds in Poland. Anim. Open Access J. MDPI 10. https://doi.org/10.3390/ani10020230

Salama, N.K.G., Dale, A.C., Ivanov, V.V., Cook, P.F., Pert, C.C., Collins, C.M., Rabe, B., 2018. Using biological-physical modelling for informing sea lice dispersal in Loch Linnhe, Scotland. J. Fish Dis. 41, 901-919. https://doi.org/10.1111/jfd.12693 
Samsing, F., Johnsen, I., Dempster, T., Oppedal, F., Treml, E.A., 2017. Network analysis reveals strong seasonality in the dispersal of a marine parasite and identifies areas for coordinated management. Landsc. Ecol. 32, 1953-1967. https://doi.org/10.1007/s10980-017-0557-o

Samsing, F., Johnsen, I., Treml, E.A., Dempster, T., 2019. Identifying "firebreaks" to fragment dispersal networks of a marine parasite. Int. J. Parasitol. 49, 277-286. https://doi.org/10.1016/j.ijpara.2018.11.005

Scott, H., Gilleard, J.S., Jelinski, M., Barkema, H.W., Redman, E.M., Avramenko, R.W., Luby, C., Kelton, D.F., Bauman, C.A., Keefe, G., Dubuc, J., Uehlinger, F.D., 2019. Prevalence, fecal egg counts, and species identification of gastrointestinal nematodes in replacement dairy heifers in Canada. J. DAIRY Sci. 102, 8251-8263. https://doi.org/10.3168/jds.2018-16115

Scott, K., Kelton, D.F., Duffield, T.F., Renaud, D.L., 2019. Risk factors identified on arrival associated with morbidity and mortality at a grain-fed veal facility: A prospective, single-cohort study. J. DAIRY Sci. 102, 9224-9235. https://doi.org/10.3168/jds.2019-16829

Serrano-Martínez, M.E., Cisterna, C.A.B., Romero, R.C.E., Huacho, M.A.Q., Bermabé, A.M., Albornoz, L.A.L., 2019. Evaluation of abortions spontaneously induced by Neospora caninum and risk factors in dairy cattle from Lima, Peru. Rev. Bras. Parasitol. Vet. Braz. J. Vet. Parasitol. Orgao Of. Col. Bras. Parasitol. Vet. 28, 215-220. https://doi.org/10.1590/S1984-29612019026

Småge, S.B., Brevik, Ø.J., Frisch, K., Watanabe, K., Duesund, H., Nylund, A., 2017. Concurrent jellyfish blooms and tenacibaculosis outbreaks in Northern Norwegian Atlantic salmon (Salmo salar) farms. PloS One 12, e0187476. https://doi.org/10.1371/journal.pone.0187476

Söderlund, R., Hakhverdyan, M., Aspan, A., Jansson, E., 2018. Genome analysis provides insights into the epidemiology of infection with flavobacterium psychrophilum among farmed salmonid fish in Sweden. Microb. Genomics 4. https://doi.org/10.1099/mgen.o.000241

Soler-Jiménez, L.C., Paredes-Trujillo, A.I., Vidal-Martínez, V.M., 2017. Helminth parasites of finfish commercial aquaculture in Latin America. J. Helminthol. 91, 110-136. https://doi.org/10.1017/So022149X16000833 
Solomon, D., Shpigel, N.Y., Salamon, H., Goshen, T., 2020. Epidemiology and risk factors of pyelonephritis in Israeli dairy cattle. Isr. J. Vet. Med. 75, 6-11.

Sørensen, J., Vendramin, N., Priess, C., Kannimuthu, D., Henriksen, N.H., Iburg, T.M., Olesen, N.J., Cuenca, A., 2020. Emergence and Spread of Piscine orthoreovirus Genotype 3. Pathog. Basel Switz. 9. https://doi.org/10.3390/pathogens9100823

Svendsen, J.C., Nylund, S., Kristoffersen, A.B., Takle, H., Fossberg Buhaug, J., Jensen, B.B., 2019. Monitoring infection with Piscine myocarditis virus and development of cardiomyopathy syndrome in farmed Atlantic salmon (Salmo salar L.) in Norway. J. Fish Dis. 42, 511-518. https://doi.org/10.1111/jfd.12974

Terceti, M.S., Vences, A., Matanza, X.M., Dalsgaard, I., Pedersen, K., Osorio, C.R., 2018. Molecular Epidemiology of Photobacterium damselae subsp damselae Outbreaks in Marine Rainbow Trout Farms Reveals Extensive Horizontal Gene Transfer and High Genetic Diversity. Front. Microbiol. 9. https://doi.org/10.3389/fmicb.2018.02155

Ulrich, K., Wehner, S., Bekaert, M., Di Paola, N., Dilcher, M., Muir, K.F., Taggart, J.B., Matejusova, I., Weidmann, M., 2018. Molecular epidemiological study on Infectious Pancreatic Necrosis Virus isolates from aquafarms in Scotland over three decades. J. Gen. Virol. 99, 1567-1581. https://doi.org/10.1099/jgv.0.001155

Urie, N.J., Lombard, J.E., Shivley, C.B., Kopral, C.A., Adams, A.E., Earleywine, T.J., Olson, J.D., Garry, F.B., 2018. Preweaned heifer management on US dairy operations: Part V. Factors associated with morbidity and mortality in preweaned dairy heifer calves. J. DAIRY Sci. 101, 9229-9244. https://doi.org/10.3168/jds.2017-14019

Valldecabres, A., Pires, J.A.A., Silva-Del-Río, N., 2019. Cow-level factors associated with subclinical hypocalcemia at calving in multiparous Jersey cows. J. DAIRY Sci. 102, 8367-8375. https://doi.org/10.3168/jds.2018-16180

Venjakob, P.L., Staufenbiel, R., Heuwieser, W., Borchardt, S., 2019. Serum calcium dynamics within the first 3 days in milk and the associated risk of acute puerperal metritis. J. DAIRY Sci. 102, 11428-11438. https://doi.org/10.3168/jds.2019-16721 
Vennerström, P., Välimäki, E., Lyytikäinen, T., Hautaniemi, M., Vidgren, G., Koski, P., Virtala, A.-M., 2017. Viral haemorrhagic septicaemia virus (VHSV Id) infections are detected more consistently using syndromic vs. active surveillance. Dis. Aquat. Organ. 126, 111-123. https://doi.org/10.3354/daoo3161

Wang, Yu, Robertson, I.D., Cheng, S., Wang, Yan, Hou, L., Wang, G., Wu, X., Li, X., Chen, Y., Guo, A., 2020. Evaluation of a milk ELISA as an alternative to a serum ELISA in the determination of the prevalence and incidence of brucellosis in dairy herds in Hubei Province, China. Prev. Vet. Med. 182. https://doi.org/10.1016/j.prevetmed.2020.105086

Yang, D.A., Heuer, C., Laven, R., Vink, W.D., Chesterton, R.N., 2017. Farm and cow-level prevalence of bovine digital dermatitis on dairy farms in Taranaki, New Zealand. N. Z. Vet. J. 65, 252-256. https://doi.org/10.1080/00480169.2017.1344587

Yang, D.A., Johnson, W.O., Müller, K.R., Gates, M.C., Laven, R.A., 2019. Estimating the herd and cow level prevalence of bovine digital dermatitis on New Zealand dairy farms: A Bayesian superpopulation approach. Prev. Vet. Med. 165, 76-84. https://doi.org/10.1016/j.prevetmed.2019.02.014

Yugo, D.M., Cossaboom, C.M., Heffron, C.L., Huang, Y.-W., Kenney, S.P., Woolums, A.R., Hurley, D.J., Opriessnig, T., Li, L., Delwart, E., Kanevsky, I., Meng, X.-J., 2019. Evidence for an unknown agent antigenically related to the hepatitis E virus in dairy cows in the United States. J. Med. Virol. 91, 677-686. https://doi.org/10.1002/jmv.25339

Zalcman, E., Burroughs, A., Meyer, A., Mackenzie, C., Sadler, R., Stevenson, M., Ward, M., Gallardo Lagno, A., Happold, J., Cameron, A., Cowled, B., 2021. Sea lice infestation of salmonids in Chile between 2011 and 2017: Use of regulatory data to describe characteristics and identify risk factors. Aquaculture 530, 735752. https://doi.org/10.1016/j.aquaculture.2020.735752 


\section{CHAPTER 7}

\section{General discussion}




\section{Introduction}

Aquaculture is an increasingly important source of high-quality animal protein worldwide. While salmonids are the second largest export product of Chile in terms of revenue, fish producers face significant issues in terms of fish health management. As seen in the general introduction of this thesis, SRS is major threat to the sustainability of the industry. Sea-based fish production generally involves complex systems including multiple species and pathogens. As epidemiological research allows incorporation of multiple factors in understanding disease issues, the discipline is well placed to provide tools to the aquaculture sector to improve its long-term sustainability. The work presented in this thesis explored how data and epidemiological analysis can contribute to such a goal in the context of salmonid production in Chile, based on a research platform developed to integrate the health and management data routinely collected on salmonid aquaculture farms (PIISAC).

The present chapter starts with a summary of the main findings of the work outlined in this thesis. Then, two overarching topics are further discussed. The first topic contrasts the current approaches to statistical model building, selection and inference. The second topic explores the potential for qualitative methods to be used further in veterinary epidemiology. The discussion ends with considerations on recent developments in research of waterborne transmission of SRS and futures opportunities for improving the understanding of the disease.

\section{Effectiveness of key interventions to control SRS on Chilean sea farms}

Chapter 2 looked at how the analysis of routine production and health data can support better within-farm interventions to control SRS on sea farms. In particular, the study assessed the effectiveness of antimicrobial treatment of infected fish, more specifically oxytetracycline and florfenicol administration, to manage mortality outbreaks in sea farms. The statistical regression analysis, using generalised linear mixed-effect models, considered different aspects linked to the treatment itself (e.g., time of administration, length and route of treatment) while accounting for confounding effects at fish, management and environment levels. 
The results show that treating as soon as possible after the start of the outbreak is a key factor for success, both for Atlantic salmon and rainbow trout farms. Treating cages simultaneously and minimising potential treatment interruptions were also important for Atlantic salmon. For rainbow trout, longer in-feed treatments appeared more effective at controlling mortality, and a large proportion of unexplained variance remained at the company and farm level, suggesting that some companies and farms already apply more effective practices than others. Such results could be used in further analyses to identify treatment strategies which minimise both the disease-related mortality and the quantity of antibiotics used over an entire production cycle.

Chapter 3 considered the interplay between sea lice burden, sea lice management (using bathing treatments) and SRS mortality. Observation periods at cage-level were defined and the sea lice burden and the frequency of bath treatments (e.g., azamethiphos or synthetic pyrethroids such as deltamethrin and cypermethrin) relating to these observation periods were quantified. Then, regression models were used to assess the effect of these two exposure parameters as well as their interaction on the level of SRS-attributed mortality at the end of the observation period. Results showed that both sea lice burden and bath treatments are risk factors for increased SRS mortality in Atlantic salmon and rainbow trout. This study using data collected in commercial production settings confirms the synergistic relationship between parasitic burden and piscirickettsiosis that had been previously observed in experimental conditions (Figueroa et al., 2017; Lhorente et al., 2014). Another study with similar conclusions has since been published (Arriagada et al., 2019). Such evidence highlights the challenge faced by veterinarians and fish health managers in managing ectoparasites while not increasing the stressors applied to the fish.

While chapter 2 and chapter 3 considered interventions to control SRS at the farm-level, chapter 4 provides a slightly broader perspective on disease dynamics by looking at the spatiotemporal autocorrelation in SRS mortality between sea farms located at different distances. Sea farms are distributed in the channels and inlets formed by the intricate Chilean coastline. Tides and currents create complex water movement patterns which, ultimately, mean that these farms 
are interconnected by water flows. This study looked at the effect of SRS mortality on source farms on the SRS mortality of target farms, as a function of distance, time lag and mortality levels. The spatiotemporal component of this correlation was modelled in generalised additive mixed effect models using linear functional terms. The results confirmed the spatiotemporal correlation in SRS mortality in different farms, as previously shown by others (Rees et al., 2014). However, the analysis did not provide support for the hypothesis that this correlation is due to waterborne pathogen dissemination between farms. The analysis suggested that mechanisms other than waterborne pathogen dissemination better explain the observed correlation. Further studies in dissemination pathways are warranted, for example investigating the role of fomites and wildlife in the epidemiology of $P$. salmonis in Chile. In addition, this work did not provide conclusive evidence for a threshold effect above which farms pose a substantially larger health risk to their neighbours. Such information is of importance for policy making, given that the current SRS management regulations target farms which exceed a set threshold of SRS mortality.

The results of the three studies in this first part of the thesis (chapters 2 to 4), as well as an additional study on the effectiveness of vaccination (Happold et al., 2020), were presented to and discussed with the producers in Chile. They will contribute to the growing evidence base available for veterinarians and fish health managers to make better decisions regarding the management of SRS on sea farms. This work, including the epidemiological studies and the development of the PIISAC platform, shows that analysis of routine production and health data can provide useful insights into the effectiveness of within-farm interventions to control SRS.

\section{Sources of data to improve epidemiological knowledge on salmonid health}

In the second part of this work, the role of data in epidemiological research was considered in more detail. The previous three chapters were the product of using a data integration platform (PIISAC), developed with the aim of improving how routine data is utilised, to generate better information and fill knowledge gaps 
about SRS management in field conditions. However, despite the apparent value of the platform for epidemiological research, the implementation of an industry governance body to manage the platform in the longer term and attempts to extend the life of the platform beyond the end of the initial funded project were not successful. The study presented in chapter 5 identified possible reasons for these outcomes based on key informant interviews. The results of this qualitative study, summarised in Figure 1, can be classified under two categories of obstacles: issues related to the platform's environment and those related to the platform implementation itself. The results highlight the limits of project-based approaches and reinforce the need for more targeted consultations during the design stage of such initiatives. This is often not the case, given that the design stage of projects is often conducted with little to no funding, limiting the amount of time which can be invested in such consultations. However, such consultations are critical to prepare an implementation plan which will address context-specific challenges as well as address the needs of the participants.
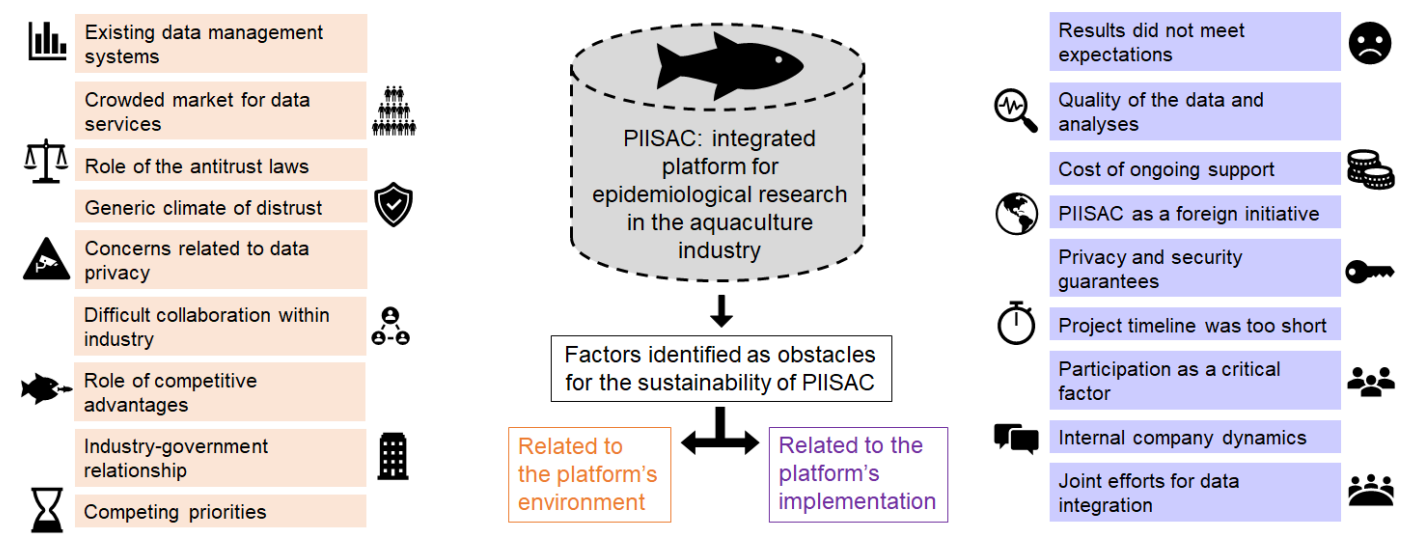

Figure 1. Summary of the findings from Chapter 5 (Source: graphical abstract associated with the publication, https://doi.org/10.1016/j.compag.2020.105853)

More work to assess the most appropriate arrangements for data curation and governance is needed to support further data integration platforms for fish health. These platforms, where producers contribute production and health data which are analysed by scientists to generate new knowledge, appear to be a powerful alternative to costly and limited field data collection (e.g., surveys). In 
addition to PIISAC, similar data integration platforms related to salmonid production include Fish-iTrends in Canada (Gautam et al., 2017) and AquaCloud in Norway (Hoel, 2018) which both focus on sea lice burden and management. A key aspect of data integration platforms is that they are able to support both improved routine data management and epidemiological research, providing benefits to all parties involved.

An alternative approach to improving the use and re-use of data in scientific communities was proposed in 2016, under the form of the FAIR (Findable, Accessible, Interoperable, Reusable) principles (Wilkinson et al., 2016). The possibility to re-use the data produced by other scientists provides another means to improve the use of data for better fish health management. This can minimise the need for new data collection when existing data are appropriate to answer new research questions. However, these principles are relatively recent, and changing long-standing habits is generally a time-consuming task. Chapter 6 investigated the progress towards sharing and re-using data among the aquaculture epidemiology community. The results showed that research data are still far from meeting the FAIR principles in non-molecular epidemiology of salmonids. Most datasets $(\approx 80 \%)$ associated with publications between 2017 and 2020 were neither findable nor accessible, a status previously named "re-useless" data by others (Mons et al., 2017). Comparison with epidemiological research in dairy cattle, which has a much longer and abundant track record revealed a similar situation. In turn, molecular epidemiology displayed more maturity in terms of FAIRness, with over $80 \%$ of selected publications displaying good results on FAIR indicators in this discipline. Comparisons with other disciplines may allow veterinary epidemiologists to progress towards more re-use of data, keeping in mind the confidential nature of some of the data used in such research. The work in this chapter highlighted the conflicting objectives between the push towards open science and data protection requirements. In animal science, considerations related to commercial aspects and privacy add a layer of complexity that may not be encountered in some of the other scientific disciplines. There is a clear need for innovative approaches, such as federated learning for example, to allow researchers to generate value from protected data. 
This concludes the summary of the previous chapters. The following sections aim to discuss some of the methodological approaches used in this research. Questions relating to statistical modelling raised by the work presented in chapters 2 to 4 are discussed first, followed by aspects related to the use of qualitative research in epidemiology, raised during chapter $\mathbf{5}$.

\section{Causal analysis and statistical modelling}

Causal analysis has been the subject of many theoretical and practical developments in the past twenty years. While several definitions have been, and are still, used in epidemiology for the notion of 'cause', as reviewed by Parascandola \& Weed (2001) for example, there is no accepted consensus at present. The work of Pearl (Pearl, 2000, 2009) has had particular impact on public health epidemiology, as well as the introduction of directed acyclic graphs (DAGs) (also called causal diagrams) to guide causal analysis (Greenland et al., 1999; Pearl, 1995). These developments have also sparked intense debates in public health (Broadbent, 2015; Vandenbroucke et al., 2016). In contrast, there is much less awareness in the veterinary science community around these concepts. There is a critical need for veterinary epidemiologists to reflect on how to conduct causal analysis, and how such work is integrated with statistical analysis. In the quantitative data analysis section of this work, an information theoretic approach (K. Burnham \& Anderson, 2002) was used for making inferences from statistical models. This approach places great emphasis on developing a range of scientific hypotheses and their corresponding statistical models a priori. In particular, the use of DAGs to generate these hypotheses allows formal consideration of the nature of variables, including primary exposures, confounders, mediators and colliders. The approach also invites the researcher to reflect on possible causal associations separately from the statistical modelling itself.

The second benefit from this approach is that it provides an alternative to the much-debated approach to model inference based on null hypothesis testing. Information theory has been formally developed in ecology and evolution, where many examples can be found. However, in the veterinary epidemiology area, null hypothesis testing remains the dominant approach, with the Bayesian approach 
also gaining traction. Despite some changes occurring over time, the use of null hypothesis testing remains highly prevalent in life sciences, for example in clinical medicine (Silva-Ayçaguer et al., 2010) and conservation biology (Fidler et al., 2006). Authors have argued whether the different approaches to model inference are compatible and can be used in a complementary way (Lukacs et al., 2007; Stephens et al., 2005, 2007). Regardless, the work presented in this thesis shows that the information theoretic approach provides a formal method to include existing knowledge and scientific reasoning in the modelling work, within a frequentist approach. This aspect proved useful when presenting and discussing results with industry or government stakeholders, who may not be familiar with the Bayesian framework at all.

The information theoretic approach provided two other types of benefits for the studies assessing the effectiveness of interventions on SRS and identifying factors which influence this effectiveness. First, the use of a criterion such as the Akaike Information Criterion or the Bayesian Information Criterion, depending on the context (K. P. Burnham \& Anderson, 2004), allows quantification and ranking of the level of support in the data for competing hypotheses. Then, parameter estimates and confidence intervals may be assessed more critically to assess the biological significance of the effects, and avoiding what has been named the 'significance fallacy' (Silva-Ayçaguer et al., 2010). Second, making inferences from an average model which combines the models that are supported by the data improves our ability to account for the complexity of SRS dynamics in sea farms. These benefits are very relevant in veterinary epidemiology, where research questions are rarely straightforward and multiple competing or complementary hypotheses are generally considered.

Understanding the experience gained in other disciplines as well as reflecting on the assumptions underlying the methods that are used in veterinary epidemiology are two of the ways to improve research practices, toward more robust studies and conclusions. A third way is to explore the use of methods that are less commonly employed. The next section presents an outline of what qualitative approaches can contribute to veterinary epidemiology. 


\section{Using qualitative approaches in veterinary research}

Qualitative approaches have been used in public health research for a long time, and the role they play in epidemiological research in particular is increasingly important (Bannister-Tyrrell \& Meiqari, 2020). These approaches are critical to understand human behaviours associated with health outcomes, and therefore, to develop health interventions which are appropriate for a given social, cultural, and political context. On the veterinary side, researchers gained interest in qualitative methods in the context of the participatory rural appraisal and rapid rural appraisal approaches initiated in the late 1980s (Alders et al., 2020; Chambers et al., 1989). However, apart from such approaches to support rural development in low- and middle-income countries, the use of qualitative research in veterinary epidemiology is much less common than it is in public health research, although there is interest both from the veterinary medicine (Christley \& Perkins, 2010; May, 2018) and veterinary epidemiology communities. One possible explanation is the general lack of training of veterinary scientists in these approaches. Consequently, researchers may not be aware of the benefits of qualitative or mixedmethod studies. They may also be dissuaded by the amount of learning required to gain familiarity with the many theoretical traditions, data collection techniques and data analysis methods which are available. Degeling \& Rock (2020) have summarised the data collection instruments which have been applied to study questions related to One Health: individual interviews, focus group discussions, participant observation, storyboarding, and several others. These authors show that qualitative research has provided valuable insights in many aspects related to One Health, in particular on how and why people comply with health-related interventions or not. For quantitative health researchers new to qualitative research, there is also a wealth of published literature and books which provide introductions to the approach, as well as tools to understand and assess the validity of published studies (Kuper et al., 2008; Mays \& Pope, 1995).

In the survey of barriers to adoption of PIISAC (chapter 5), a qualitative study was conducted, with an inductive analysis, as it appeared best placed to answer the open-ended research question, 'which reasons can explain the lack of sustainability of the PIISAC epidemiological data integration platform?'. 
Alternative options to qualitative interviews for exploring opinions are quantitative surveys, such as Likert scale surveys, and consensus methods, such as the Delphi method. Here, qualitative interviews allowed exploration of the views of relevant stakeholders and collection of data on unanticipated factors, which would have been much more difficult to identify with a quantitative survey for example. In addition, collecting common but also uncommon views was of particular interest, rather than reaching a consensus. It is important to note that the research question was not an epidemiological question by nature. Nonetheless, this study showed how such methods allow exploration of the views of stakeholders involved in interventions aiming at improving animal health, and, ultimately, to design better interventions.

Trained as a quantitative scientist, this study was a key learning experience for this dissertation's author. This section summarises some of the learnings gained during this journey. The beginner must seek the experience and oversight of an experienced qualitative researcher, as recommended by Degeling \& Rock (2020) for instance. Indeed, some of the methods, such as the thematic analysis used in chapter 5, may appear deceptively easy. This should not lead to overlooking the strategies required to ensure rigour and validity in qualitative studies, as these are different from strategies used in quantitative research. To do so, an understanding of philosophical paradigms behind the different approaches is required, as well as understanding the key differences in terms of data collection, analysis and reporting methods. While this is not the only difference between the two, the dichotomy between constructivist and positivist paradigms has long been recognised as a key difference between qualitative and quantitative research (Baum, 1995). However, the quantitative epidemiologist is not necessarily aware of the philosophical paradigm underlying the work that they conduct. Thus, using qualitative methods requires to both acknowledge this position and adopt a different mindset. Realising the role played by the researcher in their work was a valuable learning experience, as it allowed conscious identification of where and how the researcher's subjectivity influences the analysis. Identifying one's biases and interpreting their effects on the results is a competence transferable to quantitative research, where it is often overlooked. During the study described in 
chapter 5, this topic was particularly salient as the team conducting and analysing the interviews was partly made up of researchers involved in the development of PIISAC. Although this is clearly a limitation of the study, the use of a qualitative survey allowed conscious identification of this subjectivity and comparison of the team's expectations with the views provided by participants, creating a fuller and more complete picture of the situation. Finally, external validity, also called generalisability or transferability, is an important concept in both quantitative and qualitative research. However, external validity is not always an objective of qualitative studies. Qualitative work is often concerned with providing an in-depth analysis related to a given group of stakeholders in their specific context. Regardless, qualitative studies may be subject to biases as quantitative studies are, for example selection bias. Depending on the research objectives, such biases may be intentional, and would be considered in the interpretation.

\section{Recent developments and conclusion}

Further simulation modelling work is currently ongoing to better understand SRS transmission in Chile, using the InterSpread Plus model (Wada et al., 2020). In addition, Bravo et al (2020) have recently published a key study looking at waterborne transmission of SRS in Chilean salmonid farms. Their work considered between-farm connectivity based on a recently developed oceanographic model, which includes hydrodynamic features (water movements linked to tides and currents). The farm connectivity matrices were combined with a state-based epidemiological model of SRS to assess the correlation in disease-related mortality levels between farms. The analysis also accounted for the effects of water temperature and salinity on bacterial transmission. The authors found a strong correlation between SRS mortality on farms with the infection level in farms located upstream. While such findings provide additional evidence of an association between water-connected farms in terms of SRS infection, the importance of different pathways for transmission of SRS infection to new stock remains unclear. A recent study from Norway used network analysis to understand how salmonid alphavirus, the causative agent of pancreas disease in salmonids, is transmitted between farms (Amirpour Haredasht et al., 2019). The authors found 
that boat movements between farms explained disease incidence better than seaway distances, suggesting that indirect transmission via the boats may pose a larger risk than waterborne transmission. Such methods could contribute to further investigate these aspects in the context of SRS in the Chilean aquaculture. Last, molecular techniques such as whole-genome sequencing may also contribute to identify disease transmission routes, including in the aquaculture sector (Bayliss et al., 2017). Methods to better combine the findings of epidemiological enquiries and molecular sequencing of the isolates, such as tree-based methods (Klinkenberg et al., 2017), are increasingly available and could contribute to further improve the understanding of SRS dynamics in Chile. 


\section{References}

Alders, R. G., Ali, S. N., Ameri, A. A., Bagnol, B., Cooper, T. L., Gozali, A., Hidayat, M. M., Rukambile, E., Wong, J. T., \& Catley, A. (2020). Participatory Epidemiology: Principles, Practice, Utility, and Lessons Learnt. Frontiers in Veterinary Science, 7. https://doi.org/10.3389/fvets.2020.532763

Amirpour Haredasht, S., Tavornpanich, S., Jansen, M. D., Lyngstad, T. M., Yatabe, T., Brun, E., \& Martínez-López, B. (2019). A stochastic network-based model to simulate the spread of pancreas disease (PD) in the Norwegian salmon industry based on the observed vessel movements and seaway distance between marine farms. Preventive Veterinary Medicine, 167, 174-181. https://doi.org/10.1016/j.prevetmed.2018.05.019

Arriagada, G., Hamilton-West, C., Nekouei, O., Foerster, C., Müller, A., Lara, M., \& Gallardo-Escárate, C. (2019). Caligus rogercresseyi infestation is associated with Piscirickettsia salmonis-attributed mortalities in farmed salmonids in Chile. $\begin{array}{llll}\text { Preventive } \quad \text { Veterinary } & \text { Medicine, } & 171, & 104771 .\end{array}$ https://doi.org/10.1016/j.prevetmed.2019.104771

Bannister-Tyrrell, M., \& Meiqari, L. (2020). Qualitative research in epidemiology: Theoretical and methodological perspectives. Annals of Epidemiology, 49, 27-35. https://doi.org/10.1016/j.annepidem.2020.07.008

Baum, F. (1995). Researching public health: Behind the qualitativequantitative methodological debate. Social Science \& Medicine, 4O(4), 459-468. https://doi.org/10.1016/0277-9536(94)E0103-Y

Bayliss, S. C., Verner-Jeffreys, D. W., Bartie, K. L., Aanensen, D. M., Sheppard, S. K., Adams, A., \& Feil, E. J. (2017). The Promise of Whole Genome Pathogen Sequencing for the Molecular Epidemiology of Emerging Aquaculture $\begin{array}{lllll}\text { Pathogens. Frontiers in Microbiology, } & \text { 8, } & 121 .\end{array}$ https://doi.org/10.3389/fmicb.2017.00121

Bravo, F., Sidhu, J. P. S., Bernal, P., Bustamante, R. H., Condie, S., Gorton, B., Herzfeld, M., Jimenez, D., Mardones, F. O., Rizwi, F., \& Steven, A. D. L. (2020). Hydrodynamic connectivity, water temperature, and salinity are major drivers of piscirickettsiosis prevalence and transmission among salmonid farms in Chile. 
https://doi.org/10.3354/aeioo368

Broadbent, A. (2015). Causation and prediction in epidemiology: A guide to the "methodological revolution." Studies in History and Philosophy of Biological and Biomedical Sciences, https://doi.org/10.1016/j.shpsc.2015.06.004

Burnham, K., \& Anderson, D. (2002). Model selection and multimodel inference: A practical information-theoretic approach, 2nd edition. Springer, New York.

Burnham, K. P., \& Anderson, D. R. (2004). Multimodel Inference: Understanding AIC and BIC in Model Selection. Sociological Methods \& Research, 33(2), 261-304. https://doi.org/10.1177/0049124104268644

Chambers, R., Pacey, A., \& Thrupp, L. A. (1989). Farmer First: Farmer innovation and agricultural research. Intermediate Technology Publications. https://practicalactionpublishing.com/book/705/farmer-first

Christley, R. M., \& Perkins, E. (2010). Researching hard to reach areas of knowledge: Qualitative research in veterinary science. Equine Veterinary Journal, 42(4), 285-286. https://doi.org/10.1111/j.2042-3306.2010.00074.x

Degeling, C., \& Rock, M. (2020). Qualitative Research for One Health: From Methodological Principles to Impactful Applications. Frontiers in Veterinary Science, 7. https://doi.org/10.3389/fvets.2020.00070

Fidler, F., Burgman, M. A., Cumming, G., Buttrose, R., \& Thomason, N. (2006). Impact of Criticism of Null-Hypothesis Significance Testing on Statistical Reporting Practices in Conservation Biology. Conservation Biology, 2O(5), 15391544. https://doi.org/10.1111/j.1523-1739.2006.00525.x

Figueroa, C., Bustos, P., Torrealba, D., Dixon, B., Soto, C., Conejeros, P., \& Gallardo, J. A. (2017). Coinfection takes its toll: Sea lice override the protective effects of vaccination against a bacterial pathogen in Atlantic salmon. Scientific Reports, 7(1). https://doi.org/10.1038/s41598-017-18180-6

Gautam, R., Vanderstichel, R., Boerlage, A. S., Revie, C. W., \& Hammell, K. L. (2017). Effect of timing of count events on estimates of sea lice abundance and 
interpretation of effectiveness following bath treatments. Journal of Fish Diseases, 4O(3), 367-375. https://doi.org/10.1111/jfd.12519

Greenland, S., Pearl, J., \& Robins, J. M. (1999). Causal Diagrams for Epidemiologic Research. Epidemiology, 10(1), 37-48. JSTOR.

Happold, J., Sadler, R., Meyer, A., Cowled, B., Mackenzie, C., Gallardo Lagno, A., \& Cameron, A. (2020). Effectiveness of vaccination for the control of salmonid rickettsial septicaemia in commercial salmon and trout farms in Chile. Aquaculture, 520, 734968. https://doi.org/10.1016/j.aquaculture.2020.734968

Hoel, T. (2018, September 17). Data science helps Norway's fish farmers keep salmon populations healthy. IBM Cloud Computing News - Big Data. https://www.ibm.com/blogs/cloud-computing/2018/o9/17/data-sciencenorway-fish-farmers/

Klinkenberg, D., Backer, J. A., Didelot, X., Colijn, C., \& Wallinga, J. (2017). Simultaneous inference of phylogenetic and transmission trees in infectious disease outbreaks. PLOS Computational Biology, 13(5), e1005495. https://doi.org/10.1371/journal.pcbi.1005495

Kuper, A., Reeves, S., \& Levinson, W. (2008). An introduction to reading and appraising qualitative research. BMJ, 337, a288. https://doi.org/10.1136/bmj.a288

Lhorente, J. P., Gallardo, J. A., Villanueva, B., Carabaño, M. J., \& Neira, R. (2014). Disease Resistance in Atlantic Salmon (Salmo salar): Coinfection of the Intracellular Bacterial Pathogen Piscirickettsia salmonis and the Sea Louse Caligus $\begin{array}{llll}\text { rogercresseyi. } & \text { PLOSE, } & \text { 9(4), } & \end{array}$ https://doi.org/10.1371/journal.pone.0095397

Lukacs, P. M., Thompson, W. L., Kendall, W. L., Gould, W. R., Doherty, P. F., Burnham, K. P., \& Anderson, D. R. (2007). Concerns regarding a call for pluralism of information theory and hypothesis testing. Journal of Applied Ecology, 44(2), 456-46o. https://doi.org/10.1111/j.1365-2664.2006.01267.x

May, C. F. (2018). Discovering new areas of veterinary science through qualitative research interviews: Introductory concepts for veterinarians. Australian Veterinary Journal, $\quad$ 96(8), $\quad$ 278-284. https://doi.org/10.1111/avj.12718 
Mays, N., \& Pope, C. (1995). Qualitative Research: Rigour and qualitative research. $B M J$, 311(6997), 109-112. https://doi.org/10.1136/bmj.311.6997.109

Mons, B., Neylon, C., Velterop, J., Dumontier, M., da Silva Santos, L. O. B., \& Wilkinson, M. D. (2017). Cloudy, increasingly FAIR; revisiting the FAIR Data guiding principles for the European Open Science Cloud. Information Services \& Use, 37(1), 49-56. https://doi.org/10.3233/ISU-170824

Parascandola, M., \& Weed, D. L. (2001). Causation in epidemiology. Journal of Epidemiology and Community Health, 55(12), 905-912.

Pearl, J. (1995). Causal diagrams for empirical research. Biometrika, 82(4), 669-688. https://doi.org/10.1093/biomet/82.4.669

Pearl, J. (2000). Causality: Models, Reasoning, and Inference. Cambridge University Press.

Pearl, J. (2009). Causal inference in statistics: An overview. Statistics Surveys, 3, 96-146. https://doi.org/10.1214/o9-SSo57

Rees, E. E., Ibarra, R., Medina, M., Sanchez, J., Jakob, E., Vanderstichel, R., \& St-Hilaire, S. (2014). Transmission of Piscirickettsia salmonis among salt water salmonid farms in Chile. Aquaculture, 428-429, 189-194. https://doi.org/10.1016/j.aquaculture.2014.03.031

Silva-Ayçaguer, L. C., Suárez-Gil, P., \& Fernández-Somoano, A. (2010). The null hypothesis significance test in health sciences research (1995-2006): Statistical analysis and interpretation. BMC Medical Research Methodology, 1O(1), 44. https://doi.org/10.1186/1471-2288-10-44

Stephens, P. A., Buskirk, S. W., \& del Rio, C. M. (2007). Inference in ecology and evolution. Trends in Ecology \& Evolution, 22(4), 192-197. https://doi.org/10.1016/j.tree.2006.12.003

Stephens, P. A., Buskirk, S. W., Hayward, G. D., \& Rio, C. M. D. (2005). Information theory and hypothesis testing: A call for pluralism. Journal of Applied Ecology, 42(1), 4-12. https://doi.org/10.1111/j.1365-2664.2005.01002.x

Vandenbroucke, J. P., Broadbent, A., \& Pearce, N. (2016). Causality and causal inference in epidemiology: The need for a pluralistic approach. International Journal of Epidemiology, 45(6), 1776-1786. https://doi.org/10.1093/ije/dyv341 
Wada, M., Lam, C. T., Rosanowski, S., Patanasatienkul, T., Price, D., \& StHilaire, S. (2020). Development of simulation models for transmission of Salmonid Rickettsial Septicaemia between salt water fish farms in Chile. Transboundary and Emerging Diseases, Early view. https://doi.org/10.1111/tbed.13830

Wilkinson, M. D., Dumontier, M., Aalbersberg, Ij. J., Appleton, G., Axton, M., Baak, A., Blomberg, N., Boiten, J.-W., da Silva Santos, L. B., Bourne, P. E., Bouwman, J., Brookes, A. J., Clark, T., Crosas, M., Dillo, I., Dumon, O., Edmunds, S., Evelo, C. T., Finkers, R., ... Mons, B. (2016). The FAIR Guiding Principles for scientific data management and stewardship. Scientific Data, 3(1), 160018. https://doi.org/10.1038/sdata.2016.18 
Appendix 


\section{Summary}

While Chile is the fourth largest producer of finfish worldwide, a shadow to the success of the salmonid aquaculture industry in Chile is the fish health burden caused by salmonid rickettsial septicaemia (SRS), a non-zoonotic bacterial infection caused by Piscirickettsia salmonis. The work presented in this thesis builds on a research platform which was developed to integrate the health and management data routinely collected on salmonid aquaculture farms, an initiative named PIISAC ('Plataforma Integrada de Investigaci'on Sanitaria para la Acuicultura'). The overall objective of the work conducted during this $\mathrm{PhD}$ was to investigate how data may be used more effectively to improve the management of fish health in salmonid farming, in particular for salmonid rickettsial septicaemia in Chilean sea farms.

In the first part of the thesis, the PIISAC platform was used to further examine the risk factors for SRS and evaluate the effectiveness of various interventions to control the disease in farmed salmon and trout in Chile. In chapter 2, routine production and health data were analysed to assess the effectiveness of antimicrobial treatment of infected fish, identifying practices which impact positively or negatively on the management of mortality outbreaks in sea farms. In chapter $\mathbf{3}$, the analysis focused on the interplay between sea lice burden, sea lice management using bathing treatments and SRS mortality. The work highlighted the challenge for veterinarians in managing ectoparasites while not increasing the stressors applied to the fish. While chapters 2 and 3 considered interventions to control SRS at the farm-level, chapter $\mathbf{4}$ considered the correlation in SRS mortality between neighbouring sea farms. The results presented in the first part of the thesis, as well as a companion study on the effectiveness of vaccination, contribute to the growing evidence base available for veterinarians and fish health managers to make better decisions regarding the management of SRS on sea farms. This work, including the epidemiological studies and the development of the PIISAC platform, shows that analysis of routine production and health data can provide useful insights into the effectiveness of within-farm interventions to control SRS. 
The use of data in this manner requires durable data infrastructure and governance arrangements. In this context, the second part of the thesis looks at how epidemiological research may be conducted in the future in a sustainable manner. The barriers to the adoption of the PIISAC platform were analysed using a qualitative approach, which is presented in chapter 5. Such data platforms may provide a means to share and re-use data for the benefits of the data providers, while minimizing the costs and efforts of repeated rounds of data collection. This study showed that more work is needed to identify the most appropriate arrangements for data curation and governance and support future data integration platforms for fish health. An alternative approach to improving the use and re-use of data in scientific communities was proposed in 2016, under the form of the FAIR (Findable, Accessible, Interoperable, Reusable) principles. Chapter 6 investigates the progress towards implementing these principles among the aquaculture epidemiology community.

Finally, Chapter 7 provides a summarizing discussion of the thesis. It also addresses questions relating to statistical modelling, including causal analysis in veterinary epidemiology and the use of different approaches for making inferences from statistical models. Last, an outline of what qualitative approaches can contribute to veterinary epidemiology is presented, based on the experience gained during the course of this $\mathrm{PhD}$. To conclude, further work is currently ongoing to better understand SRS transmission in Chile, regularly providing new evidence to decision makers for improving the on-farm management of the disease. However, important knowledge gaps remain, which may be addressed in the future by extending the range of methods used to research this topic. For example, molecular techniques may contribute to identify disease transmission routes, thus improving the understanding of SRS dynamics in Chile. 


\section{Samenvatting}

Chili is de op drie na grootste visproducent ter wereld, maar de gezondheidslast veroorzaakt door salmonid rickettsial septicaemia (SRS), een nietzoönotische bacteriële infectie veroorzaakt door Piscirickettsia salmonis, is een schaduwkant van het succes van de zalm aquacultuur in Chili. Het werk dat in dit proefschrift wordt gepresenteerd, bouwt voort op een onderzoeksplatform dat is ontwikkeld om de gezondheids- en managementgegevens die routinematig worden verzameld op zalm aquacultuurbedrijven te integreren, een initiatief genaamd PIISAC ('Plataforma Integrada de Investigaci' on Sanitaria para la Acuicultura'). Het overkoepelende doel van het werk dat tijdens deze doctoraatstudie werd uitgevoerd, was om te onderzoeken hoe data effectiever kunnen worden gebruikt om het management van de gezondheid in de zalmkweek te verbeteren, in het bijzonder voor SRS in Chili.

In het eerste deel van het proefschrift werd het PIISAC-platform gebruikt om de risicofactoren voor SRS verder te onderzoeken en de effectiviteit van verschillende interventies ter beheersing van de ziekte bij gekweekte zalm en forel in Chili te evalueren. In hoofdstuk 2 werden routinematig verzamelde productieen gezondheidsgegevens geanalyseerd om de effectiviteit van antimicrobiële behandeling van geïnfecteerde vissen te beoordelen, waarbij handelswijzen werden geïdentificeerd die een positieve of negatieve invloed hebben op het beheersen van sterfte in de kwekerijen. In hoofdstuk 3 lag de focus van de analyse op het samenspel tussen de last als gevolg van zeeluizen, de behandeling daarvan door waterbehandelingen en de mortaliteit als gevolg van SRS. Dit werk benadrukte de uitdaging die dierenartsen hebben om bij het beheersen van ectoparasieten de stressfactoren waaraan de vissen zijn blootgesteld niet te vergroten. Terwijl de hoofdstukken 2 en 3 ingingen op interventies om SRS op kwekerijniveau te beheersen, ging hoofdstuk 4 in op de correlatie in SRS-mortaliteit tussen naburige kwekerijen. De resultaten die in het eerste deel van het proefschrift worden gepresenteerd, evenals een begeleidende studie naar de effectiviteit van vaccinatie, dragen bij aan de groeiende wetenschappelijke basis die beschikbaar is voor dierenartsen en visgezondheidsmanagers om betere beslissingen te nemen met betrekking tot het beheer van SRS op zalmkwekerijen. Dit werk, inclusief de 
epidemiologische studies en de ontwikkeling van het PIISAC-platform, toont aan dat analyse van routinematig verzamelde productie- en gezondheidsgegevens nuttige inzichten kunnen opleveren voor de effectiviteit van interventies binnen de boerderij om SRS te beheersen.

Het op deze manier gebruiken van data vereist een duurzame datainfrastructuur en governance. In dit verband kijkt het tweede deel van het proefschrift naar hoe epidemiologisch onderzoek in de toekomst op een duurzame manier kan worden uitgevoerd. De belemmeringen voor de acceptatie van het PIISAC-platform werden geanalyseerd met behulp van een kwalitatieve benadering, die wordt gepresenteerd in hoofdstuk 5. Dergelijke dataplatforms kunnen een middel zijn om gegevens te delen en te hergebruiken ten faveure van de dataproviders, terwijl de kosten en inspanningen van herhaalde rondes van gegevensverzameling worden geminimaliseerd. Deze studie toonde aan dat er meer werk nodig is om de meest geschikte regelingen voor datacuratie en -beheer te identificeren en om toekomstige data-integratieplatforms voor de gezondheid van vissen te ondersteunen. In 2016 werd een alternatieve benadering voorgesteld om het gebruik en hergebruik van data in wetenschappelijke gemeenschappen te verbeteren, in de vorm van de FAIR-principes (Findable, Accessible, Interoperable, Reusable). Hoofdstuk 6 onderzoekt de voortgang bij de implementatie van deze principes onder onderzoekers in de aquacultuurepidemiologie.

Ten slotte geeft Hoofdstuk 7 een samenvattende discussie van het proefschrift. Het behandelt ook vragen met betrekking tot statistische modellering, inclusief causale analyse in veterinaire epidemiologie en het gebruik van verschillende benaderingen om conclusies te trekken uit statistische modellen. Ook wordt een globaal overzicht gegeven van kwalitatieve benaderingen die kunnen bijdragen aan veterinaire epidemiologie, gebaseerd op de ervaring opgedaan tijdens dit doctoraat. Momenteel wordt verder gewerkt aan een beter begrip van de overdracht van SRS in Chili, waarbij regelmatig nieuwe inzichten worden verstrekt aan managers om ziekte op het bedrijf beter te beheersen. Er zijn nog belangrijke hiaten in de kennis, die in de toekomst mogelijk kunnen worden aangepakt door uitbreiding van de methoden zoals toegepast voor dit proefschrift. Moleculaire technieken kunnen bijvoorbeeld bijdragen aan het nader identificeren 
van transmissieroutes, waardoor het begrip van SRS-dynamiek in Chili wordt verbeterd. 


\section{About the author}

Anne Meyer was born in France in 1987, where she grew up and studied. She graduated as a Doctor of Veterinary Medicine from Maisons-Alfort Veterinary School (France) in 2012, after completing several internships in veterinary practices in France, Germany, the United Kingdom and the USA. The same year, she also completed as Master's Degree in "Animal Health and Epidemiology in Southern Countries" at the University of Montpellier. During this MSc, she conducted an internship with the University of Pretoria in South Africa, which fuelled her interest for working abroad. After graduation, she spent two years in Africa, gaining fieldwork experience in epidemiology and veterinary research in South Africa and Gabon. She then joined the Veterinary Epidemiology, Economics and Public Health group at the Royal Veterinary College in London as a research assistant, developing advanced skills in data management, analysis and visualisation. In April 2017, Anne started to work as a consultant in epidemiology with Ausvet in Australia, later moving back to France with Ausvet Europe. In January 2019, Anne started as a PhD candidate at the Veterinary Faculty of Utrecht University under the supervision of Prof. Dr. Arjan Stegeman and Dr. Angus Cameron, executive consultant at Ausvet. During her candidacy, Anne conducted the work presented in this thesis, investigating how data may be used more effectively to improve the management of fish health in salmonid farming. In parallel, she continued her work with Ausvet, on a variety of projects such as animal health information systems in Indonesia and Australia, and disease surveillance and epidemiology in both terrestrial animal production and aquaculture.

\section{List of peer-reviewed publications:}

Herbert A., Boundenga L., Meyer A., Moukodoum D.N., Okouga A.P., Arnathau C., Durand P., Magnus J., Ngoubangoye B., Willaume E., Tidiane C., Rougeron V., Renaud F., Ollomo B., Prugnolle F. (2015) Malaria-like symptoms associated with a natural Plasmodium reichenowi infection in a chimpanzee, Malaria Journal, 14:220 
Meyer A., Holt H., Selby R., Guitian J. (2016) Past and ongoing tsetse and animal trypanosomiasis control operations in five African countries - a systematic review. PLoS Neglected Tropical Diseases, 10(12): e0005247. doi: 10.1371/journal.pntd.0005247.

Meyer A., Zamir L., Ben Yair Gilboa A., Gelman B., Pfeiffer D., Vergne T. (2017) Quantitative assessment of the risk of release of foot-and-mouth disease virus via export of bull semen from Israel, Risk Analysis 37(12): 2350-2359. doi: 10.1111/risa.12799.

Meyer A., Dinh X.T., Nhu V.T., Pham T.L., Newman S., Nguyen T.T.T., Pfeiffer D.U., Vergne T. (2017) Movement and contact patterns of long-distance free-grazing ducks and avian influenza persistence in Vietnam, PLoS ONE, 12(6): e0178241. doi: 10.1371/journal.pone.0178241.

Meyer A., Dinh X.T., Han A.T., Do V.D., Nhu V.T., Pham T.L., Nguyen T.T.T., Newman S., Häsler B., Pfeiffer D.U., Vergne T. (2017) Trade patterns facilitating highly pathogenic avian influenza virus dissemination in the freegrazing layer duck system in Vietnam, Transboundary and Emerging Diseases 65(2): 408-419. doi: 0.1111/tbed.12697.

Meyer A., Bond K., van Winden S., Green M., Guitian J. (2018) A probabilistic approach to the interpretation of milk antibody results for diagnosis of Johne's disease in dairy cattle, Preventive Veterinary Medicine, 150: 30-37. doi: 10.1016/j.prevetmed.2017.11.016.

Craighead L., Meyer A., Chengat B., Musallam I., Akakpo J., Kone P., Guitian J., Häsler B. (2017) Brucellosis in West and Central Africa: A review of the current situation in a changing landscape of dairy cattle systems, Acta Tropica, 179: 96 - 108. doi: 10.1016/j.actatropica.2017.12.026.

Meyer A., Holt H.R., Oumarou F., Chilongo K., Gilbert W., Fauron A., Mumba C., Guitian J. (2018) Integrated cost-benefit analysis of tsetse control and herd productivity to inform control programs for animal African trypanosomiasis, Parasites and Vectors, 11(1):154. doi: 10.1186/s13071-018-2679-x.

Mellor K., Meyer A., Long P.T., Elkholy D., Inui K., Padungtod P., Gilbert M., Newman S., Vergne T., Pfeiffer D.U., Fournié G., Stevens K.B. (2018) Comparative epidemiology of highly pathogenic avian influenza virus $\mathrm{H}_{5} \mathrm{~N}_{1}$ and 
H5N6 in Vietnamese live bird markets: spatio-temporal patterns of distribution and risk factors. Frontiers in Veterinary Science, 5: 5-51. doi: 10.3389/fvets.2018.00051.

Hutchison J., Mackenzie C., Madin B., Happold J., Leslie E., Zalcman E., Meyer A., Cameron A. (2018) New approaches to aquatic and terrestrial animal surveillance: The potential for people and technology to transform epidemiology. $\begin{array}{lllll}\text { Preventive } & \text { Veterinary } & \text { Medicine. 167:-173. doi: }\end{array}$ 10.1016/j.prevetmed.2018.10.009.

Conan A., Meyer A., Reininghaus B., van Rooyen J. \& Knobel D.L. (2018) A live weight-heart girth relationship in Nguni-type and Brahman-type cattle as a tool for small-scale farmers. Applied Animal Husbandry \& Rural Development. 11(1): 46-52.

Meyer A., McAloon C.G., Tratalos J.A., More S.J., Citer L.R., Graham D.A. \& Sergeant E.S.G. (2019) Modeling of alternative testing strategies to demonstrate freedom from Mycobacterium avium ssp. Paratuberculosis infection in testnegative dairy herds in the Republic of Ireland. Journal of Dairy Science. 102: 2427-2442 doi: 10.3168/jds.2018-14883

Vergne T., Meyer A., Long P.T., Elkholly D.A., Inui K., Padungtod P., Newman S.H., Fournié G. \& Pfeiffer D.U. (2019) Optimising the detectability of $\mathrm{H}_{5} \mathrm{~N} 1$ and $\mathrm{H}_{5} \mathrm{~N} 6$ highly pathogenic avian influenza viruses in Vietnamese live-bird markets. Scientific Reports 9(1): 1031. doi: 10.1038/s41598-018-37616-1

Meyer A., Burroughs A., Sadler R., Happold J., Cowled B., Mackenzie C., Gallardo Lagno A.L., Cameron A. (2019) Quantifying the effects of sea lice burden and lice bathing treatments on salmonid rickettsial septicaemia in commercial salmon and trout farms in Chile. Aquaculture. 513: 734411. doi: 10.1016/j.aquaculture.2019.734411

Happold J., Sadler R., Meyer A., Hillman A., Cowled B., Mackenzie C., Gallardo Lagno A.L., Cameron A. (2020) Effectiveness of vaccination for the control of salmonid rickettsial septicaemia in commercial salmon and trout farms in Chile. Aquaculture. 520: 734968. doi: 10.1016/j.aquaculture.2020.734968

Happold J., Meyer A., Sadler R., Cowled B., Mackenzie C., Stevenson, M., Ward, M.P., Gallardo Lagno A.L., Cameron A. (2020) Effectiveness of 
antimicrobial treatment of salmonid rickettsial septicaemia in commercial salmon and trout farms in Chile. Aquaculture. 525: 735323. doi: 10.1016/j.aquaculture.2020.735323

Hillman, A.E., Zalcman, E.J., Burroughs, A.L., Meyer, A., Sadler, R.J., Madin, B., Mackenzie, C., Ward, M.P., Stevenson, M.A., Lagno, A.L.G., Cameron, A.R. (2020) Use of regulatory data to describe and identify risk factors for salmonid rickettsial septicaemia in Chile, 2011-2017. Aquaculture. 526: 735324. doi: 10.1016/j.aquaculture.2020.735324

Zalcman, E., Burroughs, A., Meyer, A., Hillman, A., Sadler, R., Madin, B., Mackenzie, C., Ward, M.P., Stevenson, M., Happold, J., Hutchison, J., Gallardo Lagno, A.L., Cameron, A., Cowled, B. (2020). Sea lice infestation of salmonids in Chile between 2011 and 2017: Use of regulatory data to describe characteristics and identify risk factors. Aquaculture. 530: 735752. doi: 10.1016/j.aquaculture.2020.735752

Cameron, A., Meyer, A., Faverjon, C. and Mackenzie, C. (2020) Quantification of the sensitivity of early detection surveillance. Transboundary Emerging Diseases. oo: 1-12. doi: 10.1111/tbed.13598

Willgert, K., Meyer, A., Tung, D.X., Thu, N.V., Long, P.T., Newman, S., Thuy, N.T.T., Padungtod, P., Fournié, G., Pfeiffer, D.U. and Vergne, T. (2020) Transmission of highly pathogenic avian influenza in the nomadic free-grazing duck production system in Viet Nam. Scientific Reports. 10: 8432. doi: 10.1038/s41598-020-65413-2

Meyer, A., Sadler, R., Faverjon, C., Cameron, A.R., Bannister-Tyrrell, M. (2020) Evidence That Higher Temperatures Are Associated With a Marginally Lower Incidence of COVID-19 Cases. Frontiers in Public Health. 8: 367. doi: 10.3389/fpubh.2020.00367

Faverjon, C., Meyer, A., Howden, K., Long, K., Peters, L., Cameron, A. (2020) Risk-based early detection system of African Swine Fever using mortality thresholds. Transboundary and Emerging Diseases. oo: 1-11. doi: 10.1111/tbed.13765

Meyer, A., Sadler, R., Bannister-Tyrrell, M., Gallardo Lagno, A.L., Stegeman, J.A., Cameron, A.R. (2021) Is between-farm water-borne pathogen 
dissemination an important driver in the epidemiology of salmonid rickettsial septicaemia in Chile? Aquaculture. 530: 735751. doi: 10.1016/j.aquaculture.2020.735751

Meyer, A., Bannister-Tyrrell, M., Mackenzie, C., Stegeman, A., Cameron, A. (2020) Barriers to the adoption of a fish health data integration initiative in the Chilean salmonid production. Computers and Electronics in Agriculture. 179: 105853. doi.org/10.1016/j.compag.2020.105853. 


\section{Acknowledgments}

I would like to thank my supervisors, Arjan Stegeman and Angus Cameron, for their guidance and involvement during the past few years. I am also grateful to the entire Ausvet team, in Australia and Europe, for their continued support, encouragements and inputs. In particular, I would like to thank Melanie BannisterTyrrell, Rohan Sadler, Céline Faverjon, Catriona Mackenzie and Edwina Leslie. 
